Flávia Baggio Nerbass

\title{
Efeitos hemodinâmicos agudos da pressão positiva contínua na via aérea (CPAP) em indivíduos com cardiomiopatia hipertrófica
}

Tese apresentada à Faculdade de Medicina da Universidade de São Paulo para obtenção do título de Doutor em Ciências

Programa: Pneumologia

Orientador: Prof. Dr. Geraldo Lorenzi Filho

São Paulo 
Flávia Baggio Nerbass

\section{Efeitos hemodinâmicos agudos da pressão positiva contínua na via aérea (CPAP) em indivíduos com cardiomiopatia hipertrófica}

Tese apresentada à Faculdade de Medicina da Universidade de São Paulo para obtenção do título de Doutor em Ciências

Programa: Pneumologia

Orientador: Prof. Dr. Geraldo Lorenzi Filho

São Paulo 
Dados Internacionais de Catalogação na Publicação (CIP)

Preparada pela Biblioteca da

Faculdade de Medicina da Universidade de São Paulo

Creprodução autorizada pelo autor

\section{Nerbass, Fávia Baggio}

Efeitos hemodinâmicos agudos da pressãopositiva contínua na via aérea(CPAP) em indivídıos com cardiomiopatia hipertrófica / Flávia Baggio Nerbass. -- São Paulo, 2015.

Tese(doutorado)--Faculdade deMedicina da Universidade de São Paulo.

Programa de Pneumologia.

Orientador: Geraldo Lorenzi Filho.

Descritores: 1.Cardiomiopatia hipertró fica 2.Hemodinâmica 3.Pressão arterial 4.Ecocardiografia 5.Apneia do sono tipo obstrutiva 6.Pressãopositiva contínua nas vias aéreas 7.Polissonografia

USP/FM/DBD-001/15 
Aos meus pais, Marcos e Marilú, meus exemplos e minha inspiração. A vocês que sempre me estimularam a seguir em frente e encarar os desafios da vida com coragem... Obrigada por estarem ao meu lado e nunca me deixarem desistir.

À minha irmã Fabiana e meu cunhado Lúcio, que me receberam em São Paulo e me ajudaram a superar as dificuldades da "selva de pedras".

Às minhas amigas Paulinha e Lia, que com paciência dividiram comigo seu tempo e espaço durante esses anos de convivência.

Ao Júlio, meu esposo, sua compreensão e seu incansável incentivo me deram suporte para chegar até aqui! Obrigada pelo seu amor incondicional. 
Ao meu orientador, Prof. Dr. Geraldo Lorenzi Filho, que acreditou no meu potencial, me deu oportunidades para crescer e me desenvolver profissionalmente, além de me ensinar o que é ser um pesquisador. Minhas eternas gratidão e admiração.

Ao meu co-orientador, Prof. Dr. Luciano Ferreira Drager, por nunca me deixar desistir. Obrigada pelo conhecimento compartilhado, pela confiança, apoio e incentivo, que me estimularam a seguir em frente e estar aqui hoje.

À Prof ${ }^{\mathrm{a}}$. Dr ${ }^{\mathrm{a}}$. Vera Maria Cury Salemi, que acreditou nesse estudo desde o princípio e sempre se dispôs a me ajudar no que fosse preciso, independente de data e horário. Obrigada pela sua dedicação, comprometimento e disponibilidade. Esse trabalho com certeza não seria o mesmo sem sua participação.

Ao Dr. Rodrigo P. Pedrosa, pelas ideias e exemplo de comprometimento e pró-atividade com a pesquisa.

Ao Dr. Júlio César Ayres Ferreira Filho, pelo seu comprometimento com os ECOs e ao Dr. Natanael Portilho, pela disponibilidade na análise dos exames e pela ajuda intelectual. Vocês foram cruciais para que esse trabalho se concretizasse.

Ao Eng. Dr. Henrique Takashi Moriya, por sua prontidão e colaboração incansáveis com os equipamentos e programas de análise do Laboratório do Sono. Seus conhecimentos fizeram toda a diferença para conclusão deste trabalho. 
Ao Prof. Dr. Edmundo Arteaga Fernàndez, que confiou no meu trabalho, abriu as portas do seu ambulatório para o recrutamento dos pacientes e me auxiliou em tudo o que eu precisei durante o desenvolvimento dessa tese. Obrigada pela confiança.

Ao Dr. Murillo Oliveira Antunes, por colaborar com esse estudo e sempre encaminhar os pacientes do ambulatório.

À enfermeira Dr ${ }^{a}$. Naury de Jesus Danzi Soares, minha amiga, confidente, parceira de pós-graduação e "comadre". Obrigada por estar comigo todos esses anos. Sua garra e dedicação me inspiram. Te admiro e agradeço por tudo!

À Adriana Nogueira, Celinha e demais técnicas do laboratório de pesquisa clínica, pelo auxílio com os exames laboratoriais.

Ao Prof. Dr. Pedro Rodrigues Genta, pela sua disponibilidade em ajudar e compartilhar seu conhecimento com todos do Laboratório. Aprendi muito com o senhor.

À minha amiga e fisioterapeuta $\operatorname{Dr}^{\mathrm{a}}$ Daisy Satomi Ykeda, que me apresentou à fascinante medicina do sono e sempre me impulsionou em busca desse sonho. Obrigada para sempre.

Ao Prof. Dr. Carlos Roberto Carvalho, Titular da Disciplina de Pneumologia, pelo exemplo de pesquisador e profissional. Agradeço a oportunidade de me desenvolver profissionalmente aqui. 
Aos Prof. Dr. Mário Terra Filho e Prof. Dr. Rogério de Souza, coordenador e vice-coordenador da pós-graduação, pelo trabalho sério e incansável que fazem toda a diferença neste programa de excelência.

À Diretora do Serviço de Fisioterapia do InCor, Dra. Maria Ignes Zanetti Feltrin, pela oportunidade de fazer parte desse serviço.

A fisioterapeuta chefe da UTI Cirúrgica do InCor, Dra Emilia Nozawa, pelo incentivo, apoio e compreensão durante esses anos em que tive que me desdobrar para concluir esse doutorado.

Ao fisioterapeuta Rafael Moraes lanotti, pela amizade e pela ajuda intelectual. Obrigada, meu amigo.

Às fisioterapeutas Vera Regina Coimbra e Denise Peres, por me ajudarem a conciliar o trabalho assistencial com a pesquisa. Vocês foram fundamentais nessa caminhada.

Às minhas companheiras de pós-graduação Fabíola Schorr, Lilian Khelen de Paula, Vanessa leto, Fabiane Kayamori e Raquel Hirata, obrigada pelo companheirismo de sempre... e vamos em frente.

A todos os fisioterapeutas do Laboratório do Sono, nossa profissão é linda e fundamental para o sucesso do tratamento desses pacientes. Me orgulho muito de ter feito parte desta equipe.

À Vandinha, por resolver nossos problemas de secretaria e nos receber todos os dias no laboratório; e aos técnicos de polissonografia Paulo 
Henrique Fernandes e Robson Martins, grandes colaboradores deste estudo.

A toda equipe multiprofissional do laboratório do sono, que andam juntos nessa estrada árdua, mas gratificante da pesquisa.

Às secretárias da pós-graduação Luciana Vitalle e Alessandra pelo auxilio administrativo.

A toda equipe do Serviço de Fisioterapia do InCor, minha gratidão pela parceria, paciência e compreensão.

Aos pacientes participantes deste estudo, que se dispuseram a ajudar, muitas vezes vindo de longe, e compartilharam suas vidas conosco em prol do conhecimento. Meus eternos reconhecimento, respeito e gratidão. 
Alcançar objetivos depende de esforço e persistência. Apesar dos riscos e das dificuldades, chegar até aqui é um privilégio de poucos! 
Lista de Abreviaturas

Lista de Tabelas

Lista de Figuras

Lista de Gráficos

Resumo

Summary

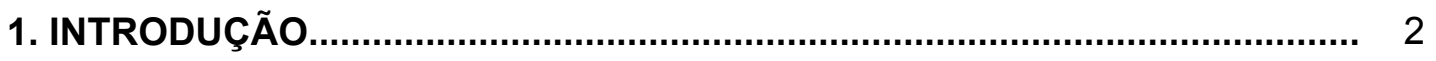

1.1 Cardiomiopatia Hipertrófica................................................................ 2

1.1.1 Alterações cardíacas estruturais.................................................... 2

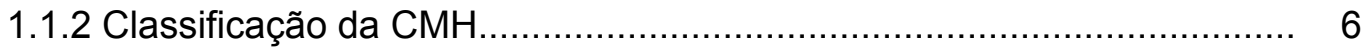

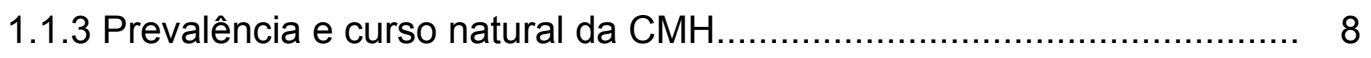

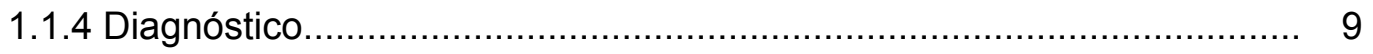

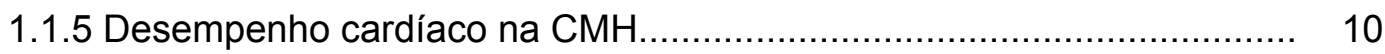

1.1.6 Sintomatologia clínica e tratamento............................................. 14

1.2 Apneia Obstrutiva do Sono.................................................................... 16

1.2.1 AOS e consequências cardiovasculares........................................ 16

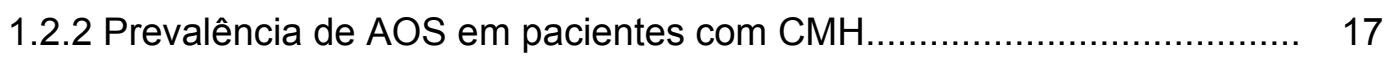

1.2.3 AOS, CMH e desfecho cardiovascular............................................ 18

1.3 Pressão positiva contínua na via aérea (CPAP) .................................... 21

1.3.1 Tratamento da AOS com CPAP e desfecho cardiovascular.................. 22

1.3.2 Efeitos hemodinâmicos agudos do CPAP - interação cardiopulmonar.... 23 


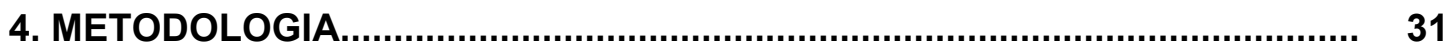

4.1 Seleção de pacientes ............................................................................. 31

4.1.1 Critério de interrupção do protocolo......................................... 32

4.2 Desenho do estudo............................................................................... 32

4.2.1 Avaliação inicial......................................................................... 32

4.2.2 Randomização........................................................................... 34

4.2.3 Aquisição de variáveis ecocardiográficas e hemodinâmicas.................. 35

4.3 Monitorizações.............................................................................. 39

4.3.1 Monitorização contínua da pressão arterial batimento-a-batimento -

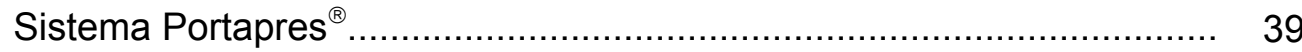

4.3.2 Pressão de CPAP e EtCO

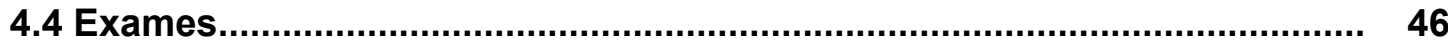

4.4.1 Ecocardiograma transtorácico..................................................... 46

4.4.2 Polissonografia Noturna Completa (PSG) .................................. 53

4.4.3 BNP - Peptídeo Natriurético Cerebral ............................................. 55

4.4.4 Colesterol total e frações e glicemia ............................................. 55

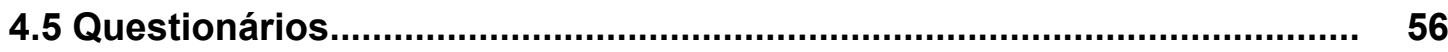

4.5.1 Escala de sonolência de Epworth.................................................. 56

4.5.2 Questionário Clínico de Berlin........................................................... 56 
4.5.3 Índice de Qualidade de Sono de Pittsburgh...................................... 56

4.5.4 Classificação Funcional New York Heart Association (NYHA) ............ 57

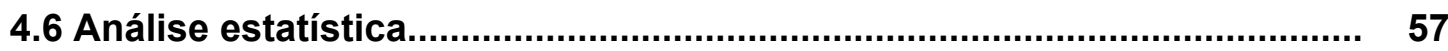

4.6.1 Variáveis clínicas, demográficas, polissonográficas e ecocardiográficas basais entre grupos CMHN-Obst e CMHObst...................................... 58

4.6.2 Análise das variáveis ecocardiográficas considerando o grupo, a pressão de CPAP, o protocolo e o desenho crossover.

4.6.3 Comparações entre os gradientes de via de saída do ventrículo esquerdo.

4.6.4 Reprodutibilidade das medidas ecocardiográficas.

62

4.6.5 Análise das variações da pressão arterial batimento-a-batimento.

5. RESULTADOS

5.1 Características da população estudada 66

5.2 Dados ecocardiográficos de ambos os grupos ao longo do estudo.

5.3 Análise dos gradientes de via de saída do ventrículo esquerdo ao longo do estudo.

5.4 Reprodutibilidade das medidas ecocardiográficas. 91

5.5 Dados da pressão arterial de ambos os grupos ao longo do estudo........ 96

5.6 Variações nas pressões de CPAP e $\mathrm{EtCO}_{2}$ 101

6. DISCUSSÃO 103

6.1 Considerações sobre as características da população estudada. 103

6.1.1 Características clínicas e demográficas. 103 
6.1.2 Achados relacionados ao sono. 104

6.2 Considerações sobre os achados ecocardiográficos basais. 105

6.3 Considerações sobre os efeitos da pressão positiva na anatomia e função cardíacas e hemodinâmica. 106

6.3.1 variações nas câmaras cardíacas 107

6.3.2 Alterações no relaxamento e função diastólica... 110

6.3.4 Variações nas pressões da artéria pulmonar. 112

6.3.5 Variações no refluxo mitral. 114

6.3.6 Variações na hemodinâmica 115

6.4 Forças e limitações do estudo. 117

6.5 Considerações finais e perspectivas futuras. 118

7. CONCLUSÃO 121

8. ANEXOS 122

ANEXO A - Termo de Consentimento Livre e Esclarecido. 123

ANEXO B - Ficha de coleta de dados. 127

ANEXO C - Questionário de Berlin e Escala de Sonolência de Epworth........ 130

ANEXO D - Índice de qualidade de sono de Pittsburgh 131

ANEXO E - Avaliação da classe funcional pela NYHA 133

9. REFERÊNCIAS 
APÊNDICES

APÊNDICE 1 - Artigo publicado: Obstructive sleep apnea and hypertrophic cardiomyopathy: a common and potential harmful combination. Sleep Med Rev. 2013 Jun;17(3):201-6.

APÊNDICE 2 - Artigo publicado: Lack of reliable clinical predictors to identify obstructive sleep apnea in patients with hypertrophic cardiomyopathy. Clinics (Sao Paulo). 2013 Jul;68(7):992-6. 


\begin{tabular}{|c|c|}
\hline$A D$ & Átrio direito \\
\hline $\mathrm{AE}$ & Átrio esquerdo \\
\hline ANOVA & Análise de variância \\
\hline AP & Artéria Pulmonar \\
\hline AOS & Apneia Obstrutiva do Sono \\
\hline BNP & Brain Natriuretic Peptide \\
\hline CAPpesq & $\begin{array}{l}\text { Comissão de Ética para Análise de Projetos de } \\
\text { Pesquisa }\end{array}$ \\
\hline $\mathrm{CCl}$ & Coeficiente de correlação intraclasse \\
\hline $\mathrm{CMH}$ & Cardiomiopatia Hipertrófica \\
\hline CMHN-Obst & Cardiomiopatia Hipertrófica não-obstrutiva \\
\hline CMHObst & Cardiomiopatia hipertrófica obstrutiva \\
\hline CPAP & Pressão Positiva Contínua na Via Aérea \\
\hline CPAP-10 & CPAP em $10 \mathrm{cmH}_{2} \mathrm{O}$ \\
\hline DdVE & Diâmetro diastólico-final do ventrículo esquerdo \\
\hline DC & Débito Cardíaco \\
\hline DsVE & Diâmetro sistólico-final do ventrículo esquerdo \\
\hline DVD & Digital versatile disc \\
\hline ECA & Enzima conversora da angiotensina \\
\hline ECO & Ecocardiograma transtorácico \\
\hline ECG & Eletrocardiograma \\
\hline $\mathrm{EtCO}_{2}$ & Gás carbônico exalado final \\
\hline$E^{\prime}$ & Velocidade de pico da diástole precoce \\
\hline
\end{tabular}




\section{Lista de Abreviaturas}

\begin{tabular}{|c|c|}
\hline $\mathrm{E} / \mathrm{E}^{\prime}$ & reflete as pressões de enchimento ventricular \\
\hline FA & Fibrilação atrial \\
\hline FEVE & Fração de ejeção do ventrículo esquerdo \\
\hline FC & Frequência cardíaca \\
\hline GPD & Gradiente pressórico dinâmico \\
\hline HCFMUSP & $\begin{array}{l}\text { Hospital das Clínicas da Faculdade de Medicina da } \\
\text { Universidade de São Paulo }\end{array}$ \\
\hline HDL & Lipoproteína de alta densidade \\
\hline $\mathrm{IAH}$ & Îndice de apneia/hipopneia \\
\hline IC 95\% & $95 \%$ do intervalo de confiança \\
\hline IMC & Îndice de massa corpórea \\
\hline InCor & Instituto do Coração \\
\hline LDL & Lipoproteína de baixa densidade \\
\hline MAPA & Monitorização ambulatorial da pressão arterial \\
\hline MAS & Movimento anterior sistólico da Valva Mitral \\
\hline NREM & Non rapid eye movement \\
\hline NYHA & New York Heart Association \\
\hline Onda A & pico de velocidade de enchimento tardio do VE \\
\hline Onda E & pico de velocidade de enchimento precoce do VE \\
\hline PA & Pressão arterial \\
\hline PAD & Pressão arterial diastólica \\
\hline PAS & Pressão arterial sistólica \\
\hline PEEP & Positive end expiratory pressure \\
\hline
\end{tabular}




\section{Lista de Abreviaturas}

$\begin{array}{ll}\text { Portapres } & \begin{array}{l}\text { Equipamento para medida da pressão arterial } \\ \text { batimento-a-batimento }\end{array} \\ \text { PSG } & \text { Polissonografia completa } \\ \text { Ptm } & \text { Pressão transmural } \\ \text { REM } & \text { Rapid eye movement } \\ \text { Sham-CPAP } & \left.\text { CPAP placebo (1,5cmH }{ }_{2} \mathrm{O}\right) \\ \text { SIV } & \text { Septo interventricular } \\ \text { SNS } & \text { Sistema Nervoso Simpático } \\ \text { SpO } & \text { Saturação periférica da oxihemoglobina } \\ \text { TD } & \text { Tempo de desaceleração da onda E } \\ \text { TRIV } & \text { Tempo de relaxamento isovolumétrico } \\ \text { VD } & \text { Ventrículo direito } \\ \text { VE } & \text { Ventrículo esquerdo } \\ \text { VHS } & \text { Víme saída do ventrículo esquerdo } \\ \text { VSV } & \end{array}$


Tabela 1 Critérios de inclusão e exclusão

Tabela 2 Análise dos efeitos fixos do modelo linear misto inicial para "Fração do volume regurgitante (\%)".

Tabela 3 Análise dos efeitos fixos do modelo linear misto final para "Fração do volume regurgitante (\%)".

Tabela 4 Características demográficas, clínicas e de medicações utilizadas pela população total e classificada em CMHN-Obst e CMHObst.

Tabela 5 Exames laboratoriais da população total e classificada em CMHN-Obst e CMHObst.

Tabela 6 Dados polissonográficos da população total e classificada em CMHN-Obst e CMHObst.

Tabela 7 Dados dos questionários de sono da população total e classificada em CMHN-Obst e CMHObst.

Tabela 8 Dados ecocardiográficos basais dos pacientes classificados em CMHN-Obst e CMHObst.

Tabela 9 Dados ecocardiográficos de ambos os grupos ao longo do estudo

Tabela 10 Concordância interobservador para variáveis ecocardiográficas avaliadas pelo coeficiente de correlação intraclasse

Tabela 11 Concordância intraobservador para variáveis ecocardiográficas avaliadas pelo coeficiente de correlação intraclasse.

Tabela 12 Comparação das médias das pressões arteriais sistólicas e diastólicas nos grupos CMHN-Obst e CMHObst ao longo do estudo.

Tabela 13 Análise comparativa da variação das pressões arteriais sistólica e diastólica no $10^{\circ}$ minuto com CPAP- $10 \mathrm{cmH}_{2} \mathrm{O}$ e $1^{\circ}$ minuto do momento seguinte. 
Figura 1 Figura ilustrativa de um coração normal e um coração com cardiomiopatia hipertrófica assimétrica de predomínio septal

Figura 2 Representação esquemática dos mecanismos envolvidos na obstrução da via de saída do ventrículo esquerdo.

Figura 3 A: músculo papilar acessório advindo da parede livre anterior do ventrículo esquerdo, com cordoalhas anexas ao folheto mitral e parede livre. B: cordoalha anômala originada de um músculo papilar e inserida no septo

Figura 4 Aspectos morfológicos anatômicos da cardiomiopatia hipertrófica, quanto à distribuição da hipertrofia.

Figura 5 Representação esquemática das fases do ciclo cardíaco, demonstrando a ejeção do sangue na sístole inicial, seguida pela obstrução da via de saída do ventrículo esquerdo na fase final da sístole provocada pela hipertrofia septal, e movimento anterior sistólico da valva mitral contra o septo.....

Figura 6 Mecanismos de refluxo mitral em pacientes com $\mathrm{CMH}$ pela falha de coaptação das cúspides.

Figura 7 Vias comuns, mas independentes dos mecanismos de desfecho cardiovascular na apneia obstrutiva do sono e na cardiomiopatia hipertrófica.

Figura 8 Representação esquemática da ação do CPAP na abertura das vias aéreas superiores por meio de uma interface nasal..

Figura 9 Representação esquemática dos efeitos da pressão positiva sobre as vias aéreas, pulmões, coração e hemodinâmica......

Figura 10 Foto ilustrativa do posicionamento do paciente $\mathrm{e}$ equipamentos utilizados para a aquisição de dados

Figura 11 Fluxograma do desenho do estudo.

Figura 12 Foto ilustrativa dos equipamentos utilizados para aquisição das variáveis respiratórias conectados à máscara nasal e ao CPAP modificado

Figura 13 Figura ilustrativa do Portapres ${ }^{\circledR}$

Figura 14 Manguito do Portapres ${ }^{\circledR}$ com cuff posicionado no dedo do paciente. 


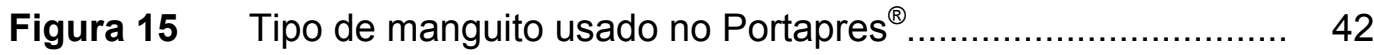

Figura 16 Sistema de correção de altura do Portapres ${ }^{\circledR}$....................... 44

Figura 17 Labview demonstrando aquisição de dados fisiológicos......... 45

Figura 18 Tela de monitorização do sistema Dixtal ${ }^{\circledR}$ com registros do eletrocardiograma e $\mathrm{EtCO}_{2}$

Figura 19 Imagem ecocardiográfica bidimensional em corte apical quatro câmaras, demonstrado a hipertrofia septal basal e o movimento anterior sistólico (MAS) do folheto anterior da valva mitral em direção ao septo na sístole ventricular.

Figura 20 A - Imagem ecocardiográfica em corte apical quatro câmaras. B - no mesmo corte, planimetria do átrio esquerdo para quantificar área e volume; C - no mesmo corte, planimetria do jato regurgitante.

Figura 21 Imagem ecocardiográfica de Doppler pulsado contínuo do fluxo da via de saída do ventrículo esquerdo, com cálculo do pico de velocidade.

Figura 22 Representação de 5 minutos de sono em uma tela de polissonografia noturna

Figura 23 Fluxograma dos participantes do estudo

Figura 24 Variáveis ecocardiográficas relacionadas à magnitude do refluxo mitral para ambos os grupos.

Figura 25 Efeitos da pressão positiva na anatomia e dinâmica cardíacas dos pacientes com CMHN-Osbt e CMHObst.

Figura 26 Reduções nos volumes diastólico-finais das câmaras cardíacas com aumentos das pressões ventilatórias de zero (PPV0 - Positive-pressure ventilation), $10 \mathrm{cmH}_{2} \mathrm{O}$ (PPV10) e $20 \mathrm{cmH}_{2} \mathrm{O}$ (PPV20). 
Gráfico 1 Gráfico correspondente ao comportamento da área do átrio direito entre os grupos ao longo do estudo.

Gráfico 2 Representação do comportamento do gradiente de VSVE em medidas Basais e durante manobras de Valsalva e Muller, para os grupos CMHN-Obst e CMHObst......

Gráfico 3 Representação do comportamento do gradiente de VSVE em medidas Basais e com o uso da pressão positiva, para os grupos CMHN-Obst e CMHObst.

Gráfico 4 Gráfico de Bland-Altman representando os limites de concorância interobservador para "fração do volume regurgitante"

Gráfico 5 Gráfico de Bland-Altman representando os limites de concorância intraobservador para "fração do volume regurgitante"

Gráfico 6 Comportamento das pressões arteriais sistólica e diastólica registradas durante todos os momentos do estudo, em ambos os grupos. 
Nerbass FB. Efeitos hemodinâmicos agudos da pressão positiva contínua na via aérea (CPAP) em indivíduos com cardiomiopatia hipertrófica [tese]. São Paulo: Faculdade de Medicina, Universidade de São Paulo; 2015.

Introdução: Apneia obstrutiva do sono (AOS) é uma doença comum em pacientes com cardiomiopatia hipertrófica $(\mathrm{CMH})$ e está associada de forma independente a piora nos seus parâmetros cardíacos. O tratamento da AOS com CPAP (continuous positive airway pressure) é considerado benéfico em pacientes sem $\mathrm{CMH}$. Contudo, O CPAP pode agudamente piorar o desempenho cardíaco em pacientes com $\mathrm{CMH}$ e obstrução na via de saída do ventrículo esquerdo (VSVE). Métodos: Foram estudados 26 pacientes com $\mathrm{CMH}$, estáveis, divididos em 12 não-obstrutivos (CMHN-Obst) e 14 obstrutivos (CMHObst), de acordo com seu gradiente de VSVE menor ou maior que $30 \mathrm{mmHg}$, respectivamente. Pacientes foram continuamente monitorados pela pressão arterial (PA) batimento-a-batimento e eletrocardiograma, em vigília e posição supina. Um ecocardiograma bidimensional foi realizado durante o repouso (Basal) a após 20 minutos de CPAP nas pressões de $1,5 \mathrm{cmH}_{2} \mathrm{O}$ e $10 \mathrm{cmH}_{2} \mathrm{O}$, que foram aplicadas em ordem randomizada, interpostas por 10 minutos de intervalo sem CPAP. Em outra data os pacientes foram submetidos a uma polissonografia completa para diagnóstico de AOS. Resultados: Variáveis hemodinâmicas como PA, débito cardíaco, volume sistólico, frequência cardíaca, fração de ejeção do ventrículo esquerdo e gradiente de VSVE permaneceram estáveis ao longo do estudo em ambos os grupos. Em pacientes não-obstrutivos, o CPAP em $10 \mathrm{cmH}_{2} \mathrm{O}$ reduziu área do átrio direito, a complacência do ventrículo esquerdo, bem como o relaxamento de ambos os ventrículos. Nos pacientes obstrutivos, o CPAP em $10 \mathrm{cmH}_{2} \mathrm{O}$ provocou efeitos similares no coração direito e também elevou as pressões na artéria pulmonar. No coração esquerdo, houve uma redução na área e volume do átrio esquerdo, com aumento nas áreas e volumes do jato e frações regurgitantes. A polissonografia completa demonstrou que a AOS (índice de apneia e hipopneia $\geq 15$ eventos/hora) estava presente em $58 \%$ dos pacientes. Conclusões: O CPAP se mostrou uma alternativa segura para tratar AOS em pacientes com $\mathrm{CMH}$, pois não alterou agudamente a hemodinâmica. Contudo, provocou algumas alterações na dinâmica cardíaca de pacientes obstrutivos, que devem ser considerados com cautela.

Descritores: 1. Cardiomiopatia Hipertrófica 2. Hemodinâmica 3. Pressão Arterial 4. Ecocardiografia 5. Apneia Obstrutiva do Sono 6. Pressão Positiva Contínua nas Vias Aéreas (CPAP) 7. Polissonografia. 
Nerbass FB. Acute hemodynamic effects of continuous positive airway pressure (CPAP) in individuals with hypertrophic cardiomyopathy [thesis]. São Paulo: "Faculdade de Medicina, Universidade de São Paulo"; 2015.

Background: Obstructive sleep apnea (OSA) is a common disease and is independently associated with a worse in cardiac parameters among patients with hypertrophic cardiomyopathy (HCM). The treatment of OSA with CPAP (Continuous positive airway pressure) is beneficial among patients without $\mathrm{CMH}$. However, CPAP may acutely impair cardiac performance in patients with $\mathrm{HCM}$ and left ventricular outflow tract (LVOT) obstruction. Methods: We studied 26 stable HCM patients divided in 12 nonobstructive-HCM and 14 obstructive-HCM according to their LVOT pressure gradient lower or higher than $30 \mathrm{mmHg}$, respectively. Patients were continuously monitored by beatto-beat blood pressure (BP) and electrocardiogram in the supine position while awake. A 2-dimensional echocardiography was performed at resting (Baseline) and after 20 minutes of nasal CPAP at $1.5 \mathrm{cmH} 2 \mathrm{O}$ and $10 \mathrm{cmH}_{2} \mathrm{O}$, that was applied in a random order interposed by 10 minutes without CPAP. In another day all patients underwent full Polysomnography for OSA diagnosis. Results: Hemodynamic variables such as BP, cardiac output, stroke volume, heart rate, left ventricular ejection fraction and LVOT gradient did not change along the study period in both groups. CPAP at $10 \mathrm{cmH}_{2} \mathrm{O}$ in nonobstructive-HCM patients decreased right atrial area, left ventricular compliance, right and left ventricular relaxation. In obstructive-HCM patients, CPAP at $10 \mathrm{cmH}_{2} \mathrm{O}$ promoted similar effects in the right heart, and also raised pulmonary artery pressure. In the left heart, there was a decrease in left atrial area and volume with increased area and volume of both, regurgitant jet and regurgitant fraction. Full Polysomnography showed that OSA (apneahypopnea index $\geq 15$ events/h) was present in $58 \%$ of $\mathrm{HCM}$ patients. Conclusions: CPAP showed to be safe to treat OSA and did not acutely change hemodynamics in patients with HCM. However, CPAP may acutely impair cardiac dynamics in obstructive-HCM patients and this finding should be carefully considered.

Descriptors: 1. Hypertrophic Cardiomyopathy 2. Hemodynamics 3. Blood Pressure 4. Echocardiography 5. Obstructive Sleep Apnea 6. Continuous Positive Airway Pressure (CPAP) 7. Polysomnography. 


\section{Introdução}

\subsection{Cardiomiopatia Hipertrófica (CMH)}

A cardiomiopatia hipertrófica $(\mathrm{CMH})$ é uma doença genética cardíaca transmitida por herança autossômica dominante e caracterizada por pronunciada hipertrofia do ventrículo esquerdo $(V E) .{ }^{(1,2)}$ Essa hipertrofia decorre de mutações nos genes que codificam as proteínas do sarcômero e seus componentes de miofilamentos, que possuem funções contráteis, estruturais ou regulatórias. ${ }^{(2-4)}$ Até o momento, 19 genes foram relacionados à $\mathrm{CMH}$ e mais de 900 mutações nesses genes já foram descritas. ${ }^{(5)} \mathrm{A} \mathrm{CMH}$ manifesta-se, em geral, na puberdade, porém, seu desenvolvimento pode ocorrer em várias faixas etárias, variando da infância a fase adulta. ${ }^{(2)}$

Evidencias demonstram que não apenas a hipertrofia miocárdica, mas umas séries de outras alterações cardíacas estruturais estão presentes na $\mathrm{CMH}$ e parecem estar relacionadas à fisiopatologia, sintomatologia e prognóstico da doença, além de também determinarem sua forma de classificação.

\subsubsection{Alterações cardíacas estruturais}

A magnitude e distribuição da hipertrofia nas paredes ventriculares é variável, podendo acometer o VE de forma simétrica (espessura semelhante das paredes ventriculares) ou assimétrica (diferentes espessuras das paredes ventriculares), num ventrículo não dilatado. ${ }^{(6)}$ A forma assimétrica é a mais comum ( $90 \%$ dos casos), com espessura mais pronunciada 
localizada no septo interventricular $(\mathrm{SIV})^{(6)}$ (Figura 1). Em ambas as formas, como consequência dessa hipertrofia, ocorre uma rigidez intrínseca anormal da parede do VE, o que ocasiona déficit no relaxamento das fibras miocárdicas e prejudica o enchimento ventricular, representando uma disfunção diastólica. ${ }^{(6)}$ A cavidade ventricular pode ter tamanho normal ou estar reduzida e apresentar altas pressões de enchimento. Frequentemente encontram-se átrios dilatados e hipertrofiados, refletindo essa alta resistência ao enchimento do VE. A função contrátil pode permanecer inalterada ou até ser hiperdinâmica, o que garante altas frações de ejeção pelo VE. ${ }^{(7)}$

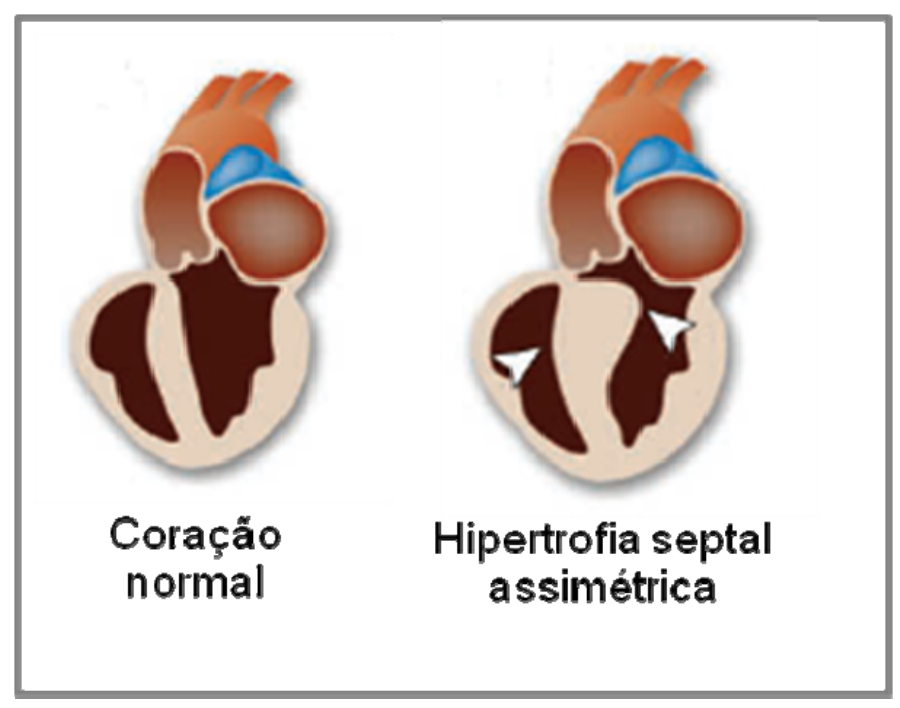

Figura 1 - Figura ilustrativa de um coração normal e um coração com cardiomiopatia hipertrófica assimétrica de predomínio septal. (Fonte: Adaptado de Chun EF et al. RadioGraphics. 2010; 30:1309-1328)(8) 
Em conjunto à hipertrofia, um espectro de anormalidades morfológicas do aparato mitral tem sido descritos como fatores importantes relacionados à $\mathrm{CMH}^{\left({ }^{(9)}\right.} \mathrm{Em}$ 1967, um grupo de pesquisadores de Maryland chamou a atenção para uma anormalidade na geometria e morfologia dos folhetos mitrais, dos músculos papilares, da via de saída do ventrículo esquerdo (VSVE) e da cavidade ventricular esquerda de pacientes com estenose subaórtica hipertrófica idiopática, avaliados por angiografia cardíaca. ${ }^{(10)}$ Desde então, muitos estudos corroboraram esse conceito de que existem deformidades estruturais primárias no aparato mitral de pacientes com $\mathrm{CMH}$. Essas deformidades incluem alongamento anormal das cúspides mitrais (folhetos anterior e posterior), mudança de posição dos músculos papilares, coaptação anormal das cúspides e frouxidão das cordoalhas tendíneas. ${ }^{(9)}$

As cúspides mitrais podem ser de $1,5 \mathrm{~cm}$ a $1,7 \mathrm{~cm}$ mais longas na $\mathrm{CMH}$ do que em corações normais. ${ }^{(11)}$ Esse alongamento anormal pode levar o folheto anterior a se movimentar contra o SIV durante a sístole, o que chamamos de movimento anterior sistólico mitral (MAS), que é outra característica comumente encontrada na $\mathrm{CMH}$. O MAS contra o septo hipertrofiado altera a geometria da VSVE, ocasionando um estreitamento nessa região e obstruindo a ejeção do sangue. Como resultado dessa obstrução, durante a sístole ventricular ocorre uma aceleração do fluxo de sangue entre o VE e valva aórtica, gerando um gradiente pressórico. Este gradiente se modifica mediante determinadas situações impostas ao coração e pode gerar implicações hemodinâmicas, por isso é denominado gradiente 
pressórico dinâmico (GPD) $)^{(6,12)}$ e será discutido a seguir. O MAS também pode ser responsável por uma falha na coaptação das cúspides mitrais, formando uma espécie de "funil" entre os folhetos, o que permite que uma quantidade de sangue reflua para dentro do átrio esquerdo $(\mathrm{AE})$ durante a sístole ventricular - regurgitação mitral ${ }^{(13)}$ (Figura 2).

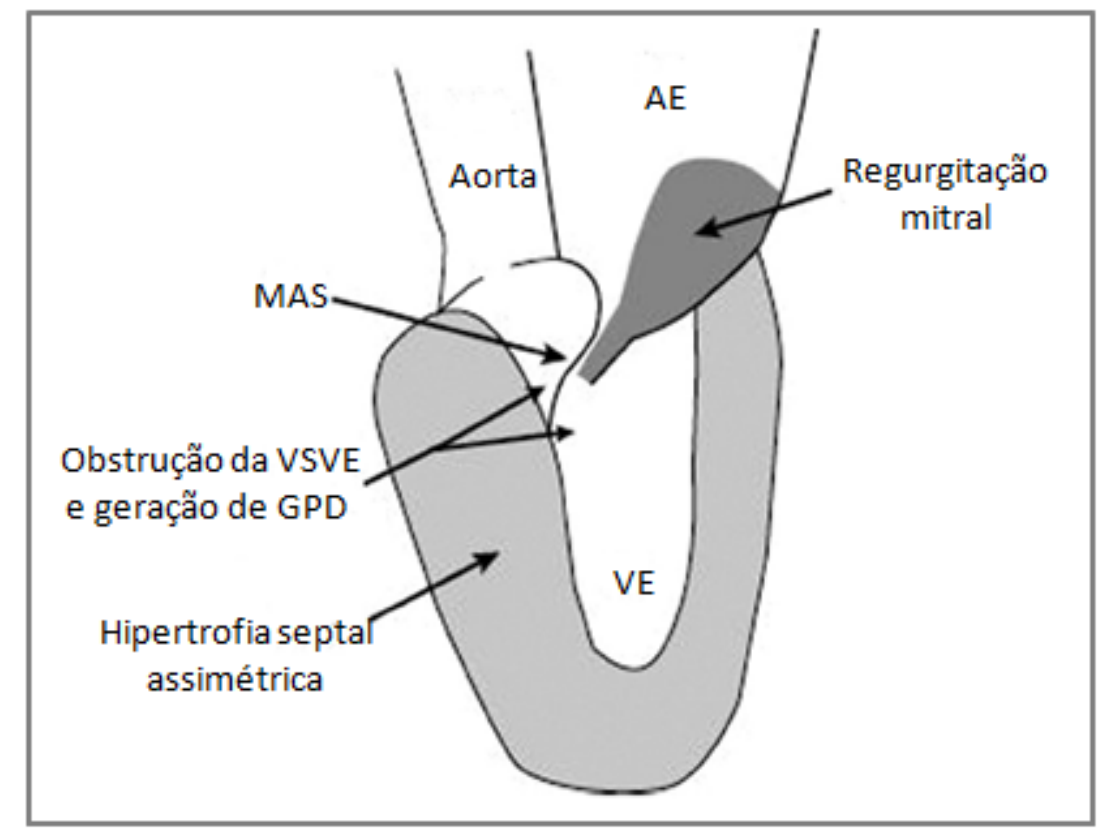

Figura 2 - Representação esquemática dos mecanismos envolvidos na obstrução da via de saída do ventrículo esquerdo: Hipertrofia septal assimétrica; movimento anterior sistólico da valva mitral contra o septo (MAS); gradiente pressórico dinâmico (GPD) e coaptação anormal das cúspides mitrais - regurgitação mitral. $\mathrm{AE}$ : átrio esquerdo, VE: ventrículo esquerdo. (Fonte: Adaptado de Fifer MA. Circulation. 2007;116(2):207-16). ${ }^{(14)}$

Anormalidades anatômicas nos músculos papilares também têm sido descritas (Figura 3), e suas morfologia, posicionamento e mobilidade 
aumentada, parecem ter importante contribuição na dinâmica da obstrução da VSVE em alguns pacientes com $\mathrm{CMH}^{\left({ }^{13)}\right.}$ As alterações atualmente descritas nos músculos papilares incluem: hipertrofia, inserção direta no folheto anterior da valva mitral, fusão no SIV, fusão na parede livre do VE, deslocamento apical anterior, músculo papilar bifurcado e acessório. ${ }^{(13)}$

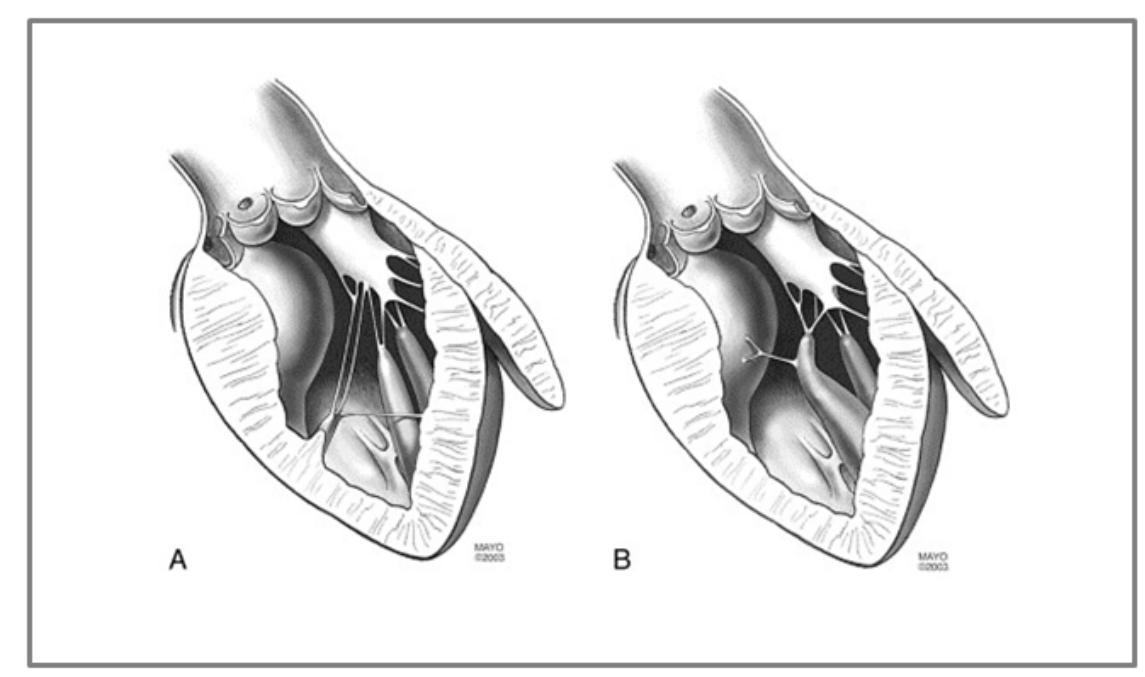

Figura 3 - A: músculo papilar acessório advindo da parede livre anterior do ventrículo esquerdo, com cordoalhas anexas ao folheto mitral e parede livre. B: cordoalha anômala originada de um músculo papilar e inserida no septo. (Fonte: Minakata K et al. J Thorac Cardiovasc Surg. 2004; 127:481-489)(15)

\subsubsection{Classificação da $\mathrm{CMH}$}

A $\mathrm{CMH}$ é classificada de acordo com a distribuição anatômica e predominância da hipertrofia, e como essa hipertrofia pode provocar alterações hemodinâmicas. 


\subsubsection{Quanto à distribuição anatômica}

As formas de hipertrofia mais comuns encontradas em pacientes com $\mathrm{CMH}$ são aquelas de predomínio septal, apical, medioventricular e lateral. ${ }^{(16)}$

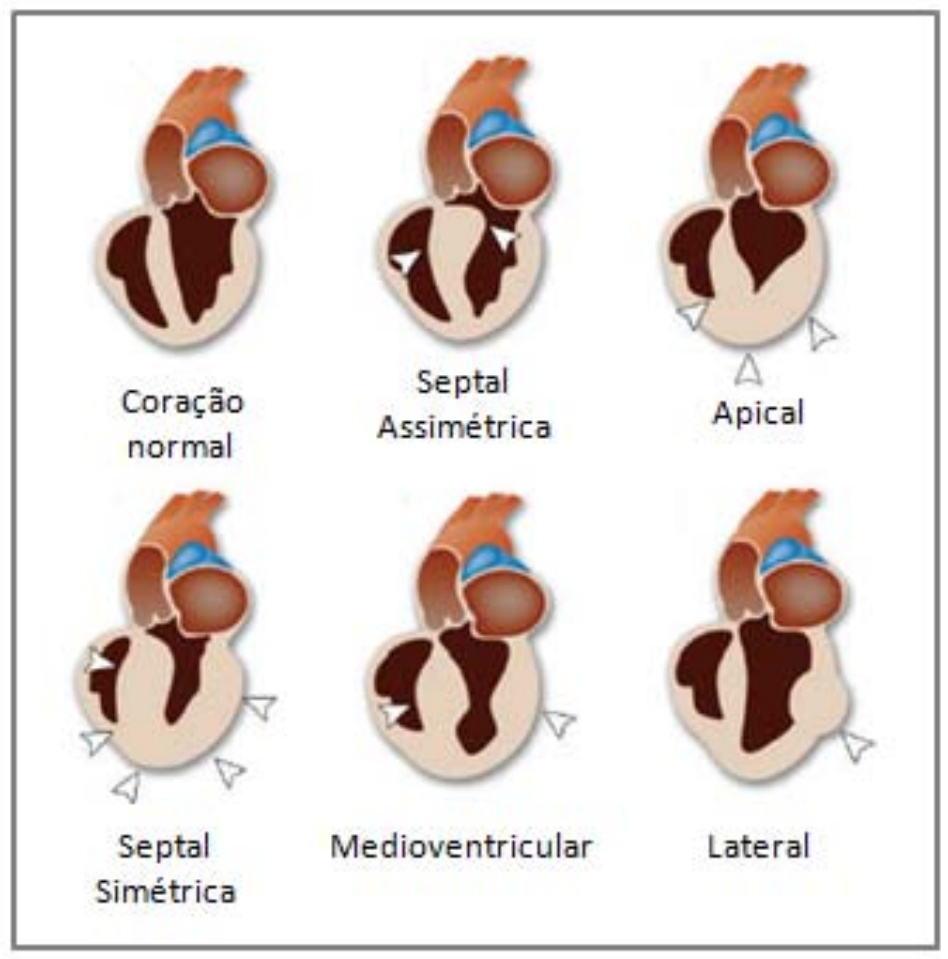

Figura 4 - Aspectos morfológicos anatômicos da cardiomiopatia hipertrófica, quanto à distribuição da hipertrofia. (Fonte: Adaptado de Chun EF et al. RadioGraphics. 2010; 30:1309-1328). ${ }^{(8)}$

\subsubsection{Quanto à hemodinâmica}

As alterações hemodinâmicas na $\mathrm{CMH}$ são consequência das variações anatômicas da doença, que causam diferentes graus de comprometimento funcional ao VE. Nas formas septal assimétrica e 
medioventricular (Figura 4), por exemplo, a porção mais hipertrofiada do septo se projeta para dentro da cavidade ventricular esquerda, provocando uma aceleração do sangue nesta região, ou seja, o GPD. Quando esse gradiente medido for $\geq 30 \mathrm{mmHg}$, denomina-se $\mathbf{C M H}$ obstrutiva e, quando $\leq$ 30mmHg, denomina-se CMH não-obstrutiva. Quanto maior for o GPD, maior será a sintomatologia da doença e pior o prognóstico.

As formas não-obstrutivas (septal simétrica, apical, lateral e/ou láteroposterior) são as mais benignas e, em geral, não causam sintomas em repouso. Contudo, cerca de $75 \%$ dos pacientes não-obstrutivos passam a apresentar obstrução quando submetidos a manobras de provocação (ex: atividade física e manobra de Valsalva). Nessas situações, podem cursar com a mesma sintomatologia apresentada por aqueles com a forma obstrutiva da $\mathrm{CMH} .{ }^{(7)}$

\subsubsection{Prevalência e curso natural da $\mathrm{CMH}$}

A $\mathrm{CMH}$ é a doença genética cardíaca mais prevalente, acometendo 1:500 habitantes da população geral. ${ }^{(2,17)}$ Os casos de aparecimento mais precoce parecem ter pior prognóstico, pois sua evolução natural ainda é causa de incapacidade pela alta prevalência de fibrilação atrial (FA), insuficiência cardíaca e morte súbita em todas as idades. ${ }^{(18-20)}$ Algumas mutações genéticas que ocasionam manifestação mais tardia parecem ter melhor prognóstico. ${ }^{(21)}$ 
A FA é a arritmia mais comum na $\mathrm{CMH}^{(2)}$ e é um preditor de mortalidade nessa população. ${ }^{(22,23)}$ A insuficiência cardíaca diastólica, que decorre da progressão da doença, é responsável pela manifestação de sintomas como: dispneia aos esforços, ortopneia, dispneia paroxística noturna e fadiga. A piora na classe funcional (NYHA III e IV) não é tão frequente, ocorrendo em cerca de $15 \%$ a $20 \%$ dos casos. $^{(2)}$ Porém, pacientes com $\mathrm{CMH}$ tem restrições à realização de exercícios físicos, por piorarem a sintomatologia. A morte súbita nos jovens é o componente mais devastador de sua história natural, com uma mortalidade anual variando de $1 \%$ a $6 \%$. $^{(24-26)}$

\subsubsection{Diagnóstico}

A suspeita clínica da $\mathrm{CMH}$ se dá por alterações de ausculta cardíaca, história familiar positiva para a doença, presença de sintomas ou alterações eletrocardiográficas. $^{(2)}$

A ecocardiografia transtorácica bi-dimensional é o exame mais empregado atualmente e recomendado para avaliação inicial, tanto na investigação de casos suspeitos, quanto para screening de parentes dos pacientes com a doença (nível de evidência B). ${ }^{(3)}$ Com a ecocardiografia é possível avaliar os aspectos morfológicos, funcionais e hemodinâmicos da $\mathrm{CMH} .{ }^{(6)} \mathrm{O}$ diagnóstico é confirmado quando encontra-se um SIV com espessura $\geq 15 \mathrm{~mm}$, na ausência de outras doenças capazes de causar hipertrofia desta magnitude (p.e: estenose aórtica e hipertensão arterial 
sistêmica), ou uma espessura $\geq 13 \mathrm{~mm}$ em indivíduos que já tenham parentes de primeiro grau com a doença confirmada. ${ }^{(2,27)}$

A ressonância magnética é recomendada quando a ecocardiografia for inconclusiva para o diagnóstico (nível de evidência $B)^{(3)}$ ou apresentar dificuldade técnica para avaliar hipertrofia segmentar. ${ }^{(2)}$

Os testes genéticos são uma estratégia potente para o diagnóstico definitivo do status genético e na identificação de parentes de primeiro grau de famílias com $\mathrm{CMH}^{\left({ }^{(3)}\right.}$ Com base no histórico familiar, triagem clínica e análises na genealogia, o padrão de herança é apurado para identificar e acompanhar parentes em risco. Como se trata de uma doença familiar autossômica dominante, o risco de um paciente afetado transmitir a doença a cada descendente é de 50\%. Quando uma mutação patogênica é identificada num doente, o padrão genético de cada membro da família pode ser facilmente determinado. ${ }^{(3)}$

\subsubsection{Desempenho cardíaco na $\mathrm{CMH}$}

Cerca de $25 \%$ dos pacientes com $\mathrm{CMH}$ tem a forma obstrutiva da doença. Uma teoria sobre essa obstrução suporta o fato de que a projeção do septo para dentro da cavidade ventricular criaria um efeito "Venturi" no fluxo sanguíneo, que por sua vez projetaria a valva mitral contra a VSVE. ${ }^{(28)}$ No entanto, esse fenômeno de "Venturi" é falho no que diz respeito à presença do MAS em baixas velocidades de sangue na VSVE. ${ }^{(13)}$ Assim, uma outra hipótese atualmente a mais aceita, é de que a aceleração do fluxo 
de sangue em torno o septo produza um efeito de "arrastamento" numa valva mitral alongada e deslocada, empurrando-a contra o septo, ${ }^{(28)}$ sendo uma força hidrodinâmica dominante a causadora do MAS. ${ }^{(13)}$ De qualquer forma, esse aumento na velocidade de passagem do sangue pela VSVE é o responsável pela formação do GPD e por suas consequências.

\section{Gradiente pressórico dinâmico:}

Didaticamente, descrevemos os mecanismos envolvidos na geração do GPD como: 1) o espessamento septal e 2) o deslocamento anormal da valva mitral contra o septo. Ambos, em conjunto, ocasionam um estreitamento da região subaórtica denominado: obstrução (Figura 2).

Acredita-se que durante a formação do GPD, na fase inicial da sístole, uma porção do volume de sangue seja ejetado antes da obstrução, com rápido esvaziamento ventricular, o que gera frações de ejeção normais ou até elevadas. Evidências sugerem que, mais tarde, durante a fase final da sístole é que está presente a obstrução verdadeira, em que uma pequena fração de sangue residual é impedida de ser ejetada. Por isso, a duração da sístole pode ser mais prolongada. ${ }^{(7)}$ 


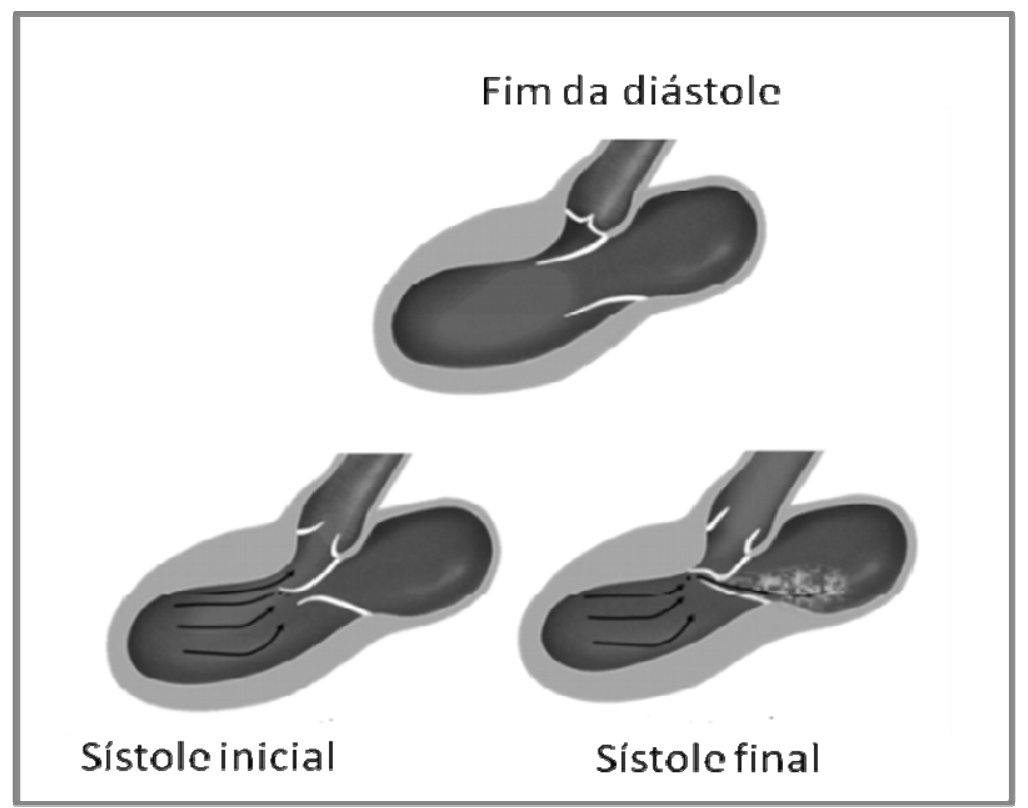

Figura 5 - Representação esquemática das fases do ciclo cardíaco, demonstrando a ejeção do sangue na sístole inicial, seguida pela obstrução da via de saída do ventrículo esquerdo na fase final da sístole provocada pela hipertrofia septal, e movimento anterior sistólico da valva mitral contra o septo. (Fonte: Adaptado de Geske JB et al. Clin Cardiol 2009; 32: 397-402). ${ }^{(28)}$

A natureza dinâmica da obstrução na VSVE é resultado das alterações na carga imposta ao VE e da contratilidade miocárdica, que são sensíveis a variações de status volêmico, atividade nervosa autonômica, variações circadianas, farmacoterapia e exercício. ${ }^{(28)}$ Assim, todas as intervenções que provoquem aumento da contratilidade (p.e. exercício físico), que reduzam o volume ventricular - pré-carga (p.e. manobra de valsalva) e reduzam a impedância e a pressão aórtica - pós-carga do VE, são mecanismos que podem causar o aumento do gradiente. ${ }^{(29)}$ Por outro lado, uma redução na contratilidade e aumento na pré e pós-carga do VE, que aumentam o tamanho do VE, reduzem essa obstrução. ${ }^{(29)}$ Observe que 
os estímulos que aumentam o gradiente em corações hipertróficos e pioram a obstrução, são os mesmos que melhoram o desempenho cardíaco em corações normais.

A caracterização do GPD na VSVE é primordial no manejo dos pacientes com $\mathrm{CMH}$, por ser responsável pela sintomatologia, pela ocorrência de pré-síncope e síncope, além de ser determinante importante de aumento de morbi-mortalidade cardíaca. ${ }^{(13)}$

\section{$\underline{\text { Regurgitação mitral }}$}

A regurgitação mitral, uma característica também frequente em pacientes obstrutivos, decorre das alterações dinâmicas na geometria do aparato mitral citadas anteriormente, sendo o MAS um dos principais fatores envolvidos nessa alteração. Aparentemente, quanto maior for a distância do ponto de coaptação entre as cúspides mitrais e quanto maior for a distância entre os músculos papilares, mais difícil será a coaptação adequada entre os folhetos anterior e posterior, e mais importante será o MAS. ${ }^{(13,30)}$ Conforme já comentado, essa falha de coaptação entre os folhetos gera um orifício ("funil"), que favorece o "escape" de sangue para dentro do AE durante a sístole ventricular. Esse orifício pode ser resultante de: 1) um MAS pronunciado na porção distal do folheto anterior ou dos 2 folhetos; $\left.{ }^{(31)} 2\right)$ uma redução de mobilidade e de comprimento da cúspide posterior ou 3) uma diferença de comprimento entre as duas cúspides. Em síntese, a incapacidade da cúspide posterior seguir a anterior durante o MAS, 
associada a uma redução na sua mobilidade e um tamanho relativo menor, resultam nesse funil entre os folhetos que permite que o refluxo mitral ocorra. ${ }^{(9,13)}$ Além disso, o volume residual de sangue dentro do VE (impedido de ser ejetado para a Aorta), também contribui para que uma maior quantidade de sangue reflua por esse orifício na fase final da sístole.

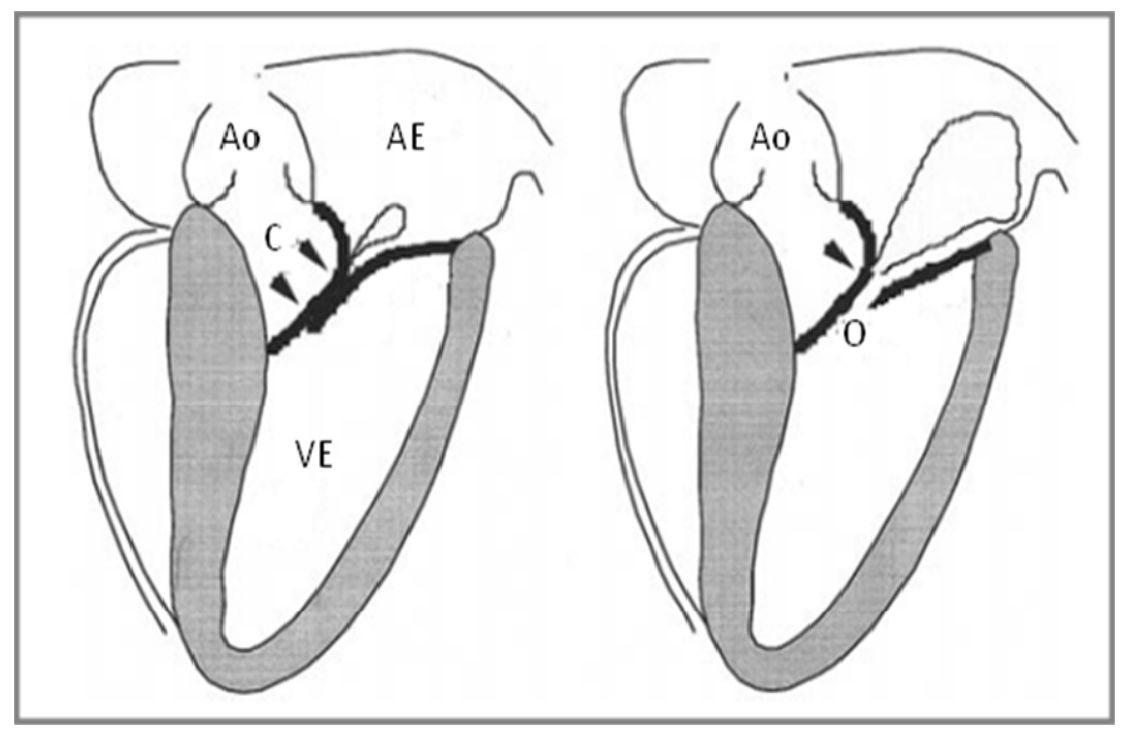

Figura 6 - Mecanismos de refluxo mitral em pacientes com $\mathrm{CMH}$ pela falha de coaptação das cúspides. À esquerda, o folheto posterior é alongado e as duas cúspides se coaptam em um longo trajeto (ponto de contato "C"). O folheto anterior se projeta contra o septo (MAS) e o refluxo mitral é pequeno dentro do átrio esquerdo (AE). À direita o folheto posterior não coapta adequadamente com o anterior, gerando um orifício visível (funil "O") que permite um refluxo de sangue para dentro do AE durante a sístole ventricular. AO: aorta; VE: ventrículo esquerdo. (Fonte: Adaptado de Schwammenthal E et al. Circulation. 1998 Sep;98(9):856$65)^{(9)}$

\subsubsection{Sintomatologia clínica e tratamento:}


Muitos pacientes com $\mathrm{CMH}$ apresentam-se assintomáticos ou com sintomas leves, sendo aqueles associados ao GPD os mais comuns. ${ }^{(32)} \mathrm{A}$ dispneia é o mais frequente ( $90 \%$ dos pacientes), seguido por angina e síncopes. ${ }^{(3)} \mathrm{O}$ tratamento da $\mathrm{CMH}$ consiste em terapias que minimizem essa sintomatologia relacionada ao GPD. Fármacos que reduzam a frequência cardíaca (FC) (betabloqueadores e bloqueadores de canais de cálcio) ${ }^{(1)}$ e antiarrítmicos (amiodarona ou disopiramida) são muito utilizados. ${ }^{(19)}$ Casos refratários ao tratamento clínico podem se beneficiar da redução do SIV por alcoolização via cateterismo intervencionista ou por miectomia cirúrgica. ${ }^{(33,}$ 34) O implante de cardioversor-desfibrilador é atualmente indicado em casos de alto risco de morte súbita ou naqueles sobreviventes de arritmias graves. $^{(33)}$ Nos pacientes em estágio final de disfunção diastólica, o transplante cardíaco pode ser considerado. ${ }^{(2)}$

Diante do exposto, como a $\mathrm{CMH}$ é uma doença de caráter hereditário e per se possui uma evolução natural, até recentemente, pouco era o interesse da comunidade científica na pesquisa de possíveis comorbidades que pudessem contribuir para o aumento no risco cardiovascular e piora no prognóstico desses pacientes. Dentre as comorbidades atualmente estudadas que comprovadamente implicam em prejuízos ao sistema cardiovasculares e pioram o risco cardiovascular de seus portadores, está a apneia obstrutiva do sono (AOS). 


\subsection{Apneia Obstrutiva do Sono (AOS)}

Conceitualmente, a AOS caracteriza-se por episódios repetidos de obstrução parcial ou completa das vias aéreas superiores durante o sono, associada à queda da saturação da oxihemoglobina e despertares frequentes. É chamada de Síndrome, quando associada à presença de sonolência diurna e doenças cardiovasculares. ${ }^{(35)}$

\subsubsection{AOS e consequências cardiovasculares}

Os potenciais efeitos da AOS sobre o sistema cardiovascular são múltiplos: 1) as obstruções recorrentes das vias aéreas superiores aumentam o esforço inspiratório e causam maior negativação da pressão intrapleural, que por sua vez aumenta o retorno venoso para dentro do átrio direito (AD), causando distensão do ventrículo direito (VD) e podendo deslocar do SIV para a esquerda (prejuízo ao enchimento do VE); 2) as variações na pressão intratorácica durante os episódios obstrutivos aumentam a pressão transmural do VE (pós-carga do VE); 3) a hipóxia e hipercapnia intermitentes levam a despertares frequentes, que aumentam a estimulação dos quimiorreceptores centrais e periféricos e elevarem a atividade nervosa simpática. ${ }^{(36,37)}$ Cabe destacar que estes fenômenos ocorrem inúmeras vezes durante uma noite e por todos os períodos de sono do indivíduo.

Evidencias indicam que as consequências sistêmicas dos eventos obstrutivos não são restritas apenas à noite, podendo estender-se ao longo 
do dia. Assim, a AOS desencadeia uma grande lista de respostas neurohormonais e inflamatórias que são potencialmente prejudiciais para o sistema cardiovascular, incluindo: aumento da atividade nervosa simpática, liberação de produtos do estresse oxidativo, aumento nas concentrações plasmáticas de proteína C-reativa, de fibrinogênio, de citocinas e de leptina, além de ser mediadora de aumento na resistência à insulina e na disfunção endotelial. ${ }^{(38,39)}$ Estudos sugerem que a presença de AOS contribui para o desenvolvimento da aterosclerose, pois nesses estudos, os pacientes com AOS apresentaram aumento da rigidez arterial e da espessura da camada íntima-média da artéria carótida quando comparados aos controles. ${ }^{(40,41)}$

No entanto, a maioria das informações relevantes na literatura derivadas de estudos em pacientes com AOS, foi realizada sem associação com a $\mathrm{CMH}$. Com isso, a pergunta se a AOS será menos, tão ou mais prejudicial nessa classe de pacientes permanece incerta.

\subsubsection{Prevalência de AOS em pacientes com CMH}

A primeira evidência que AOS pudesse ser prevalente entre os pacientes com $\mathrm{CMH}$ foi publicada em 2004 por Banno e colaboradores. ${ }^{(42)}$ Os autores avaliaram pacientes com diversas cardiomiopatias e relataram, em uma pequena amostra de 15 pacientes com $\mathrm{CMH}$, que sete deles (47\%) tinham AOS diagnosticada por polissonografia completa (PSG). Esta observação inicial só foi totalmente investigada nos últimos anos (2009 a 2011), quando três grupos independentes relataram a alta prevalência de 
AOS, variando de $32 \%$ a $71 \%$, num total de 334 pacientes com $\mathrm{CMH}^{(43-46)}$ Contudo, esses estudos recentes apresentam algumas limitações que valem ser destacadas. Em primeiro lugar, a AOS foi diagnosticada por meio de oximetria de pulso noturna ${ }^{(43,45)}$ ou monitor portátil, ${ }^{(44,46)}$ não sendo usada a PSG, que é o padrão-ouro para diagnostico de AOS. Entretanto, no estudo de Eleid e colaboradores, que utilizou oximetria noturna em 100 pacientes com $\mathrm{CMH}$, os autores confirmaram o diagnóstico e gravidade da AOS por PSG em uma sub-amostra de 24 deles. ${ }^{(43)}$ Em segundo lugar, os critérios de corte para o diagnóstico de AOS variaram entre os estudos. Finalmente, o número de estudos é relativamente pequeno e o impacto do reconhecimento e tratamento da AOS entre os pacientes com $\mathrm{CMH}$ ainda precisa ser estabelecido. Por outro lado, esses estudos somam mais de 300 pacientes e seus principais achados são relativamente consistentes entre eles.

\subsubsection{AOS, CMH e desfecho cardiovascular.}

Diversos são os mecanismos que estão associados ao aumento do risco cardiovascular, tanto em pacientes com AOS, quanto naqueles com $\mathrm{CMH}$ (Figura 7). Os pacientes com AOS sofrem de hiperestimulação do sistema nervoso simpático (SNS) durante a noite, que permanece elevada durante o dia. Esse é um achado também encontrado na $\mathrm{CMH}$, que pode não ser apenas um marcador de gravidade da doença, ${ }^{(47)}$ mas sim um fator de risco adicional, pois elevados níveis de catecolaminas circulantes podem influenciar o aumento da hipertrofia ventricular esquerda e suas pressões de 
enchimento, diminuindo o débito cardíaco (DC). Essa redução no DC por sua vez, pode iniciar ou agravar a obstrução na VSVE e a regurgitação mitral. ${ }^{(48)}$ A hiperestimulação simpática também pode contribuir para o aumento da incidência de arritmias ventriculares e supraventriculares em portadores de $\mathrm{CMH}$. Neste contexto, dois desses estudos recentes demonstraram que a presença de AOS em pacientes com $\mathrm{CMH}$, elevou em $4^{(45)}$ a $5^{(44)}$ vezes a prevalência de FA. Os preditores de FA nessa população foram: o índice de apneia-hipopneia (IAH - gravidade da AOS), ${ }^{(44,45)} \mathrm{O}$ tamanho de $\mathrm{AE}^{(44)}$ e $\mathrm{o}$ índice de dessaturação noturna. ${ }^{(45)}$ Esses achados sugerem que a AOS pode sim ter um efeito aditivo negativo sobre a estrutura e função cardíaca, dos pacientes com $\mathrm{CMH}$.

Além disso, a hipertrofia septal tipicamente encontrada em pacientes com $\mathrm{CMH}$, tem sido associada de forma independente com a gravidade da AOS em casos sem $\mathrm{CMH}^{(49,50)}$ estando presente mesmo frente a valores normais de pressão arterial (PA). Esse fato sugere que outros fatores, além da sobrecarga hemodinâmica, contribuam para aumento dessa hipertrofia. A AOS também está independentemente associada com a dilatação do AE, refletindo remodelamento cardíaco, ${ }^{(41,51,52)}$ achado também comum em pacientes com $\mathrm{CMH}^{(44-46)}$ que é um preditor de morbi-mortalidade nessa população. Um estudo realizado por Nistri e colaboradores, ${ }^{(22)}$ evidenciou que um aumento de $5 \mathrm{~mm}$ no $\mathrm{AE}$ elevou em $20 \%$ a chance de morte em pacientes com $\mathrm{CMH}$, num período de 10 anos. Quando a AOS está presente em pacientes com $\mathrm{CMH}$, a dimensão do $\mathrm{AE}$ se torna ainda maior do que em pacientes com $\mathrm{CMH}$ sem $\mathrm{AOS}$, o que foi demonstrado por estudos de três 
grupos distintos. ${ }^{(43-45)}$ No estudo de Pedrosa e colaboradores, ${ }^{(44)}$ pacientes com $\mathrm{AOS}+\mathrm{CMH}$ apresentaram um aumento de $9 \%$ no $\mathrm{AE}$ quando comparados aos pacientes com $\mathrm{CMH}$ sem $\mathrm{AOS}$, sendo o $\mathrm{IAH}$ o único preditor desse aumento. Nos estudos de Konecny e colaboradores ${ }^{(45)}$ e Prinz e colaboradores, ${ }^{(46)}$ houve uma correlação positiva entre o volume do AE e a gravidade da AOS. Esse achado pode ser explicado pelo aumento da pressão transmural do VE durante as apneias, que é um importante determinante da maior pós-carga ventricular e atrial esquerda e pode, portanto, resultar em maiores diâmetros atriais. ${ }^{(41)}$

Finalmente, pacientes com AOS podem ter um maior risco de morte súbita, ${ }^{(53)}$ principalmente no período noturno, ${ }^{(54)}$ que por sua vez é uma complicação comum na história natural da $\mathrm{CMH} .{ }^{(1,55)}$

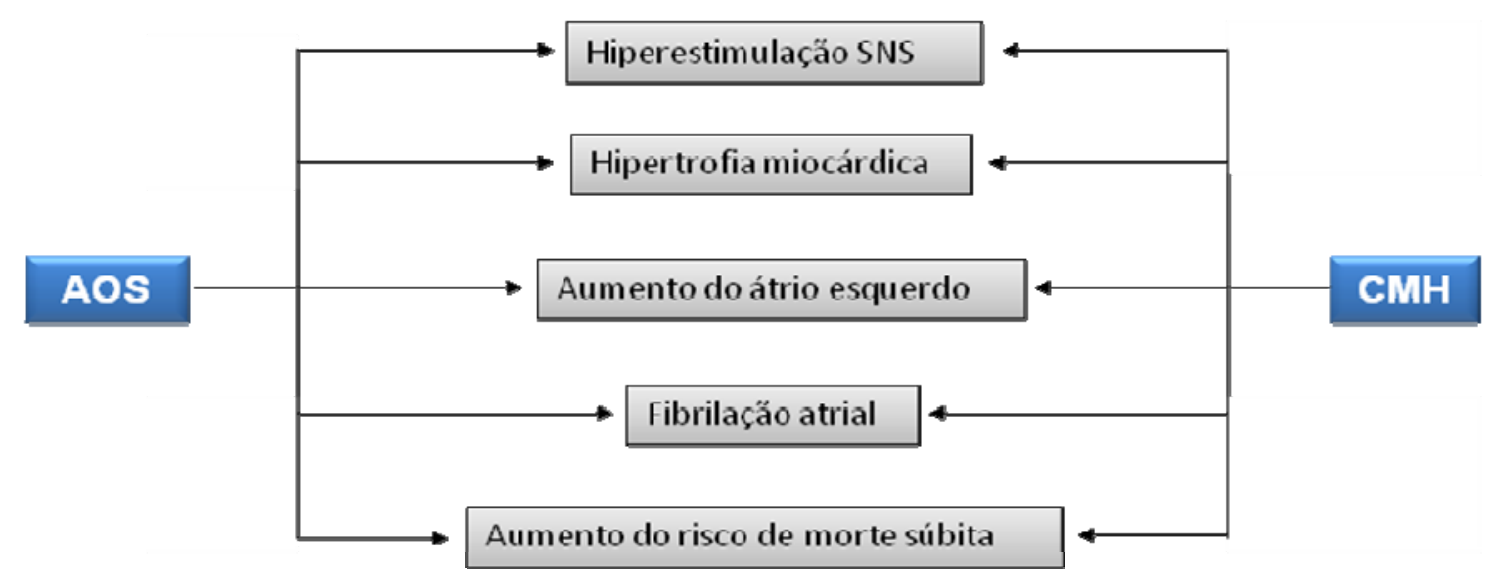

Figura 7 - Vias comuns, mas independentes dos mecanismos de desfecho cardiovascular na apneia obstrutiva do sono e na cardiomiopatia hipertrófica. SNS: Sistema Nervoso Simpático (Fonte: Adaptado de Nerbass FB et al. Sleep Med Rev. 2013;17(3):201-6). ${ }^{(56)}$ 
Atualmente, o tratamento de escolha para AOS moderada e grave, é o uso do CPAP (Pressão Positiva Contínua na Via Aérea), que tem apresentado resultados benéficos nas variáveis de desfecho cardiovascular e serão discutidos s seguir

\subsection{Pressão positiva contínua na via aérea (CPAP)}

O CPAP é um gerador de fluxo de ar que provoca uma pressão positiva, a qual é aplicada continuamente ao indivíduo por meio de uma máscara nasal ou oronasal. Quando utilizado em pacientes com AOS, o CPAP atua como uma prótese pneumática que mantém as vias aéreas superiores abertas em todo o ciclo respiratório, durante o sono ${ }^{(57)}$ (Figura 8$) .^{2}$ Assim, promove remissão dos eventos obstrutivos, da hipóxia intermitente e dos despertares, melhorando a arquitetura e qualidade do sono.

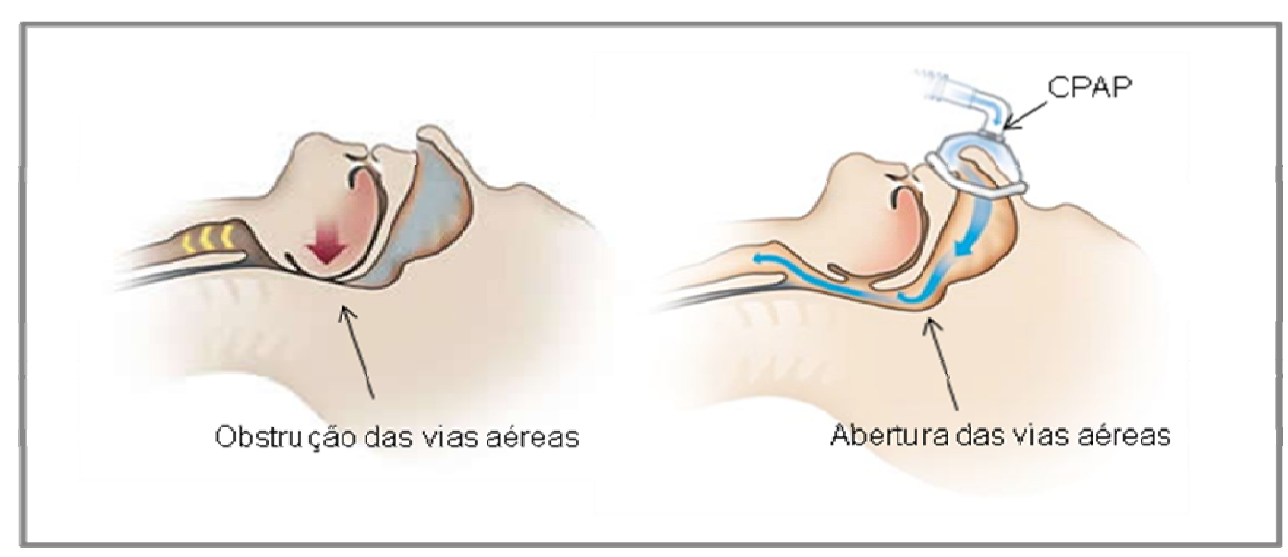

Figura 8 - Representação esquemática da ação do CPAP na abertura das vias aéreas superiores por meio de uma interface nasal. (Fonte: http://torontocpap.com/sleep-apnea-advacare-sleep-products-services.html) 


\subsubsection{Tratamento da AOS com CPAP e desfecho cardiovascular}

Estudos observacionais e ensaios clínicos randomizados têm sido amplamente realizados com intuito de investigar os efeitos benéficos do tratamento da AOS com CPAP, nas variáveis cardiovasculares e metabólicas. Evidências crescentes demonstram que o CPAP é capaz diminuir a atividade simpática, reduzir concentração de proteína C-reativa, melhorar a resistência à insulina e a função endotelial, além de minimizar os sinais precoces de aterosclerose. ${ }^{(39,58-60)}$

AOS é uma causa reconhecida de hipertensão secundária e seu tratamento com CPAP tem sido capaz de reduzir a PA. ${ }^{(61,62)}$ Duas recentes meta-análises demonstraram que a redução global da PA com CPAP foi de $\sim 2 \mathrm{mmHg}^{(63,64)} \mathrm{e}$, apesar de ser uma redução aparentemente pequena, parece ser clinicamente relevante. ${ }^{(65)} \mathrm{Em}$ hipertensos resistentes, o tratamento da AOS com CPAP por 6 meses reduziu $\sim 6.5 \mathrm{mmHg}$ a PA sistólica e $\sim 4.5 \mathrm{mmHg}$ a PA diastólica. ${ }^{(66)}$

Uma forte correlação encontrada entre a velocidade da onda de pulso carótida-femoral (estimativa de rigidez arterial da aorta) com o índice de massa do VE em pacientes com AOS, sugere que a pós-carga aumentada provocada pela elevação da pressão transmural durante as apneias/hipopneias, possa contribuir para a progressão do remodelamento cardíaco. ${ }^{(41)}$ Esse remodelamento ainda pode ajudar a explicar a forte associação entre a AOS e FA. A prevalência de AOS entre os pacientes com 
FA é em torno de $50 \%$ e uso do CPAP parece reduzir o risco de episódios recorrentes dessa arritmia. ${ }^{(51)}$ Um estudo observacional muito importante demonstrou que o tratamento de pacientes com AOS, com CPAP, foi capaz de reduzir de forma significativa os eventos cardiovasculares fatais e não fatais, num seguimento de 10 anos. ${ }^{(67)}$

Contudo, apesar de tantas evidências benéficas relacionadas ao uso do CPAP para tratamento da AOS, é importante considerar que a imposição de uma pressão positiva nos sistemas respiratório e cardiovascular pode alterar a hemodinâmica, por modificar a pré-carga e a pós-carga de ambos os ventrículos. Esses efeitos serão discutidos a seguir, pois são especialmente importantes nos pacientes com $\mathrm{CMH}$, por aumentares seu gradiente na VSVE.

\subsubsection{Efeitos hemodinâmicos agudos do CPAP - interação} cardiopulmonar

Numa condição de normalidade da mecânica respiratória, durante a insuflação pulmonar, também ocorre expansão da caixa torácica e há pouco efeito compressivo dos pulmões sobre o coração e os grandes vasos. Contudo, quando imposta uma pressão positiva, há um aumento da pressão intratorácica, que provoca: no lado direito do coração: 1) redução no retorno venoso ( $\downarrow$ pré-carga do VD), com diminuição do DC direito e 2) aumento na resistência vascular pulmonar, dificultando a ejeção do sangue pelo VD ( $\uparrow$ pós-carga do VD), reduzindo ainda mais o DC. Pelo fato de as duas 
circulações estarem dispostas em série, todas as consequências ao VD refletirão diretamente no VE. Assim, no lado esquerdo do coração ocorrem: 3) menor pressão de enchimento do VE pelo DC direito reduzido ( $\downarrow$ précarga do VE) e 4) diminuição da pressão transmural do VE ( $\downarrow$ pós-carga do VE), que se dá pela diminuição no gradiente de pressão entre as pleuras e a raiz da aorta $(P t m$ = pressão no VE - pressão pleural $)$, facilitando a ejeção do sangue para Aorta ${ }^{(68)}$ (Figura 9).

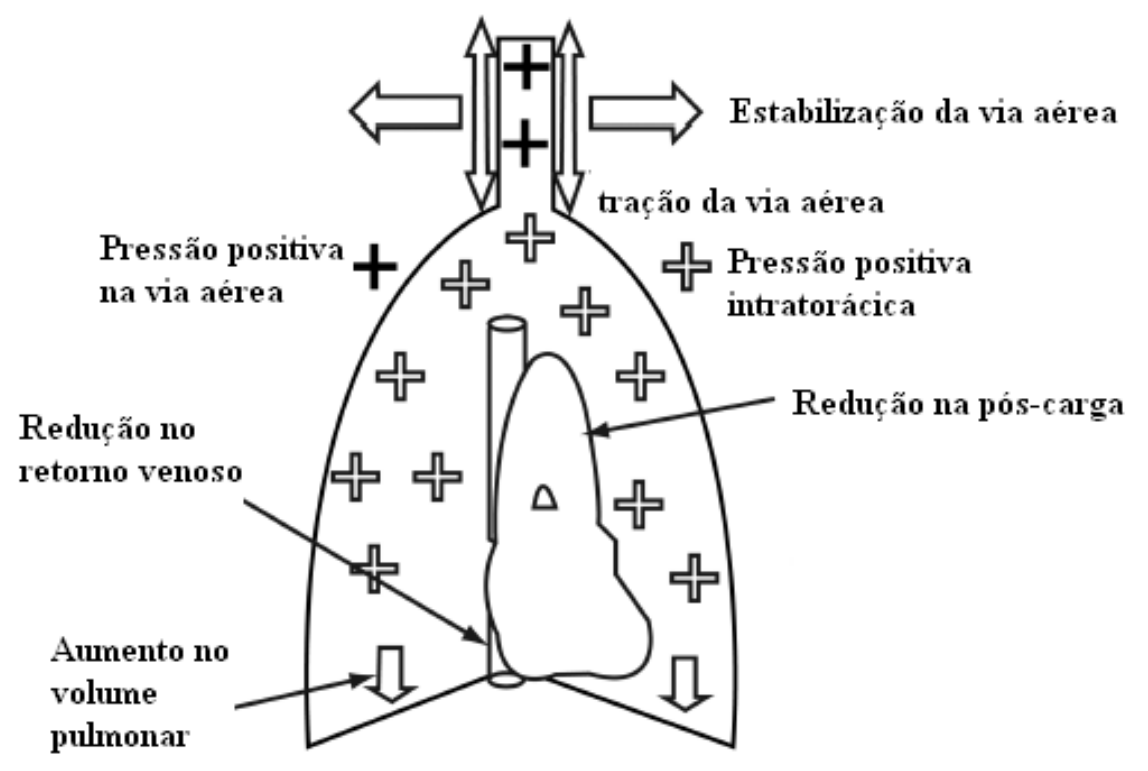

Figura 9 - Representação esquemática dos efeitos da pressão positiva sobre as vias aéreas, pulmões, coração e hemodinâmica. (Fonte: Adaptado de AntonescuTurcu A, Parthasarathy S. Respir Care 2010;55(9):1217). ${ }^{(69)}$

Esses efeitos do CPAP são considerados benéficos por melhorarem o desempenho cardíaco em corações normais e dilatados, além de eliminarem 
os eventos respiratórios durante o sono. Entretanto, considerando que pacientes com $\mathrm{CMH}$ se beneficiam de pré e pós-carga do VE aumentadas, e a pressão positiva provoca efeitos contrários, é razoável especular que o CPAP possa não ser uma modalidade segura para tratamento de AOS em pacientes com $\mathrm{CMH}$, por talvez piorar o gradiente na VSVE. Na literatura atual, há apenas um único relato de 3 casos de pacientes com $\mathrm{AOS}$ e $\mathrm{CMH}$ obstrutiva, que foram tratados empiricamente com CPAP por $\sim 18$ a 19 meses e apresentaram melhora na classe funcional (NYHA), reduções no volume do $A E$ e no gradiente de VSVE. ${ }^{(48)}$ Contudo, a segurança da aplicação do CPAP nessa população, considerando seus efeitos na hemodinâmica e no desempenho cardíaco, nunca foi investigada. 


\section{Racional do estudo}

A AOS é uma condição clínica comum em pacientes com $\mathrm{CMH}$. Mesmo no cenário de uma doença cardíaca determinada geneticamente, a AOS pode contribuir negativamente para o remodelamento cardíaco, para sua evolução natural e até mesmo para o pior prognóstico desses pacientes.

O CPAP é o tratamento de escolha para AOS moderada a grave e seu uso tem sido associado à uma melhora nas variáveis metabólicas, imunológicas e cardiovasculares. No entanto, apesar dos resultados benéficos do CPAP em pacientes com $\mathrm{AOS}$, sem $\mathrm{CMH}$, há um possível efeito deletério desse dispositivo sobre a hemodinâmica e desempenho cardíaco de pacientes com $\mathrm{CMH}$. Neste contexto, a realização de estudos mais detalhados em curto e longo prazo acerca dos efeitos do CPAP nesta classe de pacientes são necessários, para que se torne uma alternativa segura para o tratamento da AOS. 
Objetivo 


\section{Objetivo}

Os objetivos deste estudo foram avaliar a segurança da aplicação do CPAP em pacientes com cardiomiopatia hipertrófica, bem como analisar seus efeitos agudos nas variáveis hemodinâmicas e de desempenho cardíaco de pacientes com as formas obstrutiva e não-obstrutiva da doença, durante a vigília. 
Metodologia 


\section{Metodologia}

Trata-se de um estudo crossover, intitulado "Efeitos hemodinâmicos agudos da pressão positiva contínua na via aérea (CPAP) em indivíduos com cardiomiopatia hipertrófica", que foi aprovado pela Comissão de Ética para Análise de Projetos de Pesquisa (CAPpesq), do HCFMUSP, sob o número de protocolo: 0213/09 e SDC: 3252/09/003. Este estudo é parte do projeto de pesquisa "Prevalência e importância cardiovascular dos distúrbios respiratórios do sono na miocardiopatia hipertrófica" e está registrado no ClinicalTrials.gov (NCT01631006).

\subsection{Seleção de pacientes}

Foram recrutados pacientes com $\mathrm{CMH}$ no ambulatório da Unidade Clínica de Miocardiopatias do Instituto do Coração (InCor - HCFMUSP) entre dezembro de 2010 a abril de 2013. O diagnóstico e a classificação da doença quanto a forma obstrutiva (CMHObst) e não-obstrutiva (CMHNObst), foram previamente estabelecidos por Ecocardiografia transtorácica (ECO), que é um exame de rotina do ambulatório de cardiomiopatias e seus resultados são disponibilizados no Intranet. Todos os pacientes foram esclarecidos a cerca do objetivo do estudo e como procederia o protocolo. Mediante aceitação em participar da pesquisa por meio do Termo de Consentimento Livre e Esclarecido assinado (Anexo A), os pacientes foram orientados a comparacer no Laboratório do Sono do InCor, em data e horário agendados. 
Tabela 1 - Critérios de inclusão e exclusão

\begin{tabular}{|c|c|}
\hline Critérios de inclusão & Critérios de exclusão \\
\hline (a) idade > 18 anos; & $\begin{array}{lll}\text { (a) presença } & \text { de } & \text { cardioversor- } \\
\text { desfibrilador } & \text { ou } & \text { marca-passo }\end{array}$ \\
\hline (b) ambos os sexos; & implantados \\
\hline $\begin{array}{l}\text { (c) ausência de fibrilação atrial } \\
\text { previamente diagnosticada; }\end{array}$ & $\begin{array}{l}\text { (b) episódios prévios de parada } \\
\text { cardiorrespiratória; }\end{array}$ \\
\hline $\begin{array}{l}\text { (d) estáveis hemodinamicamente (sem } \\
\text { alterações de medicações, classe } \\
\text { funcional (NYHA) ou hospitalizações nos } \\
\text { últimos } 30 \text { dias); }\end{array}$ & $\begin{array}{l}\text { (c) desistência espontânea; } \\
\text { (d) presença de fibrilação atrial durante } \\
\text { o ecocardiograma que prejudicassem a } \\
\text { realização do exame; }\end{array}$ \\
\hline $\begin{array}{l}\text { (e) ausência de outras doenças cardíacas } \\
\text { concomitantes; }\end{array}$ & $\begin{array}{l}\text { (e) não adaptação à máscara e/ou ao } \\
\text { aparelho de CPAP. }\end{array}$ \\
\hline (f) sem cirurgias cardíacas prévias; & \\
\hline $\begin{array}{l}\text { (g) aceitar a participação por meio do } \\
\text { termo de consentimento assinado. }\end{array}$ & \\
\hline
\end{tabular}

\subsubsection{Critério de interrupção do protocolo:}

Queda da PA sistólica 25\% abaixo do valor basal, acompanhada por sintomas clínicos: tontura, náusea e/ou queixa de mal-estar. ${ }^{(70)}$

\subsection{Desenho do estudo}

\subsubsection{Avaliação inicial}


Inicialmente os pacientes foram submetidos a uma anamnese e exame físico detalhados (Anexo B), que incluíam informações pessoais, dados clínicos e antropométricos, como: peso, altura, medidas de circunferência cervical e abdominal, histórico familiar da doença, hábitos de vida, medicações em uso, dentre outros. O índice de massa corpórea (IMC) foi calculado como peso( $\mathrm{Kg}) /$ altura $(\mathrm{m})^{2}$. Os valores de circunferência cervical foram adquiridos pela medida realizada em nível do bordo superior da membrana cricotireoidea, sendo considerados aumentados quando $\geq 43 \mathrm{~cm}$ em homens e $\geq 41 \mathrm{~cm}$ em mulheres. ${ }^{(71)}$ A circunferência abdominal foi medida a partir da distância média entre o bordo superior da crista ilíaca e bordo inferior do último arco costal, sendo considerada aumentada quando $\geq 102 \mathrm{~cm}$ para homens e $\geq 88 \mathrm{~cm}$ para mulheres. ${ }^{(72)}$ A mensuração da PA basal foi obtida em posição sentada, por meio de um esfigmomanômetro digital (OMRON, modelo HEM-742INT - Illinois, EUA), com o braço direito elevado à altura do ombro, após 5 minutos de repouso. Foram realizadas 3 medidas com intervalo de um minuto entre elas, sendo a média das duas últimas o valor considerado. ${ }^{(73)}$

Em seguida foram aplicados questionários para avaliação da queixa de sonolência diurna (Escala de sonolência de Epworth); do risco para AOS (Questionário de Berlim) (Anexo C); qualidade do sono nos últimos trinta dias (Índice de qualidade de sono de Pittsburgh) (Anexo D) e classe funcional - NYHA (Anexo E), conforme descritos na sessão seguinte. 
Antes do início da coleta de dados, em repouso, todos os voluntários foram orientados sobre os procedimentos que seriam realizados. Amostras de sangue para análise laboratorial [colesterol total e frações, triglicérides, glicemia e BNP (Brain Natriuretic Peptide)] foram colhidas. Em seguida, os voluntários foram adaptados a uma máscara nasal conectada ao aparelho de CPAP modificado, por um período de 10 minutos, nas diferentes pressões de $1,5 \mathrm{cmH}_{2} \mathrm{O}$ e $10 \mathrm{cmH}_{2} \mathrm{O}$, que seriam aplicadas durante $\mathrm{o}$ protocolo. Ainda neste período, os voluntários foram treinados a realizar manobras de Muller e de Valsalva com o auxílio do manovacuômetro analógico (Marshalltown ${ }^{\circledR}, 200$ PSI, lowa, EUA), da seguinte forma: Manobra de Muller - realizar uma inspiração máxima a partir do fim de uma expiração tranquila (nível da capacidade residual funcional) em um sistema fechado, ou seja, o orifício do manovacuômetro ocluído, um clipe nasal que impedia o fluxo de ar pelo nariz e lábios cerrados no bocal do manovacuômetro; Manobra de Valsalva - realizar uma expiração máxima a partir da capacidade residual funcional, também contra a via aérea ocluída. Essas manobras foram efetuadas ao final do ECO basal, tendo 30 segundos de duração cada uma (10 segundos de estabilização, 10 segundos para a realização da manobra e 10 segundos de recuperação). Registro simultâneo da PA batimento-a-batimento foi realizado e o fluxo mitral e o gradiente de VSVE foram mensurados. Foram realizadas até 3 repetições de cada manobra em que o maior valor de gradiente de VSVD foi considerado. ${ }^{(74)}$

\subsubsection{Randomização}


Uma randomização prévia para cada um dos grupos de pacientes com $\mathrm{CMH}$ (CMHN-Obst e CMHObst) foi realizada por sorteio e os resultados foram transcritos para uma planilha Excel, que indicava qual pressão de CPAP o paciente iniciaria a coleta de dados. Apenas o pesquisador executante teve acesso à randomização e o ecocardiografista permaneceu cego quanto à pressão de CPAP.

\subsubsection{Aquisição das variáveis ecocardiográficas e} hemodinâmicas:

Todos os pacientes foram convidados a permanecer deitados numa cama, usando roupas confortáveis, na posição de decúbito dorsal semilateral esquerdo, posição necessária para realização do ECO (Figura 10). Foram monitorados com o Portapres ${ }^{\circledR}$ para registro da PA batimento-abatimento e o com o eletrocardiograma (ECG). Após 10 minutos em repouso nessa posição, os dados de PA e ECG começaram a ser gravados por mais 10 minutos, período "Basal”, e continuaram a ser registrados continuamente até o término do protocolo. 


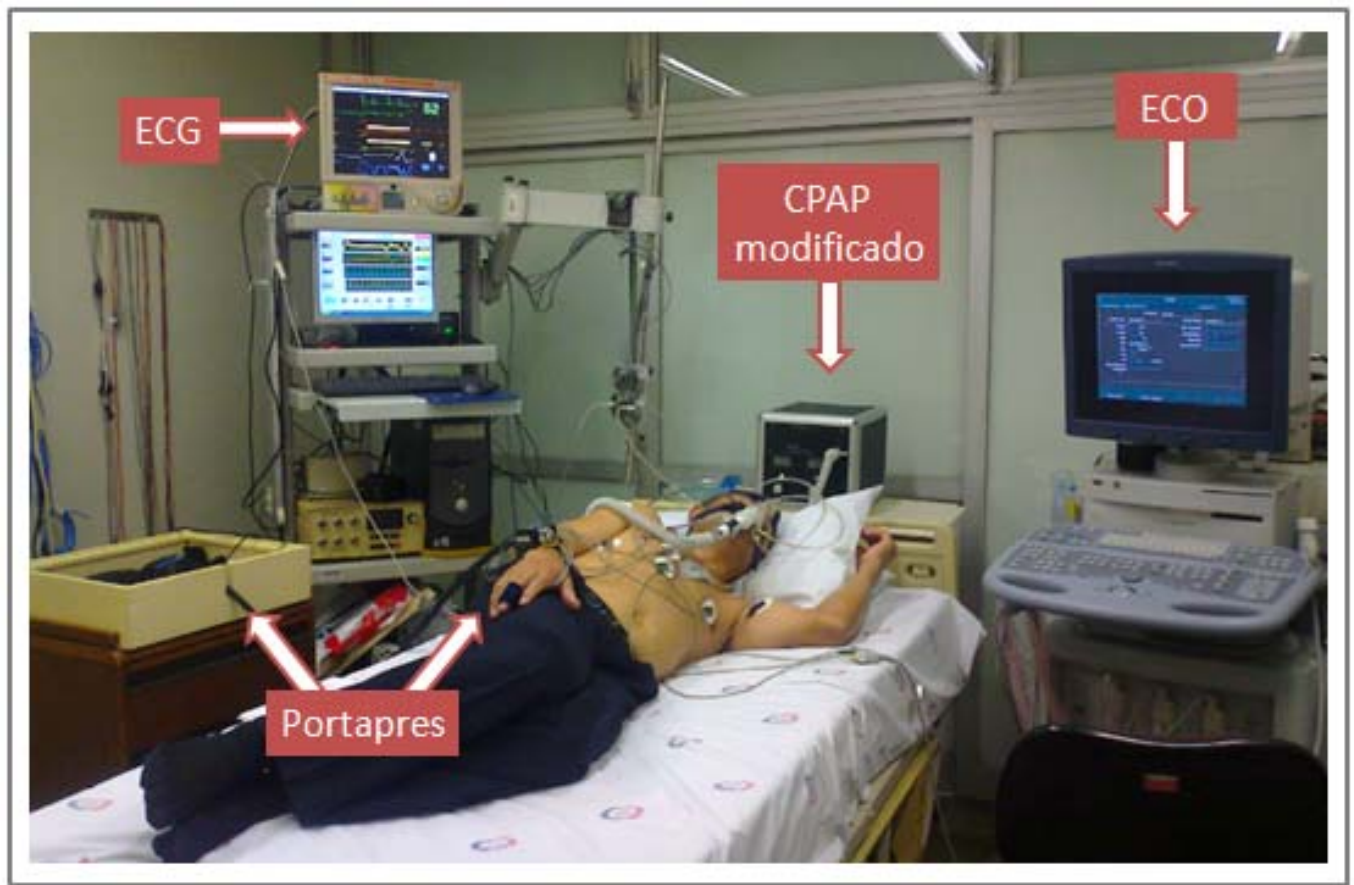

Figura 10 - Foto ilustrativa do posicionamento do paciente e equipamentos utilizados para a aquisição de dados. (Fonte: Laboratório do Sono - InCor)

Em seguida, um ECO completo "ECO basal" foi realizado para avaliação dos volumes e dimensões das câmaras esquerdas, fração de ejeção, função diastólica, função valvar, gradientes na VSVE, dentre outras variáveis que estão descritas ainda nesta sessão. ${ }^{(75)}$ Com esse exame foi possível conhecer as características anatômicas e de desempenho cardíacos individuais, além de confirmar o diagnóstico e a classificação da CMH de acordo com seu gradiente de VSVE. CMHN-Obst foi considerada quando a medida do gradiente na VSVE era $<30 \mathrm{mmHg}$, e CMHObst quando o gradiente medido era $\geq 30 \mathrm{mmHg}$.

Finda esta etapa, cada paciente iniciou o uso do CPAP na pressão definida pela randomização. CPAP na pressão de $1,5 \mathrm{cmH}_{2} \mathrm{O}$ foi denominado 
como "Sham-CPAP" e na pressão de $10 \mathrm{cmH}_{2} \mathrm{O}$ foi definido como "CPAP10" (Figura 11). Os valores das pressões selecionados para o modo ShamCPAP e CPAP-10 foram previamente descritos na literatura. ${ }^{(76,77)}$ Para ambos os protocolos, afim de observarmos os efeitos instantâneos da pressão positiva sobre as variações de carga ao VE, no momento da instalação do Sham-CPAP ou CPAP-10 o gradiente entre o VE e aorta foi mensurado e denominado "Grad 1". Após 20 minutos nesta pressão foi repetido o ECO completo "ECO 1" com mensuração dos mesmos parâmetros analisados no ECO basal. Em seguida, todos os pacientes permaneceram 10 minutos em repouso "intervalo", sem CPAP, para que as variáveis de desempenho cardíaco e hemodinâmicas retornassem aos valores basais. O protocolo foi repetido com a outra pressão, seguindo as mesmas mensurações instantâneas de "Grad 2", e ao final dos 20 minutos, "ECO 2" completo. Finalizamos o protocolo com mais 10 minutos de "recuperação" 


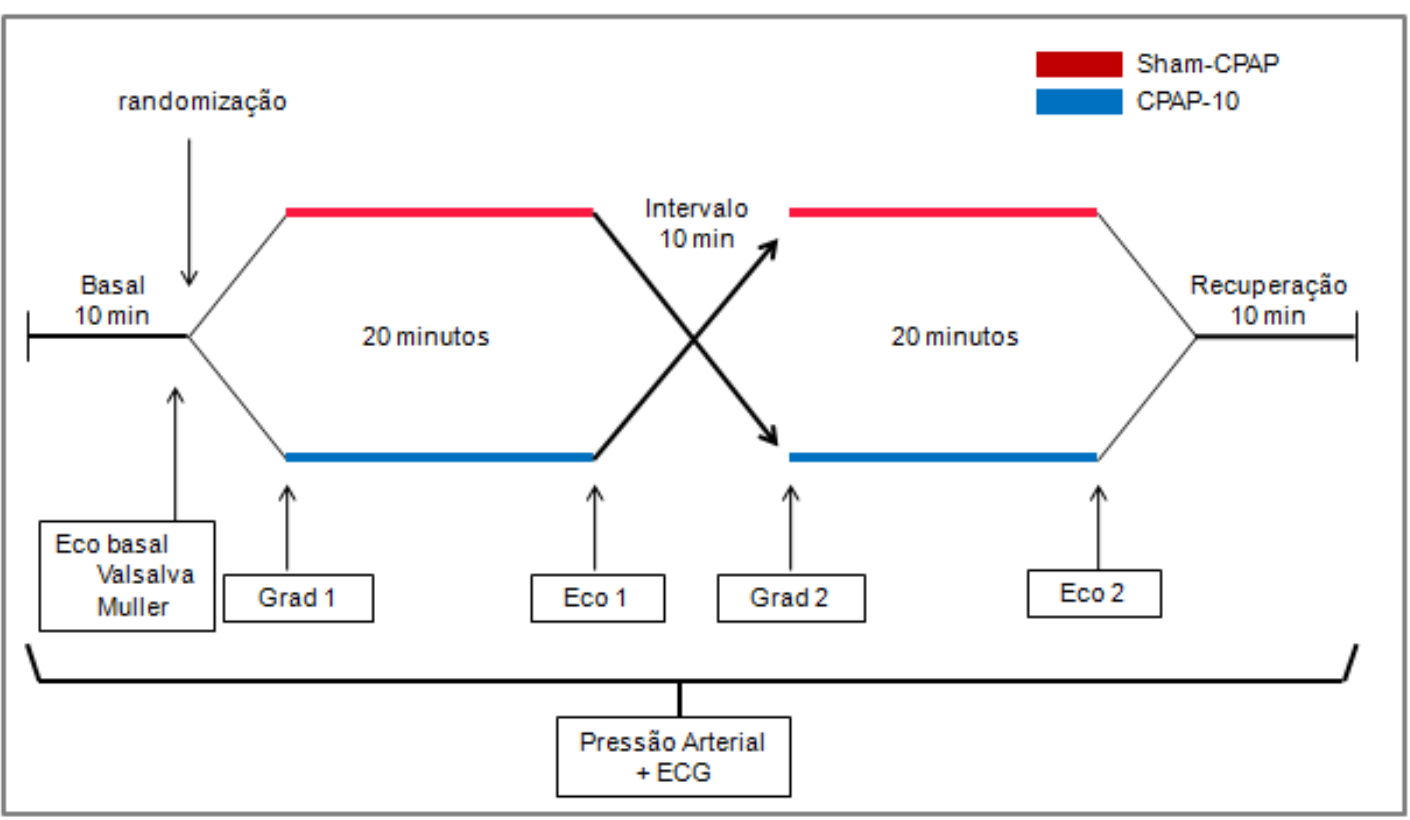

Figura 11 - Fluxograma do desenho do estudo.

Para a mensuração da pressão de CPAP e do fluxo inspiratório, a máscara nasal foi respectivamente conectada a um pneumotacógrafo aquecido e a um transdutor de pressão diferencial. Para análise do gás carbônico exalado $\left(\mathrm{EtCO}_{2}\right)$, um capnógrafo (Dixtal ${ }^{\circledR}$ ) também foi conectado entre o pneumotacógrafo e a válvula exalatória. O gerador de pressão utilizado foi um CPAP modificado (Philips Respironics, Murrysville, PA) que titula pressões entre $-20 \mathrm{cmH}_{2} \mathrm{O}$ e $+20 \mathrm{cmH}_{2} \mathrm{O}$, sendo capaz de manter a pressão de Sham-CPAP em 1,5 $\mathrm{cmH}_{2} \mathrm{O}$ (Figura 12). 


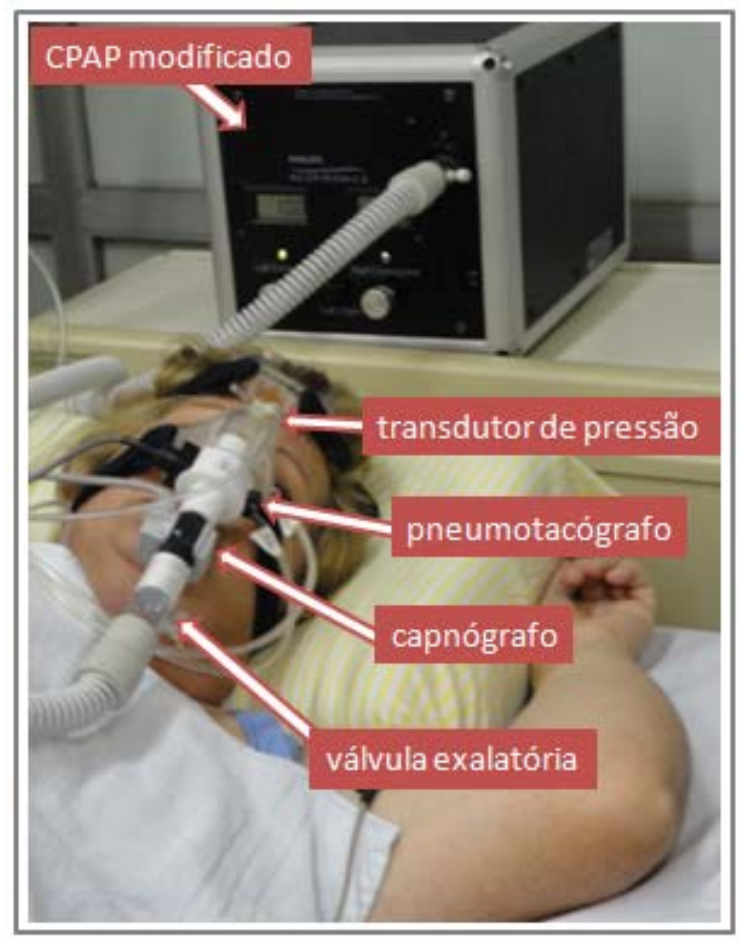

Figura 12 - Foto ilustrativa dos equipamentos utilizados para aquisição das variáveis respiratórias conectados à máscara nasal e ao CPAP modificado. (Fonte: Laboratório do Sono - InCor)

Em outra data previamente agendada, cada paciente foi convidado a comparecer no Laboratório do Sono do InCor para realização de uma PSG noturna completa, a fim de avaliar a presença ou ausência de AOS, conforme descrito à seguir.

\subsection{Monitorizações:}

\subsection{1 - Monitorização contínua da pressão arterial batimento-a-} batimento - Sistema Portapres ${ }^{\circledR}$ 
O registro da PA batimento-a-batimento foi obtido pelo aparelho Portapres $^{\circledR}$ (Model 2 - TNO Biomedical Instrumentation, Amsterdam, Holanda), que é um instrumento de monitorização contínua e não-invasiva da PA (Figura 13).

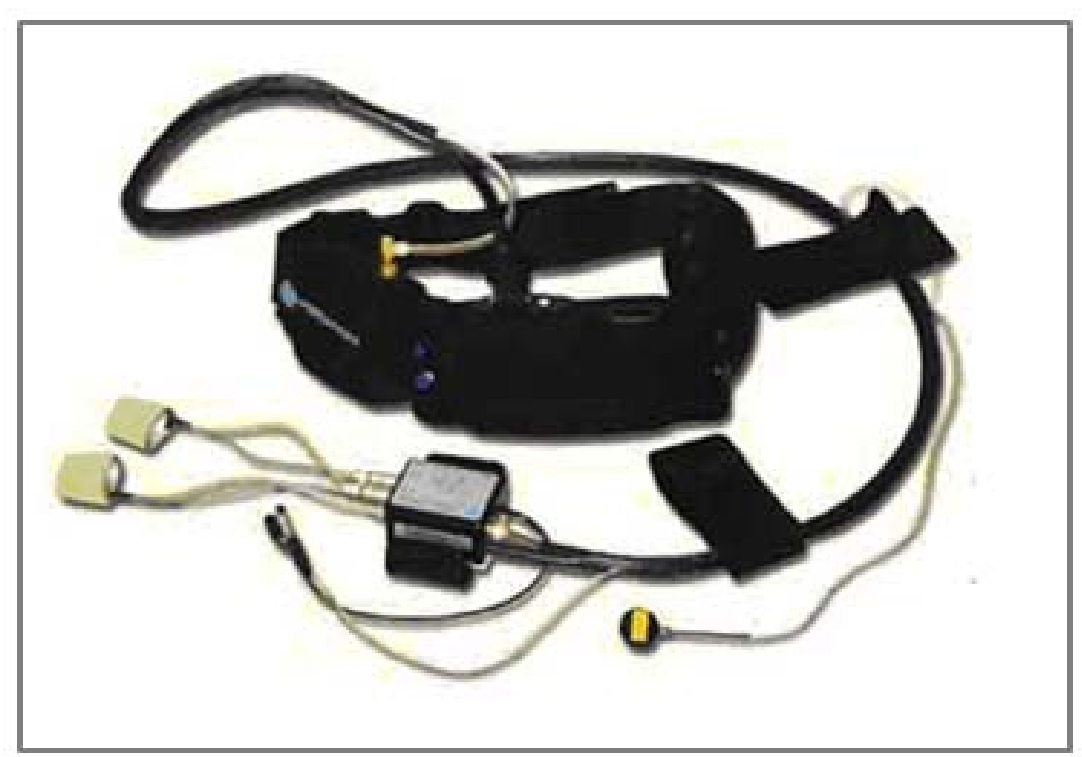

Figura 13 - Figura ilustrativa do Portapres ${ }^{\circledR}$ (Fonte: Portapres Model-2 User's Guide. In: Instrumentation T-TB, editor. 1999) ${ }^{(78)}$

O Portapress ${ }^{\circledR}$ possui cuff que é posicionado no dedo do voluntário e registra as ondas de pulso batimento-a-batimento (Figura 14). Os resultados são armazenados e posteriormente analisados por um Software de computador (LabVIEW, National Instruments, Austin, TX) (Figura 17). 


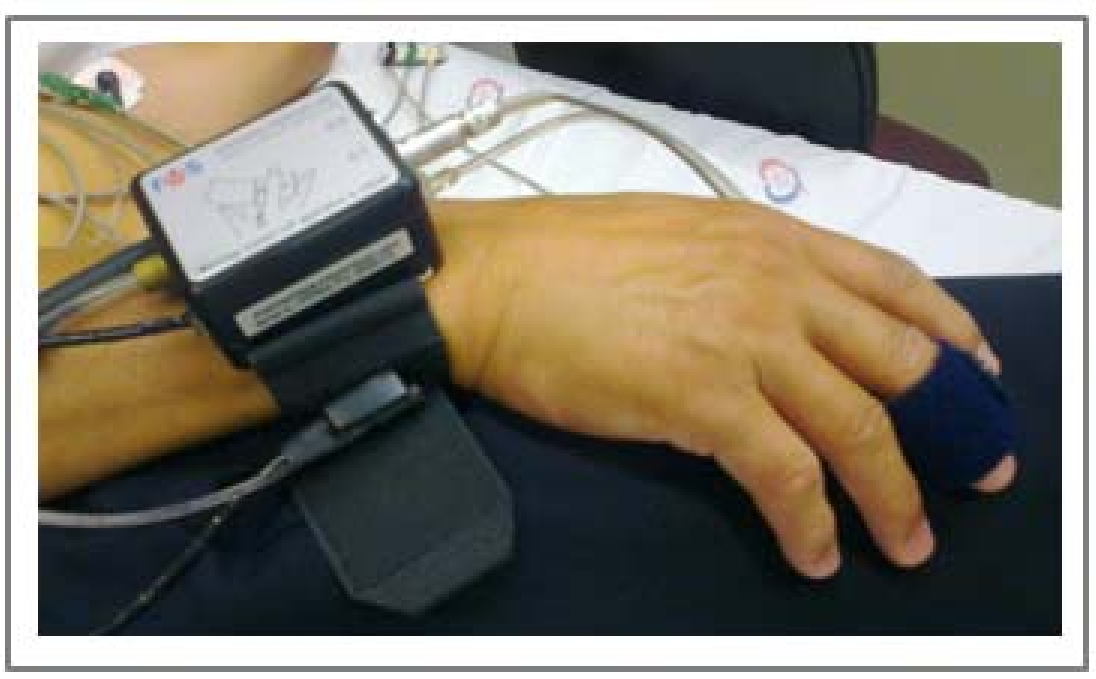

Figura 14 - Manguito do Portapres ${ }^{\circledR}$ com cuff posicionado no dedo do paciente. (Fonte: Laboratório do Sono - InCor)

Cada manguito é constituído por uma câmara de ar, diversas camadas de plástico, borracha e velcro (Figura 15). Existem 3 tamanhos distintos, sendo a escolha do tamanho ideal, essencial para a confiabilidade das medidas, já que se baseiam na circunferência da falange média do dedo onde está sendo realizada a aferição da PA. 


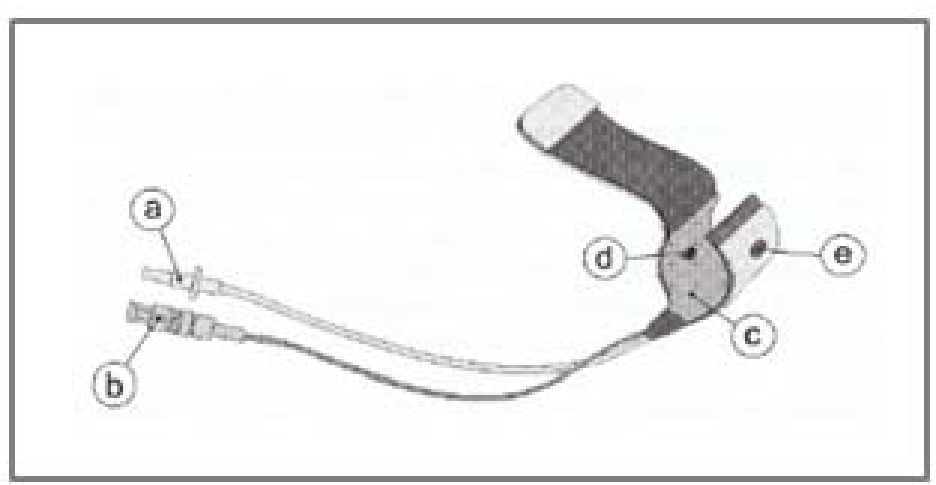

a) Conector de ar flexível

b) Conector cabo do manguito

c) Reservatório de ar

d) Detector de luz (Foto-diodo)

e) Fonte de luz

Figura 15 - Tipo de manguito usado no Portapres ${ }^{\circledR}$. (Fonte: Portapres Model-2 User's Guide. In: Instrumentation T-TB, editor. 1999) ${ }^{(78)}$

Os manguitos contém dispositivos eletrônicos que compõem a pletismografia por raios infravermelhos, que permitem a obtenção da PA pelo método do clampe volumétrico. Por este método, o diâmetro de uma artéria do dedo envolto por um manguito (clampe) é mantido constante, a despeito das mudanças da PA a cada batimento cardíaco. Variações no diâmetro arterial detectados pela fotoplestimografia são rapidamente contrabalançados por um sistema controlador, que promoverá mudanças na pressão da câmara de ar na tentativa de manter o diâmetro da artéria. Este método foi validado na literatura, especialmente quando comparado à monitorização da pressão intra-arterial. Embora não seja possível medir de forma invasiva a pressão de uma artéria digital para direta comparação com 
o Portapres ${ }^{\circledR}$, há evidências de que os valores obtidos com estes dois sistemas tenham boa correlação. ${ }^{(79-81)}$

O sistema Portapres ${ }^{\circledR}$ também possui uma unidade de correção de altura, que é especialmente importante no nosso estudo, pois para permitir acesso a algumas janelas cardíacas durante a realização do ECO, os pacientes precisavam movimentar o tronco anterior e posteriormente. Considerando que a PA poderia sofrer influências da gravidade devido ao posicionamento do membro superior em relação ao coração, a confiabilidade das medidas poderia ficar comprometida. O sistema de correção de altura consiste em: uma coluna de líquido conectada em uma extremidade a um transdutor de pressão, localizado junto ao manguito, e em outra extremidade conectada a outro sensor colocado no nível de referência, geralmente no nível do coração (Figura 16). Uma calibração prévia da altura é realizada, o sinal é filtrado e adicionado ao valor da PA.

Esta particularmente do equipamento é importante quando o objetivo da medida da PA requeira a mínima interferência do pesquisador sobre o indivíduo, ou da posição corporal. Sem ela, a diferença hidrostática gerada pela altura entre os manguitos e o nível de referência (coração) poderia causar diferenças tão significantes quanto $20 \mathrm{mmHg}$. 


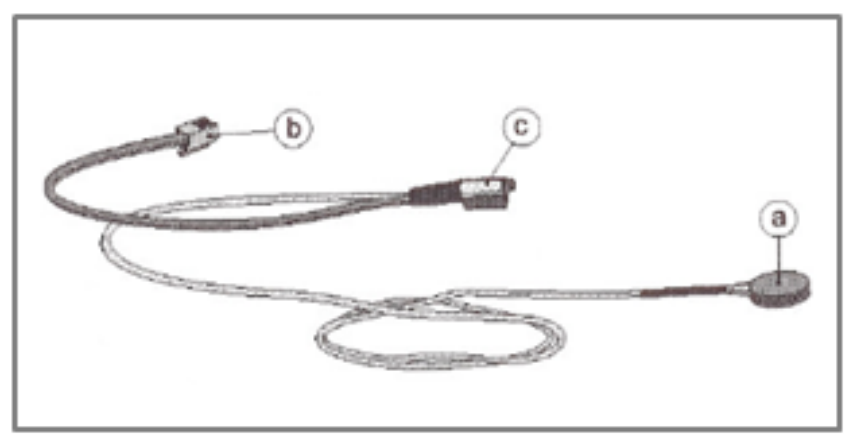
a) Referencial
b) Conector da unidade de correção de altura
c) Transdutor

Figura 16 - Sistema de correção de altura do Portapres ${ }^{\circledR}$. (Fonte: Portapres Model2 User's Guide. In: Instrumentation T-TB, editor. 1999) ${ }^{(78)}$

O sistema Portapres ${ }^{\circledR}$ é muito superior à utilização da monitorização ambulatorial da pressão arterial (MAPA), já que a MAPA possibilita apenas medidas com intervalos de tempo pré-definidos, o que dificulta a detecção e a análise de rápidas e transitórias variações hemodinâmicas que podem ocorrer durante a utilização do CPAP. ${ }^{(78)}$

\subsubsection{Pressão de CPAP e EtCO}

Para a medição das pressões de CPAP e $\mathrm{EtCO}_{2}$, a máscara nasal foi respectivamente conectada a um pneumotacógrafo aquecido (3700A, Hans Rudolf, EUA), a um transdutor de pressão diferencial (MP45, Validyne, EUA) e a um capnógrafo (modelo DX 2022 L-C Dixtal, Royal Philips Electronics, Holanda), localizados antes da valva exalatória. Tanto a pressão da máscara, quanto o fluxo de ar foram monitorados e gravados em um 
computador pessoal, usando um conversor analógico-digital (National Instruments, EUA) e um software de aquisição de dados implementado em ambiente de instrumentação virtual (LabVIEW, National Instruments, EUA) (Figura 17). Os dados de $\mathrm{EtCO}_{2}$ e da frequência respiratória foram monitorizados por meio de um módulo de aquisição acoplado ao sistema de monitorização Dixtal ${ }^{\circledR}$, em que a curva de capnografia foi registrada em tempo real, com indicação numérica do $\mathrm{EtCO}_{2}$ na tela do monitor (Figura 18). $\mathrm{O} \mathrm{EtCO}_{2}$ foi considerado normal quando entre 35 a $45 \mathrm{mmHg}$. Se houvesse aumento nos níveis de $\mathrm{EtCO}_{2}$ registrados, uma segunda saída de ar na válvula exalatória era aberta, para que esses valores retornassem à níveis aceitáveis.

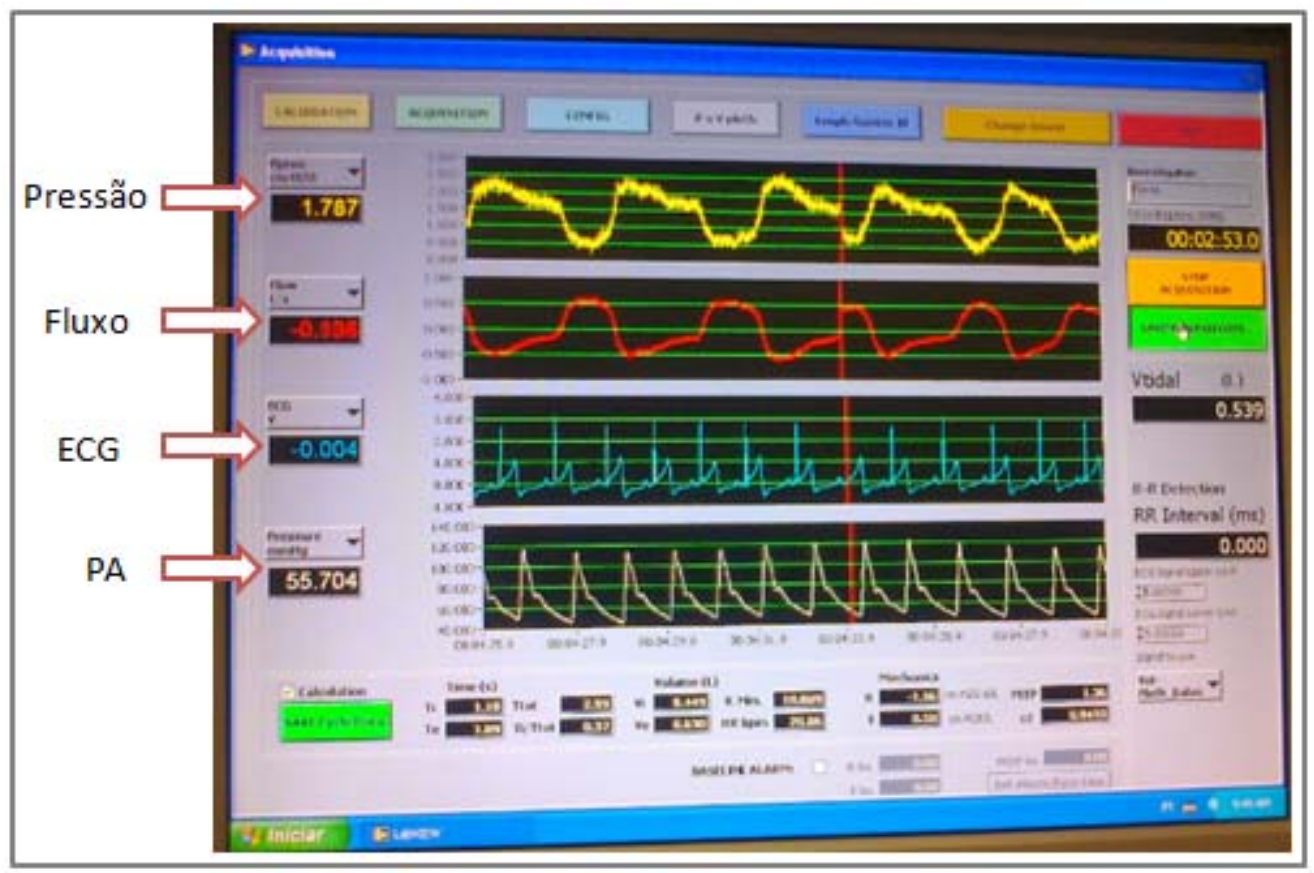

Figura 17 - Sistema Labview demonstrando aquisição de dados fisiológicos: No canal 1: pressão imposta pelo CPAP e suas variações no ciclo respiratório; canal 2 : fluxo respiratório; canal 3: registro do eletrocardiograma; canal 4: curva da pressão arterial batimento-a-batimento pelo Portapres ${ }^{\circledR}$. (Fonte: Laboratório do Sono - InCor) 


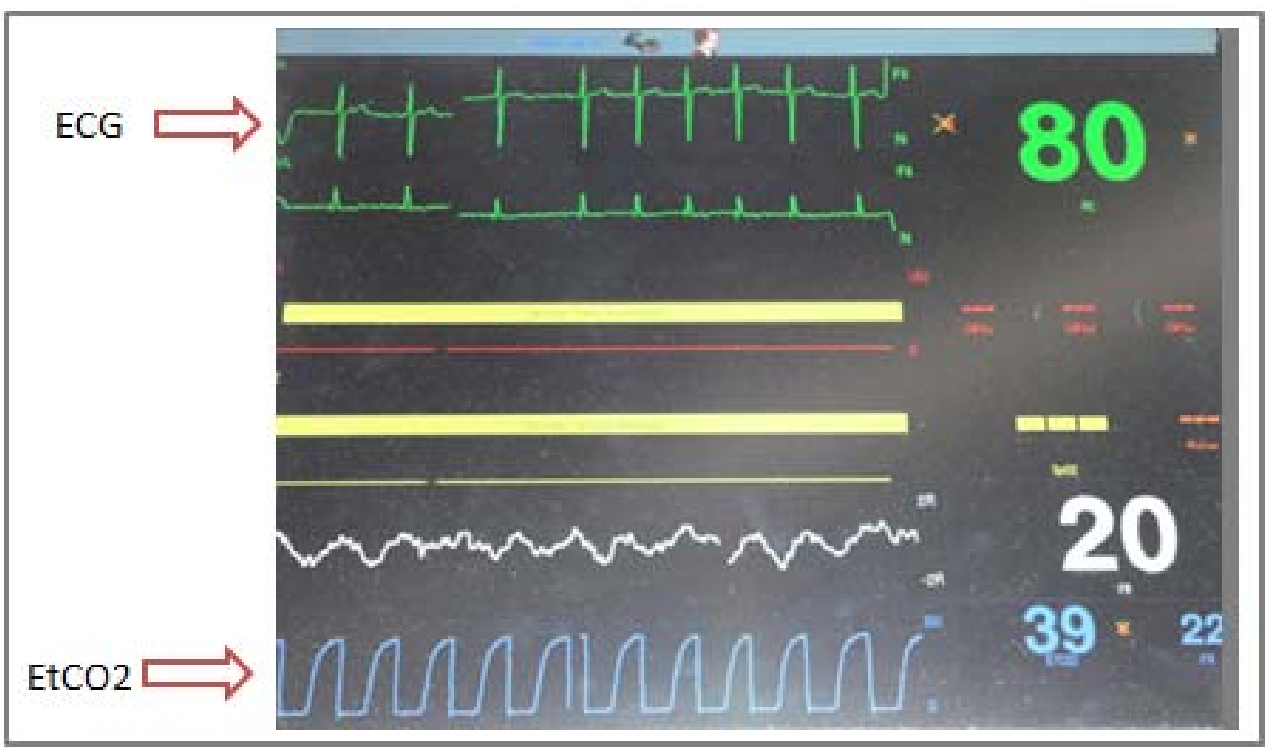

Figura 18 - Tela de monitorização do sistema Dixtal ${ }^{\circledR}$ com registros do eletrocardiograma e $\mathrm{EtCO}_{2}$. (Fonte: Laboratório do Sono - InCor)

\subsection{Exames}

\subsection{1 - Ecocardiograma transtorácico}

O estudo ecocardiográfico completo de repouso unidimensional (Modo-M), bidimensional, com Doppler pulsado, contínuo e em cores, foi realizado em equipamento de ultrassom Sequoia 512 (Acuson, Mountain View, CA, EUA), com transdutor de imagem harmônica de 2,5 MHz.

Os pacientes foram posicionados em decúbito dorsal semi-lateral esquerdo, com três eletrodos no tórax para registro simultâneo do ECG no sistema de ultrassom. Foram obtidos os seguintes cortes: paraesternal eixo longo, paraesternal eixo curto (ao nível de aorta/AE, da valva mitral e do músculo papilar) e apical quatro e duas câmaras. 
No corte paraesternal transverso de eixo curto foram obtidos os seguintes índices: diâmetros da aorta e AE, espessuras diastólicas do septo e da parede posterior do VE e diâmetros diastólico e sistólico-finais do VE. Estes índices foram corrigidos pela área de superfície corporal. A massa do VE foi calculada pela ecocardiografia modo-M, em corte transversal de eixo curto pela medida das dimensões das cavidades e espessura de suas paredes, de acordo com Devereux. ${ }^{(82)}$ A fração de encurtamento foi calculada a partir da fórmula: Diâmetro diastólico do VE - diâmetro sistólico do VE / diâmetro diastólico do VE x 100. A fração de ejeção (FEVE) foi calculada pelo método Teichholz Volume $=7 /(2.4+$ diâmetro do VE) + diâmetro do $\mathrm{VE}^{3}$.(83)

A presença do MAS foi avaliada pelo modo-M, durante a sístole ventricular, quando a valva mitral fechada encosta no SIV (Figura 19). A função diastólica foi avaliada pelo Doppler pulsado das velocidades de fluxo mitral obtidos com o transdutor em corte apical quatro câmaras, com a amostra de volume nas pontas do folheto mitral. Foram obtidos os picos de velocidade do enchimento precoce (onda $E$ ) e tardio (onda $A$ ), a relação $E / A$, o tempo de desaceleração da onda $E$ (TD), assim como o tempo de relaxamento isovolumétrico (TRIV). 


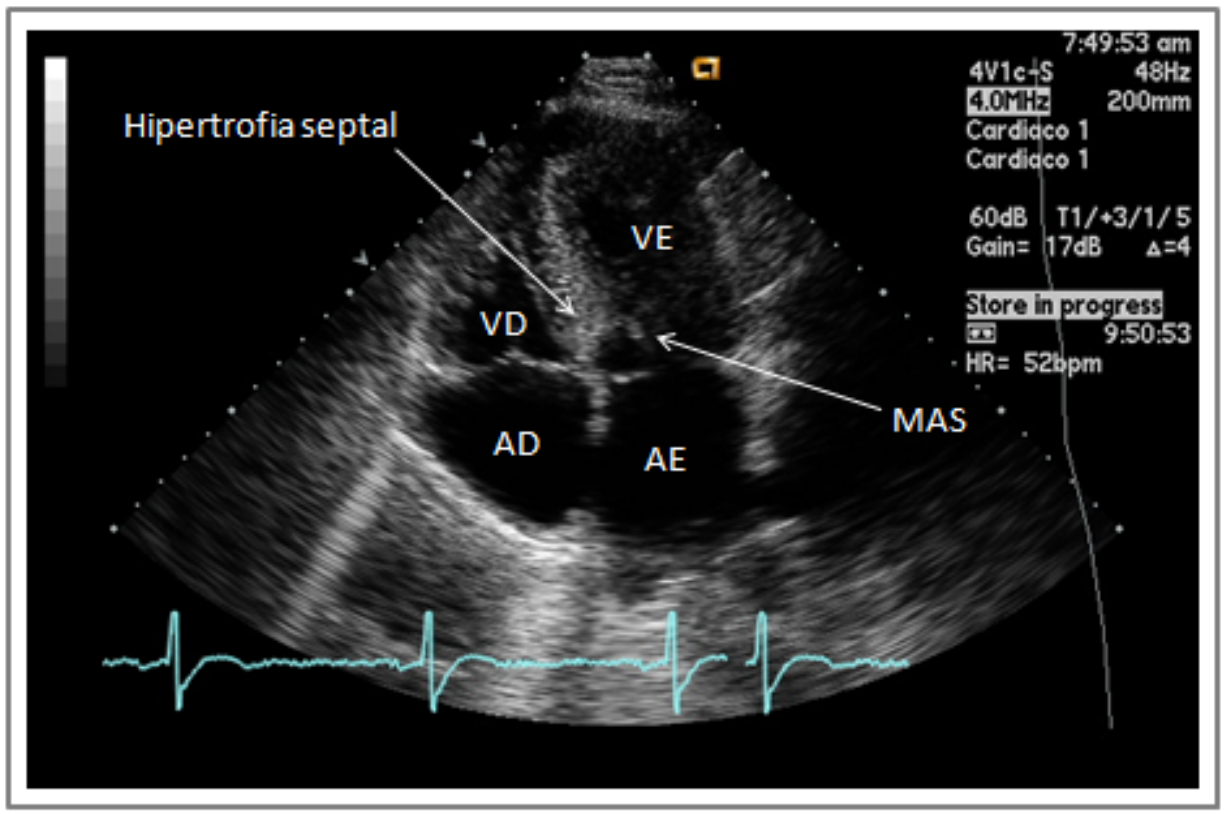

Figura 19 - Imagem ecocardiográfica bidimensional em corte apical quatro câmaras, demonstrado a hipertrofia septal basal e o movimento anterior sistólico (MAS) do folheto anterior da valva mitral em direção ao septo na sístole ventricular. VD: ventrículo direito; $A D$ : átrio direito; VE: ventrículo esquerdo; $A E$ : átrio esquerdo. (Fonte: Laboratório do Sono - InCor)

Para quantificar as velocidades do movimento do VE em seu eixo longitudinal, utilizou-se o Doppler pulsado tecidual guiado por imagens bidimensionais, em cortes apicais quatro câmaras, nas regiões do anel mitral: septal, lateral e região lateral do anel tricúspide. O volume de amostragem foi de $2-5 \mathrm{~mm}$ e a velocidade de varredura foi de $50-100 \mathrm{~mm} / \mathrm{s}$. O ganho foi mínimo para eliminar os sinais produzidos pelo fluxo mitral. ${ }^{(84)}$ Foi obtida a média da velocidade de pico na diástole precoce (E'), e a relação E/E', que reflete as pressões de enchimento ventricular.

A regurgitação mitral analisada pelo Doppler em cores se apresenta como fluxo turbulento, em mosaico, devido ao jato sistólico de alta velocidade no $A E$. Foi quantificada por planimetria de imagem 
correspondente à área e volume máximos do jato regurgitante do Doppler colorido em relação à área e volume do $\mathrm{AE}$, respectivamente, em cortes apical quatro e duas câmaras ${ }^{(85)}$ (Figura 20). Para obtenção dessas medidas, o AE foi tracejado ao longo da superfície interna de sua parede e, ao nível do anel mitral, uma linha reta conectou, automaticamente, a base dos dois folhetos, não sendo necessário tracejar sua superfície interna. Desse tracejado excluíram-se as veias pulmonares e os apêndices atriais. da mesma forma e na mesma imagem o jato regurgitante também foi tracejado. Assim, obtivemos uma medida semi-quantitativa (\%) da área $\left(\mathrm{cm}^{2}\right)$ e do volume $(\mathrm{ml})$ do jato regurgitante em relação ao volume e área do $A E,{ }^{(85)}$ que denominaremos de fração regurgitante. 


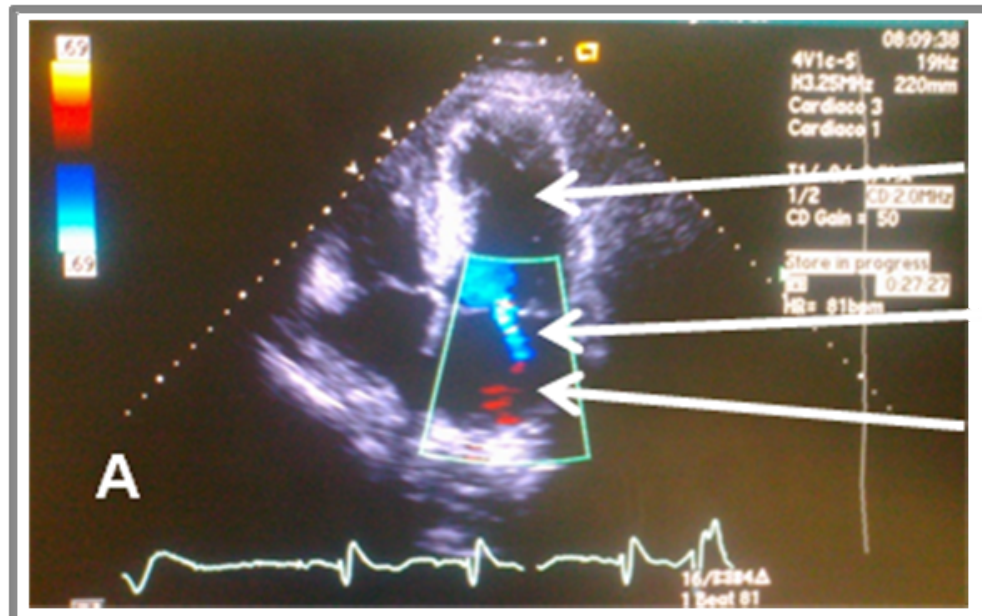

Ventrículo esquerdo

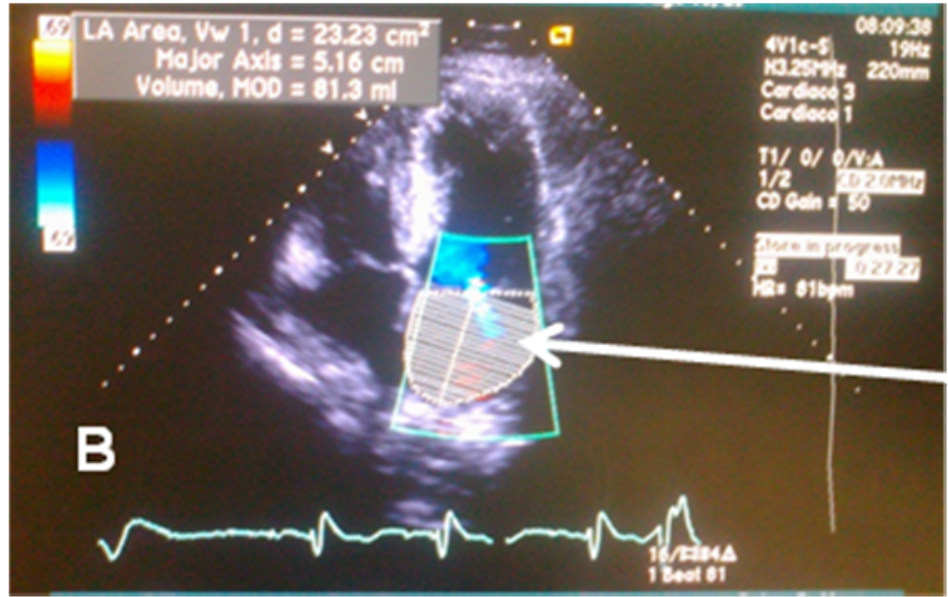

Planimetria do Átrio esquerdo

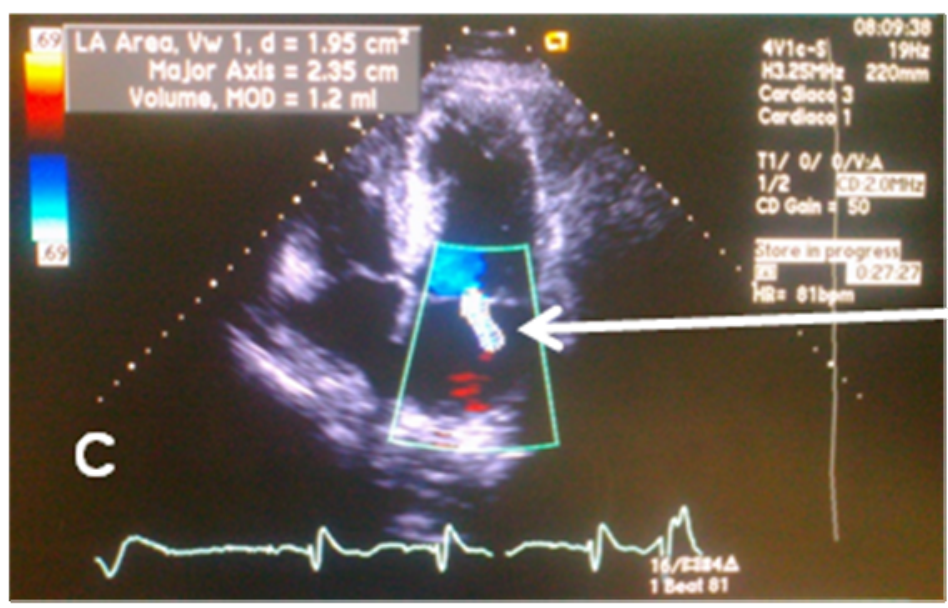

Planimetria do Jato regurgitante

Figura 20 - A - Imagem ecocardiográfica em corte apical quatro câmaras. B - no mesmo corte, planimetria do átrio esquerdo para quantificar área e volume; C - no mesmo corte, planimetria do jato regurgitante. (Fonte: Laboratório do Sono - InCor) 
O índice de desempenho miocárdico ou índice de Tei foi medido pela proporção do tempo total gasto na atividade isovolumétrica (tempo de contração isovolumétrica e TRIV) em relação ao tempo de ejeção. Para derivar a soma do tempo de contração isovolumétrica e TRIV, o tempo de ejeção foi subtraído do intervalo entre a cessação e início do fluxo da válvula atrioventricular.

Os gradientes sistólicos de VSVE e/ou intraventricular foram obtidos com a amostra de volume do Doppler contínuo nas respectivas regiões e calculados o pico de velocidade (Figura 21).

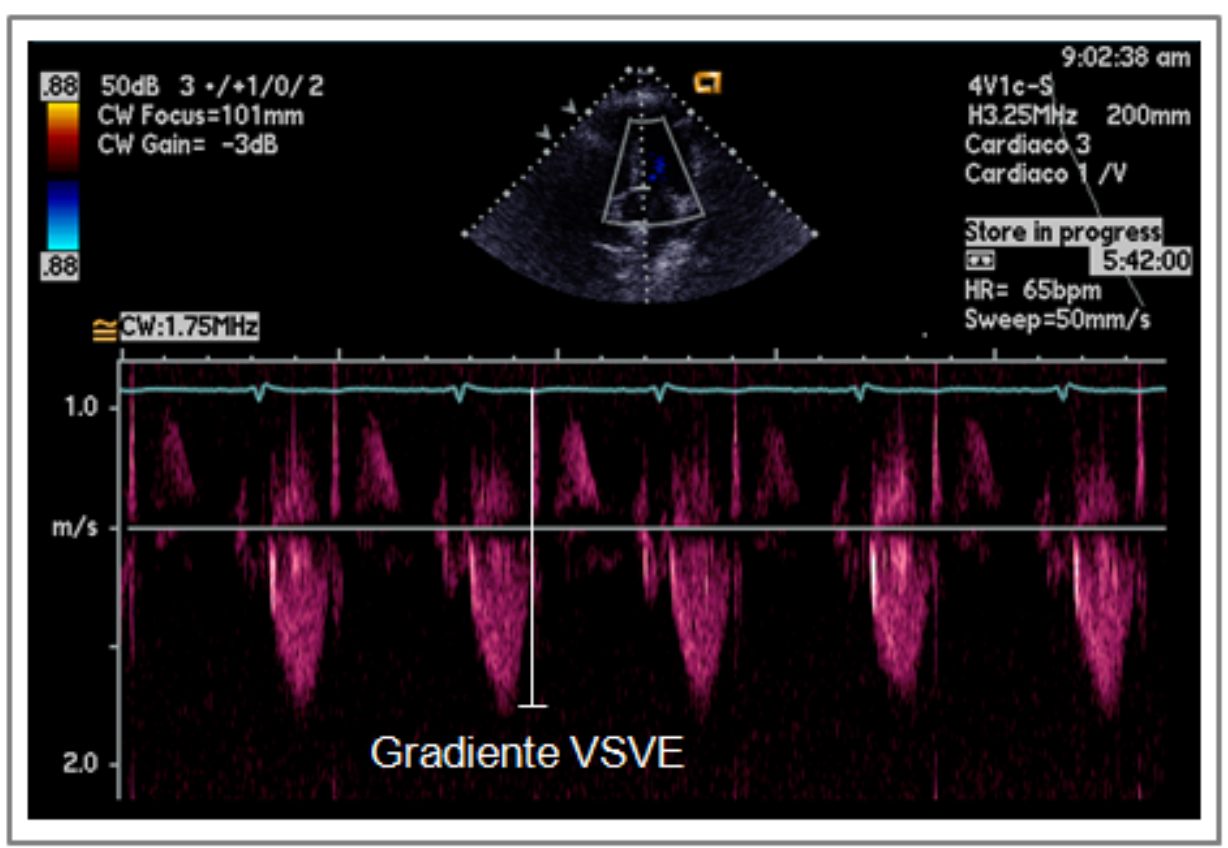

Figura 21 - Imagem ecocardiográfica de Doppler pulsado contínuo do fluxo da via de saída do ventrículo esquerdo, com cálculo do pico de velocidade. (Fonte: Laboratório do Sono - InCor)

Em relação aos índices do VD, foram avaliados: tempo de aceleração da artéria pulmonar (AP) obtido pelo Doppler pulsado do fluxo da via de 
saída do VD; comprimentos longitudinal e transverso da região basal e media do VD; a variação da área fracional do VD, expresso por 100 x área diastólica final - área sistólica final / área sistólica final. $A$ área do $A D$ em diástole foi obtida por planimetria do $A D$, da mesma forma que foi obtida a do $A E$.

Após ECO basal, foram realizadas duas manobras de provocação: Valsalva e Muller, com avaliações simultâneas do fluxo mitral e do gradiente de VSVE, conforme descrito anteriormente. O maior de gradiente de VSVE nas manobras foi considerado. ${ }^{(74)}$ Nos três momentos do protocolo em que foi realizado ECO completo (ECO basal, ECO1 e ECO2), independente da pressão de CPAP, a mesma metodologia foi seguida. Todas as medidas foram médias derivadas de três ciclos cardíacos consecutivos e foram gravadas em fitas VHS e DVDs (4.7 GB,.RW Philips) para posterior análise off-line.

Os exames de ecocardiografia deste estudo foram executados por um examinador experiente. As leituras off-line foram realizadas por um segundo examinador experiente. Para testar a variabilidade intraobservador, duas leituras foram realizadas pelo segundo examinador, num intervalo de 4 semanas, em 20 variáveis de um total de $20 \%$ dos exames basais, ambos selecionados aleatoriamente. ${ }^{(86)}$ Para a variabilidade interobservador, um terceiro examinador experiente realizou a leitura de 25 variáveis, em $70 \%$ dos casos, também selecionados aleatoriamente. Todos os observadores eram cegos em relação a pressão de CPAP que estava sendo aplicada ao paciente. Os resultados foram analisados pelo Coeficiente de Correlação 
Intraclasse $(\mathrm{CCl})$ e os limites de concordância obtidos pelo método gráfico sugerido por Bland-Altman, (Gráficos 4 e 5), descritos na análise estatística.

\subsubsection{Polissonografia Noturna Completa (PSG):}

A PSG convencional de noite inteira consiste em um sistema de registro de diversos parâmetros fisiológicos durante o sono, com a utilização de um multi-canal que monitoriza, em ambiente controlado, o eletroencefalograma, eletrooculograma, eletromiograma, saturação de oxigênio, fluxo de ar, esforço respiratório e FC. É o padrão-ouro para o diagnostico dos distúrbios respiratórios do sono. ${ }^{(35)}$ Para este estudo, utilizamos o polígrafo da marca Embla (Medical Devices, Broomfield, CO, USA). Foram monitoradas as fases do sono, quantificadas as porcentagens de cada estágio do sono, o tempo total de sono, a latência do sono, eficiência do sono e episódios de despertar. Classificamos as diferentes fases do sono em: 1) sono NREM (Non Rapid eyes movement), subdividida em estágios S1, S2 e S3 (sono de ondas lentas) e 2) sono REM (Rapid eyes movement). ${ }^{(87)}$ As mudanças no fluxo de ar foram registradas por sensor térmico sensível à variações de calor - termistor oronasal, pelo cateter nasal conectado a um transdutor de pressão e um pequeno microfone localizado na região cervical para a detecção de roncos. A saturação de oxigênio arterial foi detectada pela oximetria de pulso. As curvas de esforço respiratório do tórax e abdômen foram registradas por cintas piezo elétricas e, para FC, utilizamos o ECG com derivação precordial. 
O IAH foi obtido somando o número de apeias + hipopneias e as dividindo pelas horas de sono. Apneia foi definida pela cessação completa ou redução de $90 \%$ do fluxo de ar, por no mínimo 10 segundos, associado à dessaturação da oxihemoglobina em no mínimo 3\%. Hipopneia foi definida como uma redução $>50 \%$ nos do fluxo aéreo por no mínimo 10 segundos, associado à dessaturação da oxihemoglobina em no mínimo $3 \%$. Consideramos apneia leve quando encontrado um IAH entre 5 e 14,9 eventos/hora, moderada quando IAH entre 15 e 29,9 eventos/hora, e grave quando $\mathrm{IAH} \geq 30$ eventos/hora $^{(87)}$ (Figura 22). A montagem da PSG foi realizada e monitorada durante toda a noite, no Laboratório do sono do InCor, por um técnico especializado.

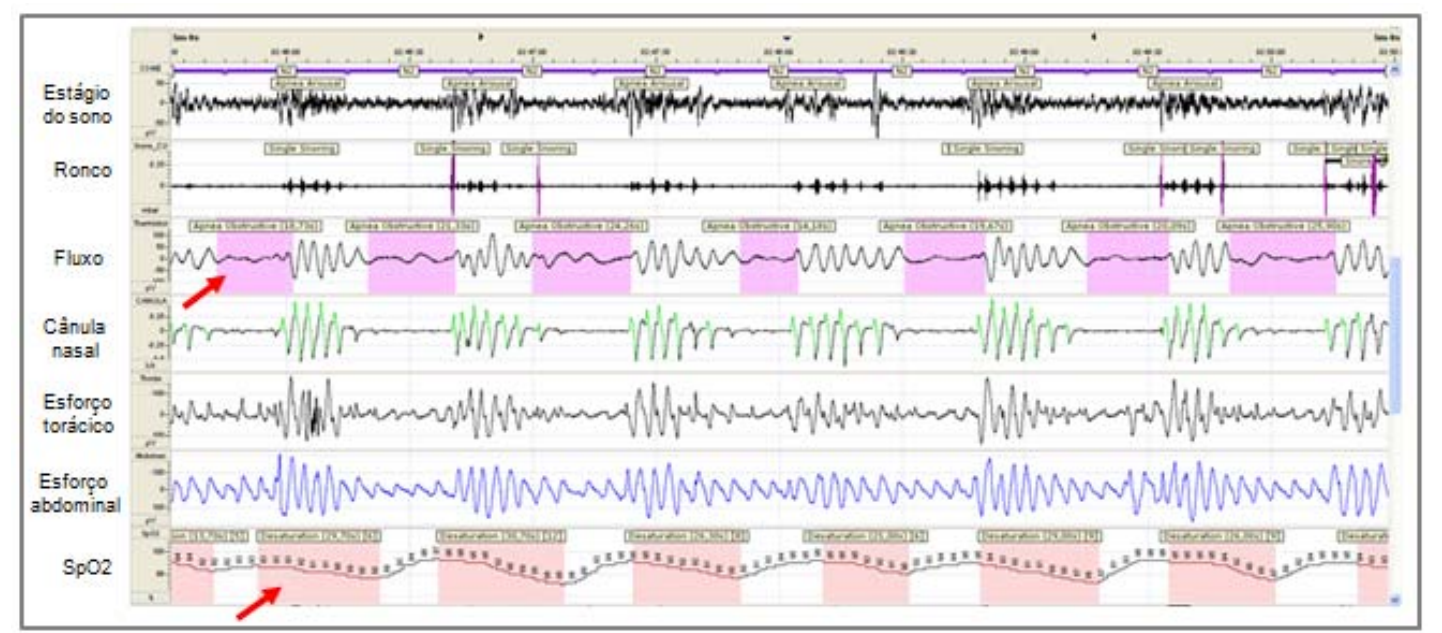

Figura 22 - Representação de 5 minutos de sono em uma tela de polissonografia noturna: variáveis de eletroencefalograma (estágio do sono), sensor de ronco, fluxo aéreo, cânula nasal, cintas de esforço torácico e abdominal e saturação periférica de $\mathrm{O}_{2}\left(\mathrm{SpO}_{2}\right)$. A seta vermelha no fluxo representa os eventos de apneia obstrutiva e na $\mathrm{SpO}_{2}$ representa as quedas de saturação decorrentes das apneias. (Fonte: Laboratório do Sono - InCor). 


\subsection{3: BNP - Peptídeo Natriurético Cerebral}

O BNP é o produto da ativação neuro-hormonal secretado por células miocárdicas ventriculares em resposta a elevações nos volumes e pressões diastólicos finais. Existem evidências de que o BNP se correlaciona com sintomas clínicos, presença e magnitude da insuficiência cardíaca e com GPD em pacientes com $\mathrm{CMH} \cdot{ }^{(88,89)} \mathrm{A}$ concentração plasmática de BNP foi obtida por meio de um imunoensaio tipo sanduíche de duas etapas, que utilizou tecnologia quimioluminescente direta e quantidades constantes de dois anticorpos monoclonais. Para isso, foi utilizado o kit comercial ADVIA Centaur $^{\circledR}$ (Siemens Medical Solutions Diagnostic, Los Angeles, CA, USA) em equipamento automatizado da mesma marca. Os resultados estão apresentados em pg/ml.

\subsection{4: Colesterol total e frações e glicemia.}

Colesterol total e triglicérides foram dosados por método colorimétrico

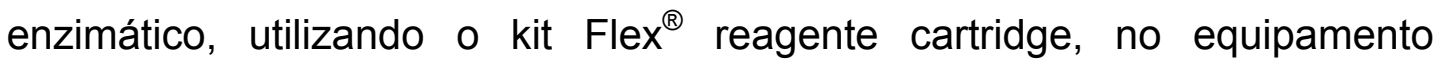
Dimension RXL, Siemens Healthcare (Newark, USA). O HDL Colesterol (Lipoproteína de alta densidade) foi dosado por método colorimétrico enzimático homogêneo, utilizando-se o mesmo Kit e equipamentos acima. $O$ LDL Colesterol (Lipoproteína de baixa densidade), foi estimado pela equação de Friedewald. A Glicose foi dosada por método enzimático automatizado, utilizando-se kit específico para o equipamento automatizado Dimension RXL, Siemens Healthcare (Newark, USA). 


\subsection{Questionários}

\subsubsection{Escala de Sonolência de Epworth}

A Escala de Epworth foi utilizada para avaliar subjetivamente a sonolência excessiva diurna. Os pacientes foram questionados em relação à possibilidade de cochilar em 8 situações cotidianas diferentes. Cada situação foi pontuada de "zero" a 3, sendo: "zero" = nenhuma chance de cochilar; 1 = pequena chance; 2 = moderada chance e $3=$ grande chance de cochilar. O escore total varia de 0 a 24 pontos e, quando acima de 9 , traduz uma sonolência excessiva patológica. ${ }^{(90)}$ (Anexo C).

\subsubsection{Questionário Clínico de Berlin}

Classifica os pacientes em alto e baixo risco para ter AOS, baseado em respostas de três categorias de sintomas. Categoria 1 é definida como positiva se o paciente apresenta sintomas de ronco persistentes (> 3 a 4 vezes/semana). Categoria 2 é definida como positiva pela presença persistente de cansaço na hora de acordar (> 3 a 4 vezes/semana). Categoria 3 é definida como positiva se o paciente for hipertenso ou obeso, representado por um IMC $\geq 30 \mathrm{~kg} / \mathrm{m}^{2}$. Com um resultado positivo em duas ou mais categorias, o paciente é considerado de alto risco para ter AOS. ${ }^{(91)}$ (Anexo C)

\subsection{3 Índice de Qualidade de Sono de Pittsburgh}


Avalia a qualidade do sono relacionada aos últimos trinta dias, de acordo com sete componentes: a) qualidade subjetiva do sono; b) latência do sono; c) duração do sono; d) eficiência habitual do sono; e) distúrbios do sono; f) uso de medicamentos para dormir e g) disfunção diária (a forma pela qual este distúrbio do sono interfere nas atividades de vida diárias). A soma final destes componentes pode ser interpretada da seguinte forma: 0 - 4: boa qualidade de sono; 5 - 10: má qualidade do sono e acima de 10: presença de distúrbio do sono. ${ }^{(92)}$ (Anexo D).

\subsubsection{Classificação Funcional da New York Heart Association} (NYHA):

Classifica os pacientes de acordo com o grau de sintomas relatados por eles, para realizar as atividades habituais ou menores do que as habituais. Subdivide-se em 4 níveis: classe funcional I - Sintomas apenas aos esforços extra-habituais. Nenhuma limitação, apesar de doença cardíaca diagnosticada; classe funcional II - assintomático em repouso. Sintomas aos esforços habituais. Limitação física leve; classe funcional III Sintomas aos esforços menores que os habituais. Limitação física moderada; classe funcional IV - graves limitações físicas e sintomas presentes mesmo em repouso. ${ }^{(93)}$ (Anexo E).

\subsection{Análise estatística}


Os dados foram analisados com os softwares estatísticos SPSS 17.0 (SPSS Inc., Chicago, Illinois, USA) e R 2.15.1 (R Core Team, 2012).

\subsubsection{Variáveis clínicas, demográficas, polissonográficas e ecocardiográficas basais entre os grupos CMHN-Obst e CMHObst.}

Análise descritiva foi utilizada para caracterizar a população do estudo. A normalidade da distribuição dos dados foi testada pelo teste Kolmogorov-Smirnov. Comparações entre as variáveis contínuas paramétricas foram realizadas pelos testes t-Student não pareado, com resultados expressos em média e desvio padrão. Variáveis contínuas não paramétricas foram avaliadas pelo teste Mann-Whitney, tendo resultados expressos em mediana e intervalo interquartil (25\%-75\%). A análise das frequências foi realizada pelo teste qui-quadrado e estão expressas em porcentagem.

\footnotetext{
4.6.2 Análise das variáveis ecocardiográficas considerando o grupo, a pressão de CPAP, o protocolo e o desenho crossover.

O presente ensaio clínico foi realizado em dois grupos de pacientes com $\mathrm{CMH}$ (CMHN-Obst e CMHObst) e avaliou medidas de desempenho cardíaco por meio do ECO em 3 momentos, Basal, após aplicação do Sham-CPAP e após aplicação do CPAP-10. Essas pressões de CPAP, por sua vez, foram aplicadas de forma randomizada em crossover, ou seja,
} 
uma parte dos indivíduos iniciou o protocolo com Sham-CPAP - intervalo CPAP-10 (Protocolo A) e outra parte iniciou com CPAP-10 - intervalo Sham-CPAP (Protocolo B). ${ }^{(94)}$

Como se trata de um estudo crossover, testamos o carryover effect, ou seja, se mesmo após o período de intervalo, a pressão inicial influenciou algum resultado encontrado na pressão seguinte. No modelo abaixo, descrevemos esse efeito como "efeito do protocolo". Para construção do modelo, selecionamos as variáveis "Fração do volume regurgitante (\%)" e "Fração da área regurgitante (\%)", que representam e quantificam o refluxo mitral, além de serem medidas dinâmicas que poderiam sofrer influência da pressão positiva.

Inicialmente analisamos a variável "Fração do volume regurgitante (\%)", comparando os Grupos (CMHN-Obst e CMHObst), os tratamentos (Sham-CPAP e CPAP-10) e os Protocolos (A ou B). Com essa análise encontramos uma alta variabilidade dos dados, principalmente no grupo CMHObst. Com isso, propusemos um modelo linear misto, ${ }^{(95)}$ com Protocolo interagindo com o tratamento; Tratamento interagindo com Grupo e efeito aleatório do indivíduo (Tabela 2). Este efeito aleatório traduz a grande variabilidade das medidas obtidas logo no Basal, que e se mantiveram nos demais momentos medidos. Observe na Tabela abaixo que não houve diferença estatística quando avaliado interação entre Tratamento e Protocolo, nem para efeito de Protocolo (ambos em negrito), o que nos permite assumir que não houve influencia do desenho crossover do estudo 
(carryover effect) para essa variável. Assim simplificamos o modelo retirando ambos da análise.

Tabela 2 - Análise dos efeitos fixos do modelo linear misto inicial para "Fração do volume regurgitante (\%)".

\begin{tabular}{lccc}
\hline & $\begin{array}{c}\text { Graus de liberdade } \\
\text { do numerador }\end{array}$ & Valor F & $\mathrm{p}$ \\
\hline Intercepto & 1 & 20,96 & $<0,001$ \\
Tratamento (Sham-CPAP e CPAP-10) & 2 & 0,03 & 0,968 \\
Grupo (CMHN-Obst e CMHObst) & 1 & 11,05 & 0,003 \\
Protocolo (A ou B) & $\mathbf{1}$ & $\mathbf{1 , 2 7}$ & $\mathbf{0 , 2 7 2}$ \\
Tratamento:Grupo & 2 & 4,78 & 0,013 \\
Tratamento:Protocolo & $\mathbf{2}$ & $\mathbf{0 , 1 0}$ & $\mathbf{0 , 9 0 9}$ \\
\hline
\end{tabular}

${ }^{*} \mathrm{p} \leq 0,05$

A tabela 3 simplificada, nos mostra que para a "Fração do volume regurgitante", os grupos eram diferentes em todos os momentos (efeito de grupo) e houve uma interação do tratamento com o grupo, o que indica que o tratamento (Sham-CPAP ou CPAP-10) causou algum efeito na diferença encontrada entre os grupos. Veja os resultados mais detalhados na Tabela 9, sessão de resultados. 
Tabela 3 - Análise dos efeitos fixos do modelo linear misto final para "Fração do volume regurgitante (\%)".

\begin{tabular}{lccc}
\hline & $\begin{array}{c}\text { Graus de liberdade } \\
\text { do numerador }\end{array}$ & Valor F & $\mathrm{p}$ \\
\hline Intercepto & 1 & 20,71 & $<0,001^{*}$ \\
Tratamento (Sham-CPAP e CPAP-10) & 2 & 0,06 & 0,940 \\
Grupo (CMHN-Obst e CMHObst) & $\mathbf{1}$ & $\mathbf{1 0 , 9 8}$ & $\mathbf{0 , 0 0 3 ^ { * }}$ \\
Tratamento:Grupo & $\mathbf{2}$ & $\mathbf{4 , 8 4}$ & $\mathbf{0 , 0 1 3 ^ { * }}$ \\
\hline
\end{tabular}

$* \bar{p} \leq 0,05$

Obtivemos resultados semelhantes para a "Fração da área regurgitante (\%)", que também estão descritos na sessão de resultados. Assim, consideramos que o modelo linear misto foi eficaz em demonstrar que não houve efeito do protocolo nem do desenho do estudo (carryover effect), além de identificar o efeito do tratamento no grupo. Julgamos ser um bom modelo para analisarmos as variáveis ecocardiográficas, assumindo que essas variáveis apresentam variabilidade nas medidas.

Para obtermos resultados mais específicos e consistentes sobre em que grupo e em qual momento esses efeitos ocorreram, para todas as variáveis que apresentaram efeito de tratamento e interação entre tratamento e grupo, realizamos comparações múltiplas entre os grupos (intergrupo) e entre os momentos (Basal, Sham-CPAP e CPAP-10) de cada grupo (intragrupo), por meio do teste de Bonferroni. Os dados estão expressos em média e intervalo de confiança (IC 95\%). 


\subsubsection{Comparações entre os gradientes de via de saída do} ventrículo esquerdo

Para comparações entre os gradientes de VSVE utilizamos o teste estatístico ANOVA two-way considerando variâncias distintas entre os grupos. Os dados estão apresentados nos gráficos em média e desvio padrão.

\subsection{4: Reprodutibilidade das medidas ecocardiográficas}

Para análise da variabilidade intra e interobservador, utilizamos o $\mathrm{CCl}$ para concordância absoluta. Esse método avalia a concordância entre as diferentes medidas de variáveis contínuas, sendo uma das ferramentas estatísticas mais utilizadas para mensuração da confiabilidade e homogeneidade entre duas ou mais medidas. É interpretado como a proporção da variabilidade total da variável medida. Um valor de $\mathrm{CCl}>0,05$ representa concordância moderada; $\mathrm{CCl}>0,07$ indica boa concordância e $\mathrm{CCl}>0,08$, muito boa concordância. Os dados são expressos em coeficiente e IC (95\%). ${ }^{(96)}$ Os limites de concordância inter e intraobservador foram obtidos pelos gráficos de Bland-Altman. ${ }^{(97)}$

4.6.5 Análise das variações da pressão arterial batimento-abatimento 
Considerando que as diferentes pressões de CPAP poderiam causar variações da PA, avaliamos inicialmente a distribuição dos valores de PA batimento-a-batimento individuais, medidos durante todos os momentos do estudo (Basal, Sham-CPAP, intervalo, CPAP-10 e recuperação), levando em consideração que os momentos Sham-CPAP e CPAP-10 ocorreram de forma inversa, dependendo da randomização. Observamos que de uma forma geral, esses valores foram constantes na avaliação individual em todos os momentos. Assim, optamos por analisar o comportamento das pressões arteriais sistólica (PAS) e diastólica (PAD) pelo modelo linear misto, em períodos de 1 minuto. Para isso, selecionamos as médias e desvios-padrão dos $1^{\circ}, 5^{\circ}$ e $10^{\circ}$ minutos de cada momento, em ambos os grupos.

Para a primeira análise, utilizamos o modelo misto para compararmos as médias das PAS e PAD entre: os 3 minutos no mesmo momento de cada grupo; os diferentes momentos no mesmo grupo; em cada momento entre os grupos. (Ver Tabela 12, sessão de resultados) Uma vez que os grupos não influenciaram as variações da pressão, consideramos as médias de todos os pacientes, em cada minuto, formando um só grupo. Assim, para uma segunda análise, comparamos as variações da PA durante os momentos Sham-CPAP e CPAP-10. Para uma terceira análise, testamos se o Tratamento com CPAP em $10 \mathrm{cmH}_{2} \mathrm{O}$ fez com que a pressão variasse. Para tal, comparamos os valores de PAS e PAD entre o $10^{\circ}$ minuto com CPAP-10 e o $1^{\circ}$ minuto do momento subsequente (intervalo ou recuperação) (Ver Tabela 13, sessão de resultados). Todas as comparações da segunda e 
terceira análise da PA foram obtidas por meio do teste t-Student. Os dados estão apresentados em média e desvio padrão nas Tabelas e em média e IC (95\%) nos gráficos. O nível de significância para todas as análises foi estabelecido em $\mathrm{p} \leq 0,05$. 
Resultados 


\section{Resultados}

Os resultados obtidos neste estudo serão descritos a seguir, seguindo os seguintes tópicos:

5.1 Características da população estudada;

5.2 Dados ecocardiográficos de ambos os grupos ao longo do estudo;

5.3 Análise dos gradientes de via de saída do ventrículo esquerdo ao longo do estudo;

5.4 Reprodutibilidade das medidas ecocardiográficas;

5.5 Dados da pressão arterial de ambos os grupos ao longo do estudo;

5.6 Variações nas pressões de CPAP e $\mathrm{EtCO}_{2}$

\subsection{Características da população estudada}

Para realização desse estudo foram recrutados 43 pacientes com CMH durante o período de dezembro de 2010 a abril de 2013. Destes, $n=6$ recusaram participar e $n=11$ não puderam comparecer ao InCor na data agendada. Portanto, 26 pacientes com $\mathrm{CMH}$ foram incluídos, sendo $\mathrm{n}=12$ com $\mathrm{CMHN}$-Obst e $\mathrm{n}=14$ com $\mathrm{CMHObst.} \mathrm{Abaixo} \mathrm{segue} \mathrm{o} \mathrm{fluxograma} \mathrm{dos}$ participantes do estudo. 


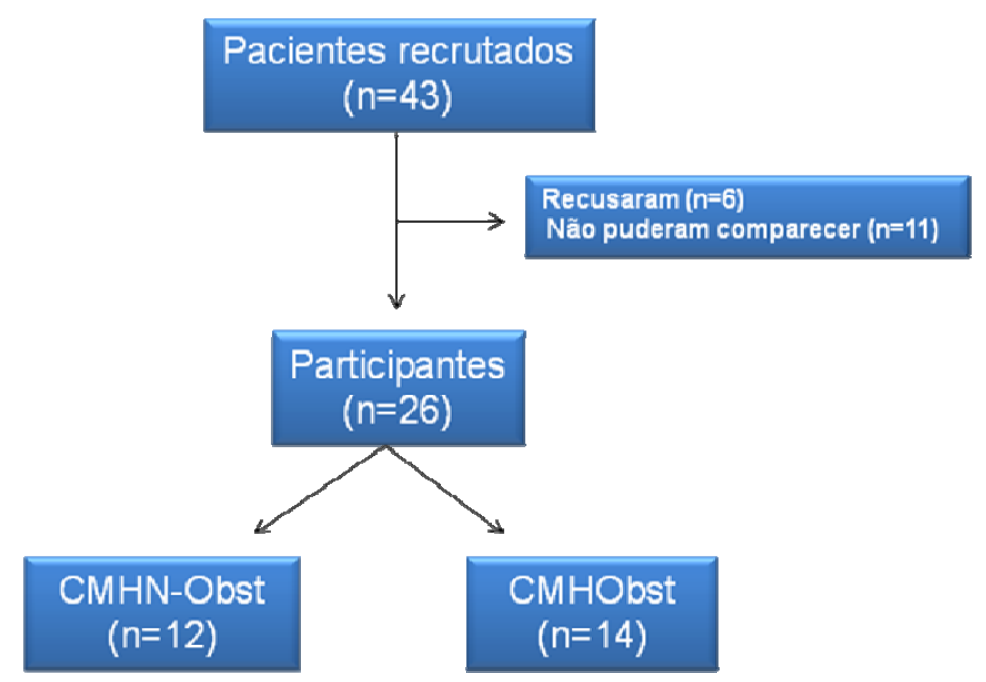

Figura 23 - Fluxograma dos participantes do estudo.

$\mathrm{Na}$ Tabela 4 estão sumarizadas as características demográficas, clínicas e referentes ao uso de medicações da população total, bem como de acordo com a classificação em CMHN-Obst e CMHObst. A amostra foi composta predominantemente por adultos jovens, caucasianos, do sexo masculino e com sobrepeso. Todas as variáveis demográficas, clínicas e de uso de medicações foram semelhantes entre os grupos. Oitenta e oito por cento dos pacientes estavam em uso de pelo menos uma medicação para tratamento da $\mathrm{CMH}$. 
Tabela 4 - Características demográficas, clínicas e de medicações utilizadas pela população total e classificada em CMHN-Obst e CMHObst.

\begin{tabular}{|c|c|c|c|c|}
\hline & $\begin{array}{l}\text { Total } \\
(n=26)\end{array}$ & $\begin{array}{l}\text { CMHN-Obst } \\
\qquad(n=12)\end{array}$ & $\begin{array}{l}\text { CMHObst } \\
\qquad(n=14)\end{array}$ & $P$ \\
\hline Idade, anos & $46 \pm 11$ & $46 \pm 12$ & $45 \pm 11$ & 0,833 \\
\hline Homens, n (\%) & $20(77)$ & $9(75)$ & $11(78)$ & 0,829 \\
\hline Caucasianos, n (\%) & $15(58)$ & $6(50)$ & $9(64)$ & 0,462 \\
\hline Índice de massa corpórea, kg/m² & $28,0 \pm 6,4$ & $28,6 \pm 5,5$ & $29,1 \pm 4,0$ & 0,766 \\
\hline Circunferência cervical, cm & $39,8 \pm 3,6$ & $39,2 \pm 3,9$ & $40,3 \pm 3,5$ & 0,461 \\
\hline Circunferência abdominal, $\mathrm{cm}$ & $101,5 \pm 10,7$ & $101,2 \pm 12,4$ & $101,7 \pm 9,6$ & 0,911 \\
\hline Frequência cardíaca, bpm & $63 \pm 9$ & $65 \pm 11$ & $61 \pm 8$ & 0,319 \\
\hline Pressão arterial sistólica, mmHg & $126 \pm 16$ & $128 \pm 12$ & $125 \pm 19$ & 0,621 \\
\hline Pressão arterial diastólica, $\mathrm{mmHg}$ & $70 \pm 18$ & $70 \pm 22$ & $70 \pm 16$ & 0,974 \\
\hline Pressão arterial média, mmHg & $88 \pm 16$ & $89 \pm 17$ & $88 \pm 16$ & 0,849 \\
\hline Classe funcional NYHA III-IV,n (\%) & $10(38)$ & $4(33)$ & $6(43)$ & 0,619 \\
\hline \multicolumn{5}{|l|}{ Medicações } \\
\hline Betabloqueador, n (\%) & $21(81)$ & $9(75)$ & $12(86)$ & 0,635 \\
\hline Inibidor de ECA, n (\%) & $1(4)$ & $1(8)$ & $0(0)$ & 0,462 \\
\hline Bloqueador de canais de cálcio, n (\%) & $5(19)$ & $3(25)$ & $2(14)$ & 0,635 \\
\hline Bloqueador de Angiotensina 1, n (\%) & $5(19)$ & $3(25)$ & $2(14)$ & 0,635 \\
\hline Antiarrítmicos, $\mathrm{n}(\%)$ & $4(15)$ & $3(25)$ & $1(4)$ & 0,306 \\
\hline Diuréticos, n (\%) & $6(23)$ & $3(25)$ & $3(21)$ & 1,000 \\
\hline
\end{tabular}

Classe funcional NYHA: classe funcional de insuficiência cardíaca da New York Heart Association; ECA: enzima conversora de angiotensina; Dados apresentados como média e desvio padrão e percentil. ${ }^{*} p \leq 0,05$.

$\mathrm{Na}$ Tabela 5 estão descritos os resultados dos exames laboratoriais da população total e classificadas em CMHN-Obst e CMHObst. Apenas o BNP foi estatisticamente diferente e maior para o grupo obstrutivo. 
Tabela 5 - Exames laboratoriais da população total e classificada em CMHNObst e CMHObst.

\begin{tabular}{|c|c|c|c|c|}
\hline & $\begin{array}{l}\text { Total } \\
(n=26)\end{array}$ & $\begin{array}{c}\text { CMHN-Obst } \\
(n=12)\end{array}$ & $\begin{array}{c}\text { CMHObst } \\
(n=14)\end{array}$ & $p$ \\
\hline Colesterol, mg/dL & $187 \pm 28$ & $186 \pm 37$ & $189 \pm 18$ & 0,766 \\
\hline LDL, mg/dL & $122 \pm 29$ & $119 \pm 35$ & $124 \pm 24$ & 0,647 \\
\hline $\mathrm{HDL}, \mathrm{mg} / \mathrm{dL}$ & $44 \pm 10$ & $44 \pm 13$ & $44 \pm 6$ & 0,928 \\
\hline Triglicérides, mg/dL & $116 \pm 48$ & $113 \pm 53$ & $118 \pm 45$ & 0,792 \\
\hline Glicemia, mg/dL & $97 \pm 15$ & $98 \pm 18$ & $96 \pm 14$ & 0,854 \\
\hline BNP, pg/ml & $252(149-488)$ & $149(113-284)$ & $383(237-538)$ & $0,005^{*}$ \\
\hline
\end{tabular}

LDL: lipoproteína de baixa densidade; HDL: lipoproteína de alta densidade, BNP: Peptídeo natriurético cerebral; Dados apresentados como média e desvio padrão. ${ }^{*} p \leq 0,05$.

Os dados polissonográficos da população total e de ambos os grupos estão descritos na Tabela 6 . Não verificamos diferença estatística para a maioria das variáveis avaliadas. O grupo CMHObst apresentou menor média de latência para início do sono e maior eficiência de sono. Os eventos respiratórios foram em sua maioria obstrutivos (apneias e hipopneias) e o IAH médio correspondeu a AOS de grau moderado para ambos os grupos. Do total de 12 pacientes do grupo $\mathrm{CMHN}-$ Obst, $\mathrm{n}=4$ pacientes não tinham AOS; nenhum paciente foi diagnosticado com AOS leve; $n=8$ pacientes apresentaram AOS moderada e grave (67\%). Já no grupo CMHObst, dos 14 casos, $n=2$ não tinham AOS; $n=5$ apresentaram AOS leve e $n=7$ pacientes com AOS moderada e grave (50\%). A frequência de AOS moderada-grave na população total de pacientes com $\mathrm{CMH}$ foi de $58 \%$. 
Tabela 6 - Dados polissonográficos da população total e classificada em CMHN-Obst e CMHObst.

\begin{tabular}{|c|c|c|c|c|}
\hline & $\begin{array}{l}\text { Total } \\
(n=26)\end{array}$ & $\begin{array}{c}\text { CMHN-Obst } \\
(n=12)\end{array}$ & $\begin{array}{c}\text { CMHObst } \\
(n=14)\end{array}$ & $p$ \\
\hline Tempo de registro, min & $455,3 \pm 38,8$ & $464,6 \pm 35,8$ & $447,3 \pm 41,0$ & 0,275 \\
\hline Tempo total de sono, min & $394,2 \pm 44,6$ & $379,2 \pm 50,1$ & $408,0 \pm 35,3$ & 0,108 \\
\hline Latência início sono, min & $16,1 \pm 22,2$ & $25,9 \pm 29,0$ & $7,12 \pm 5,8$ & $0,031^{*}$ \\
\hline Latência REM, min & $98,2 \pm 57,2$ & $78,9 \pm 48,9$ & $116,1 \pm 60,3$ & 0,105 \\
\hline Eficiência do sono, \% & $86,9 \pm 10,3$ & $82,1 \pm 12,3$ & $91,4 \pm 5,2$ & $0,019^{*}$ \\
\hline Despertares, $n$ & $142,4 \pm 84,7$ & $124,7 \pm 82,3$ & $158,8 \pm 86,8$ & 0,325 \\
\hline Despertares completos, $\mathrm{n}$ & $20,1 \pm 11,3$ & $20,2 \pm 13,6$ & $20 \pm 9,2$ & 0,957 \\
\hline Estágio1, \% & $10,2 \pm 5,3$ & $11,7 \pm 5,7$ & $8,8 \pm 4,7$ & 0,177 \\
\hline Estágio 2, \% & $60,4(52,2-66,1)$ & $53,8(48,8-62,8)$ & $61,6(59,8-68,3)$ & 0,073 \\
\hline Estágio 3, \% & $17,2 \pm 8,8$ & $17,0 \pm 8,9$ & $17,4 \pm 9,0$ & 0,911 \\
\hline REM, \% & $12,8 \pm 6,7$ & $14,8 \pm 7,4$ & $10,9 \pm 5,7$ & 0,146 \\
\hline $\mathrm{IAH}, \mathrm{ev} / \mathrm{h}$ & $24,4 \pm 20,5$ & $28,5 \pm 23,8$ & $21,8 \pm 17,6$ & 0,351 \\
\hline AOS leve, $n(\%)$ & $5(19)$ & $0(0)$ & $5(36)$ & $0,049^{*}$ \\
\hline AOS mod, $\mathrm{n}(\%)$ & $7(27)$ & $3(25)$ & $4(29)$ & 0,866 \\
\hline AOS grave, $n(\%)$ & $8(31)$ & $5(42)$ & $3(21)$ & 0,200 \\
\hline Saturação media, \% & $94 \pm 2$ & $94 \pm 3$ & $94 \pm 2$ & 0,742 \\
\hline Saturação mínima, \% & $85 \pm 5$ & $85 \pm 7$ & $85 \pm 4$ & 0,970 \\
\hline Tempo Saturação < $90 \%$, s & $17,4 \pm 49,1$ & $10,7 \pm 14,5$ & $23,6 \pm 67,4$ & 0,525 \\
\hline
\end{tabular}

REM: Rapid eye moviment; IAH: índice de apneia/hipopneia. Dados apresentados como média e desvio padrão ou mediana $\left(25 \%-75 \%\right.$ intervalo interquartil) ${ }^{*} p \leq 0,05$.

Os dados relacionados aos questionários de sono estão descritos na Tabela 7. Considerando os valores médios, $n=6$ pacientes em cada grupo apresentaram alto risco para ter AOS (Questionário de Berlin), embora não 
fossem sonolentos (Escala de Epworth). Pacientes de ambos os grupos relataram ter má qualidade do sono, (Índice de Qualidade de Sono de Pittsburgh), porém com piores índices para o grupo de obstrutivos.

Tabela 7 - Dados dos questionários de sono da população total e classificada em CMHN-Obst e CMHObst.

\begin{tabular}{lcccc}
\hline & $\begin{array}{c}\text { Total } \\
(\mathbf{n = 2 6})\end{array}$ & $\begin{array}{c}\text { CMHN-Obst } \\
(\mathbf{n = 1 2})\end{array}$ & $\begin{array}{c}\text { CMHObst } \\
(\mathbf{n = 1 4 )}\end{array}$ & $\boldsymbol{p}$ \\
\hline Berlin Alto risco, n (\%) & $12(46)$ & $6(50)$ & $6(43)$ & 1,000 \\
Escala de sonolência de Epworth & $9,1 \pm 4,5$ & $9,2 \pm 5,1$ & $9,0 \pm 4,1$ & 0,892 \\
Pittsburgh & $8.5(5-12)$ & $6(4-12)$ & $10(5.5-13)$ & 0.394 \\
\hline
\end{tabular}

Dados apresentados como média e desvio padrão e percentil * $p \leq 0,05$.

Na Tabela 8 estão descritos os dados ecocardiográficos basais de ambos os grupos. Pacientes do grupo CMHObst apresentaram maiores médias para índice de massa do VE, gradiente de VSVE e para variáveis relacionadas às pressões de enchimento ventricular (E/E'septal; E/E' lateral e E/E' médio do VE), além da maior prevalência de MAS. Considerando a planimetria do $\mathrm{AE}$ e do jato regurgitante, notamos também que os pacientes obstrutivos apresentaram maiores áreas e volumes em relação aos nãoobstrutivos. Ao avaliarmos frações regurgitantes, embora as médias também tenham sido maiores no grupo CMHObst, apenas a fração da área regurgitante refletiu significância estatística. Não encontramos diferença entre as variáveis que avaliam a morfologia e função de VD pra ambos os grupos. 
É importante ressaltar que durante a realização do ECO, o acesso às janelas cardíacas de alguns pacientes foi limitado. Assim, algumas variáveis ecocardiográficas apresentadas nas Tabelas 8 e 9 não foram analisadas com o " $\mathrm{n}$ " total de cada grupo, sendo elas para CMHN-Obst e CMHObst, respectivamente: E'médio do VE ( $n=9$ e $n=9)$; tempo de aceleração da AP ( $n=5$ e n=9), E/E' do VD ( $n=4$ e $n=6)$; comprimento basal, médio e longitudinal do VD e variação da área fracional do VD ( $n=8$ e $n=13)$ e área do $A D(n=10$ e $n=13)$. Desta forma, alguns dos resultados comparativos entre os grupos referentes a essas variáveis devem ser considerados com cautela.

Tabela 8 - Dados ecocardiográficos basais dos pacientes classificados em CMHN-Obst e CMHObst.

\begin{tabular}{|c|c|c|c|}
\hline & $\begin{array}{l}\text { CMHN-Obst } \\
(n=12)\end{array}$ & $\begin{array}{c}\text { CMHObst } \\
(n=14)\end{array}$ & $\boldsymbol{P}$ \\
\hline Septo interventricular, $\mathrm{mm}$ & $19,8 \pm 2,7$ & $22,0 \pm 3,5$ & 0,090 \\
\hline Parede posterior, $\mathrm{mm}$ & $12,4 \pm 1,31$ & $13,3 \pm 2,1$ & 0,203 \\
\hline Diâmetro diastólico do VE, mm & $42,8 \pm 7,3$ & $46,8 \pm 7,5$ & 0,177 \\
\hline Diâmetro sistólico do VE, mm & $25,5 \pm 5,7$ & $27,9 \pm 5,5$ & 0,274 \\
\hline Fração de encurtamento do VE, \% & $41 \pm 5$ & $41 \pm 4$ & 0,900 \\
\hline Fração de ejeção do VE, \% & $72 \pm 6$ & $71 \pm 5$ & 0,850 \\
\hline Índice de massa do VE, $\mathrm{g} / \mathrm{m}^{2}$ & $220,5 \pm 67,8$ & $313,1 \pm 132,7$ & $0,039^{*}$ \\
\hline Seio aórtico, $\mathrm{mm}$ & $30,4 \pm 3,6$ & $30,5 \pm 1,9$ & 0,962 \\
\hline Volume sistólico do VE, ml & $60,1 \pm 21,5$ & $67,5 \pm 14,6$ & 0,324 \\
\hline Débito cardíaco, L/m & $4,0 \pm 1,3$ & $4,0 \pm 1,0$ & 0,972 \\
\hline
\end{tabular}


Tabela 8 - Dados ecocardiográficos basais dos pacientes classificados em CMHN-Obst e CMHObst (continuação).

\begin{tabular}{|c|c|c|c|}
\hline & $\begin{array}{l}\text { CMHN-Obst } \\
\quad(n=12)\end{array}$ & $\begin{array}{c}\text { CMHObst } \\
(n=14)\end{array}$ & $P$ \\
\hline Índice Tei (Doppler pulsátil VE) & $0,67 \pm 0,3$ & $0,52 \pm 0,10$ & 0,081 \\
\hline Onda $\mathrm{E}, \mathrm{cm} / \mathrm{s}$ & $71,9 \pm 21,9$ & $85,4 \pm 19,4$ & 0,110 \\
\hline Onda $A, \mathrm{~cm} / \mathrm{s}$ & $47,0 \pm 23,3$ & $59,6 \pm 28,4$ & 0,248 \\
\hline Relação E/A & $1,7 \pm 0,9$ & $1,7 \pm 0,8$ & 0,880 \\
\hline Tempo relaxamento isovolumétrico, ms & $117,1 \pm 40,9$ & $99,3 \pm 19,9$ & 0,163 \\
\hline Tempo de desaceleração, MS & $202,3 \pm 48,5$ & $215,3 \pm 55,2$ & 0,533 \\
\hline Gradiente de VSVE, $\mathrm{mmHg}$ & $6,1(5,1-10,1)$ & $56,7(48,7-109,1)$ & $<0,001^{*}$ \\
\hline MAS +, n (\%) & $2(17)$ & $13(93)$ & $<0,001^{*}$ \\
\hline E' septo, $\mathrm{cm} / \mathrm{s}$ & $8,5 \pm 2,6$ & $7,4 \pm 3,7$ & 0,409 \\
\hline $\mathrm{E}^{\prime}$ lateral, $\mathrm{cm} / \mathrm{s}$ & $12,1 \pm 3,0$ & $9,7 \pm 2,5$ & $0,041^{*}$ \\
\hline E' médio do VE, cm/s & $10,7 \pm 2,2$ & $8,8 \pm 2,5$ & 0,178 \\
\hline E/E' septo, cm/s & $9,9(9,4-10,8)$ & $14,2(10,1-17,6)$ & $0,024^{*}$ \\
\hline E/E' lateral, $\mathrm{cm} / \mathrm{s}$ & $6,3 \pm 2,5$ & $9,7 \pm 4,4$ & $0,028^{*}$ \\
\hline E/E' médio, cm/s & $7,0(5,3-9,0)$ & $10,5(8,2-14,2)$ & $0,021^{*}$ \\
\hline Área do átrio esquerdo, $\mathrm{cm}^{2}$ & $17,6(13,2-23,0)$ & $27,0(22,5-31,1)$ & $0,003^{*}$ \\
\hline Volume do átrio esquerdo, ml & $41,7(30,1-70,9)$ & $93,4(70,0-120,1)$ & $0,002^{*}$ \\
\hline Área do jato regurgitante, $\mathrm{cm}^{2}$ & $2,0(0,0-2,6)$ & $5,5(2,7-11.7)$ & $0,007^{*}$ \\
\hline Volume do jato regurgitante, $\mathrm{ml}$ & $1,2(0,0-2,1)$ & $6,0(2,4-18,1)$ & $0,005^{*}$ \\
\hline Fração da área regurgitante, \% & $12,6 \pm 14,1$ & $25,5 \pm 16,9$ & $0,049^{*}$ \\
\hline Fração do volume regurgitante, \% & $5,4 \pm 7,8$ & $11,0 \pm 9,4$ & 0,114 \\
\hline Tempo de aceleração pulmonar, ms & $145 \pm 36$ & $133 \pm 37$ & 0,559 \\
\hline Onda $S$ do ventrículo direito, $\mathrm{cm} / \mathrm{s}$ & $14 \pm 2$ & $15 \pm 3$ & 0,718 \\
\hline $\mathrm{E}^{\prime}$ do ventrículo direito, $\mathrm{cm} / \mathrm{s}$ & $14,6 \pm 3,2$ & $13,2 \pm 3,2$ & 0,289 \\
\hline
\end{tabular}


Tabela 8 - Dados ecocardiográficos basais dos pacientes classificados em CMHN-Obst e CMHObst (continuação).

\begin{tabular}{|c|c|c|c|}
\hline & $\begin{array}{l}\text { CMHN-Obst } \\
(n=12)\end{array}$ & $\begin{array}{c}\text { CMHObst } \\
(n=14)\end{array}$ & $P$ \\
\hline Comprimento basal do VD, $\mathrm{mm}$ & $36,2 \pm 5,4$ & $35,3 \pm 4,4$ & 0,679 \\
\hline Comprimento médio do VD, mm & $28,5 \pm 4,7$ & $26,4 \pm 4,4$ & 0,310 \\
\hline Comprimento longitudinal do VD, $\mathrm{mm}$ & $67,6 \pm 9,8$ & $67,6 \pm 6,5$ & 0,984 \\
\hline Variação da área fracional do VD, \% & $46,7 \pm 6,9$ & $50,6 \pm 8,7$ & 0,285 \\
\hline Área do átrio direito, $\mathrm{cm}^{2}$ & $16,4 \pm 3,0$ & $16,0 \pm 3,1$ & 0,751 \\
\hline
\end{tabular}

\subsection{Dados ecocardiográficos de ambos os grupos ao longo do} estudo

Os resultados a seguir referem-se aos achados ecocardiográficos de ambos os grupos durante os momentos Basal, Sham-CPAP e CPAP-10. Todas as variáveis medidas no ECO basal foram mensuradas novamente com Sham-CPAP e CPAP-10. No entanto, para facilitar a compreensão desses resultados, optamos por manter na Tabela 9 apenas as variáveis que poderiam ser e/ou foram alteradas pela pressão positiva. As demais variáveis que não estão contidas na Tabela 9, não demonstraram significância estatística.

Para avaliar os efeitos da pressão positiva em todas as variáveis ecocardiográficas, utilizamos o modelo linear misto estabelecendo efeitos de grupo, de tratamento e interação entre tratamento e grupo. Para cada um 
desses efeitos, a significância estatística $(p \leq 0,05)$ está representada por símbolos localizados ao lado da variável medida (primeira coluna). Para efeito de grupo, a significância está representada por "T"; para efeito do tratamento está representada por "†" e para interação entre tratamento e grupo, por “ $\phi$ ”. Esses efeitos podem ser interpretados da seguinte forma: Efeito de grupo: indica que os grupos foram diferentes em todos os momentos (Basal, Sham-CPAP e CPAP-10); Efeito de tratamento: o tratamento aplicado (Sham-CPAP ou CPAP-10) foi responsável por alterar a medida em ambos os grupos; Interação entre tratamento e grupo: a diferença entre as medidas dos grupos foi causada por algum dos tratamentos. Os dados estão expressos em média e IC (95\%). Para as variáveis que não apresentaram nenhum desses efeitos na análise do modelo misto, concluímos que a pressão positiva não provocou, em qualquer nível, nem diferenças significativas entre os momentos, nem entre os grupos estudados.

Como o efeito de grupo apenas nos indica que os grupos foram diferentes em todos os momentos, e como os pacientes com CMHObst são os que apresentam alterações mais pronunciadas de estrutura e função cardíacas, utilizaremos suas médias como referência para comentar os resultados encontrados na Tabela 9. Assim, o grupo CMHObst obteve maiores médias, em todos os momentos, em relação ao grupo CMHNObst, para: gradiente de VSVE, E/E'médio (reflete as pressões de enchimento do VE), área e volume do $A E$ e do jato regurgitante, bem como área e volume das frações regurgitantes. Dentre as variáveis que os 
CMHObst apresentaram menores médias estão: FC, E'médio do VE e índice Tei (índice de desempenho miocárdico, que reflete a função global do VE).

Todas as variáveis que resultaram em efeito de tratamento e interação tratamento e grupo estão destacadas em negrito na Tabela 9. Para essas variáveis realizamos comparações múltiplas intergrupo (no mesmo momento entre os dois grupos) e intragrupo (entre os diferentes momentos no mesmo grupo), que nos permitiram avaliar em qual momento e/ou em qual grupo essas alterações ocorreram. As significâncias estatísticas estão representadas por símbolos ao lado dos valores numéricos (colunas 2 a 7 ) na Tabela abaixo. Para facilitar o entendimento, ilustramos alguns dos principais achados desse estufo numa série de gráficos (Figura 24 e Gráfico 1). Os demais resultados estão descritos em seguida. 
Tabela 9 - Dados ecocardiográficos de ambos os grupos ao longo do estudo.

\begin{tabular}{|c|c|c|c|c|c|c|}
\hline & \multicolumn{3}{|c|}{ CMHN-Obst } & \multicolumn{3}{|c|}{ CMHObst } \\
\hline & Basal & Sham-CPAP & CPAP-10 & Basal & Sham-CPAP & CPAP-10 \\
\hline DdVE, mm & $42,8(38,1-47,4)$ & $42,7(37,7-47,7)$ & $43,4(37,7-49,1)$ & $46,8(42,5-51,2)$ & $45,2(40,9-49,5)$ & $45,2(41,7-48,7)$ \\
\hline DsVE, mm & $25,5(21,9-29,1)$ & $25,8(22,5-9,0)$ & $25,3(20,9-29,8)$ & $27,9(24,8-31,1)$ & $27,4(23,7-31,0)$ & $26,5(23,3-29,7)$ \\
\hline Fração de ejeção do VE, \% & $72(68-76)$ & $70(68-73)$ & $73(68-77)$ & $71(68-74)$ & $70(66-74)$ & $72(67-77)$ \\
\hline Volume Sistólico do VE, ml & $60,1(46,4-73,8)$ & $56,6(41,9-71,4)$ & $59,4(43,1-75,8)$ & $67,5(58,6-76,3)$ & $66,9(54,4-79,4)$ & $68,3(57,5-79,2)$ \\
\hline Frequência cardíaca, bpm $\boldsymbol{\Upsilon}$ & $67(62-71)$ & $64(60-68)$ & $64(59-69)$ & $59(56-62)$ & $60(56-64)$ & $59(53-64)$ \\
\hline Debito Cardíaco, L/m & $4,0(3,1-4,8)$ & $3,7(2,6-4,7)$ & $3,8(2,7-4,9)$ & $4,0(3,4-4,5)$ & $3,9(3,2-4,6)$ & $4,0(3,3-4,8)$ \\
\hline Índice Tei $\mathbb{T}$ & $0,67(0,49-0,84)$ & $0,82(0,54-1,10)$ & $0,77(0,58-0,96)$ & $0,52(0,46-0,58)$ & $0,49(0,39-0,59)$ & $0,49(0,39-0,58)$ \\
\hline Onda $E, \mathrm{~cm} / \mathrm{s} \dagger$ & $71,9(58,0-85,8)$ & $71,7(57,4-86,0)$ & $59,8(46,3-73,3)^{\star a^{* *}}$ & $85,4(74,2-96,5)$ & $81,1(69,7-92,6)$ & $83,6(67,2-100,1) \#$ \\
\hline Onda $\mathrm{A}, \mathrm{cm} / \mathrm{s}$ & $47,0(31,4-62,6)$ & $55,6(36,9-74,2)$ & $54,9(41,3-74,4)$ & $59,6(43,1-76,0)$ & $57,7(41,1-74,1)$ & $57,9(41,3-74,4)$ \\
\hline Relação E/A $\phi$ & $1,7(1,1-2,4)$ & $1,4(1,0-1,8)^{*}$ & $1,1(0,8-1,5)^{* *}$ & $1,7(1,2-2,2)$ & $1,7(1,2-2,2)$ & $1,7(1,2-2,3)$ \\
\hline TRIV, MS & $117(91-143)$ & $106(89-123)$ & $127(102-152)$ & $99(89-111)$ & $109(84-134)$ & $100(85-116)$ \\
\hline Tempo desaceleração, ms $\phi$ & $202(171-233)$ & $227(184-269)$ & $238(195-280)$ & $215(183-247)$ & $223(184-262)$ & $192(172-213)$ \\
\hline Gradiente de VSVE, mmHg ף & $7,3(5,5-9,0)$ & $7,2(5,1-9,2)$ & $7,3(5,4-9,2)$ & $65,5(51,7-79,3)$ & $71,9(57,0-86,9)$ & $70,0(58,5-81,4)$ \\
\hline $\mathrm{E}^{\prime}$ médio do $\mathrm{VE}, \mathrm{cm} / \mathrm{s}$ đ & $10,7(9,0-12,4)$ & $9,6(8,4-10,8)$ & $9,7(7,6-11,7)$ & $8,8(7,2-11,7)$ & $8,5(7,1-10,0)$ & $7,8(6,6-9,0)$ \\
\hline Área do $\mathrm{AE}, \mathrm{cm}^{2} \boldsymbol{\pi}$ & $17,6(14,4-20,9) \#$ & $17,8(14,3-21,2) \#$ & $18,4(15,7-21,1)$ & $27,0(22,5-31,4)$ & $24,7(20,5-28,9)$ & $22,2(18,7-25,8) \ddagger$ \\
\hline
\end{tabular}


Tabela 9 - Dados ecocardiográficos de ambos os grupos ao longo do protocolo (continuação).

\begin{tabular}{|c|c|c|c|c|c|c|}
\hline & \multicolumn{3}{|c|}{ CMHN-Obst } & \multicolumn{3}{|c|}{ CMHObst } \\
\hline & Basal & Sham-CPAP & CPAP-10 & Basal & Sham-CPAP & CPAP-10 \\
\hline 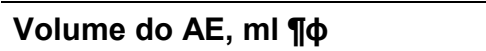 & $48,9(35,1-62,7) \#$ & $50,0(33,6-66,3) \#$ & $54,9(42,5-67,3)$ & $94,7(71,7-117,7)$ & $84,0(63,7-104,2)$ & $72,0(54,9-89,0) \ddagger$ \\
\hline Área jato regurgitante, $\mathrm{cm}^{2} \mathbb{q}$ & $2,3(1,0-4,0) \#$ & $2,2(0,8-3,6) \#$ & $2,3(1,2-3,5) \#$ & $7,2(4,0-10,4)$ & $8,6(4,9-12,4)$ & $9,5(5,6-13,4)$ \\
\hline Volume jato regurgitante, $\mathrm{ml}$ ף & $2,7(0,0-5,3)$ & $2,2(0,5-3,8) \#$ & $2,1(0,8-3,4) \#$ & $11,1(4,8-17,3)$ & $17,2(6,4-28,1)$ & $18,1(7,3-29,0)$ \\
\hline Fração área regurgitante, $\%$ I $\phi$ & $12,6(3,6-21,6)$ & $12,9(5,6-20,1) \#$ & $12,1(6,4-17,7) \#$ & $25,5(15,7-35,3)$ & $34,2(20,4-47,9)$ & $45,7(27,9-63,5) \ddagger \S$ \\
\hline Fração vol. regurgitante, \% $\| \phi$ & $5,4(0,4-10,3)$ & $5,0(1,2-8,9) \#$ & $3,5(1,5-5,6) \#$ & $11,0(5,6-16,4)$ & $17,2(6,4-28,1)$ & $27,4(13,5-41,3) \ddagger$ \\
\hline Tempo aceleração da AP, ms $\dagger$ & $145(100-190)$ & $127(92-163)$ & $130(83-177)$ & $133(105-161)$ & $126(92-160)$ & $107(83-131) \ddagger$ \\
\hline E' do VD, cm/s † & $14,6(12,6-16,6)$ & $12,0(10,6-13,4)^{*}$ & $11,7(10,1-13,2)^{\star *}$ & $13,2(11,3-15,1)$ & $13,0(10,9-15,1)$ & $10,5(8,9-12,1) \mp \S$ \\
\hline E/E' do VD & $3,4(2,3-4,5)$ & $3,6(2,2-5,1)$ & $3,3(1,7-4,9)$ & $3,0(1,6-4,5)$ & $4,2(2,2-6,2)$ & $4,8(3,4-6,1)$ \\
\hline Área do $\mathrm{AD}, \mathrm{cm}^{2}+\phi$ & $16,4(14,2-18,6)$ & $13,6(11,9-15,2)^{*}$ & $12,7(11,1-14,3)^{\star *}$ & $16,0(14,1-17,8)$ & $14,8(13,2-16,4)$ & $14,7(12,3-17,1) \ddagger$ \\
\hline
\end{tabular}

VE: ventrículo esquerdo; Índice TEI: índice de desempenho miocárdico; TRIV: tempo de relaxamento isovolumétrico; VSVE: via de saída do ventrículo esquerdo; AE: átrio esquerdo; AP: artéria pulmonar; VD: ventrículo direito e AD: átrio direito. Dados apresentados como média e intervalo de confiança (95\%). p $\leq 0,05$ - П: efeito de grupo; †: efeito de tratamento; $\boldsymbol{\phi}$ : interação entre tratamento e grupo. \#comparação intergrupo no mesmo momento; *comparação Basal x Sham-CPAP CMHN-Obst

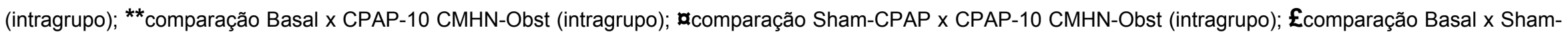
CPAP CMHObst (intragrupo); łcomparação Basal x CPAP-10 CMHObst (intragrupo) e §comparação Sham-CPAP x CPAP-10 CMHObst (intragrupo). 
A Figura 24 refere-se a variáveis que influenciam e quantificam o refluxo mitral. Observe na primeira sequencia de gráficos, os efeitos da pressão positiva sobre o tamanho do AE. Veja que em condições basais, os pacientes obstrutivos apresentavam um AE com maior aera $(p<0,001)$ e volume $(p<0,001)$ em relação aos não-obstrutivos (intergrupo). Com a aplicação da pressão positiva, houve uma redução progressiva no tamanho do $A E$ apenas no grupo obstrutivo, ainda mantendo uma diferença intergrupo durante o Sham-CPAP para área $(p=0,005)$ e volume do $A E(p=0,004)$. No entanto, com CPAP-10, o tamanho do AE reduziu tão substancialmente nos CMHObst, de forma a tornar suas médias tão próximas às dos CMHN-Obst (intergrupo), que não refletiram mais diferença estatística [área $(p=0,188)$ e volume do $\operatorname{AE}(p=0,258)]$. Verificamos com isso, que nos pacientes obstrutivos (intragrupo), o CPAP-10 provocou uma redução de cerca de $4,8 \mathrm{~cm}^{2}$ de área e $22,7 \mathrm{ml}$ de volume do $A E$ em relação aos seus valores Basais $(p=0,021$ e $p=0,044$, respectivamente). Essas variações não foram observadas nos CMHN-Obst, em que o tamanho do $A E$ se manteve semelhante nas diferentes pressões aplicadas.

Considerando agora os efeitos da pressão positiva sobre o jato regurgitante, observe que na comparação intergrupo as médias da área do jato regurgitante foram maiores no grupo obstrutivo em todos os momentos, quando comparadas aos não-obstrutivos (Basal $p=0,011$; Sham-CPAP $p=0,001$ e CPAP-10 $p<0,001)$. Para o volume do jato, porém, no momento Basal os grupos foram semelhantes (intergrupo $p=0,103$ ), e diferiram com a aplicação da pressão positiva [Sham-CPAP $(p=0,007)$ e CPAP-10 
$(p=0,001)]$ em que as médias nos obstrutivos aumentaram progressivamente. No entanto, não encontramos significância estatística na comparação intragrupo para nenhum dos grupos avaliados.

$\mathrm{Na}$ terceira série de dados, estão representadas as frações regurgitantes, variáveis quantitativas do refluxo mitral. Trata-se de uma medida da proporção entre área e volume do jato regurgitante em relação à área e volume do $A E$, respectivamente. Observe que no momento Basal os grupos eram semelhantes para ambas variáveis. Entretanto, com a aplicação da pressão positiva, as frações regurgitantes aumentaram progressivamente nos $\mathrm{CMHObst,} \mathrm{tornando-os} \mathrm{diferentes} \mathrm{dos} \mathrm{não-obstrutivos}$ (intergrupo) com o Sham-CPAP e com o CPAP-10, tanto para fração da área regurgitante $(p=0,007$ e $p<0,001$, respectivamente), quanto para de volume regurgitante ( $p=0,047$ e $p<0,001$, respectivamente). Na comparação intragrupo, verificamos que houve diferença estatística nos CMHObst entre momentos Basal X CPAP-10 $(p=0,004)$ e Sham-CPAP X CPAP-10 $(p=0,036)$ para fração de área e entre os momentos Basal x CPAP-10 $(p=0,012)$ para fração de volume. Mais uma vez, não observamos alterações dessas variáveis na comparação intragrupo dos pacientes não-obstrutivos. 


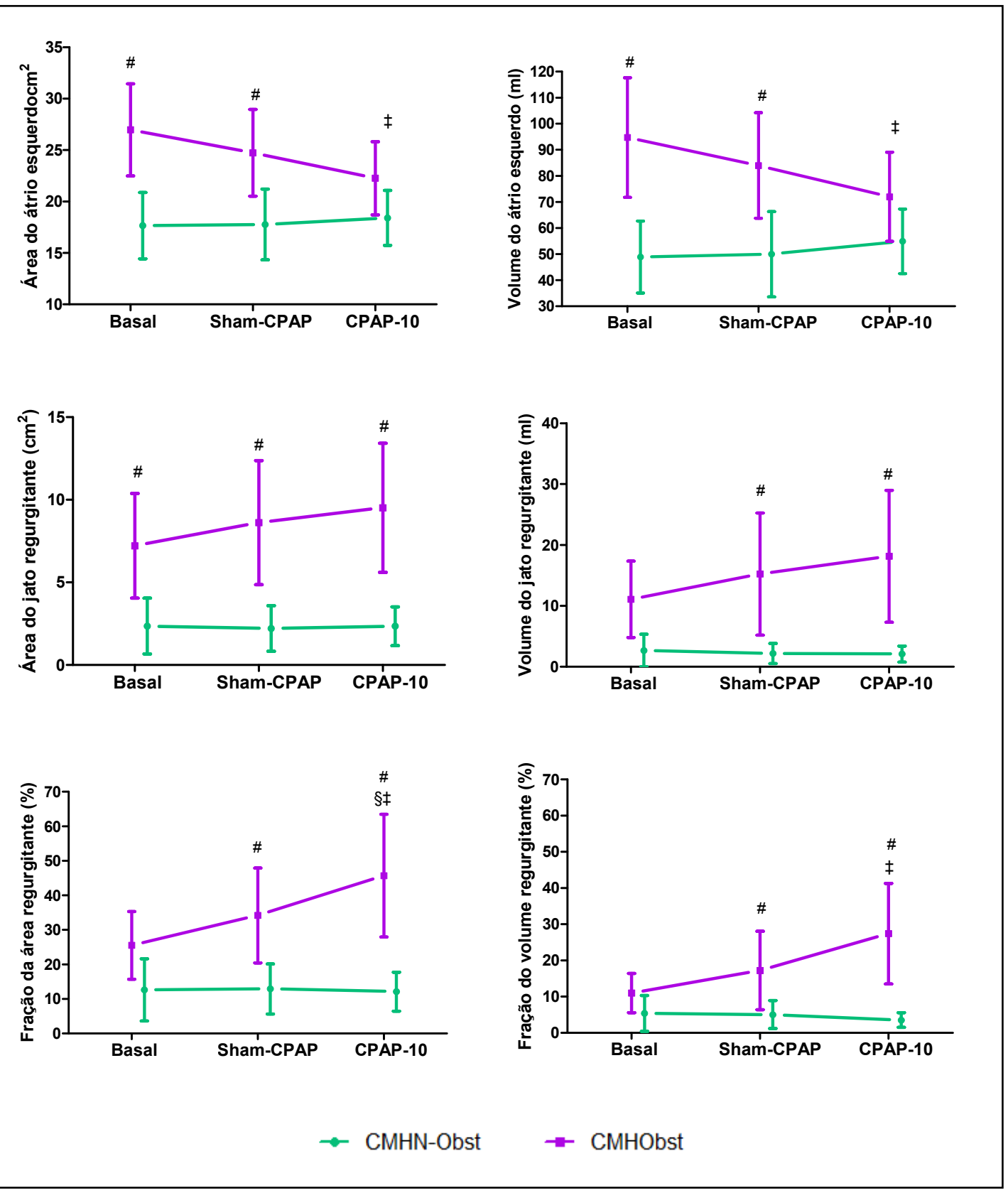

Figura 24 - Variáveis ecocardiográficas relacionadas à magnitude do refluxo mitral para ambos os grupos.

$p \leq 0,05$ \#comparação intergrupo no mesmo momento; $\ddagger$ comparação Basal x CPAP-10 CMHObst (intragrupo) e § comparação Sham-CPAP x CPAP-10 CMHObst (intragrupo).

A pressão positiva também provocou alterações no tamanho do AD. Veja no Gráfico 1 que no momento Basal (intergrupo), a área do $A D$ era muito semelhante entre os grupos $(p=0,942)$. A pressão positiva reduziu 
essa área de forma similar em ambos os grupos, não ocasionando, portanto, diferenças na análise intergrupo para os momentos Sham-CPAP $(p=0,702)$ e CPAP-10 ( $p=0,231)$. Na análise intragrupo dos pacientes não-obstrutivos, a diferença estatística ocorreu quando comprado o momento Basal com Sham-CPAP e com CPAP-10 ( $p=0,018$ e $p \leq 0,001$, respectivamente). Já nos obstrutivos, observamos diferença estatística apenas quando comparado Basal com CPAP-10 ( $p=0,032)$.

Gráfico 1 - Gráfico correspondente ao comportamento da área do átrio direito entre os grupos ao longo do estudo.

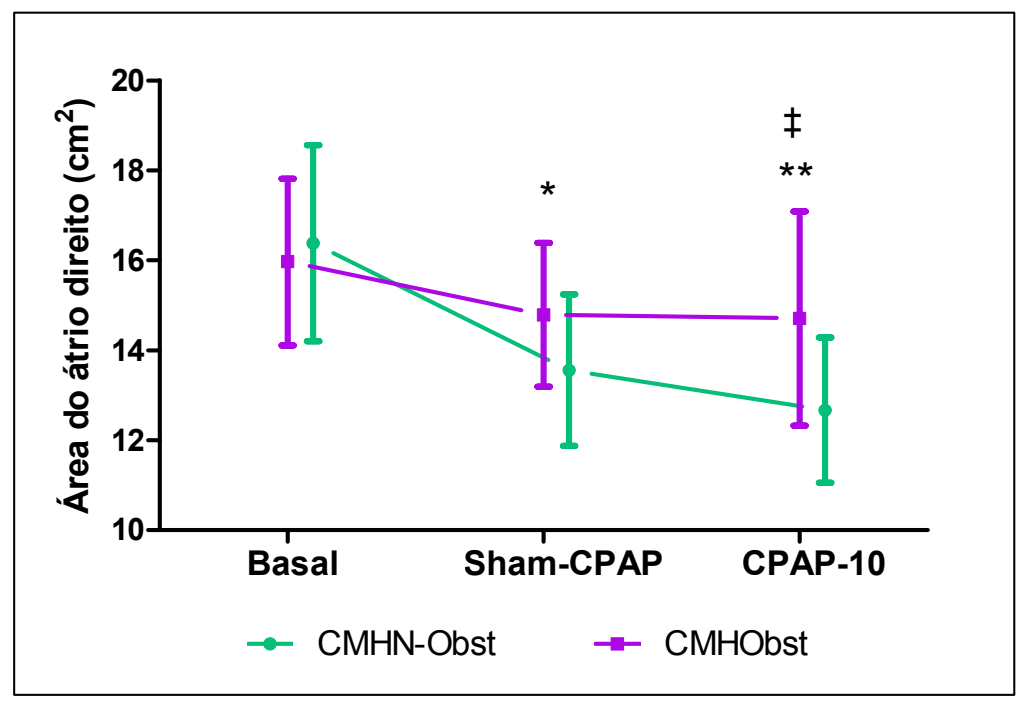

$\mathrm{p} \leq 0,05$ *comparação Basal x Sham-CPAP CMHN-Obst (intragrupo); ${ }^{* *}$ comparação Basal x CPAP-10 CMHN-Obst (intragrupo); łcomparação Basal x CPAP-10 CMHObst (intragrupo).

As demais variáveis que apresentaram efeito de tratamento e interação tratamento e grupo, estão sumarizadas a seguir. 
É importante ressaltar que as alterações nas funções sistólica e diastólica das câmaras cardíacas decorrem de complexos mecanismos, que envolvem diferentes variáveis ecocardiográficas. Os valores de referência para algumas dessas variáveis oscilam em parábola e não de forma crescente ou decrescente. Desta forma, afirmações a cerca de "melhora" ou "piora" nesses parâmetros decorrentes da pressão positiva, tornam-se inadequadas. Assim, descreveremos as mudanças em cada uma dessas variáveis de forma individual e simplificada, apenas para elucidar os mecanismos de resposta dos hipertróficos ao CPAP.

Onda E: A onda E representa o pico da velocidade de enchimento rápido e passivo do VE durante a diástole ventricular. É predominantemente determinado pelo relaxamento ventricular, pela pressão atrial e pela pré-carga. Reduções nos valores da onda $E$ podem sugerir diminuição na complacência ventricular. ${ }^{(98)}$ Observe na Tabela 9 que os valores Basais da Onda E permaneceram semelhantes com a aplicação do Sham-CPAP, não diferindo na comparação inter e intragrupo. Contudo, com a aplicação do CPAP10 houve uma redução da onda $E$ apenas nos pacientes nãoobstrutivos, gerando uma diferença de $p=0,015$ na comparação intergrupo. Na comparação intragrupo, essa diferença foi de $p=0,002$ e $p<0,001$ em relação ao Basal e Sham-CPAP, respectivamente. Não observamos alterações para essa variável nos pacientes CMHObst. Esse resultado nos sugere uma redução na 
complacência ventricular nos pacientes não-obstrutivos causada pelo CPAP-10.

Relação E/A: A relação E/A é a proporção do enchimento ventricular durante as fases precoce (onda E) e tardia (onda A) da diástole. ${ }^{\left({ }^{(9)}\right.}$ É um dos parâmetros utilizados para estimar a função diastólica do VE e reduções nos seus valores podem inferir alteração no relaxamento do VE. Observe que no momento Basal, as médias de ambos os grupos eram muito semelhantes e compatíveis com função diastólica normal do VE. Para os pacientes com CMHObst, as médias permaneceram estáveis durante todos os momentos avaliados. Já nos pacientes do grupo CMHN-Obst, tanto o Sham-CPAP quanto o CPAP-10 reduziram progressivamente suas médias em relação aos valores Basais ( $p=0,036$ e $p=0,001$, respectivamente), indicando que a pressão positiva possa ter provocado uma alteração no relaxamento do VE neste grupo.

Tempo de desaceleração da onda E (TD): Representa a rapidez com que a fase de enchimento precoce (onda E) acaba e pode refletir a complacência efetiva do VE. ${ }^{(100)}$ Embora sem significância estatística, a pressão positiva ocasionou uma tendência ao aumento progressivo do TD nos não-obstrutivos (intragrupo), sem tais variações nos obstrutivos. Esse comportamento diferente entre os grupos foi o que provocou uma interação entre tratamento e grupo na análise do modelo misto inicial, visto que também não houve diferença estatística entre os momentos na comparação intergrupo. 
E' do ventrículo direito: Esta variável representa o relaxamento do VD. Quanto menor o valor, mais lento será o relaxamento. Observe na Tabela 9, que os valores basais dessa variável eram semelhantes entre os grupos (intergrupo) e, mesmo apresentando reduções em suas médias com aplicação da pressão positiva, não houve diferença na comparação intergrupo nos três momentos avaliados. Já na análise intragrupo dos não-obstrutivos, essa redução ocorreu de forma significativa quando comparados Sham-CPAP e CPAP-10, ambos em relação ao Basal ( $p=0,010$ e $p=0,009$, respectivamente). No grupo CMHObst, essa diferença tornou-se significante apenas quando com a aplicação do CPAP-10 em relação ao Sham-CPAP e também ao Basal $(p=0,023$ e $p=0,038$, respectivamente). Esses achados sugerem que a pressão positiva possa ter provocado um relaxamento mais lento do VD, em ambos os grupos.

Tempo de aceleração da AP: esta variável estima indiretamente a pressão na AP pela medida da velocidade do fluxo de sangue nessa artéria. Quanto maior for a pressão dentro do vaso, menor será o tempo de aceleração. Note que, embora sem significância estatística, os pacientes obstrutivos apresentavam um menor tempo de aceleração no basal, em relação aos não-obstrutivos, sugerindo uma maior pressão arterial pulmonar em condições basais. Com a aplicação da pressão positiva, esse tempo aceleração foi progressivamente reduzido em ambos os grupos, sem gerar diferença na comparação intergrupo. $\mathrm{Na}$ análise intragrupo, porém, 
encontramos diferença estatística apenas para os CMHObst, quando comparados os momentos CPAP-10 x Basal $(p=0,002)$. Esse resultado sugere que o CPAP $10 \mathrm{cmH}_{2} \mathrm{O}$ aumentou de forma significante a pressão arterial pulmonar nos obstrutivos. Vale lembrar que o tempo de aceleração foi uma das variáveis analisadas sem o "n" total de pacientes em cada grupo, o que pode ter sub ou superestimado esse resultado.

Sabemos que algumas medidas ecocardiográficas são influenciadas por características antropométricas individuais, como peso e altura. Por isso, para nos certificarmos que os resultados desse trabalho não sofreram tais influências, realizamos uma nova análise estatística indexando as seguintes variáveis para a superfície de área corporal: SIV; parede posterior do VE, diâmetros sistólico e diastólico do VE (DdVE e DsVE, respectivamente); diâmetro do $\mathrm{AE}$; volume sistólico do $\mathrm{VE}$; $\mathrm{DC}$; área do $\mathrm{AE}$; volume do $\mathrm{AE}$ e área do AD. Tanto na análise do modelo misto inicial (efeitos de grupo, de tratamento e interação entre tratamento e grupo), quanto nas comparações múltiplas (intragrupo e intergrupo), encontramos resultados muito semelhantes aos descritos acima, com as significâncias estatísticas mantidas para essas variáveis, modificando-se apenas em magnitude. Assim, esta constatação nos permite inferir que os achados deste trabalho foram, de fato, ocasionados pelo uso da pressão positiva e não decorrentes de características individuais. 
Diante do exposto, percebemos que a aplicação aguda do CPAP provocou efeitos sobre algumas varáveis de desempenho cardíaco dos pacientes com $\mathrm{CMH}$. De uma forma geral, em ambos os grupos essas respostas foram progressivas aos aumentos nas pressões $\left(1,5 \mathrm{cmH}_{2} \mathrm{O}\right.$ e $10 \mathrm{cmH}_{2} \mathrm{O}$ ), sendo mais pronunciadas quando em $10 \mathrm{cmH}_{2} \mathrm{O}$. Portanto, consideramos que os efeitos independentes provocados pelo CPAP, foram:

\section{Grupo CMHN-Obst:}

- lado direito do coração: diminuição da área do $A D$ com relaxamento mais lento do VD ( $\downarrow E^{\prime}$ do VD).

- lado esquerdo do coração: redução da complacência ventricular esquerda ( $\downarrow$ Onda E) e lentificação do relaxamento do VE ( \relação E/A) (Figura 25).

\section{Grupo CMHObst}

- lado direito do coração: diminuição no tamanho do AD ( لárea), com relaxamento mais lento do VD ( $\downarrow$ E' do VD) e aumento na pressão da AP ( $\downarrow$ do tempo de aceleração pulmonar).

- lado esquerdo do coração: redução no tamanho do AE ( $\downarrow$ área e

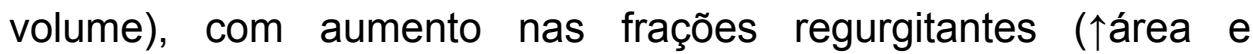
$\uparrow$ volume) (Figura 25). 


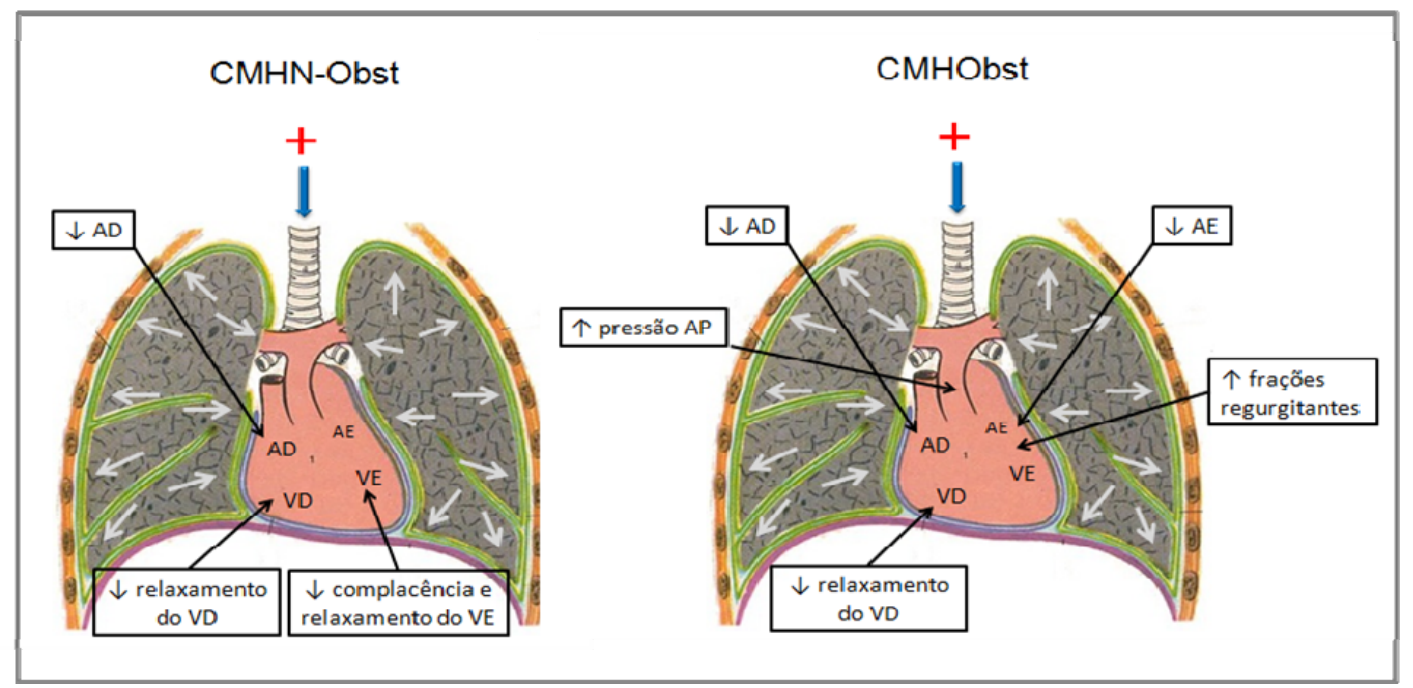

Figura 25 - Efeitos da pressão positiva na anatomia e dinâmica cardíacas dos pacientes com CMHN-Osbt e CMHObst.

\subsection{Análise dos gradientes de via de saída do ventrículo} esquerdo ao longo do estudo

De acordo com os resultados apresentados na Tabela 9, observamos que os gradientes de VSVE se mantiveram estáveis para ambos os grupos em todos os momentos avaliados (Basal, Sham-CPAP e CPAP-10). Contudo, conforme elucidado na sessão de introdução, sabe-se que fatores que alteram pré e pós-carga do VE como: manobras de Muller, Valsalva e a própria pressão positiva, podem gerar variações no gradiente de VSVE, principalmente nos pacientes obstrutivos. Assim, para avaliarmos essas possíveis variações, durante o protocolo foram realizadas sete medidas de gradientes de VSVE (Figura 11), sendo elas: no Eco basal, durante manobras de "Muller" e "Valsalva"; no instante da instalação de cada pressão de CPAP, obedecendo a ordem de randomização (no desenho do 
estudo denominado como "Grad 1" e "Grad 2" e aqui nos resultados chamados de "Sham agudo" e "CPAP agudo"), e após 20 minutos em cada pressão de CPAP (no desenho do estudo medido durante a realização dos "ECO 1" e "ECO 2" e aqui chamado de "Sham 20" e "CPAP 20"). Os resultados estão ilustrados nos gráficos abaixo (Gráfico 2 e 3).

No Gráfico 2 estão ilustrados os resultados das análises realizadas entre os gradientes Basais, Valsalva e Muller. Considerando a análise do modelo misto, obtivemos apenas um efeito de grupo $(p<0,001)$, já esperado, devido aos gradientes mais elevados nos obstrutivos. Observe que em ambos os grupos a manobra de Muller [que aumenta o retorno venoso ( pré-carga), pela diminuição na pressão intratorácica] reduziu as médias dos gradientes em relação ao Basal, porém sem provocar diferença estatística intragrupo $(p=0,185$ CMHObst e $p=0,102$ CMHN-Obst). Para a manobra de Valsalva [que diminui o retorno venoso ( $\downarrow$ pré-carga), pelo aumento na pressão intratorácica], não observamos variações nos gradientes de ambos os grupos em relação ao Basal ( $p=0,903$ CMHObst e $p=0,691$ CMHN-Obst). 
Gráfico 2 - Representação do comportamento do gradiente de VSVE em medidas Basais e durante manobras de Valsalva e Muller, para os grupos CMHN-Obst e CMHObst.

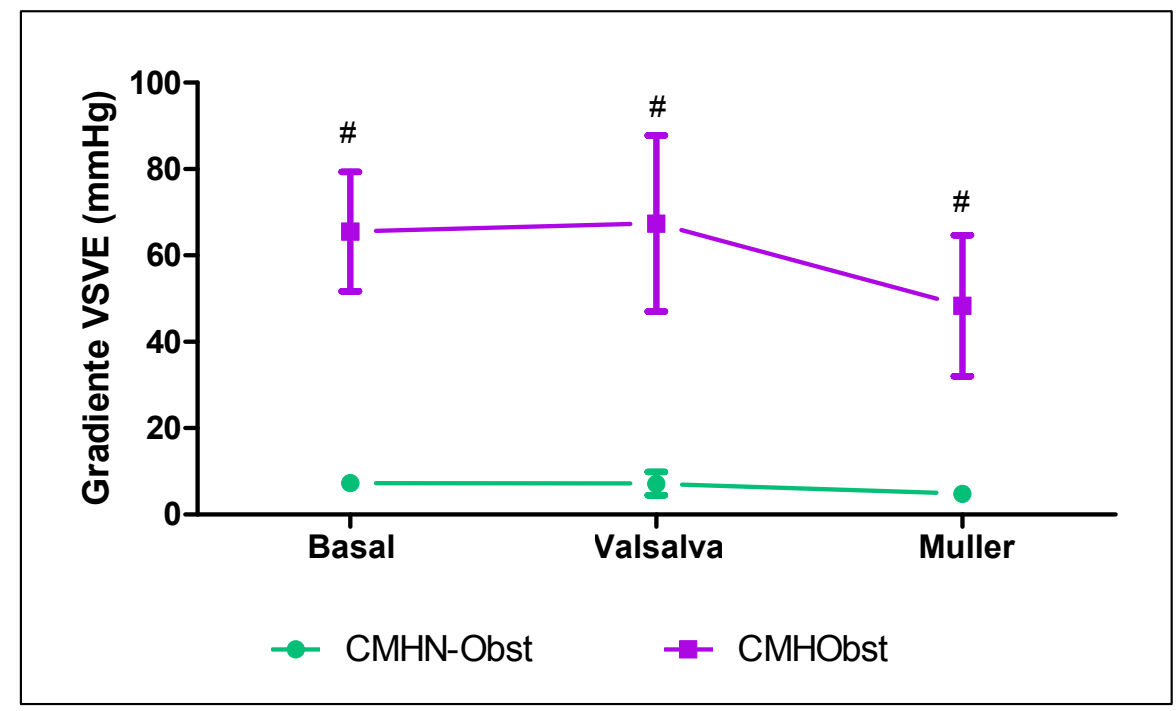

p $\leq 0,05$ \#comparação intergrupo no mesmo momento.

O gráfico seguinte (Gráfico 3), mostra as médias dos gradientes de VSVE nos demais momentos medidos (Basal, Sham agudo; Sham 20; CPAP agudo e CPAP 20). Além do efeito de grupo já esperado $(p<0,001)$, observe que os gradientes demonstraram pequenas variações com a aplicação da pressão positiva para ambos os grupos, sem ocasionar nenhuma diferença estatística quando comparados ao basal. 
Gráfico 3 - Representação do comportamento do gradiente de VSVE em medidas Basais e com o uso da pressão positiva, para os grupos CMHN-Obst e CMHObst.

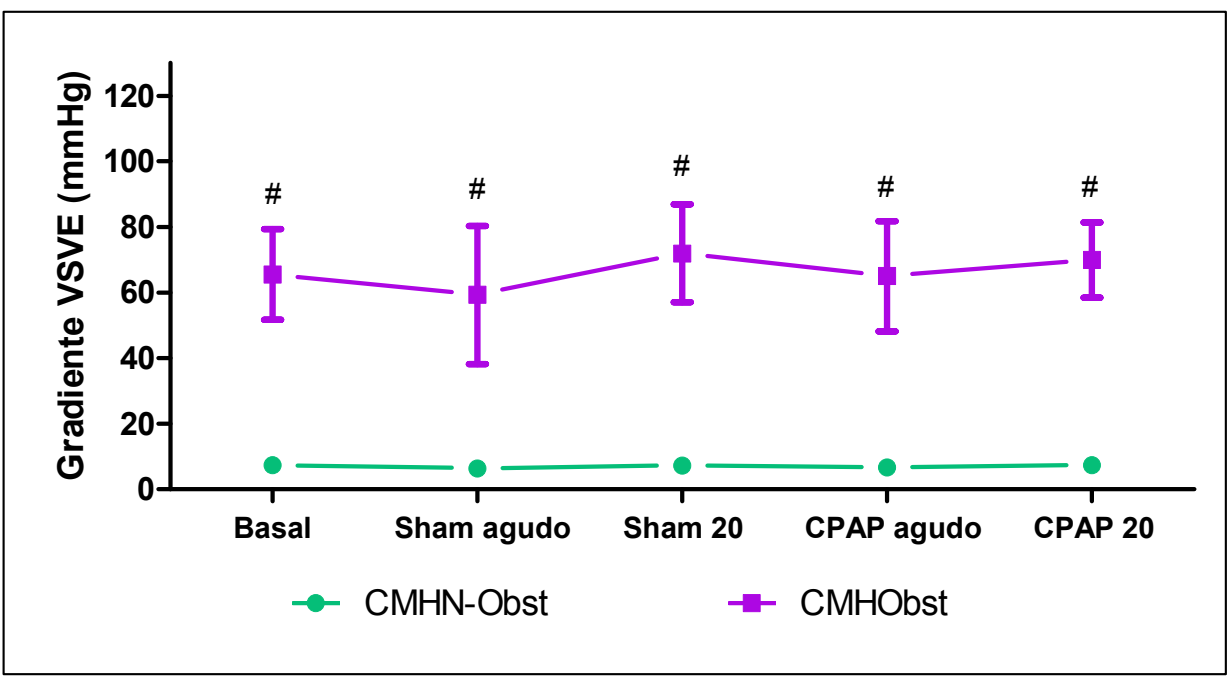

p $\leq 0,05$ \#comparação intergrupo no mesmo momento.

Esses achados podem sugerir que o CPAP $\left(1,5 \mathrm{cmH}_{2} \mathrm{O}\right.$ e $\left.10 \mathrm{cmH}_{2} \mathrm{O}\right)$, não provocou efeitos tão importantes de reduções de pré e pós-carga ao VE, a ponto de modificar os gradientes de VSVE dos pacientes com $\mathrm{CMH}$, sendo eles obstrutivos ou não.

\subsection{Reprodutibilidade das medidas ecocardiográficas}

As concordâncias das medidas ecocardiográficas inter e intraobservador foram avaliadas pelo $\mathrm{CCl}$ e estão descritas nas tabelas $10 \mathrm{e}$ 11, respectivamente. As médias da diferença entre as medidas e seus limites de concordância estão ilustradas nos Gráficos de Bland-Altman a seguir (Gráfico 4 e 5). Lembramos que um valor de $\mathrm{CCl}>0,05$ representa 
concordância moderada; $\mathrm{CCl}>0,07$ indica boa concordância e $\mathrm{CCl}>0,08$, muito boa concordância.

Tabela 10 - Concordância interobservador para variáveis ecocardiográficas avaliadas pelo coeficiente de correlação intraclasse.

\begin{tabular}{lc}
\hline \multicolumn{1}{c}{ Componente } & CCI (IC95\%) \\
\hline Septo interventricular & $0,85(0,60-0,94)$ \\
Parede posterior do ventrículo esquerdo & $0,56(-0,11-0,83)$ \\
Diâmetro diastólico do ventrículo esquerdo & $0,94(0,83-0,98)$ \\
Diâmetro sistólico do ventrículo esquerdo & $0,85(0,60-0,95)$ \\
Indice de massa do ventrículo esquerdo & $0,68(0,19-0,88)$ \\
Seio aórtico & $0,54(-0,10-0,82)$ \\
Volume sistólico do ventrículo esquerdo & $0,71(0,21-0,90)$ \\
Débito cardíaco & $0,68(0,11-0,88)$ \\
Relação E/A & $0,92(0,77-0,97)$ \\
Tempo de relaxamento isovolumétrico & $0,38(-0,29-0,73)$ \\
Tempo de desaceleração da onda E & $0,82(0,51-0,93)$ \\
Índice Tei & $0,37(-0,32-0,74)$ \\
Gradiente VSVE & $0,99(0,98-1,00)$ \\
E' septal & $0,97(0,92-0,99)$ \\
E' lateral & $0,96(0,90-0,99)$ \\
E/E'septal & $0,93(0,79-0,97)$ \\
E/E' médio & $0,92-0,99)$ \\
Diâmetro do átrio esquerdo & continua
\end{tabular}


Tabela 10 - Concordância interobservador para variáveis ecocardiográficas avaliadas pelo coeficiente de correlação intraclasse (continuação).

\begin{tabular}{lc}
\hline \multicolumn{1}{c}{ Componente } & CCI (IC95\%) \\
\hline Volume do átrio esquerdo & $0,92(0,45-0,98)$ \\
Área do jato regurgitante & $0,95(0,86-0,98)$ \\
Volume do jato regurgitante & $0,93(0,83-0,98)$ \\
Fração área regurgitante & $0,88(0,68-0,95)$ \\
Fração do volume regurgitante & $0,80(0,48-0,93)$ \\
E' do ventrículo direito & $0,97(0,91-0,99)$ \\
\hline
\end{tabular}

VSVE: via de saída do ventrículo esquerdo

Tabela 11 - Concordância intraobservador para variáveis ecocardiográficas avaliadas pelo coeficiente de correlação intraclasse.

\begin{tabular}{lc}
\hline \multicolumn{1}{c}{ Componente } & CCI (IC95\%) \\
\hline Septo interventricular & $0,93(0,04-0,99)$ \\
Parede posterior do ventrículo esquerdo & $0,53(-2,48-0,95)$ \\
Diâmetro diastólico do ventrículo esquerdo & $0,88(0,18-0,99)$ \\
Fração de encurtamento do ventrículo esquerdo & $0,93(0,47-0,99)$ \\
Indice de massa do ventrículo esquerdo & $0,70(-0,89-0,97)$ \\
Débito Cardíaco & $0,89(0,21-0,99)$ \\
Indice Tei & $0,88(-0,07-0,99)$ \\
Tempo de desaceleração da onda E & $0,99(0,91-1,00)$ \\
Gradiente VSVE & $0,99(0,99-1,00)$
\end{tabular}


Tabela 11 - Concordância intraobservador para variáveis ecocardiográficas avaliadas pelo coeficiente de correlação intraclasse (continuação).

\begin{tabular}{lc}
\hline \multicolumn{1}{c}{ Componente } & CCI (IC95\%) \\
\hline E' lateral do ventrículo esquerdo & $0,98(0,79-1,00)$ \\
E' do ventrícuo direito & $0,99(0,92-0,99)$ \\
Área do átrio esquerdo & $0,98(0,84-0,99)$ \\
Área do jato regurgitante & $0,96(0,66-1,00)$ \\
Fração da área regurgitante & $0,89(0,19-0,99)$ \\
Fração do volume regurgitante & $0,98(0,78-1,00)$ \\
Tempo de aceleração (pulmonar) & $0,98(0,82-1,00)$ \\
E/E' do ventrículo direito & $0,91(0,32-0,99)$ \\
Diâmetro longitudinal do ventrículo direito & $0,99(0,91-1,00)$ \\
Variação da área fracional do ventrículo direito & $0,71(-0,34-0,97)$ \\
Área do átrio direito & $0,89(0,19-0,99)$
\end{tabular}

VSVE: via de saída do ventrículo esquerdo

Esses resultados de $\mathrm{CCl}$ nos permitem inferir que há sim uma variabilidade entre os observadores e entre as medidas realizadas nos exames, porém, apresentando boa concordância entre elas.

Os gráficos de Bland-Altman abaixo mostram os limites de concordância inter e intraobservador para a variável "fração do volume regurgitante". No eixo das ordenadas do Grafico 4 (interobservador), estão representadas as médias aritméticas dos valores de "fração do volume regurgitante" encontradas pelos dois observadores. No eixo das abcissas 
estão representadas as diferenças entre as medidas encontradas pelos dois observadores. Veja na linha pontilhada (cinza), que a média da diferença da "fração do volume regurgitante", entre os dois observadores, foi de 1,30\%, muito pequena, o que indica que os observadores não mostraram erro sistemático importante nas suas avaliações. Note ainda que, exceto o último caso localizado à direita, os demais estão muito próximos da linha média, o que sugere uma boa concordância entre o observador 1 e observador 2 .

Gráfico 4 - Gráfico de Bland-Altman representando os limites de concorância interobservador para "fração do volume regurgitante".

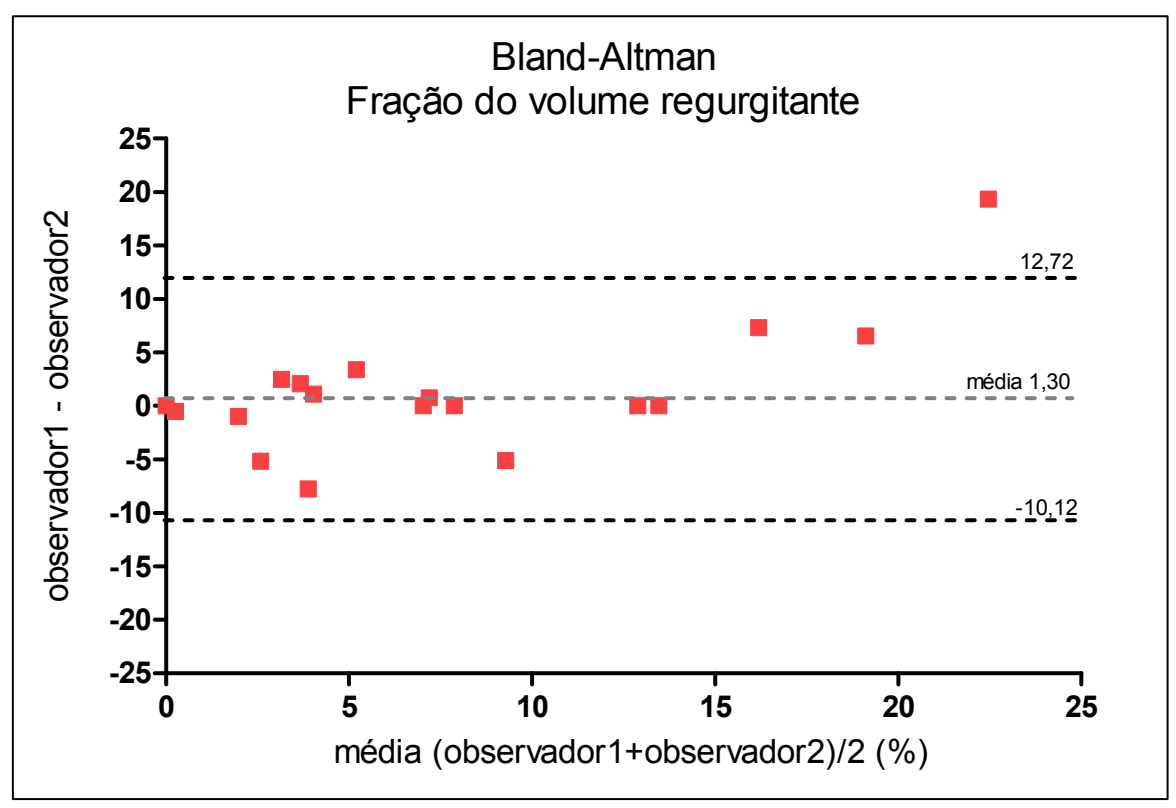

O Grafico 5 representa os limites de concordânica intraobservador. No eixo das ordenadas estão representadas as médias aritméticas dos valores obtidos em duas diferentes análises, realizadas pelo mesmo observador, em 
5 exames, com intervalo de 4 semanas entre elas. Da mesma forma que o gráfico acima, a média da diferença obtida entre as duas análises foi de $0,92 \%$, sugerindo um erro sistemático muito pequeno, com discreta dispersão dos dados.

Gráfico 5 - Gráfico de Bland-Altman representando os limites de concorância intraobservador para "fração do volume regurgitante".

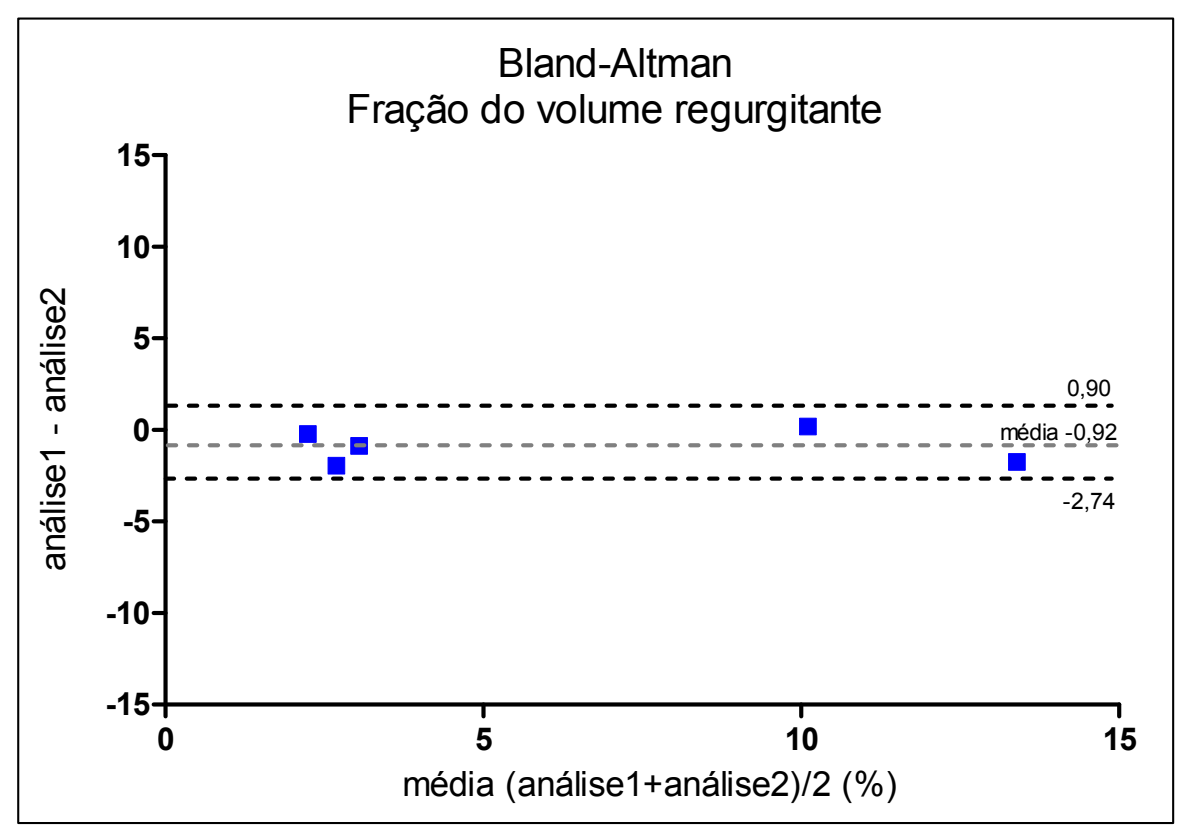

\subsection{Dados da pressão arterial de ambos os grupos ao longo do estudo}

Para as análises da PA é importante ressaltar que, por problemas técnicos com o Portapres $^{\circledR}, \mathrm{n}=2$ pacientes não tiveram suas pressões batimento-a-batimento registradas ( $n=1$ CMHN-Obst e $n=1$ CMHObst). Assim, durante a coleta de dados, a PA desses dois pacientes foi aferida no braço direito com esfigmomanômetro digital (OMRON, modelo HEM-742INT 
- Illinois, EUA), no primeiro minuto de cada momento, e a cada 5 minutos subsequentes, até o fim dos registros. Embora os valores de PAS e PAD tenham se mantido estáveis nesses dois casos, por não termos dados batimento-a-batimento, optamos por excluí-los desta análise. Portanto, para todas as análises de $\mathrm{PA}$, contaremos com $n=11$ pacientes no grupo $\mathrm{CMHN}$ Obst e $n=13$ CMHObst, totalizando 24 casos.

Conforme descrito na sessão de métodos, a PA batimento-abatimento foi registrada continuamente pelo Portapres ${ }^{\circledR}$, desde o momento Basal até a Recuperação. A Tabela 12 e o Gráfico 6, abaixo, resumem os resultados do comportamento das PAS e PAD, com as médias de todos os batimentos contidos nos $1^{\circ}, 5^{\circ}$ e $10^{\circ}$ minutos de cada momento, para ambos os grupos. Observe na Tabela 12, que na anáslise intragrupo houveram apenas pequenas variações nas médias da PAS e PAD, sem causar diferença estatística. Apesar de os pacientes obstrutivos apresentarem maiores médias em relação aos não-obstrutivos, a comparação intergrupo também não refletiu diferença estatística. Curiosamente, apenas no $10^{\circ}$ minuto do Intervalo a PAS foi diferente na comparação intergrupo (destacado em negrito na Tabela 12). Atribuimos esse achado a uma menor variabilidade das medidas individuais dos CMHN-OBST nesse minuto, o que fez com que o desvio padrão ficasse menor. Contudo, esse não nos parece um achado relevante, visto que o valor médio da PAS permaneceu semelhante aos dos demais minutos desse mesmo momento $\left(1^{\circ}\right.$ e $\left.5^{\circ}\right)$, além de estarem dentro dos padrões da normalidade e não terem sido acompanhados por quaisquer sintomas referidos pelos pacientes. 
Tabela 12 - Comparação das médias das pressões arteriais sistólicas e diastólicas nos grupos CMHN-Obst e CMHObst ao longo do estudo.

\begin{tabular}{|c|c|c|c|c|c|c|c|}
\hline & & \multicolumn{3}{|c|}{ Pressão arterial sistólica } & \multicolumn{3}{|c|}{ Pressão arterial diastólica } \\
\hline & & CMHN-Obst & CMHObst & & CMHN-Obst & CMHObst & \\
\hline & & $(n=11)$ & $(n=13)$ & $p$ & $(n=11)$ & $(n=13)$ & $P$ \\
\hline & $1^{\circ} \mathrm{min}$ & $117,2 \pm 15,3$ & $119,8 \pm 16,4$ & 0,699 & $50,2 \pm 15,7$ & $54,4 \pm 10,1$ & 0,443 \\
\hline \multirow[t]{3}{*}{ Basal } & $5^{\circ} \mathrm{min}$ & $116,4 \pm 13,4$ & $121,8 \pm 15,4$ & 0,372 & $50,6 \pm 13,7$ & $55,2 \pm 10,6$ & 0,368 \\
\hline & $10^{\circ} \mathrm{min}$ & $118,3 \pm 12,4$ & $122,1 \pm 18,6$ & 0,561 & $50,9 \pm 16,7$ & $53,9 \pm 11,2$ & 0,602 \\
\hline & $1^{\circ} \mathrm{min}$ & $115,1 \pm 13,9$ & $116,3 \pm 24,7$ & 0,885 & $49,4 \pm 10,2$ & $53,4 \pm 12,2$ & 0,39 \\
\hline \multirow[t]{3}{*}{ Sham-CPAP } & $5^{\circ} \mathrm{min}$ & $112,4 \pm 14,4$ & $118,2 \pm 17,7$ & 0,386 & $50,7 \pm 7,9$ & $54,0 \pm 10,3$ & 0,382 \\
\hline & $10^{\circ} \mathrm{min}$ & $111,5 \pm 17,9$ & $119,2 \pm 16,5$ & 0,284 & $50,7 \pm 7,7$ & $54,1 \pm 9,6$ & 0,351 \\
\hline & $1^{\circ} \mathrm{min}$ & $108,5 \pm 15,1$ & $118,2 \pm 21,2$ & 0,209 & $49,2 \pm 10,9$ & $54,3 \pm 11,5$ & 0,281 \\
\hline \multirow[t]{3}{*}{ Intervalo } & $5^{\circ} \mathrm{min}$ & $109,2 \pm 15,8$ & $122,1 \pm 21,1$ & 0,104 & $49,8 \pm 9,2$ & $55,5 \pm 11,4$ & 0,195 \\
\hline & $10^{\circ} \mathrm{min}$ & $108,1 \pm 8,7$ & $122,4 \pm 18,7$ & $0,025^{\star}$ & $49,5 \pm 8,6$ & $55,3 \pm 10,9$ & 0,157 \\
\hline & $1^{\circ} \mathrm{min}$ & $110,3 \pm 16,4$ & $116,1 \pm 17,4$ & 0,41 & $51,1 \pm 9,9$ & $50,2 \pm 14,9$ & 0,872 \\
\hline \multirow[t]{3}{*}{ CPAP-10 } & $5^{\circ} \mathrm{min}$ & $110,7 \pm 15,3$ & $111,9 \pm 14,5$ & 0,842 & $52,2 \pm 13,2$ & $50,4 \pm 9,8$ & 0,702 \\
\hline & $10^{\circ} \mathrm{min}$ & $112,0 \pm 15,7$ & $111,9 \pm 14,5$ & 0,988 & $53,6 \pm 13,3$ & $51,1 \pm 10,6$ & 0,617 \\
\hline & $1^{\circ} \mathrm{min}$ & $105,8 \pm 13,8$ & $112,3 \pm 26,7$ & 0,465 & $46,6 \pm 11,8$ & $50,3 \pm 12,7$ & 0,483 \\
\hline \multirow[t]{2}{*}{ Recuperação } & $5^{\circ} \mathrm{min}$ & $108,8 \pm 17,1$ & $114,3 \pm 29,8$ & 0,592 & $47,4 \pm 13,8$ & $50,1 \pm 14,1$ & 0,652 \\
\hline & $10^{\circ} \mathrm{min}$ & $107,4 \pm 19,2$ & $105,9 \pm 28,2$ & 0,884 & $46,3 \pm 13,9$ & $47,3 \pm 14,4$ & 0,866 \\
\hline
\end{tabular}


Gráfico 6 - Comportamento das pressões arteriais sistólica e diastólica registradas durante todos os momentos do estudo, em ambos os grupos.

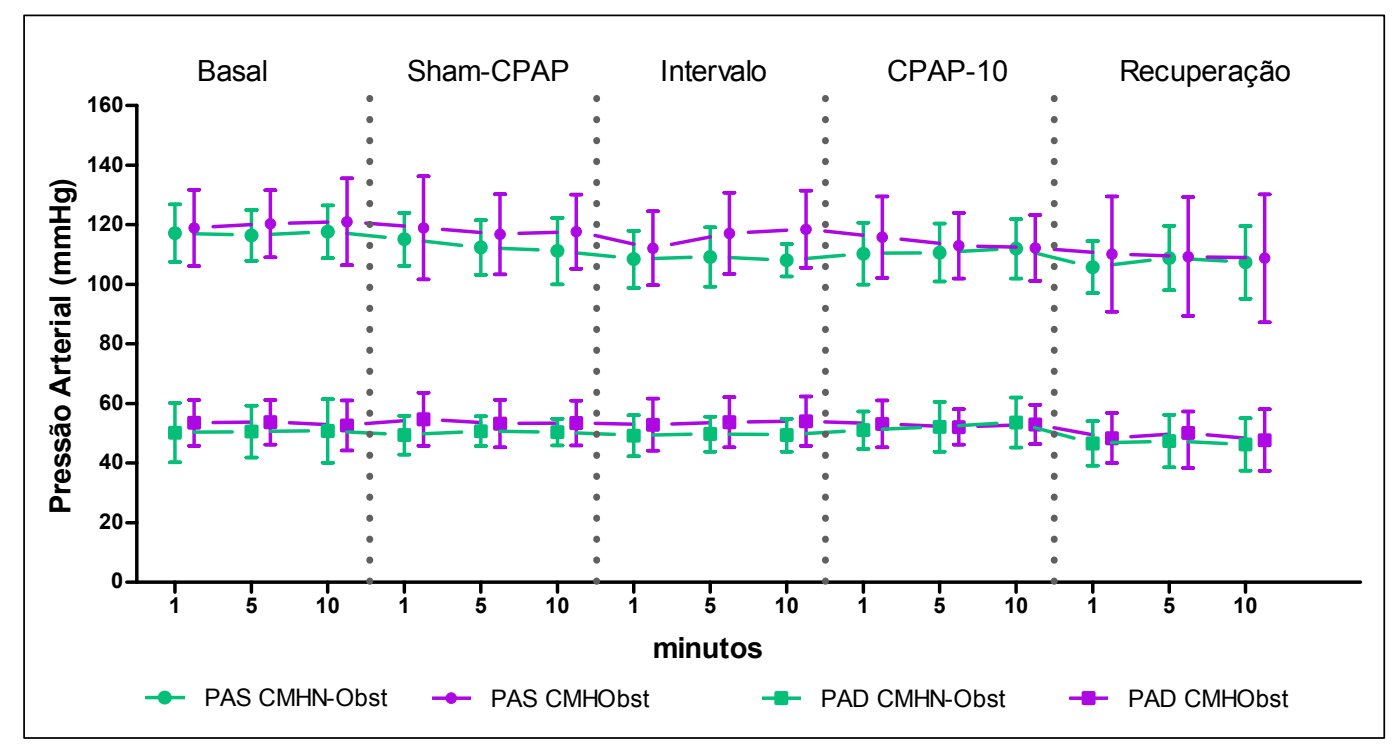

Dados apresentados em média e IC (95\%).

Consideramos, portanto, que a PA permaneceu estável ao longo de todo estudo nos dois grupos de pacientes. Assim, para a análise seguinte, todos os 24 pacientes passaram ser avaliados como parte de um mesmo grupo.

No intuito de avaliarmos se os diferentes níveis de pressão postitiva $\left(1,5 \mathrm{cmH}_{2} \mathrm{O}\right.$ ou $\left.10 \mathrm{cmH}_{2} \mathrm{O}\right)$ causariam variações na $\mathrm{PA}$, fizemos a seguinte análise: calculamos uma média única dos 3 desvios-padrão do $1^{\circ}, 5^{\circ}$ e $10^{\circ}$ minutos de ambas PAS e PAD, tanto para o momento Sham-CPAP, quanto para o CPAP-10. Ao compará-las (média dos 3 desvios-padrão de PAS e PAD do Sham-CPAP $x$ média dos 3 desvios-padrão de PAS e PAD do CPAP-10), encontramos uma diferença muito pequena, de $0,65 \mathrm{mmHg}$ para PAS e $0,26 \mathrm{mmHg}$ para PAD ( $p=0,130$ e $p=0,260$, respectivamente), o que 
nos permite aceitar que a imposição da pressão positiva em qualquer desses níveis não provocou variações importantes da PA.

Finalmente, testamos se a retirada do CPAP-10 e a tranzição para o momento seguinte fez com que a pressão variasse. Lembrando que, dependendo do protocolo, o momento CPAP-10 foi seguido pela recuperação ou intervalo. Para isso comparamos as médias de PAS e PAD do $10^{\circ}$ minuto com CPAP-10, com as respectivas médias do $1^{\circ}$ minuto do momento seguinte (respeitando a ordem da randomização - Protocolo A ou B). Os resultados estão descritos na tabela abaixo. Veja que não há indícios estatísticos que essa variação aconteça.

Tabela 13 - Análise comparativa da variação das pressões arteriais sistólica e diastólica no $10^{\circ}$ minuto com CPAP $-10 \mathrm{cmH}_{2} \mathrm{O}$ e $1^{\circ}$ minuto do momento seguinte.

\begin{tabular}{ccc}
\hline & $\begin{array}{c}\text { Diferenças entre as } \\
\text { médias }\end{array}$ & $P$ \\
\hline Protocolo A (CPAP-10 - Recuperação) & 2,38 & 0,552 \\
Pressão arterial sistólica, $\mathrm{mmHg}$ & 3,72 & 0,173 \\
Pressão arterial diastólica, $\mathrm{mmHg}$ & & \\
Protocolo B (CPAP-10 - intervalo) & $-2,18$ & 0,761 \\
Pressão arterial sistólica, $\mathrm{mmHg}$ & 0,97 & 0,841 \\
Pressão arterial diastólica, $\mathrm{mmHg}$ & &
\end{tabular}

Assim, concluimos que a pressão positiva não influênciou as medidas da PA dos pacientes com $\mathrm{CMH}$, independente de serem ou não obstrutivos. 


\subsection{Variações nas pressões de CPAP e EtCO 2}

As pressões de CPAP utilizadas nesse estudo foram de $1,5 \mathrm{cmH} 2 \mathrm{O}$ e $10 \mathrm{cmH} 2 \mathrm{O}$. Embora o objetivo do CPAP seja oferecer uma pressão contínua na inspiração e expiração, observamos pequenas variações nesses valores durante o ciclo respiratório $\left(\sim 1,5 \mathrm{cmH}_{2} \mathrm{O}\right)$, devido a mudanças no fluxo e volume pulmonar.

$\mathrm{O} \mathrm{EtCO}_{2}$ foi monitorado em todos os pacientes e em ambas pressões de CPAP. A média de $\mathrm{EtCO}_{2}$ durante a aplicação do Sham-CPAP foi de 41,0 $\pm 3,7 \mathrm{cmH}_{2} \mathrm{O}$ e de $36,8 \pm 2,6 \mathrm{cmH}_{2} \mathrm{O}$ durante o CPAP-10 ( $\left.p=0,003\right)$. Em 8 dos 26 participantes do estudo, a segunda saída e ar da válvula exalatória precisou ser aberta, apenas durante o uso do Sham-CPAP. A média de $\mathrm{EtCO}_{2}$ nesses 8 pacientes antes da abertura da válvula foi de $43,4 \pm 2,4$ $\mathrm{cmH}_{2} \mathrm{O}$ e, após a abertura, esse valor médio reduziu para $40,1 \pm 1,7 \mathrm{cmH}_{2} \mathrm{O}$ $(p=0,073)$, passando a níveis aceitáveis de normalidade . 
O presente estudo avaliou os efeitos agudos do CPAP nas variáveis hemodinâmicas e de desempenho cardíaco de indivíduos com Cardiomiopatia Hipertrófica.

\subsection{Considerações sobre as características da população estudada}

\subsubsection{Características clínicas e demográficas:}

Nossa amostra foi composta por adultos jovens, predominantemente caucasianos (58\%), do sexo masculino (77\%) e com sobrepeso. A maioria deles $(88 \%)$ estava em uso de pelo menos uma medicação para tratamento da $\mathrm{CMH}$.

Pacientes obstrutivos apresentaram níveis de BNP mais elevados em relação aos não-obstrutivos. O BNP é neuro-hormônio derivado dos ventrículos e liberado quando há distensão da parede ventricular. ${ }^{(101)}$ Está independentemente associado com a gravidade e prognóstico da insuficiência cardíaca, por exemplo. ${ }^{(101,102)} \mathrm{Em}$ pacientes com $\mathrm{CMH}$, níveis elevados de BNP tem se correlacionado com o grau de disfunção diastólica, ${ }^{(103)}$ pior classe funcional $(\mathrm{NYHA}),{ }^{(88)}$ com o status clínico (queixa de dispneia e angina), ${ }^{\left({ }^{89)}\right.}$ maior espessura da parede do $\mathrm{VE}^{\left({ }^{(8)}\right)}$ e com a maior obstrução da VSVE, ${ }^{(103)}$ justificando, portanto, o fato de os pacientes obstrutivos serem mais graves e comprometidos do ponto de vista clínico e genético. 


\subsubsection{Achados relacionados ao sono}

Nosso estudo confirmou por PSG completa, padrão-ouro para diagnóstico dos distúrbios respiratórios do sono, dados recentes que utilizaram monitor portátil $^{(44,46)}$ e oximetria noturna, ${ }^{(43,45)}$ de que AOS é uma doença muito frequente em pacientes com $\mathrm{CMH}$. Nesses estudos, que utilizaram diferentes critérios diagnósticos e diferentes tipos de monitorização, a prevalência de AOS variou de $32 \%$ a $71 \% .{ }^{(56)}$ Na nossa amostra, a frequência de AOS foi extremamente alta, $58 \%$, e similar entre os grupos não-obstrutivos e obstrutivos (67\% e 50\%, respectivamente). Essa observação chama nossa atenção, pois como a $\mathrm{CMH}$ é uma doença genética, pouca tem sido a investigação de AOS nessa população. No entanto, essa alta prevalência de AOS (moderada a grave) levanta a possibilidade e necessidade de tratar esses pacientes com CPAP.

Nossos resultados mostraram ainda que o grupo obstrutivo apresentou maior eficiência do sono, com menor latência para início do sono. Acreditamos que esses dados, apesar de parecerem favoráveis, sejam apenas um achado do nosso estudo, não refletindo um sono de melhor qualidade por esse grupo, pois os pacientes obstrutivos apresentaram conjuntamente, um número mais elevado de microdespertares (sono mais fragmentado) e altos escores no questionário de Pittsburgh, compatíveis com uma percepção de má qualidade de sono. Nesse contexto, resultados semelhantes foram encontrados por Pedrosa e colaboradores, ${ }^{(104)}$ em que 
pacientes com $\mathrm{CMH}$ referiram pior qualidade subjetiva de sono quando comparados a controles pareados para características demográficas e status tabágico. Apesar disso, nossos pacientes com $\mathrm{CMH}$ de ambos os grupos não apresentavam queixas de sonolência excessiva diurna, um dos principais sintomas relacionados à AOS. Esse achado confirma os resultados de um estudo prévio realizado pelo nosso grupo, ${ }^{(105)}$ em que 90 pacientes com $\mathrm{CMH}$ foram avaliados ( $n=53$ com AOS e $n=37$ sem AOS) e também observamos baixos escores de sonolência, sendo semelhantes entre os grupos e independentes da presença da AOS. Com esse estudo prévio, percebemos que existem poucos preditores de AOS nessa população de $\mathrm{CMH}$ (apenas idade $\geq 45$ anos e presença de FA), o que justifica e mantém a baixa suspeita clínica da associação dessas duas doenças.

\subsection{Considerações sobre os achados ecocardiográficos basais}

Os achados ecocardiográficos basais deste estudo demonstraram, conforme esperado, que pacientes obstrutivos apresentaram maiores alterações na anatomia e dinâmica cardíacas em relação aos nãoobstrutivos. ${ }^{(3)}$ Destacamos que algumas dessas alterações são características genéticas da doença obstrutiva, como: maior índice de massa do VE, maior gradiente de VSVE e maior prevalência de MAS. ${ }^{(28,106)}$ Outras, porém, se desenvolvem em consequência à essas alterações primárias ou de forma compensatória, no intuito de manter a função cardíaca preservada, 
incluindo: maiores pressões de enchimento ventricular; maior tamanho do $A E ;$ maior frequência de refluxo mitral. ${ }^{(107-109)}$

Fisiologicamente, o que ocorre é que a hipertrofia miocárdica leva a uma desorganização das fibras ventriculares esquerdas, com fibrose celular, que restringem a distensibilidade ${ }^{(110)}$ e aumentam a rigidez do VE. Esses efeitos lentificam seu relaxamento e elevam as pressões de enchimento na câmara esquerda, que, cronicamente, a dilatam. ${ }^{(108)}$ Associado a isso, o maior gradiente na VSVE e a presença do refluxo mitral elevam a pressão diastólica final no VE, que atua como uma pós-carga aumentada ao AE. Essa pós-carga aumentada ao $\mathrm{AE}$ favorece a piora do refluxo mitral, ${ }^{(30,110,}$ 111) e, ambos, em conjunto, sobrecarregam e dilatam ainda mais essa câmara. Em suma, quanto maiores forem a rigidez ventricular, o gradiente na VSVE e o refluxo mitral, maior poderá ser o remodelamento do AE. ${ }^{(112)}$ Como resultado negativo dessa dilatação, em longo prazo, pode haver maior ocorrência de FA, um preditor de morbi-mortalidade nessa população. ${ }^{(19,22,}$ $113,114)$

\subsection{Considerações sobre os efeitos da pressão positiva na anatomia e função cardíacas e hemodinâmica.}

Até a presente data, este foi o primeiro estudo que avaliou os efeitos agudos provocados pelo CPAP em pacientes com $\mathrm{CMH}$. Nossos resultados demonstraram que a pressão positiva, principalmente o CPAP-10, causou algumas alterações na anatomia e dinâmica cardíacas de ambos os grupos, 
porém, sem modificar a hemodinâmica. No lado direito do coração, houve redução na área do $A D$ com relaxamento mais lento do VD em ambos os grupos, e um aumento da pressão na AP apenas nos obstrutivos. No lado esquerdo do coração, observamos uma redução na complacência e no relaxamento do VE no grupo não-obstrutivo e aumentos importantes nas frações regurgitantes (achado resultante da diminuição significativa no tamanho do $A E$ em relação a um aumento discreto do jato regurgitante) apenas nos obstrutivos. Medidas hemodinâmicas incluíram PA, DC, volume sistólico, FC, FEVE e gradiente na VSVE, que permaneceram estáveis ao longo de todo o estudo.

Os potenciais mecanismos envolvidos nessas respostas são múltiplos e muito complexos. Contudo, a fim de facilitar o entendimento do leitor, basearemos os achados no nosso trabalho nos efeitos da pressão positiva sobre a interação coração-pulmão.

\subsubsection{Variações nas câmaras cardíacas}

Ao ser instituída, a pressão positiva provoca um aumento instantâneo na pressão intratorácica, que se transmite às câmaras cardíacas e vasos sanguíneos localizados dentro do tórax. Assim, as pressões no AD e nas veias cavas se elevam em relação à pressão venosa sistêmica média, ${ }^{(115,116)}$ com consequente redução do retorno venoso para dentro do AD ( $\downarrow$ na précarga $)^{(116-118)}$ e, por conseguinte, para o $A E$, já que as câmaras estão dispostas em série. Esse menor volume de sangue na câmara atrial pode 
reduzir seu tamanho. Aliado a isso, um maior volume pulmonar quando em pressão positiva, exerce um efeito compressivo sobre todas as câmaras cardíacas, com efeito mais pronunciado nos átrios, por possuírem paredes mais finas e compressíveis do que as ventriculares. ${ }^{(118)}$ No presente estudo, encontramos uma diminuição no AD em ambos os grupos e no $A E$ apenas nos obstrutivos, que exibiam uma câmara mais dilatada em condições basais e, talvez, mais predisposta a essa compressão extrínseca de um pulmão hiperinflado.

Esses efeitos supracitados foram descritos previamente. DeMaria e colaboradores $^{(119)}$ avaliaram o volume do $A D$ por meio de um cateter de impedância, em dez suínos anestesiados e ventilados mecanicamente, durante aplicação de diferentes níveis de PEEP (Positive end expiratory pressure) 5, 10 e $15 \mathrm{cmH}_{2} \mathrm{O}$. Seus resultados incluíram redução no volume do $A D$, que foi progressiva aos aumentos da PEEP e acompanhado por reduções no DC, com elevações na pressão de capilar pulmonar. ${ }^{(119)}$ Em indivíduos saudáveis, Kyhl e colaboradores ${ }^{(120)}$ observaram que aumentos progressivos nas pressões inspiratórias $\left(0,10\right.$ e $\left.20 \mathrm{cmH}_{2} \mathrm{O}\right)$, provocaram reduções correspondentes em todos os volumes cardíacos (diastólico e sistólico-finais do $A D$; do VD, do $A E$, do VE e no volume sistólico dos átrios e ventrículos), sendo mais evidente nos volumes atriais em relação aos ventriculares, e no do AD quando comparado ao AE (Figura 26). 


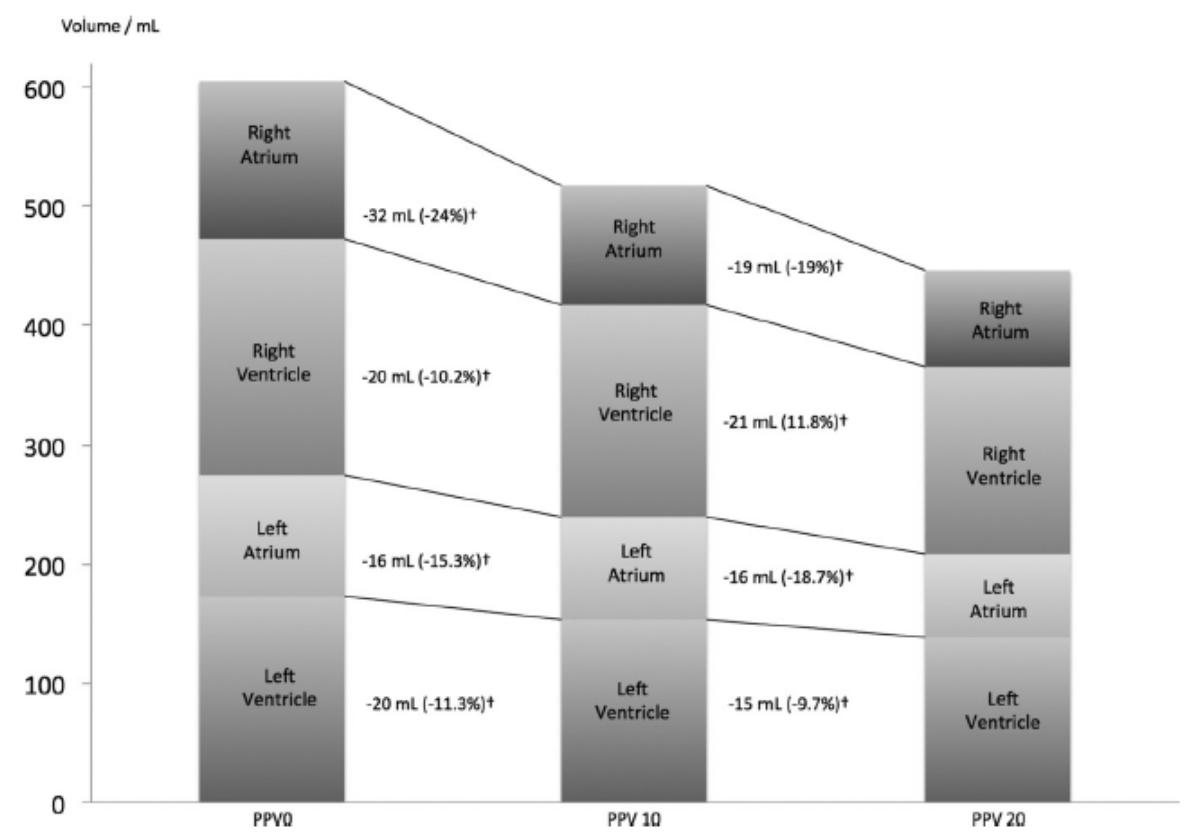

Figura 26: Reduções nos volumes diastólico-finais das câmaras cardíacas com aumentos das pressões ventilatórias de zero (PPVO - Positive-pressure ventilation), $10 \mathrm{cmH}_{2} \mathrm{O}$ (PPV10) e $20 \mathrm{cmH}_{2} \mathrm{O}$ (PPV20). Right atrium: Atrio direito; Right ventricle: ventrículo direito; Left atrium: átrio esquerdo; Left ventricle: venrículo esquerdo. (Fonte: $\mathrm{Kyhl} \mathrm{K}$ et al. The decrease of cardiac chamber volumes and output during positive-pressure ventilation. Am J Physiol Heart Circ Physiol. 2013;305(7):H1004-9). ${ }^{(120)}$

Embora não tenhamos demonstrado os valores dos volumes sistólico e diastólico-finais do VE, não encontramos diferença estatística em seus respectivos diâmetros. Como essas variáveis se modificam proporcionalmente, podemos inferir que os volumes também não se alteraram de forma significativa com a pressão positiva. Esses achados são similares aos de Mehta e colaboradores, ${ }^{(121)}$ em que os volumes das câmaras ventriculares de 13 pacientes com cardiomiopatia isquêmica foram comparados, via ecocardiografia, a 9 pacientes com cardiomiopatia dilatada, 
ambos submetidos a 30 minutos com CPAP $10 \mathrm{cmH}_{2} \mathrm{O}$. No grupo de isquêmicos, o CPAP não provocou nenhuma alteração nos volumes diastólico e sistólico-finais, enquanto os pacientes dilatados evoluíram com reduções significativas nestes parâmetros de ambos os ventrículos. Os autores justificam esse achado a uma menor complacência ventricular de corações isquêmicos em relação aos dilatados. Essa é uma característica semelhante a dos nossos pacientes com $\mathrm{CMH}$, que também apresentam câmaras ventriculares menos complacentes pela presença da hipertrofia.

\subsubsection{Alterações no relaxamento e função diastólica}

Outro achado do nosso trabalho foi uma lentificação no relaxamento do VD (redução do E' do VD) em ambos os grupos e do relaxamento e complacência do VE (diminuição na relação E/A e onda $E$, respectivamente) apenas nos não-obstrutivos. Sabe-se que o relaxamento ventricular é um processo complexo e um dos principais determinantes do enchimento desta câmara durante a diástole ventricular. ${ }^{(122)}$ Alguns autores já demonstraram em seus estudos que a complacência ventricular direita e/ou esquerda estão reduzidas durante a ventilação com pressão positiva. ${ }^{(116,123,124)}$ Esses mecanismos são influenciados por alguns fatores: 1) a pressão positiva aumenta a pressão intratorácica, que exerce um efeito compressivo dos pulmões sobre o coração, incluindo os ventrículos. Esse efeito em conjunto com uma resistência vascular pulmonar mais elevada (pós-carga aumentada ao VD), reduzem a complacência efetiva do VD, que também se reflete ao 
VE; $\left.{ }^{(125)} 2\right)$ reduções na pré-carga (retorno venoso) diminuem a pressão atrial na diástole precoce (onda E) em relação a pressão ventricular, resultando em um menor gradiente de pressão transvalvar (driving pressure).$^{(98)} \mathrm{A}$ combinação desses fatores, contribuem ainda mais para uma lentificação do relaxamento pelo ventrículo.

Além disso, como o relaxamento ventricular interfere na função diastólica, nossos resultados estão de acordo com os encontrados por Yamada $^{(98)}$ e Chin $^{(122)}$ e seus colaboradores. No primeiro estudo, os autores avaliaram, via ecocardiografia, 14 mulheres saudáveis em cirurgia ginecológica eletiva e verificaram que os aumentos progressivos de pressão - PEEP zero, 5, 10, 15 e $20 \mathrm{cmH}_{2} \mathrm{O}$ - foram acompanhados por: reduções nos picos de velocidade da onda $E$ e da relação $E / A$; elevações no TD; sem alterações no pico de velocidade da onda A e no TRIV. Os autores atribuíram essas alterações a ambos, redução na pré-carga e menor complacência ventricular ocasionadas pela PEEP. No segundo estudo, a função diastólica de 17 pacientes durante cirurgia de revascularização do miocárdio foi avaliada por Doppler Tecidual, ao final de 10 minutos em PEEP zero, 5 e $10 \mathrm{cmH}_{2} \mathrm{O}$, selecionadas em ordem randomizada. Neste estudo, todos os pacientes apresentavam anormalidade pré-existentes no relaxamento do VE. Como resultados, os autores encontraram uma lentificação ainda maior no relaxamento do VE, subsequente aos aumentos de PEEP, além de prolongamento do TD quando em PEEP $10 \mathrm{cmH}_{2} \mathrm{O}$.

Curiosamente, na nossa população de pacientes com $\mathrm{CMH}$ obstrutiva, não observamos alteração no relaxamento do VE, como ocorreu 
com os não-obstrutivos, que tem hipertrofia miocárdica mais discreta. Sabemos que com a maior hipertrofia, corações obstrutivos apresentam maiores espessura da parede do VE, massa muscular e pressões de enchimento ventriculares. Essas variáveis em conjunto provocam, continuamente, uma tensão mais elevada nas paredes do ventrículo. ${ }^{(126)}$ Essas alterações tornam os ventrículos mais "rígidos" e, quiçá, os efeitos da maior pressão intratorácica talvez não tenham sido grandes o suficiente a ponto de influenciar ainda mais o relaxamento ventricular esquerdo nesse grupo.

\subsubsection{Variações nas pressões da artéria pulmonar}

Nos pacientes obstrutivos a pressão positiva causou, agudamente, um aumento na pressão da AP ( $\downarrow$ tempo de aceleração pulmonar). Veja na Tabela 8, que em condições basais o tempo de aceleração pulmonar nesses pacientes já era diminuído em relação aos não-obstrutivos, refletindo, embora sem diferença estatística, maiores pressões de AP. Aliado a isso, pacientes obstrutivos também exibiam maiores pressões de enchimento ventricular (E/E`septal, lateral e médio) e maior prevalência de refluxo mitral. O refluxo mitral, quando presente, aumenta as pressões atriais direita e esquerda, ${ }^{(111)}$ com consequente elevação da pressão hidrostática nos capilares pulmonares. ${ }^{(68)}$ Esses efeitos isolados ou em conjunto com as maiores pressões de enchimento ventricular, cronicamente, podem provocar um aumento reativo na pressão desses vasos (mais resistência 
vascular). ${ }^{(127)}$ Além disso, quando sob efeito da pressão positiva, que aumenta a pós-carga do VD, reduções mais evidentes no tempo de aceleração do fluxo de sangue pulmonar podem ocorrer. Esse também foi um achado do estudo de Kyhl e colaboradores, ${ }^{(120)}$ que constataram uma redução progressiva no fluxo da AP após 30 minutos de ventilação não invasiva (VNI) nas pressões $\left(0,10\right.$ e $\left.20 \mathrm{cmH}_{2} \mathrm{O}\right)$, aplicados em voluntários saudáveis, por máscara oronasal.

Esse resultado parece ser um potencial efeito negativo da aplicação do CPAP em pacientes com $\mathrm{CMH}$ obstrutiva. Entretanto, é importante considerarmos que essa foi uma resposta aguda e encontrada com o paciente em vigília. Com isso, a pergunta se esse aumento na pressão pulmonar se manteria com o uso do CPAP em longo prazo, para o tratamento da AOS, permanece incerta e ainda precisa ser estudada. Apenas é interessante acrescentar que a hipoxemia e a hipercapnia intermitentes provocadas pela AOS durante o sono, possam aumentar ainda mais a resistência vascular pulmonar, pela vasoconstrição hipóxica e mediada pelo $\mathrm{CO}_{2}$, respectivamente. Com isso, é possível acreditarmos que a reversão desse quadro com o uso do CPAP possa contribuir positivamente para os pacientes com CMHObst + AOS.

Por outro lado, conforme comentado na sessão de resultados, o tempo de aceleração pulmonar foi uma das variáveis analisadas sem o " $\mathrm{n}$ " total de pacientes em cada grupo, o que pode ter sub ou superestimado esse resultado. Assim, esse achado deve ser considerado, porém, com cautela. 


\subsubsection{Variações no refluxo mitral}

No presente estudo, observamos que em condições basais os pacientes obstrutivos apresentavam maior frequência e importância de refluxo mitral em relação aos não-obstrutivos, avaliado pela maior área e volume do jato regurgitante e suas frações. Essas últimas, medidas quantitativas do refluxo mitral e calculadas pela razão entre a área e o volume do jato, em relação à área e volume do $\mathrm{AE}$, respectivamente. Nesses pacientes, a aplicação aguda da pressão positiva provocou elevações progressivas e importantes das frações regurgitantes.

Estudos prévios a cerca dos efeitos agudos ${ }^{(128)}$ e em longo prazo ${ }^{(111)}$ da pressão positiva (CPAP/Binível) em pacientes com insuficiência cardíaca grave, mostraram reduções significativas da área do refluxo mitral ${ }^{(128)}$ e das frações regurgitantes. ${ }^{(111)}$ Contudo, os mecanismos desse refluxo em corações dilatados são diferentes dos hipertróficos, pois ocorrem secundariamente à dilatações no ânulo mitral e disfunção dos músculos papilares. Nesses corações, a pressão positiva é benéfica na melhora da função cardíaca e do refluxo, por reduzirem a pré-carga e pós-carga do VE e melhorarem a FEVE e o DC. ${ }^{(111,128)}$ Já nos corações hipertróficos, o refluxo decorre de alterações morfológicas no aparato mitral que dependem de uma complexa interdependência de fatores, como presença e importância do MAS, tamanho e mobilidade dos folhetos anterior e posterior, além do 
posicionamento e função dos músculos papilares e cordoalhas tendíneas. ${ }^{(9,}$ 13)

Embora os aumentos nas frações regurgitantes dos pacientes obstrutivos também pareçam um resultado negativo do nosso estudo, foram consequência principalmente das reduções no tamanho do $A E$, visto que o jato regurgitante pouco se modificou. É possível que esse último tenha ocorrido em resposta ao aumento nas pressões do $A E$, além da não alteração nas pressões de enchimento do VE, que também são mecanismos que podem ajudar a justificar o não aumento do gradiente de pressão entre o VE a Aorta. Como nosso estudo foi desenhado para avaliar os efeitos agudos do CPAP durante a vigília, não sabemos como o tratamento da AOS em longo prazo repercutiria nessas variáveis. Entretanto, no pequeno relato de Sengupta e colaboradores ${ }^{(48)}$ que tratou com CPAP 3 pacientes com AOS + $\mathrm{CMH}$ obstrutiva por $\sim 18$ a 19 meses, os autores verificaram reduções no gradiente da VSVE, um dos pontos-chave na ocorrência do refluxo mitral. ${ }^{(48)}$ Embora ainda pouco consistentes, esses achados nos permitem acreditar na importância e benefícios do tratamento da AOS na melhora da dinâmica cardíaca dessa classe de pacientes.

\subsubsection{Variações na hemodinâmica}

Os efeitos da pressão positiva nas variáveis hemodinâmicas têm sido amplamente estudados, porém, apresentam resultados conflitantes na literatura. Na maioria desses estudos, a pressão positiva provocou reduções 
no débito e índice $\operatorname{cardíacos}^{(116,117,120,126,129)} \mathrm{e}$, por conseguinte, na PA. ${ }^{(116,}$ 117, 122) Contudo, é importante comentar que grande parte deles foram realizados em diferentes condições clínicas, como hipovolemia, choque, insuficiência cardíaca, sedação e altas pressões ventilatórias (ventilação mecânica invasiva). Estas situações tornam as respostas hemodinâmicas diferentes entre eles e mais pronunciadas. ${ }^{(130)}$ Alguns autores atribuem à redução no retorno venoso (pré-carga), como provável causa desses achados. $^{(117,129,131)}$

Contudo, mesmo num cenário de pacientes estáveis e com a pressão positiva aplicada de forma não-invasiva, os resultados ainda são conflitantes. Leech e colaboradores, ${ }^{(132)}$ por exemplo, avaliaram por ecocardiografia 19 voluntários saudáveis e 6 pacientes com AOS, ambos sem doenças cardíacas preexistentes. Nesse estudo o CPAP foi aplicado por máscara nasal durante 10 minutos, nas pressões sequenciais de zero, 5, 10, e $15 \mathrm{cmH}_{2} \mathrm{O}$. Em nenhum dos grupos os autores verificaram variações no DC com incrementos das pressões de CPAP, nem alterações na FC, na forma e tamanho do VE, corroborando com nossos achados. Em contrapartida, Huemer e colaboradores, também avaliando 21 indivíduos saudáveis por ecocardiografia, não observaram variações na PA e FC com aplicação sequencial de CPAP nasal (zero, 5, 7.5, 10 e 12,5 $\mathrm{cmH}_{2} \mathrm{O}$ ), porém, encontraram reduções no DC frente aos aumento progressivos dessa pressão.

No nosso estudo, embora o CPAP tenha provocado algumas alterações de anatomia e dinâmica cardíacas de ambos os grupos, os 
parâmetros hemodinâmicos não se alteraram para nenhum deles, em nenhum dos momentos avaliados. A FC, o DC, o volume sistólico, a FEVE e o gradiente de VSVE permaneceram estáveis ao longo do estudo. A PA também não sofreu alterações frente diferentes níveis de CPAP aplicados, estando de acordo com relatos de outros autores. ${ }^{(120,129,133,134)}$ Esses achados sugerem, portanto, que o CPAP seja uma alternativa segura para o tratamento de AOS em pacientes com $\mathrm{CMH}$.

\subsection{Forças e limitações do estudo}

Nosso estudo apresenta pontos fortes e limitações, que merecem ser aclarados:

O desenho randomizado e crossover nos permitiu garantir que o ecocardiografista fosse cego às pressões de CPAP que estavam sendo aplicadas ao paciente.

A posterior análise off-line dos exames ecocardiográficos foi realizada por outros dois investigadores experientes, que eram cegos quanto ao grupo que o paciente pertencia e quanto à pressão de CPAP oferecida.

Para avaliação da PA, utilizamos medidas batimento-a-batimento, um método muito sensível para detectar variações rápidas e transitórias na hemodinâmica.

Pelo fato do nosso estudo ter se baseado em dados ecocardiográficos para análise dos efeitos do CPAP, excluímos pacientes com FA, que são 
os mais susceptíveis a variações na pré-carga. Assim, nossos resultados devem ser extrapolados com cuidado para essa população específica de pacientes com $\mathrm{CMH}+\mathrm{FA}$.

Nosso estudo foi desenhado para avaliar os efeitos agudos do CPAP durante a vigília. Portanto, as respostas fisiológicas ao CPAP durante o sono e decorrentes da eliminação da AOS não foram avaliadas e ainda precisam ser estudadas.

\subsection{Considerações finais e perspectivas futuras}

A AOS é uma comorbidade muito frequente na $\mathrm{CMH} e$, comprovadamente, propicia uma série de consequências deletérias aos parâmetros cardíacos desses pacientes. O CPAP é o padrão-ouro para tratamento da AOS e está associado, em casos sem $\mathrm{CMH}$, à melhora de inúmeras variáveis de desfecho cardiovascular. Embora tenhamos estudado os efeitos agudos do CPAP na vigília e encontrado alguns potenciais efeitos negativos nos corações hipertróficos, a PA e o gradiente de VSVE, que são os dois principais motivos de preocupação nesses pacientes, principalmente nos obstrutivos, permaneceram estáveis. Assim, sugerimos que o tratamento da AOS com CPAP em pacientes com $\mathrm{CMH}$ seja considerado, pois acreditamos que os benefícios da abolição dos eventos respiratórios se sobreponham aos potenciais efeitos negativos encontrados no presente estudo. Para esclarecer essas e outras perguntas, estudos futuros a cerca 
dos efeitos em longo prazo do CPAP para tratamento da AOS nessa classe de pacientes, ainda precisam e devem ser realizados. 
Conclusão 


\section{Conclusão}

$\checkmark$ o presente estudo revelou que a aplicação aguda do CPAP não alterou a hemodinâmica de pacientes com $\mathrm{CMH}$, visto que a $\mathrm{PA}, \mathrm{o}$ DC, o volume sistólico, a FC, a FEVE e o gradiente na VDVE permaneceram estáveis durante todo o período de estudo.

$\checkmark$ Considerando os efeitos agudos do CPAP sobre o desempenho cardíaco, observamos:

o diminuição no tamanho do átrio direito e um relaxamento mais lento do VD em ambos os grupos;

o redução na complacência e no relaxamento do VE, apenas nos não-obstrutivos;

o aumento na pressão da artéria pulmonar, redução importante na área e volume do $A E$ e aumento nas frações regurgitantes (área e volume), apenas nos obstrutivos.

Concluímos, portanto, que o CPAP é um método seguro a ser aplicado em pacientes com $\mathrm{CMH}$, pois não causou alterações hemodinâmicas em nenhum dos grupos avaliados. No entanto, como verificamos alguns potenciais efeitos negativos do CPAP sobre a dinâmica cardíaca dos pacientes obstrutivos, sua utilização em longo prazo deve ser cuidadosamente monitorada nessa classe de pacientes. 
Anexos 
HOSPITAL DAS CLÍNICAS DA FACULDADE DE MEDICINA DA

UNIVERSIDADE DE SÃO PAULO-HCFMUSP

TERMO DE CONSENTIMENTO LIVRE E ESCLARECIDO

DADOS DE IDENTIFICAÇÃO DO SUJEITO DA PESQUISA OU RESPONSÁVEL LEGAL

1.NOME:

DOCUMENTO DE IDENTIDADE N : SEXO :.$M \square \quad F \quad \square$

DATA NASCIMENTO: ........................

ENDEREÇO

$\mathrm{N}^{0}$

APTO:

BAIRRO:

CIDADE

CEP: TELEFONE: DDD ( )

2.RESPONSÁVEL LEGAL

NATUREZA (grau de parentesco, tutor, curador etc.)

DOCUMENTO DE IDENTIDADE SEXO: $M \square \quad F \square$

ENDEREÇO $\mathrm{N}^{\mathrm{O}}$ APTO:

BAIRRO:

CIDADE

CEP:.

TELEFONE: DDD ( ).

\section{DADOS SOBRE A PESQUISA}

1. TítUlo do PROTOColo DE PESQUISA: "Efeitos Hemodinâmicos Agudos da Pressão Positiva Contínua na Via Aérea (CPAP) em Indivíduos com Cardiomiopatia Hipertrófica"

PESQUISADOR EXECUTANTE: Flávia Baggio Nerbass

CARGO/FUNÇÃO: Fisioterapeuta pesquisadora - Laboratório do Sono (InCor)

INSCRIÇÃO CONSELHO REGIONAL No: 66966-F

UNIDADE DO HCFMUSP: Instituto do Coração - InCor

PESQUISADOR RESPONSÁVEL: Dr. Geraldo Lorenzi Filho

CARGO/FUNÇÃO: Diretor do Laboratório do Sono - InCor

INSCRIÇÃO CONSELHO REGIONAL N 52063

UNIDADE DO HCFMUSP: Instituto do Coração - InCor 


\title{
HOSPITAL DAS CLÍNICAS DA FACULDADE DE MEDICINA DA UNIVERSIDADE DE SÃO PAULO-HCFMUSP
}

3. AVALIAÇÃO DO RISCO DA PESQUISA:

\author{
RISCO MÍNIMO \\ RISCO MÉDIO \\ RISCO BAIXO $\mathbf{x}$ \\ RISCO MAIOR
}

4. DURAÇÃO DA PESQUISA 4 anos

\section{III - REGISTRO DAS EXPLICAÇÕES DO PESQUISADOR AO PACIENTE OU SEU REPRESENTANTE LEGAL SOBRE A PESQUISA, CONSIGNANDO:}

$\mathrm{O}$ (a) $\mathrm{Sr}(\mathrm{a})$ possui um diagnóstico de Cardiomiopatia Hipertrófica e já está em tratamento aqui no InCor. Muitas pessoas que tem essa alteração no coração igual a sua, podem também ter problemas respiratórios durante o sono, que chamamos de Apeia Obstrutiva do Sono. A apeia é aquela que causa ronco e engasgos durante a noite. A apneia pode prejudicar ainda mais o seu coração, causar arritmias, aumentar sua pressão arterial e causar derrame cerebral. $O$ tratamento para as pessoas que tem apeia é usar um aparelho para dormir chamado CPAP. Esse aparelho manda um ar por uma máscara que é colocada no rosto e faz com que o(a) $\operatorname{Sr}(a)$ não ronque mais e não tenha mais engasgos durante o sono. Mas, pouco sabemos se este aparelho pode ser usado por pessoas que tem a Cardiomiopatia Hipertrófica. Este estudo quer avaliar se esse aparelho (CPAP) é realmente bom para casos como o seu. Para isso, estamos lhe convidando a comparecer no Laboratório do sono do InCor para passar uma manhã. Durante essa manhã o(a) Sr(a) será examinado e, caso aceite participar deste estudo, o(a) $\mathrm{Sr}(\mathrm{a})$ responderá 3 questionários a respeito da sua sonolência, do seu ronco e cansaço durante o dia e sobre a qualidade do seu sono nos últimos 30 dias. Logo após, lhe será mostrado o CPAP e será colocada no seu rosto uma máscara confortável. O aparelho será ligado em 2 pressões diferentes, para que o(a) $\mathrm{Sr}(\mathrm{a})$ possa conhecer o aparelho e se adaptar a ele. Além disso, para realizarmos as medidas de pressão dentro do seu tórax, colocaremos um cateter chamado cateter esofágico, que se parece com um espaguete bem fininho. Uma parte dele é introduzida pelo nariz e descerá até seu esôfago. A outra parte dele será fixada com uma fita crepe na sua bochecha. Logo em seguida será coletado amostra do seu sangue para exames laboratoriais e o(a) Sr(a) ficará deitado em uma cama confortável para fazer um exame chamado ecocardiograma, que o(a) $\operatorname{Sr}(a)$ já deve ter realizado no ambulatório de miocardiopatias. Enquanto estiver deitado, a sua pressão e seu batimento cardíaco serão monitorados até o final. Colocaremos o CPAP com as duas pressões que o(a) $\operatorname{Sr}(a)$ já experimentou anteriormente e o ecocardiograma será repetido em cada uma delas. Esse exame não tem custos e não causa dor. Se sua pressão cair e lhe causar mal-estar ou tontura, pararemos o protocolo imediatamente. $\mathrm{O}(a) \mathrm{Sr}(a)$ será convidado a comparecer em um outro dia no Laboratório do Sono para realizar um exame completo do sono chamado Polissonografia. Com esse exame avaliaremos como é o seu sono e se o(a) Sr(a) tem apeia do sono. É importante dizer que este estudo não quer causar qualquer prejuízo ou transtorno para seus participantes. $\mathrm{O}(\mathrm{a}) \mathrm{Sr}(\mathrm{a})$ pode desistir de participar a qualquer momento, sem que isso prejudique seu tratamento aqui no $\operatorname{InCor}$. $\mathrm{O}(\mathrm{a}) \mathrm{Sr}(\mathrm{a})$ também pode ter acesso às informações sobre os procedimentos, riscos, e benefícios relacionados à pesquisa sempre que solicitar. 


\section{HOSPITAL DAS CLÍNICAS DA FACULDADE DE MEDICINA DA UNIVERSIDADE DE SÃO PAULO-HCFMUSP}

Todas as suas informações serão sigilosas e analisadas em conjunto com outros pacientes, não sendo divulgada a identificação de nenhum paciente. Não há despesas pessoais para o participante em qualquer fase do estudo. Também não há compensação financeira relacionada à sua participação.

O principal investigador é Dr. Geraldo Lorenzi Filho, que pode ser encontrado no Laboratório do Sono do Instituto do Coração, $7^{\circ}$, Bloco 1., Av. Dr. Enéias de Carvalho Aguiar, 44. Telefone: 11-30695486. Se você tiver alguma consideração ou dúvida sobre a ética da pesquisa, entre em contato com o Comitê de Ética em Pesquisa (CEP) - Rua Ovídio Pires de Campos, 225 - $5^{\circ}$ andar - tel: 3069-6442 ramais 16, 17, 18 ou 20, FAX: 3069-6442 ramal 26 - E-mail: cappesq@hcnet.usp.br

Acredito ter sido suficientemente informado a respeito das informações que li ou que foram lidas para mim, descrevendo o estudo "Efeitos Hemodinâmicos Agudos da Pressão Positiva na Via Aérea (CPAP) em Indivíduos com Cardiomiopatia Hipertrófica."

Eu discuti com a Dra. Flávia Baggio Nerbass e Dr. Geraldo Lorenzi Filho sobre a minha decisão em participar nesse estudo. Ficaram claros para mim quais são os propósitos do estudo, os procedimentos a serem realizados, seus desconfortos e riscos, as garantias de confidencialidade e de esclarecimentos permanentes. Ficou claro também que minha participação é isenta de despesas e que tenho garantia do acesso a tratamento hospitalar quando necessário. Concordo voluntariamente em participar deste estudo e poderei retirar o meu consentimento a qualquer momento, antes ou durante o mesmo, sem penalidades ou prejuízo ou perda de qualquer benefício que eu possa ter adquirido, ou no meu atendimento neste Serviço. 
HOSPITAL DAS CLÍNICAS DA FACULDADE DE MEDICINA DA UNIVERSIDADE DE SÃO PAULO-HCFMUSP

Assinatura do paciente/representante legal Data 11

(Somente para o responsável do projeto)

Declaro que obtive de forma apropriada e voluntária o Consentimento Livre e Esclarecido deste paciente ou representante legal para a participação neste estudo. 


\section{Protocolo CPAP e CMH}

Grupo:

Gradiente:

RG-HC:

Data:

\section{Identificaçao}

Nome:

Protocolo:

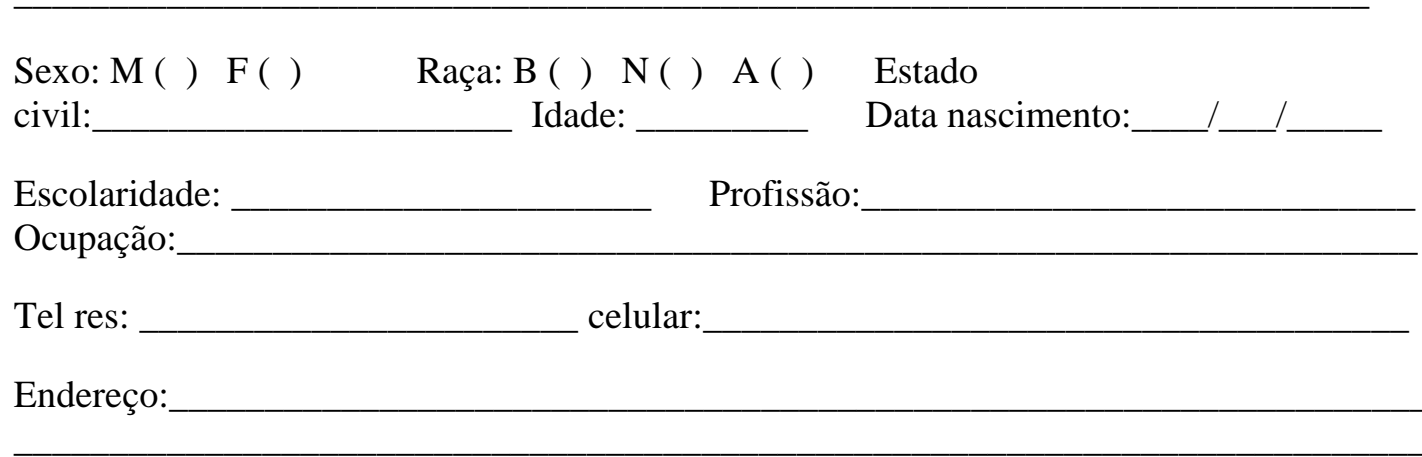

\section{Hábitos e comorbidades}

Tabaismo: ( ) não ( ) sim ( ) ex FA: ( ) não ( ) sim DM: ( ) não ( ) sim Atividade física: ( ) não ( ) sim freqüência Ronco: ( ) não ( ) sim HAS: ( ) não ( ) sim PCR: : ( ) não ( ) sim cirurgia: : ( ) não ( ) sim CDI: : ( ) não ( ) sim marcapasso: : ( ) não ( ) sim

Medicações: dose: dose: dose: dose:

\section{História familiar (parentes de 1 grau):}

IAM: ( ) não ( ) sim - idade do evento:

Morte súbita: ( ) não ( ) sim - idade do evento:

\section{Exame físico:}

Peso (Kg):

Pescoço $(\mathrm{cm})$ :

PAS (mmHg):

CF (NYHA): ( ) I ( )II ( )III ( )IV
$\operatorname{IMC}\left(\mathrm{Kg} / \mathrm{m}^{2}\right)$ :

FC (bpm):

PAM (mmHg)

Berlin: ; Pittsburgh: ; Epworth: ; Borg: 
Mallampati: ( ) I ( )II ( )III ( )IV Queixas nasais:

\section{Dados importantes do ECO basal:}

\section{Protocolo}

\section{Aquisição:}

Basal: início fim (comput) - tempo de aquisição:

ECO Basal: início fim (comput) - tempo de aquisição:

Valsalva (mitral): início fim (comput) - tempo de aquisição

Positiva ( ) negativa ( )

Muller (mitral): início fim (comput) - tempo de aquisição:

Positiva ( ) negativa ( )

Valsalva (grad): início fim (comput) - tempo de aquisição:

Gradiente: $\mathrm{mmHg}$

Muller (grad): início fim (comput) - tempo de aquisição:

Gradiente: $\mathrm{mmHg}$

CPAP agudo 1: início fim (comput) tempo de aquisição:

CPAP 20 minutos 1: início fim (comput) tempo de aquisição:

Intervalo: início fim (comput) tempo de aquisição:

CPAP agudo 2: início fim (comput) tempo de aquisição:

CPAP 20 minutos 2: início fim (comput) tempo de aquisição: fim (comput) tempo de aquisição: 
7. Dados importantes ECO com CPAP agudo 1:

8. Dados importantes ECO com CPAP 20`1:

9. Dados importantes ECO com CPAP agudo 2:

10. Dados importantes ECO com CPAP 20`2:

11. Exames: 


\begin{tabular}{|l|l|}
\hline Nome: & RG-HC \\
\hline & DATA \\
\hline
\end{tabular}

1-Seu peso mudou nos últimos tempos?
$\bigcirc$ Aumentou
$\bigcirc$ Diminuiu

Não mudou

2-Você ronca?
$\bigcirc \mathrm{Sim}$
Não
Não sabe

3- Intensidade do ronco:

$\bigcirc$ Tão alto quanto a respiração

Tão alto quanto falar

Mais alto que falar

Muito alto, ouve-se do outro quarto?

4-Freqüência do ronco:
Quase todo dia
3-4 vezes por semana
1-2 vezes por semana
1-2 vezes por mês
$\bigcirc$ Nunca ou quase nunca

5-O seu ronco incomoda outras pessoas?

$\bigcirc$ Sim $\bigcirc$ Não

6-Com que freqüência suas paradas respiratórias foram percebidas?

Quase todo dia

3-4 vezes por semana

1-2 vezes por semana

1-2 vezes por mês

Nunca ou quase nunca

Não aplicável - o paciente dorme só
7-Você se sente cansado ao acordar?
Quase todo dia
3-4 vezes por semana
1-2 vezes por semana
1-2 vezes por mês
$\bigcirc$ Nunca ou quase nunca

8- Você se sente cansado durante o dia?

$\bigcirc$ Quase todo dia

3-4 vezes por semana

1-2 vezes por semana

1-2 vezes por mês

$\bigcirc$ Nunca ou quase nunca

9- Você alguma vez dormiu enquanto dirigia?
$\bigcirc \mathrm{Sim}$
Não
$\bigcirc$ Não aplicável

10-Você tem pressão alta?
$\bigcirc$ Sim
$\bigcirc$ Não
Não sabe

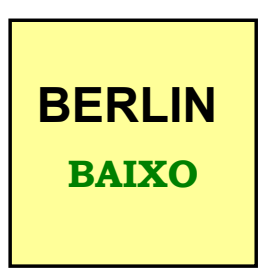

BERLIN

ALTO

\begin{tabular}{|c|c|c|c|c|}
\hline SITUAÇÃO & \multicolumn{4}{|c|}{ CHANCE DE COCHILAR } \\
\hline Sentado e lendo & 0 & 1 & 2 & 3 \\
\hline Assistindo TV & 0 & 1 & 2 & 3 \\
\hline Sentado em um lugar público (Ex: sala de espera, cinema, igreja, etc) & 0 & 1 & 2 & 3 \\
\hline Como passageiro de trem, carro ou ônibus, andando 1 hora sem parar & 0 & 1 & 2 & 3 \\
\hline Deitando-se para descansar à tarde, quando as circunstâncias permitem & 0 & 1 & 2 & 3 \\
\hline Sentado e conversando com alguém & 0 & 1 & 2 & 3 \\
\hline Sentado calmamente após o almoço (sem álcool) & 0 & 1 & 2 & 3 \\
\hline $\begin{array}{l}\text { Dentro de um carro, enquanto para por alguns minutos ao pegar trânsito } \\
\text { intenso }\end{array}$ & 0 & 1 & 2 & 3 \\
\hline EPWORTH & & & & \\
\hline
\end{tabular}




\section{ÍNDICE DE QUALIDADE DO SONO DE PITTSBURGH}

Nome:

Código: Data de nascimento:

Data do preenchimento:

Instruções:

1) As questões a seguir são referentes aos hábitos de sono apenas durante o mês passado.

2) Suas respostas devem indicar o mais corretamente possível o que aconteceu na maioria dos dias e noites do mês passado.

3) Por favor, responda a todas as questões.

1) Durante o mês passado, à que horas você foi deitar à noite na maioria das vezes? HORÁRIO DE DEITAR:

2) Durante o mês passado, quanto tempo (em minuto) você demorou para pegar no sono, na maioria das vezes?

QUANTOS MINUTOS DEMOROU PARA PEGAR NO SONO:

3) Durante o mês passado, a que horas você acordou de manhã, na maioria das vezes? HORÁRIO DE ACORDAR:

4) Durante o mês passado, quantas horas de sono por noite você dormiu? (pode ser diferente do número de horas que você ficou na cama)

HORAS DE SONO POR NOITE:

Para cada uma das questões seguinte escolha uma única resposta, que você ache mais correta. Por favor, responda a todas as questões.

5) Durante o mês passado, quantas vezes você teve problemas para dormir por causa de:

a) Demorar mais de 30 minutos para pegar no sono

( )nenhuma vez ( )menos de uma vez por semana

( )uma ou duas vezes por semana( )três vezes por semana ou mais

b) Acordar no meio da noite ou de manhã muito cedo

( )nenhuma vez ( )menos de uma vez por semana

( )uma ou duas vezes por semana( )três vezes por semana ou mais

c) Levantar-se para ir ao banheiro

( )nenhuma vez

)menos de uma vez por semana

( )uma ou duas vezes por semana( )três vezes por semana ou mais

d) Ter dificuldade para respirar

( )nenhuma vez ( )menos de uma vez por semana

( )uma ou duas vezes por semana( )três vezes por semana ou mais

e) Tossir ou roncar muito alto

( )nenhuma vez ( )menos de uma vez por semana

( )uma ou duas vezes por semana( )três vezes por semana ou mais

f) Sentir muito frio

( )nenhuma vez ( )menos de uma vez por semana

( )uma ou duas vezes por semana( )três vezes por semana ou mais

g) Sentir muito calor

( )nenhuma vez ( )menos de uma vez por semana

( )uma ou duas vezes por semana( )três vezes por semana ou mais

h)Ter sonhos ruins ou pesadelos

( )nenhuma vez

( )menos de uma vez por semana 
( ) luma ou duas vezes por semana( )três vezes por semana ou mais

i) Sentir dores

( )nenhuma vez ( )menos de uma vez por semana

( )uma ou duas vezes por semana( )três vezes por semana ou mais

j)Outra razão, por favor, descreva:

Quantas vezes você teve problemas para dormir por esta razão durante o mês passado?

( )nenhuma vez ( )menos de uma vez por semana

( )uma ou duas vezes por semana( )três vezes por semana ou mais

6) Durante o mês passado, como você classificaria a qualidade do seu sono?
( )Muito boa
( )Boa
( )ruim
( )muito ruim

7) Durante o mês passado, você tomou algum remédio para dormir, receitado pelo médico, ou indicado por outra pessoa (farmacêutico, amigo, familiar) ou mesmo por sua conta?
( )nenhuma vez
( )menos de uma vez por semana
( )uma ou duas vezes por semana( )três vezes por semana ou mais
Qual(is)?

8) Durante o mês passado, se você teve problemas para ficar acordado enquanto estava dirigindo, fazendo suas refeições ou participando de qualquer outra atividade social, quantas vezes isso aconteceu?

( )nenhuma vez
( )uma ou duas vezes por semana( )três vezes por semana ou mais

9) Durante o mês passado, você sentiu indisposição ou falta de entusiasmo para realizar suas atividades diárias?

( )Nenhuma indisposição nem falta de entusiasmo

( )indisposição e falta de entusiasmo pequenas

( )Indisposição e falta de entusiasmo moderadas

( ) muita indisposição e falta de entusiasmo

Comentários do entrevistado (se houver):
10) Você cochila?
( ) Não ( ) Sim
Comentário do entrevistado (se houver):

Caso Sim -Você cochila intencionalmente, ou seja, pôr que quer?
( ) Não
( ) Sim

Comentários do entrevistado (se houver):

Para você, cochilar é

( ) Um prazer ( )Uma necessidade $\quad$ ( )Outro - qual?
Comentários do entrevistado (se houver): 
Nome: Protocolo:

\section{Specific Activity Scale - SAS Avaliaçăo da NVHA}

(Goldm an L, Hashim oto B, Cook EF, Loscako A Circulation 1981;64:1227-1234)

Vocè pode subir um lance de esca das ( 8 degrans) sem parar?

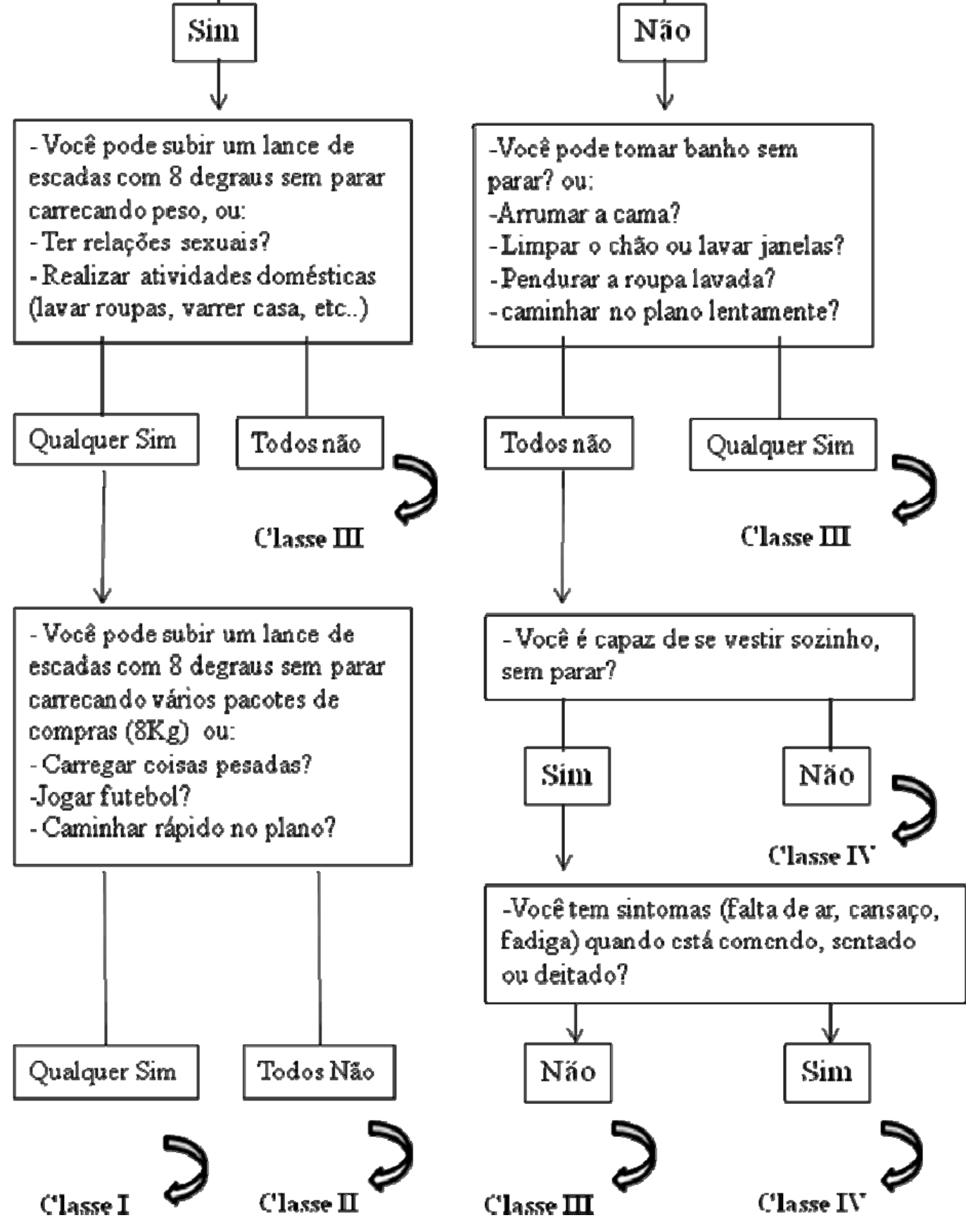


Referências 


\section{Referências}

1. Maron BJ. Hypertrophic cardiomyopathy. Lancet. 1997;350(9071):127-33.

2. Maron BJ. Hypertrophic cardiomyopathy: a systematic review. JAMA. 2002;287(10):1308-20.

3. Gersh BJ, Maron BJ, Bonow RO, Dearani JA, Fifer MA, Link MS, et al. 2011 ACCF/AHA guideline for the diagnosis and treatment of hypertrophic cardiomyopathy: a report of the American College of Cardiology Foundation/American Heart Association Task Force on Practice Guidelines. Circulation. 2011;124(24):e783-831.

4. Maron BJ, Seidman CE, Ackerman MJ, Towbin JA, Maron MS, Ommen SR, et al. How should hypertrophic cardiomyopathy be classified?: What's in a name? Dilemmas in nomenclature characterizing hypertrophic cardiomyopathy and left ventricular hypertrophy. Circ Cardiovasc Genet. 2009;2(1):81-5; discussion 6 .

5. Bos JM, Towbin JA, Ackerman MJ. Diagnostic, prognostic, and therapeutic implications of genetic testing for hypertrophic cardiomyopathy. J Am Coll Cardiol. 2009;54(3):201-11.

6. Hoss AJ, Petterson CH, Scherer L. [Hypertrophic cardiomyopathy. Role of Doppler echocardiography in the diagnosis and therapeutic approach]. Arq Bras Cardiol. 1998;70(4):301-6.

7. Brounwald E. Tratado de Medicina Cardiovascular: Editora Roca, São Paulo; 1996.

8. Chun EJ, Choi SI, Jin KN, Kwag HJ, Kim YJ, Choi BW, et al. Hypertrophic cardiomyopathy: assessment with MR imaging and multidetector CT. Radiographics. 2010;30(5):1309-28. 
9. Schwammenthal E, Nakatani S, He S, Hopmeyer J, Sagie A, Weyman AE, et al. Mechanism of mitral regurgitation in hypertrophic cardiomyopathy: mismatch of posterior to anterior leaflet length and mobility. Circulation. 1998;98(9):856-65.

10. Simon AL, Ross J, Gault JH. Angiographic anatomy of the left ventricle and mitral valve in idiopathic hypertrophic subaortic stenosis. Circulation. 1967;36(6):852-67.

11. Jiang $L$, Levine RA, King ME, Weyman $A E$. An integrated mechanism for systolic anterior motion of the mitral valve in hypertrophic cardiomyopathy based on echocardiographic observations. Am Heart J. 1987;113(3):633-44.

12. Hwang HJ, Choi EY, Kwan J, Kim SA, Shim CY, Ha JW, et al. Dynamic change of mitral apparatus as potential cause of left ventricular outflow tract obstruction in hypertrophic cardiomyopathy. Eur $\mathrm{J}$ Echocardiogr. 2011;12(1):19-25.

13. Cavalcante JL, Barboza JS, Lever HM. Diversity of mitral valve abnormalities in obstructive hypertrophic cardiomyopathy. Prog Cardiovasc Dis. 2012;54(6):517-22.

14. Fifer MA. Controversies in cardiovascular medicine. Most fully informed patients choose septal ablation over septal myectomy. Circulation. 2007;116(2):207-16; discussion 16.

15. Minakata K, Dearani JA, Nishimura RA, Maron BJ, Danielson GK. Extended septal myectomy for hypertrophic obstructive cardiomyopathy with anomalous mitral papillary muscles or chordae. J Thorac Cardiovasc Surg. $2004 ; 127(2): 481-9$.

16. Albanesi-Filho FM. Hypertrophic Cardiomyopathy: Concepts and Classification. Arq Bras Cardiol. 1996;66(2):4. 
17. Zou Y, Song L, Wang Z, Ma A, Liu T, Gu H, et al. Prevalence of idiopathic hypertrophic cardiomyopathy in China: a population-based echocardiographic analysis of 8080 adults. Am J Med. 2004;116(1):14-8.

18. Olivotto I, Maron BJ, Cecchi F. Clinical significance of atrial fibrillation in hypertrophic cardiomyopathy. Curr Cardiol Rep. 2001;3(2):141-6.

19. Olivotto I, Cecchi F, Casey SA, Dolara A, Traverse JH, Maron BJ. Impact of atrial fibrillation on the clinical course of hypertrophic cardiomyopathy. Circulation. 2001;104(21):2517-24.

20. Maron BJ. The 2009 international hypertrophic cardiomyopathy summit. Am J Cardiol. 2010;105(8):1164-8.

21. Kubo T, Kitaoka H, Okawa M, Matsumura Y, Hitomi N, Yamasaki N, et al. Lifelong left ventricular remodeling of hypertrophic cardiomyopathy caused by a founder frameshift deletion mutation in the cardiac Myosin-binding protein C gene among Japanese. J Am Coll Cardiol. 2005;46(9):1737-43.

22. Nistri S, Olivotto I, Betocchi S, Losi MA, Valsecchi G, Pinamonti B, et al. Prognostic significance of left atrial size in patients with hypertrophic cardiomyopathy (from the Italian Registry for Hypertrophic Cardiomyopathy). Am J Cardiol. 2006;98(7):960-5.

23. Yang $H$, Woo A, Monakier D, Jamorski M, Fedwick $K$, Wigle ED, et al. Enlarged left atrial volume in hypertrophic cardiomyopathy: a marker for disease severity. J Am Soc Echocardiogr. 2005;18(10):1074-82.

24. Arteaga E, lanni BM, Fernandes F, Mady C. Benign outcome in a long-term follow-up of patients with hypertrophic cardiomyopathy in Brazil. Am Heart J. 2005;149(6):1099-105.

25. Shah PM, Adelman AG, Wigle ED, Gobel FL, Burchell HB, Hardarson T, et al. The natural (and unnatural) history of hypertrophic obstructive cardiomyopathy. Circ Res. 1974;35(2):suppl II:179-95. 
26. Cecchi F, Olivotto I, Montereggi A, Santoro G, Dolara A, Maron BJ. Hypertrophic cardiomyopathy in Tuscany: clinical course and outcome in an unselected regional population. J Am Coll Cardiol. 1995;26(6):1529-36.

27. Maron BJ, Gardin JM, Flack JM, Gidding SS, Kurosaki TT, Bild DE. Prevalence of hypertrophic cardiomyopathy in a general population of young adults. Echocardiographic analysis of 4111 subjects in the CARDIA Study. Coronary Artery Risk Development in (Young) Adults. Circulation. 1995;92(4):785-9.

28. Geske JB, Sorajja P, Ommen SR, Nishimura RA. Left ventricular outflow tract gradient variability in hypertrophic cardiomyopathy. Clin Cardiol. 2009;32(7):397-402.

29. Cheng TO. Mechanisms of variability of left ventricular outflow tract gradient in hypertrophic cardiomyopathy. Int J Cardiol. 2010;145(2):169-71.

30. Hagège $A A$, Bruneval $P$, Levine RA, Desnos $M$, Neamatalla $H$, Judge DP. The mitral valve in hypertrophic cardiomyopathy: old versus new concepts. J Cardiovasc TransI Res. 2011;4(6):757-66.

31. Grigg LE, Wigle ED, Williams WG, Daniel LB, Rakowski H. Transesophageal Doppler echocardiography in obstructive hypertrophic cardiomyopathy: clarification of pathophysiology and importance in intraoperative decision making. J Am Coll Cardiol. 1992;20(1):42-52.

32. Maron MS, Olivotto I, Zenovich AG, Link MS, Pandian NG, Kuvin JT, et al. Hypertrophic cardiomyopathy is predominantly a disease of left ventricular outflow tract obstruction. Circulation. 2006;114(21):2232-9.

33. Seggewiss H, Faber L, Gleichmann U. Percutaneous transluminal septal ablation in hypertrophic obstructive cardiomyopathy. Thorac Cardiovasc Surg. $1999 ; 47(2): 94-100$. 
34. Maron BJ, McKenna WJ, Danielson GK, Kappenberger LJ, Kuhn HJ, Seidman CE, et al. American College of Cardiology/European Society of Cardiology clinical expert consensus document on hypertrophic cardiomyopathy. A report of the American College of Cardiology Foundation Task Force on Clinical Expert Consensus Documents and the European Society of Cardiology Committee for Practice Guidelines. J Am Coll Cardiol. 2003;42(9):1687-713.

35. Sleep-related breathing disorders in adults: recommendations for syndrome definition and measurement techniques in clinical research. The Report of an American Academy of Sleep Medicine Task Force. Sleep. 1999;22(5):66789.

36. Bradley TD, Floras JS. Sleep apnea and heart failure: Part I: obstructive sleep apnea. Circulation. 2003;107(12):1671-8.

37. Somers VK, Dyken ME, Clary MP, Abboud FM. Sympathetic neural mechanisms in obstructive sleep apnea. J Clin Invest. 1995;96(4):1897-904.

38. Basoglu OK, Sarac F, Sarac S, Uluer H, Yilmaz C. Metabolic syndrome, insulin resistance, fibrinogen, homocysteine, leptin, and C-reactive protein in obese patients with obstructive sleep apnea syndrome. Ann Thorac Med. 2011;6(3):120-5.

39. Jelic S, Lederer DJ, Adams T, Padeletti M, Colombo PC, Factor PH, et al. Vascular inflammation in obesity and sleep apnea. Circulation. 2010;121(8):1014-21.

40. Drager LF, Bortolotto LA, Lorenzi MC, Figueiredo AC, Krieger EM, LorenziFilho G. Early signs of atherosclerosis in obstructive sleep apnea. Am J Respir Crit Care Med. 2005;172(5):613-8. 
41. Drager LF, Bortolotto LA, Figueiredo AC, Silva BC, Krieger EM, Lorenzi-Filho G. Obstructive sleep apnea, hypertension, and their interaction on arterial stiffness and heart remodeling. Chest. 2007;131(5):1379-86.

42. Banno K, Shiomi T, Sasanabe R, Otake K, Hasegawa R, Maekawa M, et al. Sleep-disordered breathing in patients with idiopathic cardiomyopathy. Circulation Journal. 2004;68(4):338-42.

43. Eleid MF, Konecny T, Orban M, Sengupta PP, Somers VK, Parish JM, et al. High Prevalence of Abnormal Nocturnal Oximetry in Patients With Hypertrophic Cardiomyopathy. Journal of the American College of Cardiology. 2009;54(19):1805-9.

44. Pedrosa RP, Drager LF, Genta PR, Amaro ACS, Antunes MO, Matsumoto AY, et al. Obstructive Sleep Apnea Is Common and Independently Associated With Atrial Fibrillation in Patients With Hypertrophic Cardiomyopathy. Chest. 2010;137(5):1078-84.

45. Konecny T, Brady PA, Orban M, Lin G, Pressman GS, Lehar F, et al. Interactions Between Sleep Disordered Breathing and Atrial Fibrillation in Patients With Hypertrophic Cardiomyopathy. American Journal of Cardiology. 2010;105(11):1597-602.

46. Prinz C, Bitter T, Oldenburg O, Horstkotte D, Faber L. Incidence of sleepdisordered breathing in patients with hypertrophic cardiomyopathy. Congest Heart Fail. 2011;17(1):19-24.

47. Limbruno U, Strata G, Zucchi R, Baglini R, Mengozzi G, Balbarini A, et al. Altered autonomic cardiac control in hypertrophic cardiomyopathy. Role of outflow tract obstruction and myocardial hypertrophy. Eur Heart J. 1998;19(1):146-53.

48. Sengupta PP, Sorajja D, Eleid MF, Somers VK, Ommen SR, Parish JM, et al. Hypertrophic obstructive cardiomyopathy and sleep-disordered breathing: 
an unfavorable combination. Nature Clinical Practice Cardiovascular Medicine. 2009;6(1):14-5.

49. Shivalkar B, Van de Heyning C, Kerremans M, Rinkevich D, Verbraecken J, De Backer W, et al. Obstructive sleep apnea syndrome: more insights on structural and functional cardiac alterations, and the effects of treatment with continuous positive airway pressure. J Am Coll Cardiol. 2006;47(7):1433-9.

50. Usui K, Parker JD, Newton GE, Floras JS, Ryan CM, Bradley TD. Left ventricular structural adaptations to obstructive sleep apnea in dilated cardiomyopathy. Am J Respir Crit Care Med. 2006;173(10):1170-5.

51. Drager LF, Bortolotto LA, Pedrosa RP, Krieger EM, Lorenzi-Filho G. Left atrial diameter is independently associated with arterial stiffness in patients with obstructive sleep apnea: potential implications for atrial fibrillation. Int $\mathrm{J}$ Cardiol. 2010;144(2):257-9.

52. Otto ME, Belohlavek M, Romero-Corral A, Gami AS, Gilman G, Svatikova A, et al. Comparison of cardiac structural and functional changes in obese otherwise healthy adults with versus without obstructive sleep apnea. Am J Cardiol. 2007;99(9):1298-302.

53. Rössner S, Lagerstrand L, Persson HE, Sachs C. The sleep apnoea syndrome in obesity: risk of sudden death. J Intern Med. 1991;230(2):13541.

54. Gami AS, Howard DE, Olson EJ, Somers VK. Day-night pattern of sudden death in obstructive sleep apnea. N Engl J Med. 2005;352(12):1206-14.

55. Maron BJ, Olivotto I, Spirito P, Casey SA, Bellone P, Gohman TE, et al. Epidemiology of hypertrophic cardiomyopathy-related death: revisited in a large non-referral-based patient population. Circulation. 2000;102(8):858-64 .

56. Nerbass FB, Pedrosa RP, Danzi-Soares NJ, Drager LF, Arteaga-Fernández E, Lorenzi-Filho G. Obstructive sleep apnea and hypertrophic 
cardiomyopathy: a common and potential harmful combination. Sleep Med Rev. 2013;17(3):201-6.

57. Basner RC. Continuous positive airway pressure for obstructive sleep apnea. N Engl J Med. 2007;356(17):1751-8.

58. Cuhadaroğlu C, Utkusavaş A, Oztürk L, Salman S, Ece T. Effects of nasal CPAP treatment on insulin resistance, lipid profile, and plasma leptin in sleep apnea. Lung. 2009;187(2):75-81.

59. Phillips CL, Yang Q, Williams A, Roth M, Yee BJ, Hedner JA, et al. The effect of short-term withdrawal from continuous positive airway pressure therapy on sympathetic activity and markers of vascular inflammation in subjects with obstructive sleep apnoea. J Sleep Res. 2007;16(2):217-25.

60. Drager LF, Bortolotto LA, Figueiredo AC, Krieger EM, Lorenzi GF. Effects of continuous positive airway pressure on early signs of atherosclerosis in obstructive sleep apnea. Am J Respir Crit Care Med. 2007;176(7):706-12.

61. Pepperell JC, Ramdassingh-Dow S, Crosthwaite N, Mullins R, Jenkinson C, Stradling JR, et al. Ambulatory blood pressure after therapeutic and subtherapeutic nasal continuous positive airway pressure for obstructive sleep apnoea: a randomised parallel trial. Lancet. 2002;359(9302):204-10.

62. Drager LF, Pedrosa RP, Diniz PM, Diegues-Silva L, Marcondes B, Couto $R B$, et al. The effects of continuous positive airway pressure on prehypertension and masked hypertension in men with severe obstructive sleep apnea. Hypertension. 2011;57(3):549-55.

63. Bazzano LA, Khan Z, Reynolds K, He J. Effect of nocturnal nasal continuous positive airway pressure on blood pressure in obstructive sleep apnea. Hypertension. 2007;50(2):417-23.

64. Haentjens P, Van Meerhaeghe A, Moscariello A, De Weerdt S, Poppe K, Dupont A, et al. The impact of continuous positive airway pressure on blood 
pressure in patients with obstructive sleep apnea syndrome: evidence from a meta-analysis of placebo-controlled randomized trials. Arch Intern Med. $2007 ; 167(8): 757-64$.

65. Chobanian AV, Bakris GL, Black HR, Cushman WC, Green LA, Izzo JL, et al. Seventh report of the Joint National Committee on Prevention, Detection, Evaluation, and Treatment of High Blood Pressure. Hypertension. 2003;42(6):1206-52.

66. Pedrosa RP, Drager LF, de Paula LK, Amaro AC, Bortolotto LA, LorenziFilho G. Effects of OSA treatment on BP in patients with resistant hypertension: a randomized trial. Chest. 2013;144(5):1487-94.

67. Marin JM, Carrizo SJ, Vicente E, Agusti AG. Long-term cardiovascular outcomes in men with obstructive sleep apnoea-hypopnoea with or without treatment with continuous positive airway pressure: an observational study. Lancet. 2005;365(9464):1046-53.

68. Dragosauac D. Interação Cardiopulmonar Carvalho CRR, editor. São Paulo: Editora Atheneu; 2000.

69. Antonescu-Turcu A, Parthasarathy S. CPAP and bi-level PAP therapy: new and established roles. Respir Care. 2010;55(9):1216-29.

70. Akosah KO, McHugh VL, Mathiason MA, Kallies KJ, Pinter R, Thayer VB. Closing the heart failure management gap in the community: managing hypotension and impact on outcomes. J Card Fail. 2009;15(10):906-11.

71. Epstein LJ, Kristo D, Strollo PJ, Friedman N, Malhotra A, Patil SP, et al. Clinical guideline for the evaluation, management and long-term care of obstructive sleep apnea in adults. J Clin Sleep Med. 2009;5(3):263-76.

72. Grundy SM, Cleeman JI, Daniels SR, Donato KA, Eckel RH, Franklin BA, et al. Diagnosis and management of the metabolic syndrome: an American 
Heart Association/National Heart, Lung, and Blood Institute Scientific Statement. Circulation. 2005;112(17):2735-52.

73. V Diretrizes Brasileiras de Hipertensão Arterial. 2011. p. e24-e70.

74. Jensen MK, Havndrup O, Pecini R, Dalsgaard M, Hassager C, Helqvist S, et al. Comparison of Valsalva manoeuvre and exercise in echocardiographic evaluation of left ventricular outflow tract obstruction in hypertrophic cardiomyopathy. Eur J Echocardiogr. 2010;11(9):763-9.

75. Lang RM, Bierig M, Devereux RB, Flachskampf FA, Foster E, Pellikka PA, et al. Recommendations for chamber quantification. Eur $\mathrm{J}$ Echocardiogr. 2006;7(2):79-108.

76. Rodway GW, Weaver TE, Mancini C, Cater J, Maislin G, Staley B, et al. Evaluation of sham-CPAP as a placebo in CPAP intervention studies. Sleep. 2010;33(2):260-6.

77. Hukins CA. Arbitrary-pressure continuous positive airway pressure for obstructive sleep apnea syndrome. Am J Respir Crit Care Med. 2005;171(5):500-5.

78. Portapres Model-2 User`s Guide. In: Instrumentation T-TB, editor. 1999.

79. Bos WJ, Imholz BP, van Goudoever J, Wesseling KH, van Montfrans GA. The reliability of noninvasive continuous finger blood pressure measurement in patients with both hypertension and vascular disease. Am J Hypertens. 1992;5(8):529-35.

80. Idema RN, van den Meiracker AH, Imholz BP, Man in 't Veld AJ, Settels JJ, Ritsema van Eck HJ, et al. Comparison of Finapres non-invasive beat-tobeat finger blood pressure with intrabrachial artery pressure during and after bicycle ergometry. J Hypertens Suppl. 1989;7(6):S58-9. 
81. Rongen GA, Bos WJ, Lenders JW, van Montfrans GA, van Lier HJ, van Goudoever J, et al. Comparison of intrabrachial and finger blood pressure in healthy elderly volunteers. Am J Hypertens. 1995;8(3):237-48.

82. Devereux RB, Alonso DR, Lutas EM, Gottlieb GJ, Campo E, Sachs I, et al. Echocardiographic assessment of left ventricular hypertrophy: comparison to necropsy findings. Am J Cardiol. 1986;57(6):450-8.

83. Wandt B, Bojö L, Tolagen K, Wranne B. Echocardiographic assessment of ejection fraction in left ventricular hypertrophy. Heart. 1999;82(2):192-8.

84. Shan K, Bick RJ, Poindexter BJ, Shimoni S, Letsou GV, Reardon MJ, et al. Relation of tissue Doppler derived myocardial velocities to myocardial structure and beta-adrenergic receptor density in humans. J Am Coll Cardiol. 2000;36(3):891-6.

85. Helmcke F, Nanda NC, Hsiung MC, Soto B, Adey CK, Goyal RG, et al. Color Doppler assessment of mitral regurgitation with orthogonal planes. Circulation. 1987;75(1):175-83.

86. Pena JL, da Silva MG, Faria SC, Salemi VM, Mady C, Baltabaeva A, et al. Quantification of regional left and right ventricular deformation indices in healthy neonates by using strain rate and strain imaging. $J$ Am Soc Echocardiogr. 2009;22(4):369-75.

87. Iber C, Chesson AL, Quan SF. The AASM Manual for the scoring of sleep and associated events: rules, terminology and technical specifications: American Academy of Sleep Medicine.2007.

88. Maron BJ, Tholakanahalli VN, Zenovich AG, Casey SA, Duprez D, Aeppli DM, et al. Usefulness of B-type natriuretic peptide assay in the assessment of symptomatic state in hypertrophic cardiomyopathy. Circulation. 2004;109(8):984-9. 
89. Panou FK, Kotseroglou VK, Lakoumentas JA, Chrysanthopoulou SA, Armeniakos JA, Stratigou T, et al. Significance of brain natriuretic peptide in the evaluation of symptoms and the degree of left ventricular diastolic dysfunction in patients with hypertrophic cardiomyopathy. Hellenic J Cardiol. 2006;47(6):344-51.

90. Johns MW. A new method for measuring daytime sleepiness: the Epworth sleepiness scale. Sleep. 1991;14(6):540-5.

91. Netzer NC, Stoohs RA, Netzer CM, Clark K, Strohl KP. Using the Berlin Questionnaire to identify patients at risk for the sleep apnea syndrome. Ann Intern Med. 1999;131(7):485-91.

92. Buysse DJ, Reynolds CF, Monk TH, Berman SR, Kupfer DJ. The Pittsburgh Sleep Quality Index: a new instrument for psychiatric practice and research. Psychiatry Res. 1989;28(2):193-213.

93. Goldman L, Hashimoto B, Cook EF, Loscalzo A. Comparative reproducibility and validity of systems for assessing cardiovascular functional class: advantages of a new specific activity scale. Circulation. 1981;64(6):1227-34.

94. Magalhães MN, Lima ACP. Noções de Probabilidade Estatística. São Paulo2000.

95. Pinheiro JC, Bates DM. Mixed-Effects Models in S and S-PLUS. Springer; 2000. p. 528.

96. Russo C, Hahn RT, Jin Z, Homma S, Sacco RL, Di Tullio MR. Comparison of echocardiographic single-plane versus biplane method in the assessment of left atrial volume and validation by real time three-dimensional echocardiography. J Am Soc Echocardiogr. 2010;23(9):954-60.

97. Bland JM, Altman DG. Statistical methods for assessing agreement between two methods of clinical measurement. Lancet. 1986;1(8476):307-10. 
98. Yamada T, Takeda J, Satoh M, Koyama K, Hashiguchi S, Yokoi M. Effect of positive end-expiratory pressure on left and right ventricular diastolic filling assessed by transoesophageal Doppler echocardiography. Anaesth Intensive Care. 1999;27(4):341-5.

99. Oh JK, Sewards JB, Jamil-Tajik A. The Echo Manual - From the Mayo Clinic: Editora Médica e Científica Ltda; 1997.

100. Nagueh SF, Appleton CP, Gillebert TC, Marino PN, Oh JK, Smiseth OA, et al. Recommendations for the evaluation of left ventricular diastolic function by echocardiography. Eur J Echocardiogr. 2009;10(2):165-93.

101. Palazzuoli A, Gallotta M, Quatrini I, Nuti R. Natriuretic peptides (BNP and NT-proBNP): measurement and relevance in heart failure. Vasc Health Risk Manag. 2010;6:411-8.

102. Takeuchi I, Inomata T, Nishii M, Koitabashi T, Nakano H, Shinagawa H, et al. Clinical characteristics of heart disease patients with a good prognosis in spite of markedly increased plasma levels of type-B natriuretic peptide (BNP): anomalous behavior of plasma BNP in hypertrophic cardiomyopathy. Circ J. 2005;69(3):277-82.

103. Hasegawa K, Fujiwara H, Doyama K, Miyamae M, Fujiwara T, Suga S, et al. Ventricular expression of brain natriuretic peptide in hypertrophic cardiomyopathy. Circulation. 1993;88(2):372-80.

104. Pedrosa RP, Lima SG, Drager LF, Genta PR, Amaro ACS, Antunes MO, et al. Sleep Quality and Quality of Life in Patients with Hypertrophic Cardiomyopathy. Cardiology. 2010;117(3):200-6.

105. Nerbass FB, Pedrosa RP, Genta PR, Antunes MO, Arteaga-Fernández E, Drager LF, et al. Lack of reliable clinical predictors to identify obstructive sleep apnea in patients with hypertrophic cardiomyopathy. Clinics (Sao Paulo). 2013;68(7):992-6. 
106. Sherrid MV, Gunsburg DZ, Moldenhauer S, Pearle G. Systolic anterior motion begins at low left ventricular outflow tract velocity in obstructive hypertrophic cardiomyopathy. J Am Coll Cardiol. 2000;36(4):1344-54.

107. Woo A, Jedrzkiewicz S. The mitral valve in hypertrophic cardiomyopathy: it's a long story. Circulation. 2011;124(1):9-12.

108. Geske JB, Sorajja P, Nishimura RA, Ommen SR. Evaluation of left ventricular filling pressures by Doppler echocardiography in patients with hypertrophic cardiomyopathy: correlation with direct left atrial pressure measurement at cardiac catheterization. Circulation. 2007;116(23):2702-8.

109. Geske JB, Sorajja P, Nishimura RA, Ommen SR. The relationship of left atrial volume and left atrial pressure in patients with hypertrophic cardiomyopathy: an echocardiographic and cardiac catheterization study. J Am Soc Echocardiogr. 2009;22(8):961-6.

110. Bauer F, Shiota T, White RD, Lever HM, Qin JX, Drinko J, et al. Determinant of left atrial dilation in patients with hypertrophic cardiomyopathy: a real-time 3-dimensional echocardiographic study. J Am Soc Echocardiogr. 2004;17(9):968-75.

111. Tkacova R, Liu PP, Naughton MT, Bradley TD. Effect of continuous positive airway pressure on mitral regurgitant fraction and atrial natriuretic peptide in patients with heart failure. J Am Coll Cardiol. 1997;30(3):739-45.

112. Douglas PS. The left atrium: a biomarker of chronic diastolic dysfunction and cardiovascular disease risk. J Am Coll Cardiol. 2003;42(7):1206-7.

113. Maron BJ, Olivotto I, Bellone P, Conte MR, Cecchi F, Flygenring BP, et al. Clinical profile of stroke in 900 patients with hypertrophic cardiomyopathy. $\mathrm{J}$ Am Coll Cardiol. 2002;39(2):301-7. 
114. Tian T, Wang Y, Sun K, Wang J, Zou Y, Zhang W, et al. Clinical profile and prognostic significance of atrial fibrillation in hypertrophic cardiomyopathy. Cardiology. 2013;126(4):258-64.

115. Smeding L, Lust E, Plötz FB, Groeneveld AB. Clinical implications of heartlung interactions. Neth J Med. 2010;68(2):56-61.

116. Koolen JJ, Visser CA, Wever E, van Wezel H, Meyne NG, Dunning AJ. Transesophageal two-dimensional echocardiographic evaluation of biventricular dimension and function during positive end-expiratory pressure ventilation after coronary artery bypass grafting. Am $\mathrm{J}$ Cardiol. $1987 ; 59(12): 1047-51$.

117. Mitaka C, Nagura T, Sakanishi N, Tsunoda Y, Amaha K. Two-dimensional echocardiographic evaluation of inferior vena cava, right ventricle, and left ventricle during positive-pressure ventilation with varying levels of positive end-expiratory pressure. Crit Care Med. 1989;17(3):205-10.

118. Jardin F, Delorme G, Hardy A, Auvert B, Beauchet A, Bourdarias JP. Reevaluation of hemodynamic consequences of positive pressure ventilation: emphasis on cyclic right ventricular afterloading by mechanical lung inflation. Anesthesiology. 1990;72(6):966-70.

119. DeMaria EJ, Burchard KW, Carlson DE, Gann DS. Continuous measurement of atrial volume with an impedance catheter during positive pressure ventilation and volume expansion. Surg Gynecol Obstet. 1990;170(6):501-9.

120. Kyhl K, Ahtarovski KA, Iversen K, Thomsen C, Vejlstrup N, Engstrøm T, et al. The decrease of cardiac chamber volumes and output during positivepressure ventilation. Am J Physiol Heart Circ Physiol. 2013;305(7):H1004-9.

121. Mehta S, Liu PP, Fitzgerald FS, Allidina YK, Douglas Bradley T. Effects of continuous positive airway pressure on cardiac volumes in patients with 
ischemic and dilated cardiomyopathy. Am J Respir Crit Care Med. 2000;161(1):128-34.

122. Chin JH, Lee EH, Kim WJ, Choi DK, Hahm KD, Sim JY, et al. Positive endexpiratory pressure aggravates left ventricular diastolic relaxation further in patients with pre-existing relaxation abnormality. $\mathrm{Br} J$ Anaesth. 2013;111(3):368-73.

123. Jardin F, Farcot JC, Boisante L, Curien N, Margairaz A, Bourdarias JP. Influence of positive end-expiratory pressure on left ventricular performance. N Engl J Med. 1981;304(7):387-92.

124. Haynes JB, Carson SD, Whitney WP, Zerbe GO, Hyers TM, Steele P. Positive end-expiratory pressure shifts left ventricular diastolic pressure-area curves. J Appl Physiol Respir Environ Exerc Physiol. 1980;48(4):670-6.

125. Funk DJ, Jacobsohn E, Kumar A. Role of the venous return in critical illness and shock: part II-shock and mechanical ventilation. Crit Care Med. 2013;41(2):573-9.

126. Steiner S, Schannwell CM, Strauer BE. Left ventricular response to continuous positive airway pressure: role of left ventricular geometry. Respiration. 2008;76(4):393-7.

127. Campbell P. Dynamic pulmonary hypertension in decompensated heart failure with preserved ejection fraction: is functional mitral regurgitation the driver? J Card Fail. 2013;19(11):753-5.

128. Bellone A, Barbieri A, Ricci C, lori E, Donateo M, Massobrio M, et al. Acute effects of non-invasive ventilatory support on functional mitral regurgitation in patients with exacerbation of congestive heart failure. Intensive Care Med. 2002;28(9):1348-50. 
129. Huemer G, Kolev N, Kurz A, Zimpfer M. Influence of positive end-expiratory pressure on right and left ventricular performance assessed by Doppler twodimensional echocardiography. Chest. 1994;106(1):67-73.

130. Kallet RH, Diaz JV. The physiologic effects of noninvasive ventilation. Respir Care. 2009;54(1):102-15.

131. Fewell JE, Abendschein DR, Carlson CJ, Murray JF, Rapaport E. Continuous positive-pressure ventilation decreases right and left ventricular end-diastolic volumes in the dog. Circ Res. 1980;46(1):125-32.

132. Leech JA, Ascah KJ. Hemodynamic effects of nasal CPAP examined by Doppler echocardiography. Chest. 1991;99(2):323-6.

133. Lenique $F$, Habis M, Lofaso F, Dubois-Randé JL, Harf A, Brochard L. Ventilatory and hemodynamic effects of continuous positive airway pressure in left heart failure. Am J Respir Crit Care Med. 1997;155(2):500-5.

134. Philip-Joët FF, Paganelli FF, Dutau HL, Saadjian AY. Hemodynamic effects of bilevel nasal positive airway pressure ventilation in patients with heart failure. Respiration. 1999;66(2):136-43. 
Apêndices 
CLINICAL REVIEW

\title{
Obstructive sleep apnea and hypertrophic cardiomyopathy: A common and potential harmful combination
}

\author{
Flávia B. Nerbass ${ }^{a}$, Rodrigo P. Pedrosa ${ }^{a}$, Naury J. Danzi-Soares ${ }^{a}$, Luciano F. Drager ${ }^{a}$, \\ Edmundo Arteaga-Fernández ${ }^{\mathrm{b}}$, Geraldo Lorenzi-Filho ${ }^{\mathrm{a}, *}$ \\ a Sleep Laboratory, Pulmonary Division, Heart Institute (InCor), University of São Paulo School of Medicine, Brazil \\ ${ }^{\mathrm{b}}$ Cardiomyopathy Medical Unit (Clinical Unit of Cardiomyopathies), Heart Institute (InCor), University of São Paulo School of Medicine, Brazil
}

\section{A R T I C L E I N F O}

Article history:

Received 27 September 2011

Received in revised form

3 May 2012

Accepted 26 June 2012

Available online 6 October 2012

\section{Keywords:}

Hypertrophic cardiomyopathy

Obstructive sleep apnea

Atrial fibrillation

Cardiovascular diseases

Sleep-disordered breathing

\begin{abstract}
S U M M A R Y
Hypertrophic cardiomyopathy (HCM) is the most common genetic cardiac disease and is characterized by large and asymmetric septal and left ventricle hypertrophy. HCM is a cause of disability, including heart failure, atrial fibrillation, and sudden death, with an annual mortality varying from $1 \%$ to $6 \%$. Obstructive sleep apnea (OSA) is extremely common among patients with established cardiovascular disease, including hypertension and atrial fibrillation and when present may contribute to worse cardiovascular outcome. Although patients with HCM do not necessarily have typical characteristics of patients with OSA, such as obesity and increasing age, there is recent evidence that OSA is extremely common among patients with HCM, with a prevalence ranging from $32 \%$ to $71 \%$. The presence of OSA among patients with HCM is independently associated with worse structural and functional impairment of the heart, including atrial and aorta enlargement, worse New York Heart Association functional class, and worse quality of life. The prevalence of atria fibrillation, an independent marker of mortality among patients with HCM, is significantly higher ( four times) in the presence of OSA. Therefore, the recognition of OSA is a new area of research that may impact the management of patients with HCM.
\end{abstract}

(ㄷ) 2012 Elsevier Ltd. All rights reserved.

\section{Introduction}

Hypertrophic cardiomyopathy (HCM) is the most common genetic cardiac disease and is an important cause of disability, including heart failure, atrial fibrillation (AF), and sudden death in patients of all ages. ${ }^{1}$ Patients with HCM frequently have sustained supraventricular and ventricular arrhythmia. AF is an independent determinant of HCM-related morbidity and mortality due to heart failure and stroke. ${ }^{2-4}$ Despite the recent advances in the pathophysiology of HCM, little is known about the potential role of co-morbidities that may contribute to increase of cardiovascular risk.

Obstructive sleep apnea (OSA) is the most common type of sleep-disordered breathing and is characterized by recurrent

Abbreviations: AF, atrial fibrillation; BMI, body mass index; CPAP, continuous positive airway pressure; HCM, hypertrophic cardiomyopathy; LV, left ventricle; LVOT, left ventricular outflow tract; NYHA, New York Heart Association; OSA obstructive sleep apnea; PM, portable monitor; PSG, polysomnography.

* Corresponding author. Sleep Laboratory, Pulmonary Division, Heart Institute (InCor), Av. Enéas Carvalho de Aguiar, 44 São Paulo, Brazil.

E-mail address: geraldo.lorenzi@incor.usp.br (G. Lorenzi-Filho). episodes of either partial or complete upper airway obstruction during sleep, leading to episodes of interruption of respiration associated with fragmented sleep and intermittent hypoxia. ${ }^{5}$ OSA is recognized as a major public health problem, with an estimated prevalence ranging from 4 to $32.9 \%$ in the adult population, depending on the diagnostic criteria. ${ }^{6-8}$ The prevalence of OSA is extremely high among patients with established metabolic ${ }^{9,10}$ and cardiovascular disease. ${ }^{11,12}$ For instance, the estimated prevalence of OSA among patients with hypertension, ${ }^{13,14}$ resistant hypertension, ${ }^{15} \mathrm{AF}^{16}$ and metabolic syndrome ${ }^{10}$ ranges from $30 \%$ to $90 \%$. This high prevalence of OSA among patients with established cardiovascular disease is in part explained by the fact that both share several common risk factors, such as increasing age, obesity, sedentary life, and male sex. However, there is mounting evidence that OSA is not only a frequent condition associated with cardiovascular disease due to an overlap of risk factors, but when present may causally participate in the development or aggravation of the underlying cardiovascular disease.

HCM is a genetic disease, some of these patients are diagnosed at young ages and do not necessarily possess the typical traits of patients with established metabolic and cardiovascular disease. For instance, several reports found that body mass index (BMI) in 
patients with HCM ranged from 23.3 to $24.8 \mathrm{~kg} / \mathrm{m}^{2} .^{17-21}$ Therefore, the search for OSA among patients with HCM has been largely ignored. One recent comprehensive report on research priorities in HCM did not include OSA as a potential area of research. ${ }^{22}$ However, at least five recent studies that investigated a total of 349 patients with HCM consistently found a high prevalence of OSA, ranging from $32 \%$ to $71 \%$, depending on the methodology and diagnostic criteria. $^{23-27}$ There is also evidence that the presence of OSA is independently associated with worse structural and functional impairment of the heart, including over dilation of the left atrium and aorta, higher prevalence of AF, worse New York Heart Association (NYHA) functional class, as well as quality of life. ${ }^{23-28}$ The presence of OSA among patients with HCM is therefore a new area of research that may impact the management of patients with HCM and therefore justifies this review.

\section{Hypertrophic cardiomyopathy (HCM)}

HCM is the most common genetic cardiac disease ${ }^{1}$ with an estimated prevalence of 1:500 habitants, in the general population $^{29}$ and is caused by mutations in myofilaments, calcium handling and Z-disc genes. So far, 19 genes were related with HCM, and over 900 mutations were described in those genes ${ }^{30}$ (Supplementary Table S1). HCM is characterized by pronounced and asymmetric myocardial hypertrophy, predominantly in the interventricular septum. ${ }^{31,32}$ Cardiac hypertrophy increases the intrinsic rigidity of the left ventricle (LV) wall, with impairment in relaxation and ventricular filling, resulting in diastolic dysfunction. ${ }^{32}$ The diagnosis of HCM is established using two-dimensional echocardiography, by imaging a non dilated but hypertrophied LV chamber (left ventricular wall thickness $\geq 15 \mathrm{~mm}$ or $\geq 13 \mathrm{~mm}$ in patients with a first degree relative with $\mathrm{HCM}$ ), in the absence of other diseases capable of causing hypertrophy (i.e., aortic stenosis and hypertension). ${ }^{29,33}$ In approximately $25 \%$ of HCM patients, the septum becomes so thickened that it causes obstruction to blood ejection, through the left ventricular outflow tract (LVOT). ${ }^{32}$ The outflow obstruction is also manifested in about $70 \%$ of nonobstructive patients during exercise, ${ }^{1}$ causing the generation of a dynamic LVOT gradient. The dynamic nature of LVOT results from a series of changes in ventricular loading conditions and myocardial contractility that are sensitive to fluctuations in volume status, autonomic nervous activity and pharmacotherapy. ${ }^{31}$ The severity of LVOT obstruction is clinically relevant because it is a major cause of symptoms, such as dizziness, dyspnea on exertion, ${ }^{34}$ pre-syncope, syncope, as well as a predictor of poor prognosis and sudden death. ${ }^{31}$ The highest outflow gradients have been linked to severe heart failure. ${ }^{1}$ The left atrium is frequently dilated and hypertrophied, reflecting the high resistance to LV filling.

HCM is an important cause of disability, including heart failure, $\mathrm{AF}$, and death in patients of all ages. ${ }^{1}$ Sudden and unexpected death in young people is the most devastating component of its natural history, with an annual mortality varying from $1 \%$ to $6 \%{ }^{35-37} \mathrm{AF}$ is also an independent determinant of HCM-related morbidity and mortality due to heart failure and stroke. ${ }^{2-4}$ High left atrial diameter has also been found to be associated with increased risk for heart failure-related death in patients with HCM. $^{38,39}$

\section{OSA and cardiovascular burden}

The mechanisms of cardiovascular burden by which OSA can contribute to cardiovascular and metabolic disease are multiple and have been extensively investigated in patients with OSA without HCM. Acutely, the recurrent episodes of airway collapse during sleep are associated with vigorous inspiratory effort, negative swings in intrathoracic pressure, and asphyxia. These episodes of asphyxia are recurrent and typically terminate with arousals from sleep (see Fig. 1). ${ }^{40,41}$ The consequences of the repetitive obstructive events during sleep are not restricted to nighttime but may extend throughout the day. OSA triggers a large list of neuro-hormonal and inflammatory responses that are potentially deleterious to the cardiovascular system, and include increased levels of sympathetic activity, products of oxidative stress, plasma C-reactive protein, fibrinogen, cytokines, leptin, as well as insulin resistance and endothelial dysfunction. ${ }^{42-46}$ These studies suggest that OSA contributes to the development of atherosclerosis, and this hypothesis is strengthened by the demonstration that patients with OSA, compared with appropriate controls, have increased markers of atherosclerosis, including increased arterial stiffness and increased intima-media thickness of the carotid artery. ${ }^{47,48}$ The treatment of moderate to severe OSA with continuous positive airway pressure (CPAP) is able to abolish OSA and has been used in observational and randomized trials to investigate the effects of OSA on several cardiovascular and metabolic outcomes. There is mounting evidence that the treatment of OSA with CPAP improves several harmful pathways, including sympathetic activity, C-reactive protein, insulin resistance, and endothelial function and ameliorates early signs of atherosclerosis. $^{43,46,49,50}$

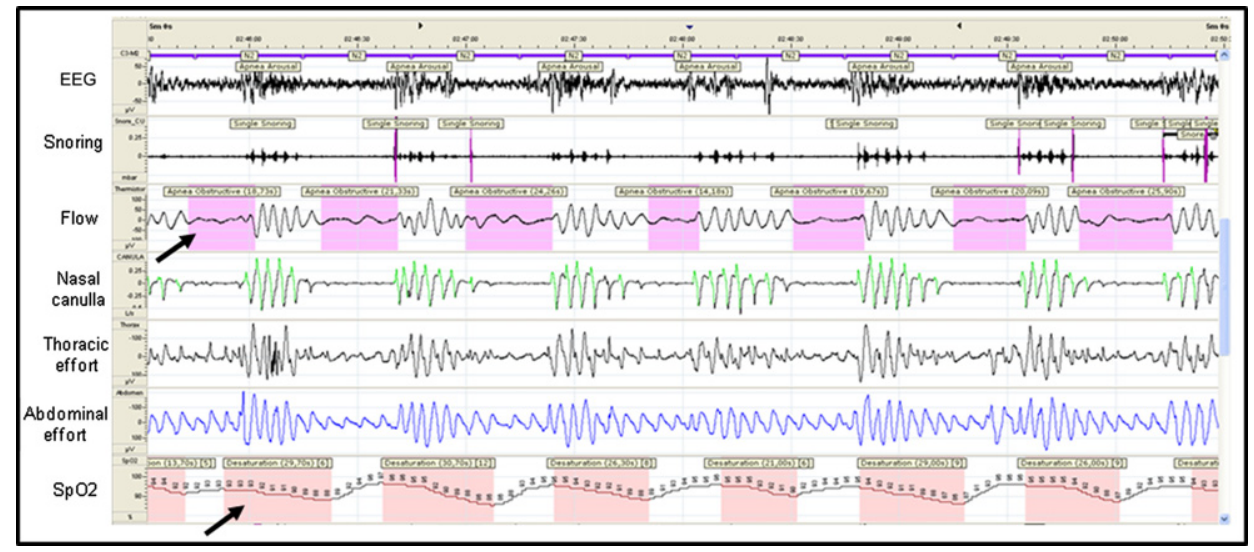

Fig. 1. Polysomnographic recording (5 min tracing) of a patient with hypertrophic cardiomyopathy presenting recurrent obstructive apneas during sleep. 
The best documented relationship between OSA and cardiovascular disease is hypertension. OSA is a recognized cause of secondary hypertension and the treatment of OSA with CPAP is able to reduce blood pressure. ${ }^{51,52}$ The overall reduction in blood pressure with CPAP treatment in two recent meta-analyses are relatively small $(\sim 2 \mathrm{mmHg}){ }^{53,54}$ However, most studies included a large number of normotensive and patients with controlled hypertension. It is also important to stress that even a small blood pressure reduction seems to be clinically relevant. ${ }^{55}$ In addition, OSA has also been associated with cardiac structural and functional changes. Untreated OSA was associated with an increase in left atrial volume, suggesting that the treatment of OSA may prevent adverse left atrial remodeling. ${ }^{56}$ OSA may promote right ventricular dilatation, right ventricle and interventricular septal hypertrophy, ${ }^{57-59}$ OSA may also impair LV diastolic function velocity and increase left atrial volume. ${ }^{60}$ The strong correlation between the carotid-femoral pulse wave velocity (estimate of the measure of arterial stiffness of the aorta) with the LV mass index in OSA patients suggests that increased afterload may contribute to heart remodeling. ${ }^{48}$ Progression of heart remodeling may help to explain the strong association between OSA and AF. The prevalence of OSA among patients with AF is extremely high, ranging around $50 \%$. More importantly, the treatment of OSA seems to reduce the risk of recurrent episodes of $\mathrm{AF}^{56}$ In addition, the presence of OSA has been associated with a two- to three-fold increased risk of recurrence of $\mathrm{AF}$ after cardioversion, compared with patients treated for OSA. ${ }^{61}$ One observational study also showed that CPAP is associated with a reduction in fatal cardiovascular events among OSA patients. $^{62}$

\section{Review criteria}

To review all studies available regarding the association between sleep disordered breathing and HCM, we conducted a search for articles published between January 1, 1980 and July 1, 2011 included in the MEDLINE and SciELO databases by using the key words hypertrophic cardiomyopathy or cardiomyopathies and the following key words: sleep, sleep-disordered breathing, obstructive sleep apnea and central sleep apnea. We found seven original articles and one case report. ${ }^{23-28,63,64}$ We carefully examined all studies and reviewed the methodology used to recruit patients, diagnose sleep disordered breathing, and the association with cardiovascular outcome and quality of life.

\section{Prevalence of OSA among HCM patients}

Sleep-disordered breathing includes a number of disorders i.e., OSA, central sleep apnea syndrome, and central alveolar hypoventilation syndrome. ${ }^{65}$ Central sleep apnea is rare in this population and we reported one patient with HCM and central sleep apnea associated with Cheyne-Stokes respiration. ${ }^{63}$ One limitation of the majority of the studies in this area is that the method of detecting sleep disordered breathing was variable, and included overnight oximetry, the type III portable monitor (PM), and full polysomnography (PSG). Despite this limitation, in this review we used the term OSA, based on the high prevalence of OSA and the evidence observed in our laboratory that this is by far the most common sleep disordered breathing among patients with HCM. Therefore, for the sake of simplicity we adopted the term OSA, even when only oximetry data were presented.

The first evidence suggesting that OSA may be a prevalent disease among HCM patients was published in 2004 by Banno and colleagues. $^{23}$ The authors evaluated patients with different cardiomyopathies and reported that in a small sample of 15 patients with HCM, seven (47\%) had OSA as diagnosed by full PSG.
This initial observation was only fully investigated in the recent years (2009-2011), when three independent groups have reported the prevalence of OSA in a total of 334 patients with HCM. ${ }^{24-27}$ Table 1 summarizes these recent studies, and it is clear that the prevalence of OSA is extremely high, ranging from $32 \%$ to $71 \%$. The major limitations of these studies are three-fold. Firstly, the methodology used to diagnose OSA was different and varied from overnight oximetry to PM, and none of the recent studies used standard full PSG. However, there is growing evidence that PM is suitable for diagnosing OSA. ${ }^{66}$ Moreover, in one study that used oximetry in 100 patients with HCM, the authors confirmed OSA in a subsample of 24 patients who underwent full PSG. ${ }^{24}$ Secondly, the cut-off criteria for OSA diagnosis were variable among studies and are clearly shown in Table 1 . Finally, it is possible to argue that the numbers of studies are relatively small and the impact of OSA recognition and treatment among $\mathrm{HCM}$ patients remains to be established. On the other hand, the sum of the studies published so far recruited over 300 patients and the main results are relatively consistent among different studies.

\section{Characteristics of patients with OSA + HCM}

The demographic characteristics of patients with and without OSA, as well as the association with cardiovascular outcomes, published are summarized in Table 2. Consistent with the general population, patients with OSA are in general predominantly male, significantly older, and more obese than patients without OSA (see Table 2). However, patients with HCM and OSA are less obese than the typical OSA patient referred to sleep laboratories, and the mean BMI among patients with HCM + OSA ranged from 27 to $31 \mathrm{~kg} / \mathrm{m}^{2}$. The observation that relatively lean patients may present OSA has also been reported in other specific populations, such as patients undergoing dialysis ${ }^{67}$ and patients with congestive heart failure. ${ }^{68}$ One interesting new unifying theory that may help to explain the propensity to OSA is provided by the observation that overnight rostral fluid shift to the neck could contribute to upper airway obstruction. ${ }^{69}$ Rostral fluid shift is particularly relevant among patients with edematous states. Among patients with congestive heart failure fluid displacement from the legs to the neck and lungs can help to explain the genesis of both central and obstructive sleep apnea. ${ }^{70}$ Among patients with end-stage renal disease, nocturnal rostral fluid shift was independently associated with the severity of OSA. ${ }^{71}$ It also has been recently demonstrated that even in nonobese healthy subjects, the shift of fluid into the nuchal structures

Table 1

Characteristics of patients with hypertrophic cardiomyopathy included in studies.

\begin{tabular}{|c|c|c|c|c|}
\hline Author & $\begin{array}{l}\text { Eleid } \\
\text { et al. }{ }^{24} 2009\end{array}$ & $\begin{array}{l}\text { Pedrosa } \\
\text { et al. }{ }^{25} 2010\end{array}$ & $\begin{array}{l}\text { Konecny } \\
\text { et al. }{ }^{26} 2010\end{array}$ & $\begin{array}{l}\text { Prinz } \\
\text { et al. }\end{array}$ \\
\hline Patients, $n$ & 100 & 80 & 91 & 63 \\
\hline Age, y & 55 & $47(32-58)$ & $52(20-83)$ & $59(34-85)$ \\
\hline Male, \% & 59 & 49 & 68 & 63 \\
\hline BMI, $\mathrm{kg} / \mathrm{m}^{2}$ & 35.3 & $26.4(17-35.8)$ & 31.6 & $26.9(21.4-32.4)$ \\
\hline Monitor & $\begin{array}{l}\text { Overnight } \\
\text { oximetry }\end{array}$ & Portable monitor & $\begin{array}{l}\text { Overnight } \\
\text { oximetry }\end{array}$ & Portable monitor \\
\hline $\begin{array}{l}\text { RDI/ODI, } \\
\text { events/h }\end{array}$ & NA & $9.2(4.1-24.8)$ & 8.6 & $34.8(2.3-67.3)$ \\
\hline Lowest $\mathrm{SpO}_{2}$ & NA & $84(78-88)$ & $\mathrm{NA}$ & $\mathrm{NA}$ \\
\hline $\begin{array}{l}\text { Cut-off, } \\
\text { events/h }\end{array}$ & ODI $>5$ & $\mathrm{RDI} \geq 15$ & ODI $>10$ & $\mathrm{RDI} \geq 15$ \\
\hline OSA, $\%$ & 71 & 40 & 32 & 44 \\
\hline
\end{tabular}

Values are mean (CI 95\%). Variables with skewed distribution are presented as median (25-75\% interquartile range) or percentage. Abbreviations: HCM: hypertrophic cardiomyopathy; BMI: body mass index; RDI: respiratory disorder index expressed in events/h; ODI: oxygen desaturation index expressed in events/h, OSA: obstructive sleep apnea; $\mathrm{NA}$ : no available data; $\mathrm{SpO}_{2}$ : lowest peripheral oxygenation. 
Table 2

Characteristics of patients with hypertrophic cardiomyopathy, with and without obstructive sleep apnea.

\begin{tabular}{|c|c|c|c|c|c|c|c|c|c|c|c|c|}
\hline & \multicolumn{3}{|c|}{ Eleid et al. ${ }^{24} 2009$} & \multicolumn{3}{|c|}{ Pedrosa et al. ${ }^{25} 2010$} & \multicolumn{3}{|c|}{ Konecny et al. ${ }^{26} 2010$} & \multicolumn{3}{|c|}{ Prinz et al. ${ }^{27} 2011$} \\
\hline & No OSA & OSA & $p$ & No OSA & OSA & $p$ & No OSA & OSA & $p$ & No OSA & OSA & $p$ \\
\hline Patients, $n$ & 29 & 71 & NA & 48 & 32 & NA & 61 & 30 & NA & 11 & 52 & NA \\
\hline Age, y & $\begin{array}{l}46 \\
(9-82)\end{array}$ & $\begin{array}{l}59 \\
(29-89)\end{array}$ & $<0.001$ & $\begin{array}{l}38 \\
(30-53)\end{array}$ & $\begin{array}{l}56 \\
(41-64)\end{array}$ & $<0.001$ & $\begin{array}{l}48 \\
(16-77)\end{array}$ & $\begin{array}{l}64 \\
(34-88)\end{array}$ & $<0.001$ & $\begin{array}{l}59 \\
(36-81)\end{array}$ & $\begin{array}{l}60 \\
(34-86)\end{array}$ & NS \\
\hline Male, \% & 45 & 59 & 0.191 & 46 & 53 & 0.52 & 66 & 70 & 0.81 & NA & NA & NA \\
\hline BMI, $\mathrm{kg} / \mathrm{m}^{2}$ & $\begin{array}{l}29 \\
(15-43)\end{array}$ & $\begin{array}{l}31 \\
(18-44)\end{array}$ & 0.159 & $\begin{array}{l}25 \\
(15-35)\end{array}$ & $\begin{array}{l}28.2 \\
(21-35)\end{array}$ & 0.01 & $\begin{array}{l}32 \\
(16-48)\end{array}$ & $\begin{array}{l}31 \\
(21-41)\end{array}$ & 0.41 & $\begin{array}{l}26 \\
(20-33)\end{array}$ & $\begin{array}{l}27 \\
(22-33)\end{array}$ & NS \\
\hline $\begin{array}{l}\text { RDI/ODI, } \\
\text { events/hour }\end{array}$ & NA & $\begin{array}{l}12 \\
(0-36)\end{array}$ & NA & $\begin{array}{l}5 \\
(2-8)\end{array}$ & $\begin{array}{l}30 \\
(21-41)\end{array}$ & $<0.001$ & $\begin{array}{l}3 \\
(0-4)\end{array}$ & $\begin{array}{l}20 \\
(0-40)\end{array}$ & $<0.001$ & NA & $\begin{array}{l}23 \\
(12-58)\end{array}$ & NA \\
\hline Atrial fibrillation, \% & - & - & - & 6 & 31 & $<0.001^{\mathrm{a}}$ & 11 & 46 & 0.005 & - & - & - \\
\hline $\begin{array}{l}\text { Left atrial } \\
\quad \text { enlargement }\end{array}$ & - & - & - & $\begin{array}{l}41 \\
(39-47)\end{array}$ & $\begin{array}{l}45 \\
(42-53)\end{array}$ & $0.01^{\mathrm{a}}$ & NA & NA & $\begin{array}{l}\text { Positive } \\
\text { correlation }^{*}\end{array}$ & NA & NA & $\begin{array}{l}\text { Positive } \\
\text { correlation }^{* *}\end{array}$ \\
\hline Aortic enlargement & - & - & - & $\begin{array}{l}29 \\
(28-32)\end{array}$ & $\begin{array}{l}34 \\
(30-37)\end{array}$ & $<0.001^{\mathrm{a}}$ & - & - & - & - & - & - \\
\hline
\end{tabular}

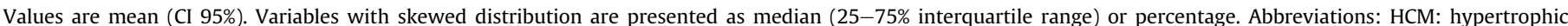

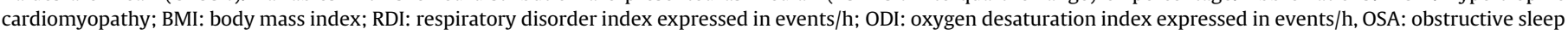
apnea; NA: notavailable, NS: notsignificant.

* Positive correlation between left atrial volume index and OSA severity expressed by the oxygen desaturation index $(R=0.32 ; p=0.002)$.

** Positive correlation between left atrial diameter and OSA severity expressed by apnea-hypopnea index $(R=0.4 ; p<0.01)$.

a Remained significant in multivariate analysis.

may contribute to increase neck circumference and upper airway resistance. ${ }^{72}$ Therefore overnight fluid shift could, at least in theory, play a role in the genesis of OSA among patients with HCM with no overt signs of leg edema.

\section{OSA, HCM and poor outcome}

It is remarkable that both OSA and HCM share common harmful pathways to the cardiovascular system as shown in Fig. 2. We acknowledge that most information derived from OSA was obtained from patients without HCM, and therefore the question whether OSA will be less, equally or more harmful in patients with and without HCM remains unclear. Firstly, patients with OSA experience overnight overstimulation of the sympathetic nervous system, which remains elevated during the day. On the other hand, patients with HCM may also have increased sympathetic activity that may not only be a marker of HCM severity, ${ }^{73}$ but once present may participate in a vicious cycle that further contributes to poor outcome. Elevated catecholamine levels in OSA could influence the pathophysiology of HCM by increasing hypertrophy and left ventricular filling pressures, decreasing cardiac output, and initiating or worsening LVOT obstruction, dyspnea, and dizziness, and mitral regurgitation. ${ }^{64}$ Moreover, patients with HCM experience a high incidence of ventricular tachyarrhythmia that is effectively treated with beta-blocking. ${ }^{64}$ Therefore, it is possible to speculate that sympathetic overstimulation associated with OSA may be particularly harmful when present in patients with HCM. Secondly, OSA is independently associated with left atrium dilation reflecting heart remodeling. ${ }^{25,27,48}$ In addition,

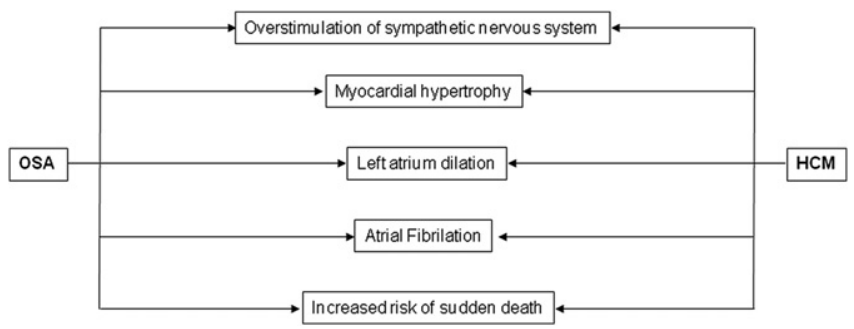

Fig. 2. Common but independent pathways in obstructive sleep apnea and hypertrophic cardiomyopathy. septal hypertrophy typically found in patients with HCM has previously been shown to be independently associated with OSA severity in patients without $\mathrm{HCM}^{58,74}$ In patients with OSA without HCM, LV hypertrophy seems to be present even in the setting of normal blood pressure, suggesting that factors other than hemodynamic overload contribute to hypertrophy. Thirdly, both OSA and HCM are independently associated with AF that may be partially explained by the structural changes promoted by both conditions. Finally, OSA patients without HCM may have a higher risk for sudden death, ${ }^{75}$ that in turn is a hallmark complication of HCM. $^{76,77}$

The recent studies reported so far among patients with $\mathrm{HCM}+\mathrm{OSA}$ are based on cross sectional data. The major limitation of any study that reports associations between OSA and poor cardiovascular outcome is that patients with OSA share traits that may independently contribute to cardiovascular dysfunction. Consistent with this observation, and as discussed above, patients with OSA and HCM are in general significantly older and more obese (see Table 2 ). Table 2 also shows a four fold higher prevalence of AF among patients with HCM and OSA than among patients with HCM but no OSA (see Table 2). It is unlikely that such differences are solely explained by the differences in the demographic characteristics. Similar to what has been shown in other populations, among patients with HCM multivariate analysis showed that the severity of OSA was independently associated with left atrial enlargement, ${ }^{25-27}$ increased left ventricular end-diastolic diameter ${ }^{27}$ and aortic enlargement. ${ }^{25}$ Prinz and colleagues ${ }^{27}$ also reported that OSA was strongly associated with clinical symptoms and worse NYHA functional class.

\section{Perspectives}

OSA is common among patients with cardiovascular disease and has many potential deleterious effects on the cardiovascular system. So, it is reasonable to speculate that even in a scenario of a genetically determined cardiac disease, such as HCM, OSA can increase sympathetic activities and contribute to cardiac remodeling, to the evolution and even to the prognosis of these patients. Further studies in this important research area should clarify the relative role of OSA in HCM prognosis. Based on the previous evidence in patients with OSA and without HCM, it is reasonable to 
speculate, that the treatment of OSA with CPAP may positively impact several outcomes in the setting of HCM. This hypothesis was raised by one preliminary report of four patients with HCM and OSA that presented improvement in functional class evaluated by NYHA, reductions in left atrial volume, and reduction in LVOT after OSA treatment. ${ }^{64}$ On the other hand, the safety of CPAP therapy in patients with HCM has not been investigated.

In conclusion, OSA is common among patients with HCM and independently associated with markers of worse cardiovascular outcome, including heart remodeling and AF. Future studies are necessary to clarify whether OSA is independently associated with increased cardiovascular risk in patients with HCM. Moreover, the impact of OSA treatment in randomized studies will clarify the role of OSA on HCM.

\section{Practice points}

1) Obstructive sleep apnea is common among patients with hypertrophic cardiomyopathy, with a prevalence ranging from $32 \%$ to $71 \%$;

2) The presence of obstructive sleep apnea among patients with hypertrophic cardiomyopathy may be independently associated with worse structural and functional impairment of the heart including left atrial and aortic enlargement as well as worse NYHA functional class, worse quality of life.

3) The presence of obstructive sleep apnea among patients with hypertrophic cardiomyopathy is associated with a four times higher prevalence of atrial fibrillation. Atrial fibrillation is in turn an independent determinant of morbidity and mortality due to heart failure and stroke among patients with hypertrophic cardiomyopathy.

\section{Research agenda}

1) Full polysomnography studies comparing patients with HCM and patients with other cardiac disease, with appropriate control group.

2) Evaluation of the impact of the association of $\mathrm{OSA}+\mathrm{HCM}$ on autonomic control variables.

3) Determination of the impact of treatment of obstructive sleep apnea in patients with hypertrophic cardiomyopathy on several outcomes, including quality of life, cardiovascular burden and mortality.

\section{Conflict of interest}

None declared.

\section{Acknowledgments}

Fundação de Amparo a Pesquisa do Estado de São Paulo - FAPESP.

\section{Appendix A. Supplementary material}

Supplementary data related to this article can be found online at http://dx.doi.org/10.1016/j.smrv.2012.06.006.

\section{References}

1. Maron BJ. The 2009 international hypertrophic cardiomyopathy summit. Am J Cardiol 2010;105:1164-8.

2. Maron BJ, Olivotto I, Bellone P, Conte MR, Cecchi F, Flygenring BP, et al. Clinical profile of stroke in 900 patients with hypertrophic cardiomyopathy. J Am Coll Cardiol 2002;39:301-7.

3. Cha YM, Gersh BJ, Maron BJ, Boriani G, Spirito P, Hodge DO, et al. Electrophysiologic manifestations of ventricular tachyarrhythmias provoking appropriate defibrillator interventions in high-risk patients with hypertrophic cardiomyopathy. J Cardiovasc Electrophysiol 2007;18:483-7.

4. Olivotto I, Cecchi F, Casey SA, Dolara A, Traverse JH, Maron BJ. Impact of atrial fibrillation on the clinical course of hypertrophic cardiomyopathy. Circulation 2001:104:2517-24

5. Sleep-related breathing disorders in adults: recommendations for syndrome definition and measurement techniques in clinical research. The report of an American Academy of Sleep Medicine Task Force. Sleep 1999;22:667-89.

6. Young T, Palta M, Dempsey J, Skatrud J, Weber S, Badr S. The occurrence of obstructive sleep apnea among middle-aged adults. $N$ Engl J Med 1993;328:1230-5.

7. Young T, Peppard PE, Gottlieb DJ. Epidemiology of obstructive sleep apnea: a population health perspective. Am J Respir Crit Care Med 2002;165:1217-39.

8. Tufik S, Santos-Silva R, Taddei JA, Bittencourt LR. Obstructive sleep apnea syndrome in the São Paulo epidemiologic sleep study. Sleep Med 2010;11:441-6.

9. Hansel B, Cohen-Aubart F, Dourmap C, Giral P, Bruckert E, Girerd X. Prevalence of sleep apnea in men with metabolic syndrome and controlled hypertension. Arch Mal Coeur Vaiss 2007;100:637-41.

10. Drager LF, Lopes HF, Maki-Nunes C, Trombetta IC, Toschi-Dias E, Alves MJ, et al The impact of obstructive sleep apnea on metabolic and inflammatory markers in consecutive patients with metabolic syndrome. PLoS One 2010;5:e12065.

11. Leung RS, Bradley TD. Sleep apnea and cardiovascular disease. Am J Respir Crit Care Med 2001;164:2147-65.

*12. Somers VK, White DP, Amin R, Abraham WT, Costa F, Culebras A, et al. Sleep apnea and cardiovascular disease: an American Heart Association/American College of Cardiology Foundation Scientific Statement from the American Heart Association Council for High Blood Pressure Research Professional Education Committee, Council on Clinical Cardiology, Stroke Council, and Council on Cardiovascular Nursing. Circulation 2008;118:1080-111.

13. Drager LF, Genta PR, Pedrosa RP, Nerbass FB, Gonzaga CC, Krieger EM, et al. Characteristics and predictors of obstructive sleep apnea in patients with systemic hypertension. Am J Cardiol 2010;105:1135-9.

14. Peppard PE, Young T, Palta M, Skatrud J. Prospective study of the association between sleep disordered breathing and hypertension. $N$ Engl J Med 2000;342:1378-84.

15. Logan AG, Perlikowski SM, Mente A, Tisler A, Tkacova R, Niroumand M, et al. High prevalence of unrecognized sleep apnoea in drug-resistant hypertension. J Hypertens 2001;19:2271-7.

16. Gami AS, Pressman G, Caples SM, Kanagala R, Gard JJ, Davison DE, et al. Association of atrial fibrillation and obstructive sleep apnea. Circulation 2004;110:364-7.

17. Severino $S$, Caso $P$, Cicala $S$, Galderisi $M$, de Simone $L$, D'Andrea A, et al Involvement of right ventricle in left ventricular hypertrophic cardiomyopathy: analysis by pulsed Doppler tissue imaging. Eur J Echocardiogr 2000;1:281-8

18. Murakami K, Shigematsu Y, Hamada M, Higaki J. Insulin resistance in patients with hypertrophic cardiomyopathy. Circ J 2004;68:650-5.

19. Ogimoto A, Shigematsu Y, Nakura J, Hara Y, Ohtsuka T, Kohara K, et al. Endothelial nitric oxide synthase gene polymorphism (Glu298Asp) in patients with coexistent hypertrophic cardiomyopathy and coronary spastic angina. J Mol Med 2005;83:619-25.

20. Rai TS, Dhandapany PS, Ahluwalia TS, Bhardwaj M, Bahl A, Talwar KK, et al ACE I/D polymorphism in Indian patients with hypertrophic cardiomyopathy and dilated cardiomyopathy. Mol Cell Biochem 2008;311:67-72.

21. Kitaoka H, Kubo T, Okawa M, Yamasaki N, Matsumura Y, Nishinaga M, et al. Plasma adiponectin levels and left ventricular remodeling in hypertrophic cardiomyopathy. Int Heart J 2010;51:51-5.

22. Force T, Bonow RO, Houser SR, Solaro RJ, Hershberger RE, Adhikari B, et al. Research priorities in hypertrophic cardiomyopathy: report of a Working Group of the National Heart, Lung, and Blood Institute. Circulation 2010;122:1130-3.

*23. Banno K, Shiomi T, Sasanabe R, Otake K, Hasegawa R, Maekawa M, et al. Sleepdisordered breathing in patients with idiopathic cardiomyopathy. Circ J 2004;68:338-42.

*24. Eleid MF, Konecny T, Orban M, Sengupta PP, Somers VK, Parish JM, et al. High prevalence of abnormal nocturnal oximetry in patients with hypertrophic cardiomyopathy. Am Coll Cardiol 2009;54:1805-9.

*25. Pedrosa RP, Drager LF, Genta PR, Amaro AC, Antunes MO, Matsumoto AY, et al. Obstructive sleep apnea is common and independently associated with atrial

\footnotetext{
* The most important references are denoted by an asterisk.
} 
fibrillation in patients with hypertrophic cardiomyopathy. Chest 2010;137:1078-84.

*26. Konecny T, Brady PA, Orban M, Lin G, Pressman GS, Lehar F, et al. Interactions between sleep disordered breathing and atrial fibrillation in patients with hypertrophic cardiomyopathy. Am J Cardiol 2010;105:1597-602.

*27. Prinz C, Bitter T, Oldenburg O, Horstkotte D, Faber L. Incidence of obstructive sleep apnea in patients with hypertrophic cardiomyopathy. Congest Heart Fail 2011;17:19-24.

*28. Pedrosa RP, Lima SG, Drager LF, Genta PR, Amaro AC, Antunes MO, et al. Sleep quality and quality of life in patients with hypertrophic cardiomyopathy. Cardiology 2010;117:200-6.

29. Maron BJ. Hypertrophic cardiomyopathy: a systematic review. JAMA 2002;287:1308-20.

30. Bos JM, Towbin JA, Ackerman MJ. Diagnostic, prognostic, and therapeutic implications of genetic testing for hypertrophic cardiomyopathy. J Am Coll Cardiol 2009;54:201-11.

31. Geske JB, Sorajja P, Ommen SR, Nishimura RA. Left ventricular outflow tract gradient variability in hypertrophic cardiomyopathy. Clin Cardiol 2009;32:397-402.

32. Hoss AJ, Petterson CH, Scherer L. Hypertrophic cardiomyopathy. Role of Doppler echocardiography in the diagnosis and therapeutic approach. Arq Bras Cardiol 1998;70:301-6.

33. Maron BJ, Gardin JM, Flack JM, Gidding SS, Kurosaki TT, Bild DE. Prevalence of hypertrophic cardiomyopathy in a general population of young adults. Echocardiographic analysis of 4111 subjects in the CARDIA Study. Coronary Artery Risk Development in (Young) Adults. Circulation 1995;92:785-9.

34. Maron MS, Olivotto I, Zenovich AG, Link MS, Pandian NG, Kuvin JT, et al. Hypertrophic cardiomyopathy is predominantly a disease of left ventricular outflow tract obstruction. Circulation 2006;114:2232-9.

35. Arteaga E, Ianni BM, Fernandes F, Mady C. Benign outcome in a long-term follow-up of patients with hypertrophic cardiomyopathy in Brazil. Am Heart J 2005;149:1099-105.

36. Shah PM, Adelman AG, Wigle ED, Gobel FL, Burchell HB, Hardarson T, et al. The natural (and unnatural) history of hypertrophic obstructive cardiomyopathy. Circ Res 1974;35(Suppl. II):79-195.

37. Cecchi F, Olivotto I, Montereggi A, Santoro G, Dolara A, Maron BJ. Hypertrophic cardiomyopathy in Tuscany: clinical course and outcome in an unselected regional population. J Am Coll Cardiol 1995;26:1529-36.

*38. Nistri S, Olivotto I, Betocchi S, Losi MA, Valsecchi G, Pinamonti B, et al. Prognostic significance of left atrial size in patients with hypertrophic cardiomyopathy (from the Italian Registry for Hypertrophic Cardiomyopathy). Am J Cardiol 2006;98:960-5.

39. Yang H, Woo A, Monakier D, Jamorski M, Fedwick K, Wigle ED, et al. Enlarged left atrial volume in hypertrophic cardiomyopathy: a marker for disease severity. J Am Soc Echocardiogr 2005;18:1074-82.

40. Lorenzi-Filho G, Bradley TD. Cardiac function in sleep apnea. In: Pack AI, editor. Sleep apnea: pathogenesis, diagnosis, and treatment. New York: M. Dekker; 2002. p. 377-410.

41. Parish JM, Somers VK. Obstructive sleep apnea and cardiovascular disease. Mayo Clin Proc 2004;79:1036-46.

42. Basoglu OK, Sarac F, Sarac S, Uluer H, Yilmaz C. Metabolic syndrome, insulin resistance, fibrinogen, homocysteine, leptin, and C-reactive protein in obese patients with obstructive sleep apnea syndrome. Ann Thorac Med 2011;6:120-5

43. Cuhadaroğlu C, Utkusavaş A, Oztürk L, Salman S, Ece T. Effects of nasal CPAP treatment on insulin resistance, lipid profile, and plasma leptin in sleep apnea. Lung 2009;187:75-81.

44. Shamsuzzaman AS, Somers VK. Fibrinogen, stroke, and obstructive sleep apnea: an evolving paradigm of cardiovascular risk. Am J Respir Crit Care Med 2000;162:2018-20.

45. Ip MS, Lam B, Ng MM, Lam WK, Tsang KW, Lam KS. Obstructive sleep apnea is independently associated with insulin resistance. Am J Respir Crit Care Med 2002;165:670-6.

46. Jelic S, Lederer DJ, Adams T, Padeletti M, Colombo PC, Factor PH, et al. Vascular inflammation in obesity and sleep apnea. Circulation 2010;121:1014-21.

*47. Drager LF, Bortolotto LA, Lorenzi MC, Figueiredo AC, Krieger EM, LorenziFilho G. Early signs of atherosclerosis in obstructive sleep apnea. Am J Respir Crit Care Med 2005;172:613-8.

48. Drager LF, Bortolotto LA, Figueiredo AC, Silva BC, Krieger EM, Lorenzi-Filho G. Obstructive sleep apnea, hypertension, and their interaction on arterial stiffness and heart remodeling. Chest 2007;131:1379-86.

49. Phillips CL, Yang Q, Williams A, Roth M, Yee BJ, Hedner JA, et al. The effect of short-term withdrawal from continuous positive airway pressure therapy on sympathetic activity and markers of vascular inflammation in subjects with obstructive sleep apnoea. J Sleep Res 2007;16:217-25.

50. Drager LF, Bortolotto LA, Figueiredo AC, Krieger EM, Lorenzi-Filho G. Effects of continuous positive airway pressure on early signs of atherosclerosis in obstructive sleep apnea. Am J Respir Crit Care Med 2007;176:706-12.

51. Pepperell JC, Ramdassingh-Dow S, Crosthwaite N, Mullins R, Jenkinson C, Stradling JR, et al. Ambulatory blood pressure after therapeutic and subtherapeutic nasal continuous positive airway pressure for obstructive sleep apnoea: a randomised parallel trial. Lancet 2002;359:204-10.

52. Drager LF, Pedrosa RP, Diniz PM, Diegues-Silva L, Marcondes B, Couto RB, et al. The effects of continuous positive airway pressure on prehypertension and masked hypertension in men with severe obstructive sleep apnea. Hypertension 2011;57:549-55.

53. Bazzano LA, Khan Z, Reynolds K, He J. Effect of nocturnal nasal continuous positive airway pressure on blood pressure in obstructive sleep apnea. Hypertension 2007;50:417-23.

54. Haentjens P, Van Meerhaeghe A, Moscariello A, De Weerdt S, Poppe K, Dupont $A$, et al. Impact of continuous positive airway pressure on blood pressure in patients with obstructive sleep apnea syndrome: evidence from a meta-analysis of placebo-controlled randomized trials. Arch Intern Med 2007; 167:757-64.

55. Chobanian AV, Bakris GL, Black HR, Cushman WC, Green LA, Izzo Jr JL, et al Joint National Committee on Prevention, Detection, Evaluation, and Treatment of High Blood Pressure. National Heart, Lung, and Blood Institute; National High Blood Pressure Education Program Coordinating Committee. Seventh report of the Joint National Committee on Prevention, Detection, Evaluation, and Treatment of High Blood Pressure. Hypertension 2003;42:1206-52.

56. Drager LF, Bortolotto LA, Pedrosa RP, Krieger EM, Lorenzi-Filho G. Left atria diameter is independently associated with arterial stiffiness in patients with obstructive sleep apnea: potential implications for atrial fibrilation. Int J Cardiol 2010;144:257-9.

57. Khan A, Latif F, Hawkins B, Tawk M, Sivaram CA, Kinasewitz G. Effects of obstructive sleep apnea treatment on left atrial volume and left atrial volume index. Sleep Breath 2008;12:141-7.

58. Shivalkar B, Van de Heyning C, Kerremans M, Rinkevich D, Verbraecken J, De Backer W, et al. Obstructive sleep apnea syndrome: more insights on structural and functional cardiac alterations, and the effects of treatment with continuous positive airway pressure. J Am Coll Cardiol 2006;47:1433-9.

59. Berman EJ, DiBenedetto RJ, Causey DE, Mims T, Conneff M, Goodman LS, et al Right ventricular hypertrophy detected by echocardiography in patients with newly diagnosed obstructive sleep apnea. Chest 1991;100:347-50.

60. Otto ME, Belohlavek M, Romero-Corral A, Gami AS, Gilman G, Svatikova A et al. Comparison of cardiac structural and functional changes in obese otherwise healthy adults with versus without obstructive sleep apnea. Am J Cardiol 2007;99:1298-302.

61. Kanagala R, Murali NS, Friedman PA, Ammash NM, Gersh BJ, Ballman KV, et al. Obstructive sleep apnea and the recurrence of atrial fibrillation. Circulation 2003;107:2589-94.

62. Marin JM, Carrizo SJ, Vicente E, Agusti AG. Long-term cardiovascular outcomes in men with obstructive sleep apnoea-hypopnoea with or without treatment with continuous positive airway pressure: an observational study. Lancet 2005;365:1046-53.

*63. Pedrosa RP, Drager LF, Antunes MO, Arteaga E, Lorenzi-Filho G. Cheyne-stokes respiration associated with hypertrophic cardiomyopathy and normal left ventricular ejection fraction. Clinics 2010;65:927-9.

*64. Sengupta PP, Sorajja D, Eleid MF, Somers VK, Ommen SR, Parish JM, et al. Hypertrophic obstructive cardiomyopathy and obstructive sleep apnea: an unfavorable combination. Nat Clin Pract Cardiovasc Med 2009;6:14-5.

65. American Academy of Sleep Medicine. International classification of sleep disorders, revised: diagnostic and coding manual. Chicago: American Academy of Sleep Medicine; 2001.

66. Kuna ST, Gurubhagavatula I, Maislin G, Hin S, Hartwig KC, McCloskey S, et al Noninferiority of functional outcome in ambulatory management of obstructive sleep apnea. Am J Respir Crit Care Med 2011;183:1238-44.

67. Elias RM, Castro MC, de Queiroz EL, Abensur H, Romão Jr JE, Lorenzi-Filho G Obstructive sleep apnea in patients on conventional and short daily hemodialysis. Am J Nephrol 2009;29:493-500.

68. Sin DD, Fitzgerald F, Parker JD, Newton G, Floras JS, Bradley TD. Risk factors for central and obstructive sleep apnea in 450 men and women with congestive heart failure. Am J Respir Crit Care Med 1999;160:1101-6.

69. Chiu KL, Ryan CM, Shiota S, Ruttanaumpawan P, Arzt M, Haight JS, et al. Fluid shift by lower body positive pressure increases pharyngeal resistance in healthy subjects. Am J Respir Crit Care Med 2006;174:1378-83.

70. Yumino D, Redolfi S, Ruttanaumpawan P, Su MC, Smith S, Newton GE, et al Nocturnal rostral fluid shift: a unifying concept for the pathogenesis of obstructive and central sleep apnea in men with heart failure. Circulation 2010;121:1598-605.

71. Elias RM, Bradley TD, Kasai T, Motwani SS, Chan CT. Rostral overnight fluid shift in end-stage renal disease: relationship with obstructive sleep apnea. Nephrol Dial Transplant 2012;27:1569-73.

72. Redolfi S, Yumino D, Ruttanaumpawan P, Yau B, Su MC, Lam J, et al. Relationship between overnight rostral fluid shift and obstructive sleep apnea in nonobese men. Am J Respir Crit Care Med 2009;179:241-6.

73. Limbruno U, Strata G, Zucchi R, Baglini R, Mengozzi G, Balbarini A, et al. Altered autonomic cardiac control in hypertrophic cardiomyopathy. Role of outflow tract obstruction and myocardial hypertrophy. Eur Heart J 1998;19:146-53.

74. Usui K, Parker JD, Newton GE, Floras JS, Ryan CM, Bradley TD. Left ventricular structural adaptations to obstructive sleep apnea in dilated cardiomyopathy. Am J Respir Crit Care Med 2006;173:1170-5.

75. Rossner S, Lagerstrand L, Persson HE, Sachs C. The sleep apnoea syndrome in obesity: risk of sudden death. J Intern Med 1991;230:135-41.

76. Maron BJ, Olivotto I, Spirito P, Casey SA, Bellone P, Gohman TE, et al. Epidemiology of hypertrophic cardiomyopathy-related death: revisited in a large non-referral-based patient population. Circulation 2000;102:858-64.

77. Maron BJ. Hypertrophic cardiomyopathy. Lancet 1997;350:127-33. 


\title{
Lack of reliable clinical predictors to identify obstruc- tive sleep apnea in patients with hypertrophic cardiomyopathy
}

\author{
Flávia B. Nerbass,' Rodrigo P. Pedrosa,' Pedro R. Genta,' Murillo O. Antunes," Edmundo Arteaga- \\ Fernández," Luciano F. Drager,' Geraldo Lorenzi-Filho'
}

'Hospital das Clínicas da Faculdade de Medicina da Universidade de São Paulo, Heart Institute (InCor), Sleep Laboratory, Pulmonary Division, São Paulo/SP, Brazil. "Hospital das Clínicas da Faculdade de Medicina da Universidade de São Paulo, Heart Institute (InCor), Cardiomyopathy Medical Unit (Clinical Unit of Cardiomyopathies), São Paulo/SP, Brazil.

OBJECTIVE: Obstructive sleep apnea is common among patients with hypertrophic cardiomyopathy and may contribute to poor cardiovascular outcomes. However, obstructive sleep apnea is largely unrecognized in this population. We sought to identify the clinical predictors of obstructive sleep apnea among patients with hypertrophic cardiomyopathy.

METHODS: Consecutive patients with hypertrophic cardiomyopathy were recruited from a tertiary University Hospital and were evaluated using validated sleep questionnaires (Berlin and Epworth) and overnight portable monitoring. Ninety patients (males, $51 \%$; age, $46 \pm 15$ years; body mass index, $26.6 \pm 4.9 \mathrm{~kg} / \mathrm{m}^{2}$ ) were included, and obstructive sleep apnea (respiratory disturbance index $\geq 15$ events/h) was present in 37 patients (41\%).

RESULTS: Compared with the patients without obstructive sleep apnea, patients with obstructive sleep apnea were older and had higher body mass index, larger waist circumference, larger neck circumference, and higher prevalence of atrial fibrillation. Excessive daytime sleepiness (Epworth scale) was low and similar in the patients with and without obstructive sleep apnea, respectively. The only predictors of obstructive sleep apnea (using a logistic regression analysis) were age $\geq 45$ years (odds ratio [OR], 4.46; 95\% confidence interval [Cl 95\%], 1.4713.54; $p=0.008$ ) and the presence of atrial fibrillation [OR, 5.37; CI 95\%, 1.43-20.12; $p=0.013]$.

CONCLUSION: Consistent clinical predictors of obstructive sleep apnea are lacking for patients with hypertrophic cardiomyopathy, which suggests that objective sleep evaluations should be considered in this population, particularly among elderly patients with atrial fibrillation.

KEYWORDS: Hypertrophic Cardiomyopathy; Obstructive Sleep Apnea; Atrial Fibrillation.

Nerbass FB, Pedrosa RP, Genta PR, Antunes MO, Arteaga-Fernández E, Drager LF, et al. Lack of reliable clinical predictors to identify obstructive sleep apnea in patients with hypertrophic cardiomyopathy. Clinics. 2013;68(7):992-996.

Received for publication on February 6, 2013; First review completed on March 1, 2013; Accepted for publication on March 25, 2013

E-mail: fbnerbass@gmail.com

Tel.: 5511 2661-5486

\section{INTRODUCTION}

Hypertrophic cardiomyopathy (HCM) is a common genetic cardiac disease that is characterized by left ventricular (LV) hypertrophy associated with non-dilated ventricular chambers in the absence of another cardiac or systemic disease capable of producing this hypertrophy (1). HCM is a potentially devastating disease; it occurs in all age groups (1) and is a significant cause of disability, including heart failure, atrial fibrillation $(\mathrm{AF})$, and sudden death (2). Despite all efforts, the sudden death

Copyright (c) 2013 CLINICS - This is an Open Access article distributed under the terms of the Creative Commons Attribution Non-Commercial License (http:// creativecommons.org/licenses/by-nc/3.0/) which permits unrestricted noncommercial use, distribution, and reproduction in any medium, provided the original work is properly cited.

No potential conflict of interest was reported.

DOI: $10.6061 /$ clinics/2013(07)17 rate in HCM patients is approximately $1 \%$ per year, and this disease primarily affects patients older than 55 years (3-5).

Obstructive sleep apnea (OSA) is characterized by recurrent episodes of either partial or complete upper airway obstruction during sleep, leading to fragmented sleep and intermittent hypoxia (6). Growing evidence shows that OSA triggers a cascade of deleterious effects to the cardiovascular system, including increased sympathetic activity, oxidative stress, systemic inflammation, insulin resistance, endothelial dysfunction, atherosclerosis, and heart remodeling $(7,8)$. OSA is considered to be a risk factor for hypertension and is independently associated with poor cardiovascular outcomes in the general population $(9,10)$. The typical features of OSA patients who are referred to sleep laboratories include male, obese, loud snoring, and symptoms of excessive daytime sleepiness.

Novel evidence shows that OSA is surprisingly common among patients with HCM, with prevalences ranging from 
$32 \%$ to $71 \%$, depending on the diagnostic criteria (11-15). Because HCM is commonly diagnosed at young ages, the presence of OSA among HCM patients has been largely ignored. Moreover, for reasons that are not completely understood, evidence indicates that the patients with HCM and OSA are typically less obese than the patients with OSA observed in sleep clinics $(13,15)$. However, crosssectional data suggest that similarly to what has been well established in other populations, the presence of OSA may contribute to poor cardiovascular outcomes in HCM patients (16). For instance, in HCM patients, OSA has been independently associated with left atrial enlargement and $\operatorname{AF}(13,14)$, which is a risk factor for sudden death in these patients.

We have previously reported a high prevalence of OSA among HCM patients (13). Though the previous study conveyed novel and important findings, the clinical characteristics and predictors of OSA were not described. Therefore, the objective of the present study was to identify the predictors of OSA that may help to increase the awareness and diagnosis of OSA in HCM patients.

\section{METHODS}

\section{Study design}

This cross-sectional observational study evaluated consecutive HCM patients who were previously diagnosed according to the standard criteria described below. All patients were recruited from the Cardiomyopathy Clinical Unit, (Clinical Unit of Cardiomyopathies) at the Heart Institute (InCor), University of São Paulo School of Medicine, São Paulo, Brazil, between March 2008 and October 2011. Each patient had been diagnosed with HCM with asymmetric septal hypertrophy, with septal thickness $\geq 15 \mathrm{~mm}$ in the absence of other known causes of left ventricular hypertrophy, such as hypertension and aortic stenosis (17). We included patients of both genders who were older than 18 years. Patients with another cardiac diseases and clinical instability, as defined by a recent hospital admission (the previous 6 months), were excluded.

\section{Clinical evaluation}

All HCM patients underwent a detailed history and physical examination, including anthropometric and clinical data. We used two questionnaires, the Berlin questionnaire and the Epworth Sleepiness Scale, to evaluate the risk of having OSA and the level of excessive daytime sleepiness, respectively, as described below:

Berlin Questionnaire - This questionnaire classifies patients at low and high risk for OSA based on responses in three symptom categories regarding: 1) snoring, 2) tiredness, and 3) the presence of obesity (BMI $\geq 30 \mathrm{~kg} / \mathrm{m}^{2}$ ) or hypertension. Patients positive for at least two symptom categories were considered at high risk for OSA (18). Because none of the patients with HCM had hypertension, the third domain of the Berlin questionnaire was restricted to obesity.

Epworth Sleepiness Scale (ESS) - The ESS is used to evaluate subjective excessive daytime sleepiness. Briefly, the patient rates the probability of dozing ( 0 to 3 ) in eight different situations. A score above 10 is considered positive for the presence of excessive daytime sleepiness (19).

\section{Sleeps study}

All participants underwent an overnight study with a standard 4-channel recording device (Stardust II, Respironics Inc., Murrysville, Pennsylvania, USA). This device records nasal pressure, thoracic excursion (as measured using a piezoelectric crystal), body position, pulse oxymetry, and heart rate. The device is classified as a type 3 monitor in accordance with the AASM recommendations (20). The portable monitoring sleep study was unattended and performed at home. Hypopnea was defined as a $\geq 50 \%$ discernible decrement in airflow lasting $\geq 10 \mathrm{~s}$ with a $3 \%$ reduction in oxygen saturation. Apnea was defined when cessation of airflow lasted $\geq 10 \mathrm{~s}$ and was further classified as central, obstructive, or mixed based on the presence of respiratory effort (21). The total recording time was used as the denominator to calculate the respiratory-disordered index (RDI) (6). The RDI was calculated as the total number of respiratory events per hour of record. The classification of OSA severity was defined according to RDI as mild (5-14.9 events/h), moderate (15-29.9 events/h), or severe ( $\geq 30$ events $/ h$ ) (6). In this study, we considered moderate to severe OSA $(\geq 15$ events $/ h$ ) as the cut-off for OSA.

\section{Statistical analysis}

Quantitative variables are expressed as means \pm SD or medians (interquartile ranges [IQRs]) or in percentages, when appropriate. The Kolmogorov-Smirnov test was used to assess the normal distribution of continuous variables. The Students t-test for independent samples and the MannWhitney U-test were used to compare continuous variables when appropriate. The chi-squared test was used for categorical variables. A univariate binary logistic regression analysis was used to evaluate variables associated with the presence of OSA, considering an RDI $\geq 15$ events $/ \mathrm{h}$. The tested variables were age ( $\geq 45$ years), BMI $\left(\geq 27 \mathrm{~kg} / \mathrm{m}^{2}\right)$, neck circumference $(\geq 43 \mathrm{~cm}$ and $\geq 41 \mathrm{~cm}$ for males and females, respectively) (22), waist circumference $(\geq 102 \mathrm{~cm}$ and $\geq 88 \mathrm{~cm}$ for males and females, respectively) (23), snoring, and a high risk for OSA, as assessed by the Berlin questionnaire. The cut-offs used for age and BMI were obtained using ROC curve analysis as the best values for sensitivity and specificity. Variables with a $p$-value $<0.1$ upon univariate analysis were entered into a multivariate binary logistic regression. Because snoring was one of the Berlin questionnaire domains, it was not included as an independent variable. In addition, sensitivity, specificity, and positive and negative predictive values of relevant variables were also calculated. Data were analyzed with SPSS 17.0 statistical software (SPSS Inc., Chicago, Illinois, USA). A $p$-value $\leq 0.05$ was considered significant.

\section{Ethics}

The institutional ethics committee approved this study (SDC 3252/09/003), which was performed in accordance with the Helsinki Declaration of 1975 (revised in 1983).

\section{- RESULTS}

We evaluated $90 \mathrm{HCM}$ patients who were consecutively recruited from the Cardiomyopathy Clinical Unit at a tertiary University Hospital. None of the patients were referred to the sleep laboratory because of sleep complaints or had a previous diagnosis of OSA. Table 1 summarizes the 
Table 1 - General and clinical characteristics of the entire population of patients with hypertrophic cardiomyopathy and the patients with and without obstructive sleep apnea.

\begin{tabular}{|c|c|c|c|c|}
\hline & Total population $(n=90)$ & No OSA $(n=53)$ & OSA $(n=37)$ & $p$-value \\
\hline Age, years & $46 \pm 15$ & $41 \pm 14$ & $53 \pm 13^{*}$ & $<0.001$ \\
\hline Male, n (\%) & $46(51)$ & $26(49)$ & $21(57)$ & 0.742 \\
\hline Caucasians, n (\%) & $67(74)$ & $40(75)$ & $27(72)$ & 0.983 \\
\hline Body Mass Index, $\mathrm{kg} / \mathrm{m}^{2}$ & $26.6 \pm 4.9$ & $25.3 \pm 5.0$ & $28.5 \pm 4.0^{*}$ & 0.003 \\
\hline Neck, cm & $37.4 \pm 4.2$ & $36.4 \pm 3.2$ & $39.0 \pm 5.0 *$ & 0.002 \\
\hline Waist, $\mathrm{cm}$ & $94.1 \pm 12.1$ & $91.0 \pm 11.0$ & $98.6 \pm 11.7^{*}$ & 0.003 \\
\hline NYHA 2 and $3, \mathrm{n}(\%)$ & $44(49)$ & $23(43)$ & $20(54)$ & 0.434 \\
\hline Atrial fibrillation, $\mathrm{n}(\%)$ & $18(20)$ & $5(9)$ & $13(35) *$ & 0.003 \\
\hline \multicolumn{5}{|l|}{ Antihypertensive, n (\%) } \\
\hline Diuretics, n (\%) & $19(23)$ & $10(20)$ & $9(27)$ & 0.718 \\
\hline Beta-blockers, n (\%) & $61(68)$ & $34(64)$ & $26(70)$ & 0.705 \\
\hline $\begin{array}{l}\text { Angiotensin-converting enzyme } \\
\text { inhibitor, } \mathrm{n}(\%)\end{array}$ & $4(5)$ & $1(2)$ & $3(8)$ & 0.302 \\
\hline Calcium channel blockers, $\mathrm{n}(\%)$ & $18(22)$ & $9(17)$ & $10(27)$ & 0.375 \\
\hline Angiotensin receptor blocker, n (\%) & $14(17)$ & $7(13)$ & $7(19)$ & 0.660 \\
\hline Hypnotics, n (\%) & $5(6)$ & $2(4)$ & $3(8)$ & 0.398 \\
\hline Antidepressants, n (\%) & $13(16)$ & $6(11)$ & $7(29)$ & 0.481 \\
\hline
\end{tabular}

Values are presented as percentages, means \pm SD or medians (interquartile ranges) for the variables, as appropriate. OSA: obstructive sleep apnea. ${ }^{*} p \leq 0.05$.

patient demographics and the medications of the entire population and divides the patients according to the absence or presence of OSA. The vast majority of patients were taking at least one cardiovascular medication $(88 \%)$ (Table 1). Consistent with recent studies of HCM patients, moderate to severe OSA (Apnea-Hypopnea Index> 15 events/h) was extremely common and was present in $41 \%$ of our population (13-15). The OSA patients were predominantly older males with higher BMIs, higher neck and waist circumferences, and higher prevalences of $\mathrm{AF}$ compared to the patients without OSA. However, in contrast to the typical patient with OSA referred to the sleep laboratory, the patients with HCM+OSA were not particularly obese (Table 1).

The sleep characteristics and sleep-related questionnaires of the entire population are summarized in Table 2 according to the presence or absence of OSA. A high OSA risk, as evaluated by the Berlin questionnaire, was more common among the patients with OSA than among the patients without OSA (Table 2). The frequencies of positive answers to the three categories of the Berlin questionnaire (snoring, tiredness, and obesity) are also shown in Table 2. Snoring and high BMI were more common in the OSA patients. In contrast, tiredness did not differ significantly among the patients with and without OSA. Moreover, complaints of excessive daytime sleepiness, as assessed by the Epworth Sleepiness Scale, were relatively low in the entire population and were similar among patients with and without OSA (Table 2).

We performed a binary logistic regression to evaluate the predictors for OSA: the only variables that were independently associated with OSA were age $\geq 45$ years and the presence of AF (Table 3). To translate our findings into clinically meaningful data, we determined the sensitivity, specificity, and positive and negative predictive values of the main traits, including demographics and OSA-associated complaints (Table 4). In general, all analyzed variables performed poorly in the analysis, which highlights the fact that several HCM patients are minimally symptomatic for OSA and do not have the typical features that helps to identify OSA.

\section{DISCUSSION}

In this study, the prevalence of OSA among consecutive HCM patients was particularly high $(41 \%)$, which aligned with data from previous studies (13-15). Our study was designed to determine the clinical characteristics that may help to identify OSA among HCM patients. The main

Table 2 - Respiratory parameters derived from portable monitoring and sleep questionnaires for the entire population and for patients with and without obstructive sleep apnea.

\begin{tabular}{|c|c|c|c|c|}
\hline & Total population $(n=90)$ & No OSA $(n=53)$ & OSA $(n=37)$ & $p$-value \\
\hline RDI, e/h & $10.2(4.5-24.8)$ & $5(2.7-8.1)$ & $30.3(21.2-39.3)^{*}$ & $<0.001$ \\
\hline Lowest $\mathrm{SpO}_{2}, \%$ & $84(78-88)$ & $87(83-89.5)$ & $80(75.7-82.5)^{*}$ & $<0.001$ \\
\hline Berlin high risk, n (\%) & $36(40)$ & $13(25)$ & $23(66) *$ & $<0.001$ \\
\hline Snoring, n (\%) & $47(52)$ & $13(35)$ & $24(65)$ & 0.056 \\
\hline Tiredness, n (\%) & $35(39)$ & $18(34)$ & $19(51)$ & 0.152 \\
\hline $\mathrm{BMI} \geq 30 \mathrm{~kg} / \mathrm{m}^{2}, \mathrm{n}(\%)$ & $22(24)$ & $9(16)$ & $13(35)$ & 0.080 \\
\hline Epworth & $7(3-11)$ & $7.5(3.5-11)$ & $7(3-12.2)$ & 0.924 \\
\hline
\end{tabular}

Values are presented as percentages, means \pm SD or medians (interquartile ranges) for the variables with skewed distribution. OSA: obstructive sleep apnea. RDI: respiratory-disordered index; BMI: body mass index.

${ }^{*} p \leq 0.05$. 
Table 3 - Binary logistic regression with the predictors of obstructive sleep apnea among patients with hypertrophic cardiomyopathy.

\begin{tabular}{lccccc}
\hline & \multicolumn{2}{c}{ Univariate } & & \multicolumn{2}{c}{ Multivariate } \\
\cline { 2 - 3 } \cline { 5 - 6 } & OR (CI 95\%) & $p$-value & OR (CI 95\%) & $p$-value \\
\hline Age $\geq 45$ years & $3.76(1.55-9.13)$ & 0.003 & & $4.46(1.47-13.54)$ & 0.008 \\
$\mathrm{BMI} \geq 27 \mathrm{~kg} / \mathrm{m}^{2}$ & $2.62(1.10-6.24)$ & 0.029 & & $0.842(0.25-2.88)$ & 0.843 \\
Large neck & $2.18(0.83-5.71)$ & 0.067 & & $2.48(0.64-9.49)$ & 0.185 \\
Large waist & $2.07(0.87-4.92)$ & 0.097 & & $2.07(0.67-6.43)$ & 0.207 \\
Atrial & $5.20(1.65-16.36)$ & 0.005 & & $5.37(1.43-20.12)$ & 0.013 \\
$\quad$ fibrillation & & & & & \\
Snoring & $4.40(1.59-12.18)$ & 0.004 & & & \\
Berlin high risk & $3.39(1.41-8.18)$ & 0.007 & & $2.46(0.83-7.28)$ & 0.103 \\
Constant & & & & 0.086 & 0.000 \\
\hline
\end{tabular}

OR: odds ratio; Cl: confidence interval; BMI: body mass index.

findings were as follows: 1) the patients with HCM+OSA did not complain of excessive daytime sleepiness; 2) the patients with $\mathrm{HCM}+\mathrm{OSA}$ were significantly older and had higher BMI and neck and waist circumferences, but on average, the patients with $\mathrm{HCM}+\mathrm{OSA}$ were overweight and typically not obese; 3 ) the Berlin questionnaire, which has been previously validated to recognize patients with OSA in other populations $(18,24,25)$, was not useful in recognizing considered, only age and the presence of AF remained statistically significant. These findings are worrisome and indicate the necessity to test the hypothesis in future studies that OSA may contribute to the genesis of heart remodeling and AF among HCM patients. Despite this evidence, the clinical suspicion of OSA among HCM patients remains uncommon. There are several potential explanations for the lack of OSA recognition among these patients. First, cardiologists are not systematically trained in sleep medicine. Second, because HCM is a genetic disease, it is often diagnosed at young ages (when OSA is not frequent). Third, HCM patients frequently do not exhibit the typical features of OSA patients, such as obesity. Fourth, OSA has only recently been shown to be extremely common in this population. Finally, in contrast to the patient population referred to the sleep laboratory (30), patients with $\mathrm{HCM}+\mathrm{OSA}$ frequently do not have typical clinical symptoms, such as tiredness and excessive daytime sleepiness. The lack of excessive daytime sleepiness in patients with OSA has also been observed in consecutive patients with established cardiovascular disease, including hypertension $(24,25)$, metabolic syndrome (31), stroke (32), atrial fibrillation (33), and coronary artery disease (34). In our study, regarding the sensitivity and specificity to predict OSA, the Epworth Sleepiness Scale and Berlin questionnaire returned low values for all of the tested variables; therefore, these

Table 4 - Performance of clinical and sleep-related characteristics of the HCM patients.

\begin{tabular}{lcccc}
\hline & Sensitivity (Cl 95\%) & Specificity (Cl 95\%) & PPV (Cl 95\%) & NPV (CI 95\%) \\
\hline Age $\geq 45$ years & $0.26(0.15-0.42)$ & $0.42(0.28-0.57)$ & $0.31(0.18-0.49)$ & $0.36(0.23-0.51)$ \\
Gender & $0.38(0.24-0.54)$ & $0.54(0.39-0.69)$ & $0.44(0.28-0.61)$ & $0.48(0.34-0.62)$ \\
BMI $\geq 27 \mathrm{~kg} / \mathrm{m}^{2}$ & $0.53(0.38-0.67)$ & $0.69(0.53-0.82)$ & $0.65(0.48-0.79)$ & $0.57(0.43-0.71)$ \\
$\mathrm{BMI} \geq 30 \mathrm{~kg} / \mathrm{m}^{2}$ & $0.59(0.36-0.78)$ & $0.63(0.50-0.74)$ & $0.34(0.20-0.51)$ & $0.82(0.69-0.91)$ \\
Large neck & $0.56(0.34-0.76)$ & $0.62(0.50-0.73)$ & $0.34(0.20-0.51)$ & $0.80(0.67-0.90)$ \\
Large waist & $0.50(0.35-0.64)$ & $0.67(0.50-0.81)$ & $0.65(0.48-0.79)$ & $0.51(0.37-0.65)$ \\
AF & $0.72(0.46-0.89)$ & $0.66(0.54-0.72)$ & $0.36(0.21-0.53)$ & $0.90(0.77-0.96)$ \\
Snoring & $0.56(0.41-0.70)$ & $0.77(0.58-0.89)$ & $0.79(0.61-0.90)$ & $0.53(0.38-0.68)$ \\
Berlin & $0.40(0.25-0.57)$ & $0.30(0.18-0.44)$ & $0.28(0.17-0.43)$ & $0.42(0.26-0.59)$ \\
Epworth $>10$ & $0.46(0.28-0.65)$ & $0.60(0.46-0.72)$ & $0.36(0.22-0.54)$ & $0.69(0.54-0.80)$ \\
\hline
\end{tabular}

PPV: positive predictive value; NPV: negative predictive value; AF: atrial fibrillation.

OSA among HCM patients and 4) age $\geq 45$ years and the presence of $\mathrm{AF}$ were the only variables that were independently associated with OSA. However, age $\geq 45$ years had a low sensitivity and specificity to predict OSA. Conversely, the presence of AF presented a relatively high sensitivity (0.72, 95\% confidence interval [CI 95\%], 0.46-0.89). Altogether, our results suggest a lack of reliable clinical predictors to identify OSA among HCM patients.

OSA is common in the general population $(26,27)$ and is independently associated with increased cardiovascular risk $(9,10)$. In HCM patients, evidence also shows that the presence of OSA may be associated with worse structural and functional impairment of the heart, including atrial and aortic enlargement, worse New York Heart Association functional class, and worse quality of life $(13-15,28)$. In HCM patients, AF is an independent marker of mortality (29), and its prevalence is significantly higher ( $\sim 5$ times) in the presence of OSA $(13,14)$. Consistent with these previous observations, in the present study, $\mathrm{AF}$ was $\sim 3$ to 4 times more common among patients with $\mathrm{HCM}+\mathrm{OSA}$ than in patients with HCM but not OSA. Moreover, in the multivariate analysis, when all possible clinical predictors were tools are not useful in clinical practice (Table 4). All of these findings are important and emphasize that cardiologists should take the responsibility to actively search for OSA among patients with HCM.

Our study has some limitations that should be addressed. First, because of the specific nature of the underlying disease, the external validity of our data should be analyzed carefully. Second, our sleep study was performed using a portable monitor. However, portable monitors have also been confirmed as a useful alternative to overnight polysomnography for the diagnosis of sleep-disordered breathing in a series of patients with cardiovascular disease (34-36).

In conclusion, our study confirms that OSA is common in HCM patients. In this population, using clinical characteristics or validated questionnaires to identify OSA does not accurately identify the patients at high risk for OSA. Our results indicate the necessity for more accurate screening strategies for identifying OSA in HCM patients. Considering the high prevalence of OSA and its potential cardiovascular consequences, sleep studies should be widely considered for diagnosing OSA in patients with $\mathrm{HCM}$, particularly among elderly patients with AF. 


\section{ACKNOWLEDGMENTS}

Fundação de Amparo a Pesquisa do Estado de São Paulo (FAPESP).

\section{AUTHOR CONTRIBUTIONS}

Nerbass FB participated in the study design, data collection, statistical analysis, and manuscript development. Pedrosa RP participated in the study design, data collection, and manuscript development. Genta PR performed the statistical analysis. Antunes MO participated in the data collection. Arteaga-Fernández E contributed to the manuscript development. Drager LF and Lorenzi-Filho G participated in the study design, statistical analysis, and manuscript development.

\section{REFERENCES}

1. Gersh BJ, Maron BJ, Bonow RO, Dearani JA, Fifer MA, Link MS, et al. 2011 ACCF/AHA guideline for the diagnosis and treatment of hypertrophic cardiomyopathy: a report of the American College of Cardiology Foundation/American Heart Association Task Force on Practice Guidelines. J Thorac Cardiovasc Surg. 2011;142(6):e153-203, http://dx.doi.org/10.1016/j.jtcvs.2011.10.020.

2. Maron BJ. The 2009 international hypertrophic cardiomyopathy summit. Am J Cardiol. 2010;105(8):1164-8, http://dx.doi.org/10.1016/j.amjcard. 2009.12.021.

3. Elliott PM, Gimeno JR, Thaman R, Shah J, Ward D, Dickie S, et al. Historical trends in reported survival rates in patients with hypertrophic cardiomyopathy. Heart. 2006;92(6):785-91

4. Wald DS, Law M, Morris JK. Mortality from hypertrophic cardiomyopathy in England and Wales: clinical and screening implications. Int J Cardiol. 2004;97(3):479-84

5. Arteaga E, Ianni BM, Fernandes F, Mady C. Benign outcome in a longterm follow-up of patients with hypertrophic cardiomyopathy in Brazil. Am Heart J. 2005;149(6):1099-105, http://dx.doi.org/10.1016/j.ahj.2004. 09.049 .

6. Flemons WW, Buysse D, Redline S, Strohl K, Wheatley J, Douglas N, et al. Sleep-related breathing disorders in adults: recommendations for syndrome definition and measurement techniques in clinical research. The Report of an American Academy of Sleep Medicine Task Force. Sleep. 1999;22(5):667-89.

7. Bradley TD, Floras JS. Obstructive sleep apnoea and its cardiovascular consequences. Lancet. 2009;373(9657):82-93, http://dx.doi.org/10.1016/ S0140-6736(08)61622-0.

8. Drager LF, Polotsky VY, Lorenzi-Filho G. Obstructive sleep apnea: an emerging risk factor for atherosclerosis. Chest. 2011;140(2):534-42, http://dx.doi.org/10.1378/chest.10-2223.

9. Marin JM, Carrizo SJ, Vicente E, Agusti AG. Long-term cardiovascular outcomes in men with obstructive sleep apnoea-hypopnoea with or without treatment with continuous positive airway pressure: an observational study. Lancet. 2005;365(9464):1046-53.

10. Punjabi NM, Caffo BS, Goodwin JL, Gottlieb DJ, Newman AB, O'Connor GT, et al. Sleep-disordered breathing and mortality: a prospective cohort study. PLoS Med. 2009;6(8):e1000132, http://dx.doi.org/10.1371/ journal.pmed.1000132.

11. Banno K, Shiomi T, Sasanabe R, Otake K, Hasegawa R, Maekawa M, et al. Sleep-disordered breathing in patients with idiopathic cardiomyopathy. Circ J. 2004:68(4):338-42, http:/ / dx.doi.org/10.1253/circj.68.338.

12. Eleid MF, Konecny T, Orban M, Sengupta PP, Somers VK, Parish JM, et al. High prevalence of abnormal nocturnal oximetry in patients with hypertrophic cardiomyopathy. Am Coll Cardiol. 2009;54(19):1805-9, http://dx.doi.org/10.1016/j.jacc.2009.07.030.

13. Pedrosa RP, Drager LF, Genta PR, Amaro AC, Antunes MO, Matsumoto $\mathrm{AY}$, et al. Obstructive sleep apnea is common and independently associated with atrial fibrillation in patients with hypertrophic cardiomyopathy. Chest. 2010;137(5):1078-84, http://dx.doi.org/10.1378/chest. 09-2335.

14. Konecny T, Brady PA, Orban M, Lin G, Pressman GS, Lehar F, et al. Interactions between sleep disordered breathing and atrial fibrillation in patients with hypertrophic cardiomyopathy. Am J Cardiol. 2010; 105(11):1597-602, http://dx.doi.org/10.1016/j.amjcard.2010.01.023.

15. Prinz C, Bitter T, Oldenburg O, Horstkotte D, Faber L. Incidence of obstructive sleep apnea in patients with hypertrophic cardiomyopathy. Congest Heart Fail. 2011;17(1):19-24, http://dx.doi.org/10.1111/j.17517133.2010.00196.x.

16. Nerbass FB, Pedrosa RP, Danzi-Soares J, Drager LF, Arteaga-Fernandez E, Lorenzi-Filho G. Obstructive sleep apnea and hypertrophic cardiomyopathy: a common and potential harmful combination. Sleep Med Rev. 2013;17(3):201-6, http://dx.doi.org/10.1016/j.smrv.2012.06.006.

17. Maron BJ, Gardin JM, Flack JM, Gidding SS, Kurosaki TT, Bild DE. Prevalence of hypertrophic cardiomyopathy in a general population of young adults. Echocardiographic analysis of 4111 subjects in the CARDIA Study. Coronary Artery Risk Development in (Young) Adults. Circulation. 1995;92(4):785-9.

18. Netzer NC, Stoohs RA, Netzer CM, Clark K, Strohl KP. Using the Berlin Questionnaire to identify patients at risk for the sleep apnea syndrome. Ann Intern Med. 1999;131(7):485-91, http://dx.doi.org/10.7326/00034819-131-7-199910050-00002.

19. Johns MW. A new method for measuring daytime sleepiness: the Epworth sleepiness scale. Sleep. 1991;14(6):540-5

20. Collop NA, Anderson WM, Boehlecke B, Claman D, Goldberg R, Gottlieb DJ, et al. Portable Monitoring Task Force of the American Academy of Sleep Medicine. Clinical guidelines for the use of unattended portable monitors in the diagnosis of obstructive sleep apnea in adult patients. Portable Monitoring Task Force of the American Academy of Sleep Medicine. J Clin Sleep Med. 2007;3(7):737-47.

21. Iber C, Ancoli-Israel S, Chesson AL, Quan SF. The AASM Manual for the Scoring of Sleep and Associated Events, Rules, Terminology and technical Specifications, American Academy of Sleep Medicine. Westchester, IL: AASM Manual for Scoring Sleep; 2007.

22. Epstein LJ, Kristo D, Strollo PJ, Friedman N, Malhotra A, Patil SP, et al. Adult Obstructive Sleep Apnea Task Force of the American Academy of Sleep Medicine. Clinical guideline for the evaluation, management and long-term care of obstructive sleep apnea in adults. J Clin Sleep Med. 2009;5(3):263-76.

23. Grundy SM, Cleeman JI, Daniels SR, Donato KA, Eckel RH, Franklin BA, et al. American Heart Association; National Heart, Lung, and Blood Institute. Diagnosis and management of the metabolic syndrome: an American Heart Association/National Heart, Lung, and Blood Institute Scientific Statement. Circulation. 2005;112(17):2735-52.

24. Drager LF, Genta PR, Pedrosa RP, Nerbass FB, Gonzaga CC, Krieger EM, et al. Characteristics and predictors of obstructive sleep apnea in patients with systemic hypertension. Am J Cardiol. 2010;105(8):1135-9, http://dx. doi.org/10.1016/j.amjcard.2009.12.017.

25. Pedrosa RP, Drager LF, Gonzaga CC, Sousa MG, de Paula LK, Amaro $\mathrm{AC}$, et al. Obstructive sleep apnea: the most common secondary cause of hypertension associated with resistant hypertension. Hypertension. 2011;58(5):811-7, http://dx.doi.org/10.1161/HYPERTENSIONAHA.111. 179788

26. Young T, Palta M, Dempsey J, Skatrud J, Weber S, Badr S. The occurrence of sleep-disordered breathing among middle-aged adults. N Engl J Med. 1993;328(17):1230-5.

27. Tufik S, Santos-Silva R, Taddei JA, Bittencourt LR. Obstructive sleep apnea syndrome in the São Paulo Epidemiologic Sleep Study. Sleep Med. 2010;11(5):441-6, http://dx.doi.org/10.1016/j.sleep.2009.10.005.

28. Pedrosa RP, Lima SG, Drager LF, Genta PR, Amaro AC, Antunes MO, et al. Sleep quality and quality of life in patients with hypertrophic cardiomyopathy. Cardiology. 2010;117(3):200-6, http://dx.doi.org/10. $1159 / 000321718$

29. Olivotto I, Cecchi F, Casey SA, Dolara A, Traverse JH, Maron BJ. Impact of atrial fibrillation on the clinical course of hypertrophic cardiomyopathy. Circulation. 2001;104(21):2517-24, http://dx.doi.org/10.1161/ hc4601.097997.

30. Roure N, Gomez S, Mediano O, Duran J, Peña Mde L, Capote F, et al. Daytime sleepiness and polysomnography in obstructive sleep apnea patients. Sleep Med. 2008;9(7):727-31, http:/ /dx.doi.org/10.1016/j.sleep. 2008.02.006.

31. Drager LF, Lopes HF, Maki-Nunes C, Trombetta IC, Toschi-Dias E, Alves MJ, et al. The impact of obstructive sleep apnea on metabolic and inflammatory markers in consecutive patients with metabolic syndrome. PLoS One 2010;5(8):e12065, http://dx.doi.org/10.1371/journal.pone. 0012065.

32. Arzt M, Young T, Peppard PE, Finn L, Ryan CM, Bayley M, et al. Dissociation of obstructive sleep apnea from hypersomnolence and obesity in patients with stroke. Stroke. 2010;41(3):e129-e34, http://dx. doi.org/10.1161/STROKEAHA.109.566463.

33. Albuquerque FN, Calvin AD, Sert Kuniyoshi FH, Konecny T, LopezJimenez F, Pressman GS, et al. Sleep-disordered breathing and excessive daytime sleepiness in patients with atrial fibrillation. Chest. 2012;141(4):967-73, http:/ /dx.doi.org/10.1378/chest.11-0975.

34. Danzi-Soares NJ, Genta PR, Nerbass FB, Pedrosa RP, Soares FS, César LA, et al. Obstructive sleep apnea is common among patients referred for coronary artery bypass grafting and can be diagnosed by portable monitoring. Coron Artery Dis. 2012;23(1):31-8.

35. Quintana-Gallego E, Villa-Gil M, Carmona-Bernal C, Botebol-Benhamou G, Martinez-Martinez A, Sanchez-Armengol A, et al. Home respiratory polygraphy for diagnosis of sleep-disordered breathing in heart failure. Eur Respir J. 2004;24(3):443-8, http://dx.doi.org/10.1183/09031936.04. 00140603 .

36. Prinz C, Bitter T, Piper C, Horstkotte D, Faber L, Oldenburg O. Sleep apnea is common in patients with coronary artery disease. Wien Med Wochenschr. 2010;160(13-14):349-55, http://dx.doi.org/10.1007/s10354009-0737-x. 